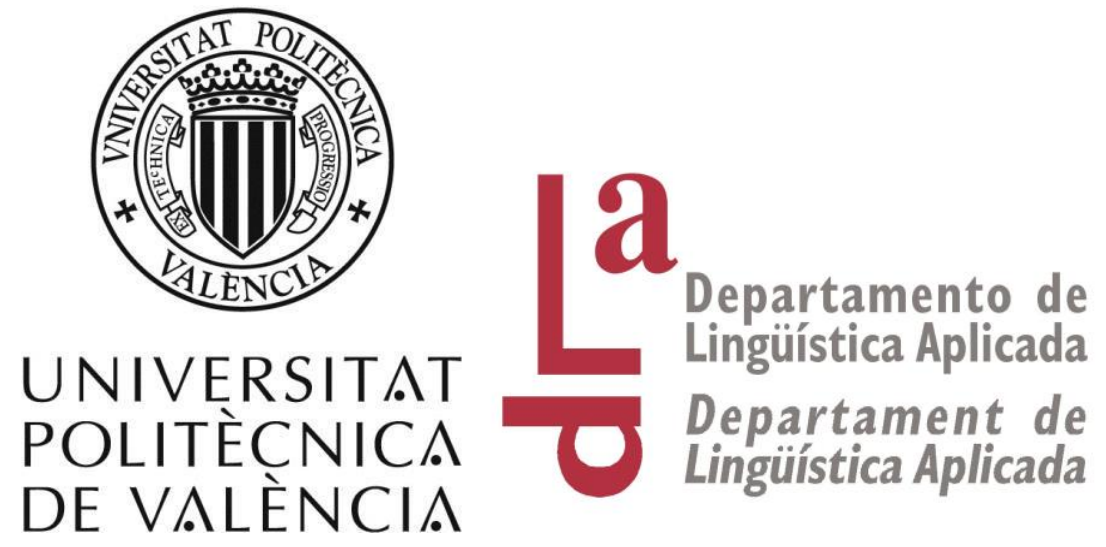

\title{
Intercultural Communication in Foreign Language Learning and Retention in Online Learning
}

Author: Liza D’Arcy Hernández

Supervisor: Dr. María Luisa Carrió Pastor

Valencia, February 2016 
To my family 




\section{ABSTRACT}

Despite the vast research into motivation in traditional Foreign Language Learning (FLL) environments, there has been little done into retention for online FLL. There are many factors that influence retention in online FLL environments and this thesis' original contribution to knowledge was to study the most important aspects for that context. Thus the objectives of this study are to explore the co-existence and interconnectedness between peers, students' indications of autonomous behaviour and the significance of relevance for continuity within a distant / online learning environment and how these issues relate to motivation. This qualitative research study developed a 5-week Intercultural Communication course for students who were at a B1 and B2 (following the Common European Framework of reference for Languages) level of Spanish and English that was delivered entirely online. These students were placed into groups for tutorials and met twice a week on Google Hangouts to practise their target language with natives of that language and discuss the course concepts and their relevance to FLL and their personal lives. These linguistic exchanges were recorded. The dataset that was analysed to draw conclusions were these recordings, statistics from the Blackboard learning platform course site and the pre- and post-course questionnaires. Research into distance and online learning shows that isolation plays a key role in students' decisions to abandon their chosen course. Despite that, current and available technologies have not yet exploited online learning tools that foster and encourage networked learning connections. This thesis concluded that those results are also true for the online FLL context and that emphasis must be placed on giving students opportunities to work autonomously; create spaces that will foster peer interaction, resulting in peer support; and ensure students are continuously aware of the relevance of what they are learning in order to maintain motivation and retention and consequently knowledge acquisition. 


\section{RESUMEN}

A pesar de la amplia investigación en motivación en los entornos tradicionales del aprendizaje de una lengua extranjera (ALE), se ha trabajado poco la cuestión de la retención del conocimiento en el ALE en línea. Existen muchos factores que influyen en la retención en entornos de ALE y la contribución al conocimiento de esta tesis es el estudio de los aspectos más importantes en ese contexto. Por lo tanto los objetivos que se plantean en esta tesis doctoral son analizar la colaboración y comunicación entre pares, los indicadores del comportamiento autónomo de los estudiantes y la importancia de continuar en un medio de aprendizaje a distancia/en línea y cómo todo ello se relaciona con la motivación. Este estudio cualitativo ha partido del desarrollo de un curso en linea de comunicación intercultural para alumnos con niveles de conocimiento de lenguas B1 y B2 (según el Marco Común Europeo de Referencia para lenguas) de cinco semanas de duración. Durante la realización del curso, estudiantes ingleses y españoles fueron distribuidos en grupos para realizar tutorías, siendo citados dos veces por semana en Google Hangouts para practicar la lengua de destino con alumnos nativos de la lengua meta (español o inglés). Los alumnos comentaban los conceptos del curso y su relevancia respecto a la enseñanza de una lengua nativa así como temas personales. Esos intercambios lingüísticos fueron grabados y junto con las estadísticas extraidas desde la plataforma de aprendizaje Blackboard y los cuestionarios previos y posteriores al curso conformaron la metodología a seguir y los resultados. Los resultados extraidos del estudio mostraron que el aislamiento juega un papel clave en la decisión de los estudiantes de abandonar el curso escogido. A pesar de eso, hemos detectado que la tecnología actual no saca provecho de las herramientas en línea para el aprendizaje de lenguas. La conclusión de esta tesis es que esos resultados son también válidos para los contextos de aprendizaje de una lengua extranjera online y por ello se ha de poner énfasis en proporcionar a los estudiantes oportunidades para trabajar autónomamente, crear espacios que fomenten la interacción entre pares, dar lugar a un apoyo mutuo, asegurándose que los estudiantes son conscientes de la relevancia de lo que aprenden para mantener la motivación y la retentiva, adquiriendo de este modo conocimiento. 


\section{RESUM}

Malgrat l'àmplia recerca en motivació en entorns tradicionals d'aprenentatge d'una llengua estrangera (ALE), s'ha treballat poc la qüestió de la retentiva per a ALE online. $\mathrm{Hi}$ ha molts factors que influeixen en la retentiva en entorns de ALE online i la contribució original al coneixement d'aquesta tesi ha sigut l'estudi dels aspectes més importants en aqueix context. Per això, els objectius d'aquesta tesis doctoral són analitzar la col.laboració i comunicació entre parells, els indicadors del comportament autònom dels estudiants i la importància de continuar en un mitjà d'aprentatge a distància/en linia i com tot això es relaciona amb la motivació. Aquest estudi de recerca qualitativa ha desenvolupat un curs de comunicació intercultural per a estudiants amb un nivell de llengua B1 i B2 (seguint el Mac Comú Europeu de Referència de llengues) de cinc setmanes de durada, que va ser realitzat enterament online. Estudiants anglesos i espanyols van ser distribuits en grups per a tutorials i citats dues vegades a la setmana en Google Hangouts per a practicar la llengua meta amb nadius en eixe idioma i comentar els conceptes del curs, la seua rellevància respecte al ALE i també questions personals. Aqueixos intercanvis lingüístics van ser gravats. Els resultats són el conjunt de dades recopilats en els enregistraments, les estadístiques des de Blackboard learning platform course site i els qüestionaris previs i posteriors al curs. La recerca sobre l'aprenentatge a distància i online va demostrar que l'aïllament juga un paper clau en la decisió dels estudiants d'abandonar el curs escollit. Malgrat açò, les tecnologies actuals disponibles no han aprofitat les eines online d'aprenentatge per a promoure les connexions en xarxa per a animar a aprendre en línea. La conclusió d'aquesta tesi és que aqueixos resultats són també vàlids per als contextos d'aprenentatge de FLL online i per açò l'èmfasi ha de ser posat a proporcionar als estudiants oportunitats per a treballar autònomament, crear espais que fomenten la interacció entre parells, donant lloc a un suport mutu i assegurar-se que els estudiants són conscients contínuament de la rellevància del que aprenen per a mantenir la motivació i la retentiva, adquirint d'aquesta manera coneixement. 



\section{INDEX}

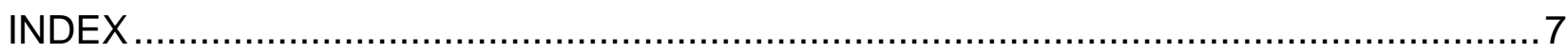

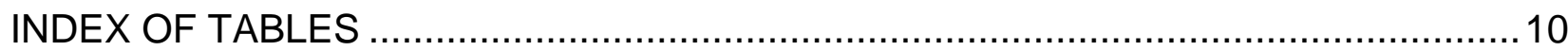

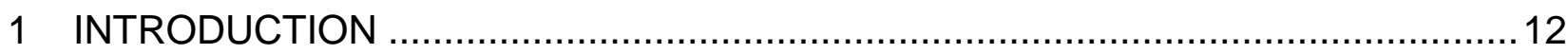

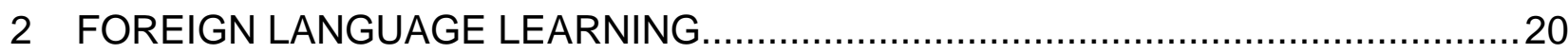

2.1 Approaches to foreign language acquisition ............................................21

2.2 Developments in the field of foreign language education...............................29

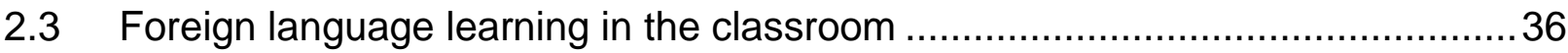

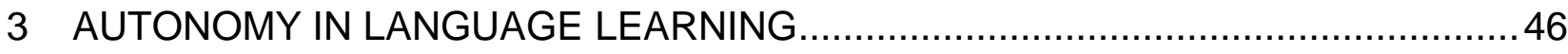

3.1 Definition of the term 'learner autonomy' ……........................................... 48

3.2 Pedagogical implications derived from the concept of learner autonomy ..........66

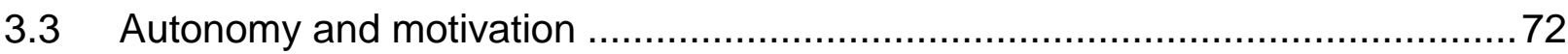

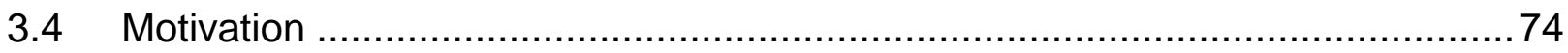

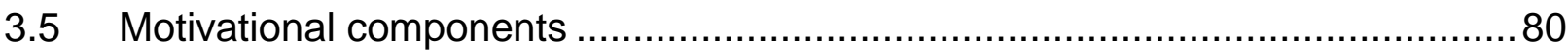

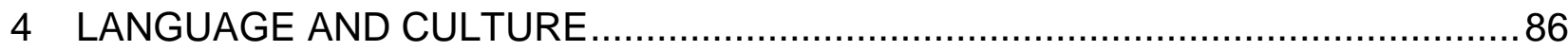

4.1 Linguistic relativity and how language shapes culture ................................. 87

4.2 Relationship between language and culture ...............................................93

4.3 Definition of culture and communication in terms of ICC ..............................96

4.4 The importance of ICC in foreign language learning ...................................102

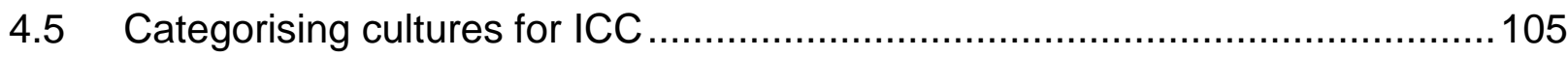

4.6 Dimensions of culture - content included in the thesis ICC course.................109

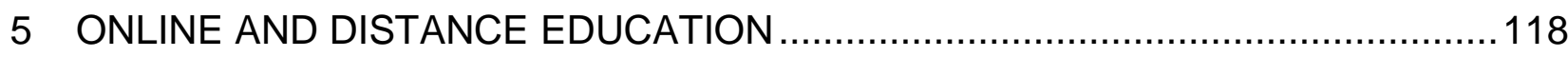

5.1 Theoretical basis of distance education ......................................................119 
5.2 Developments in technological resources in distance education ....................129

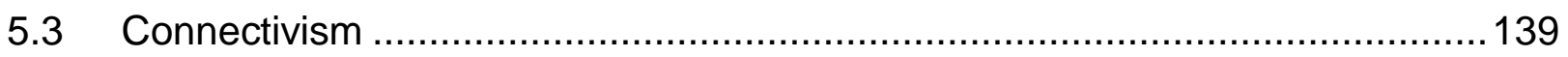

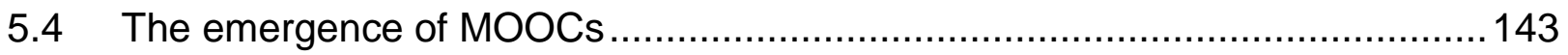

5.5 Issues with distance and online learning..................................................147

5.6 Telecollaborative exchanges and being connected for foreign language learning

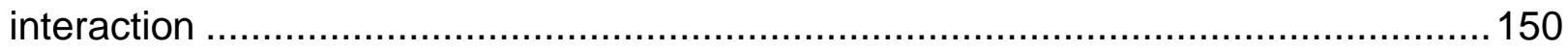

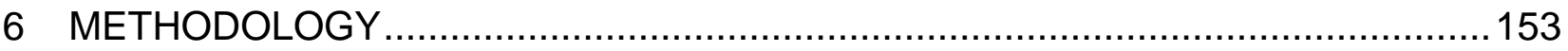

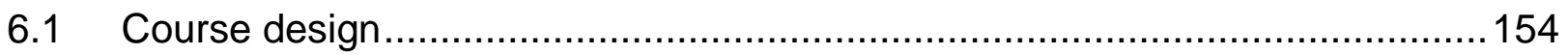

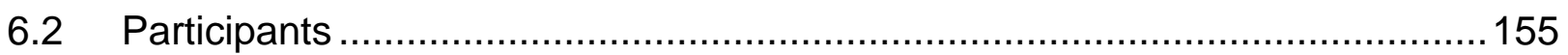

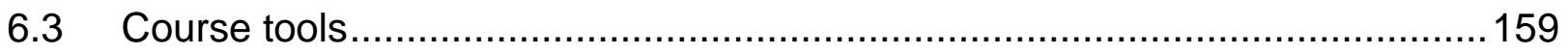

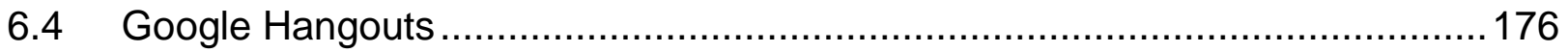

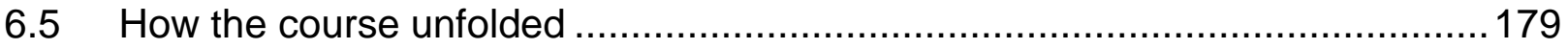

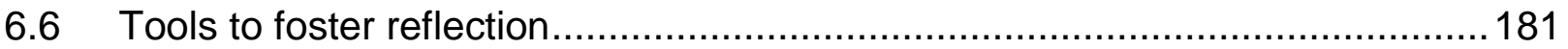

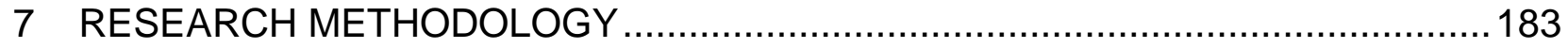

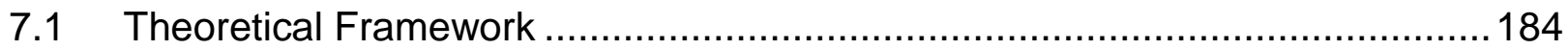

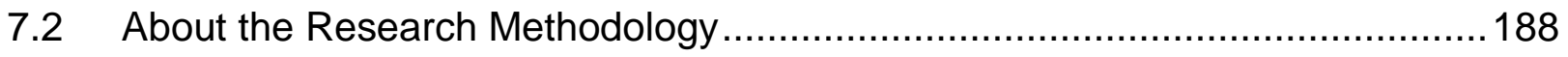

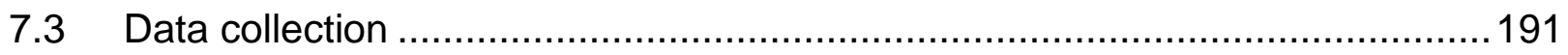

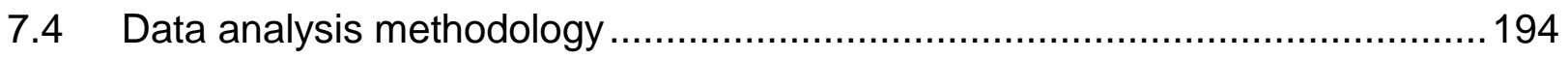

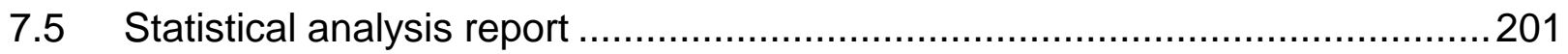

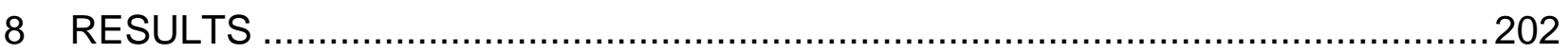

8.1 Results for research question 1 - Linguistic exchange sessions examples .....203

8.2 Results for research question 1 - Pre-course questionnaire .........................208

8.3 Results for research question 1 - Post-course questionnaire .........................211

8.4 Results for research question 2 - Linguistic exchange sessions examples .....215

8.5 Results for research question 2 - Pre-course questionnaire …....................221 
8.6 Result for research question 2 - Post-course questionnaire .........................223

8.7 Results for research question 3 - Linguistic exchange sessions examples .....227

8.8 Results for research question 3 - Pre-course questionnaire …....................233

8.9 Results for research question 3 - Post-course questionnaire ........................236

8.10 Students' reflections on their foreign language learning environment - pre- and

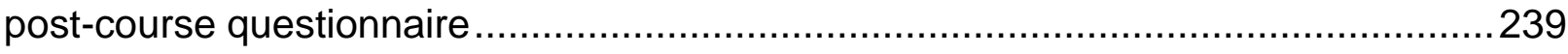

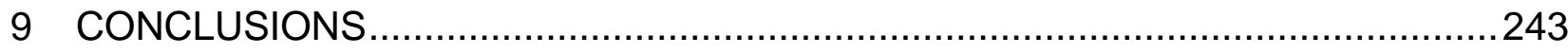

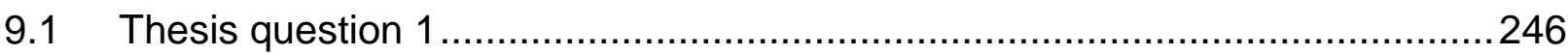

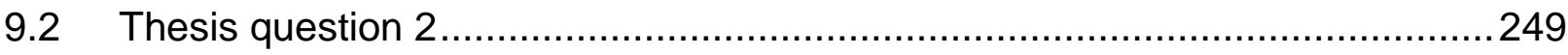

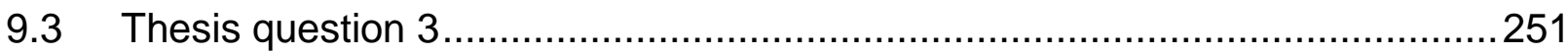

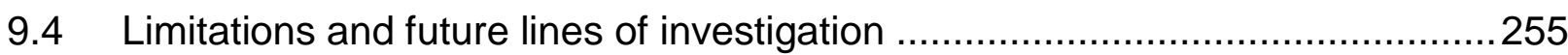

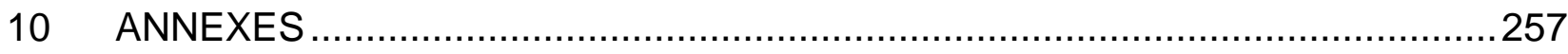

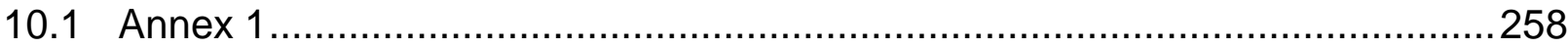

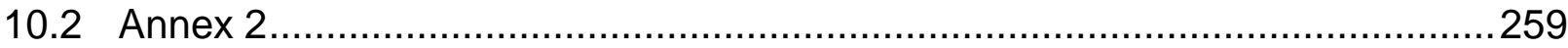

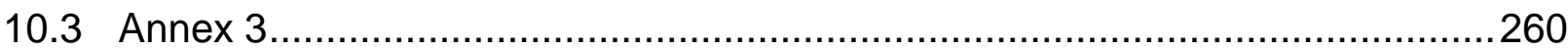

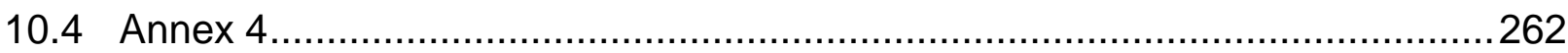

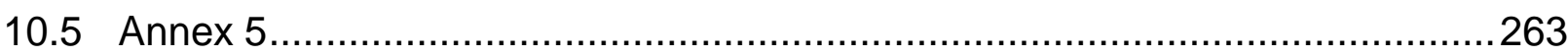

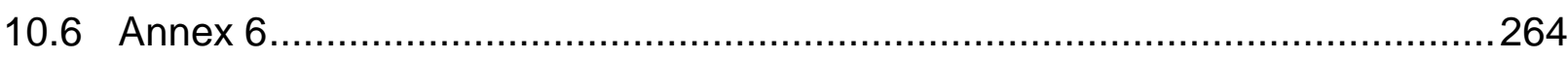

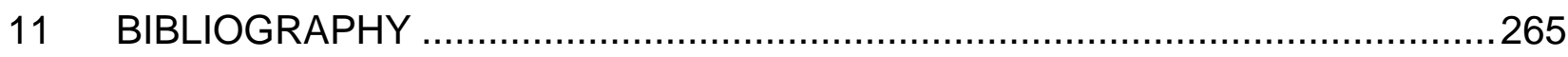




\section{INDEX OF TABLES}

Table 1: Participants and General Information about Students who Enrolled 158

Table 2: Results and Examples from the Language Sessions Relevant to Research

Question 1

Table 3: Results of the Pre-course Questionnaire for Questions which are Relevant to Research Question 1 209

Table 4: Results of the Post-course Questionnaire for Questions which are Relevant to Research Question 1

Table 5: Results and Examples from the Language Sessions Relevant to Research

Question 2

Table 6: Results of the Pre-course Questionnaire for Questions which are Relevant to Research Question 2

Table 7: Results of the Post-course Questionnaire for Questions which are Relevant to Research Question 2

Table 8: Results and Examples from the Language Sessions Relevant to Research

Question 3 .230

Table 9: Results of the Pre-course Questionnaire for Questions which are Relevant to Research Question 3

Table 10: Results of the Post-course Questionnaire for Questions which are Relevant to Research Question 3

Table 11: Results of the Pre-course Questionnaire in regard to Students' Reflections on their Foreign Language Learning Environment - Both Traditional and Online. 240 Table 12: Results of the Post-course Questionnaire in regard to Students' Reflections on their Foreign Language Learning Environment - Both Traditional and Online. 


\section{INDEX OF FIGURES}

Figure 1: Structures of Whorf's agument linking language, the individual and culture (Lucy, 1992b)

Figure 2: Stages of distance language learning - Wang and Sun's Four Generational Model (Wang \& Sun, 2001:541).

Figure 3: Content folders.

Figure 4: Home page and What's new 163

Figure 5: Course information 164

Figure 6: Journals 168

Figure 7: Tools 172

Figure 8: Help 173

Figure 9: Contact 174

Figure 10: A Google Hangout session 177

Figure 11: Theoretical framework for online foreign language learning 184

Figure 12: The student's autonomous working skills in the online Foreign Language Learning environment

Figure 13: Other learners (peer-support) in the online Foreign Language Learning environment

Figure 14: The importance of relevance in the online Foreign Language Learning environment

Figure 15: Students' understanding of intercultural communication as being relevant to learning foreign languages

Figure 16: Motivation and thus non-abandonment, retention and continuity in course because of the interaction and presence of these three areas 187

Figure 17: Flow chart of the research methodology..... 188 


\section{INTRODUCTION}

This study into the motivational aspects of online foreign language learning (FLL) was inspired by the author's personal interest in FLL and experience working in the field and because of the increasing interest in web-based, open, distance and online learning which inevitably leads to and is synonymous with autonomous learning and peer interaction. Its purpose is to find an approach that can be applied to ensure continuity in online foreign language learning. The focus of the study is on how learners can be encouraged to maintain interest and motivation in an online foreign language learning course, specifically by exploring how the relevance of the course content, peer-support and autonomous working behaviour can ensure participants do not abandon their course of studies. Using the learning management platform Blackboard to deliver an English and Spanish for Specific Purposes course in Intercultural Communication (ICC) and Google Hangouts for peer interaction and tutorials, the thesis studies and describes recurrent patterns and variations in motivational aspects of online language learning: 1) the different roles and identities which are co-constructed between peers in each group, the support and interaction that stems from those relationships and how this motivates students; 2) how learning about ICC facilitates and deepens the language learning process and how acknowledgement of this relevance motivates students to further practise and continue studying their chosen target language; and 3) the degree of involvement and awareness that students have in this course and how it is motivated by autonomous learning.

The background and theoretical review for this thesis begins with the approaches to foreign language learning (also known as second language learning, even if the language being learnt is the third or subsequent) that exist, starting with general learning theories and the main authors who exposed them in Chapter 2. Pavlov (1955) and Skinner's (1957) behaviourist theory for learning is applied to a foreign language acquisition approach whose methodology focused on repetition, continuous practice, and habit formation known as the stimulus, response and reinforcement methodology (Richards 2006). Richards (2006) wrote that techniques used in this approach included 
memorisation of phrases and entire conversations, question and answer practice, drills, guided speaking and mastery of grammar rules and structures. A structuralist approach resulted in introducing the very popular audio lingual method to the foreign language learning classroom which gave way to the rationalist approach and contrastive analysis led by Lado (1957). Later, Chomsky (1957) revolutionised the field of language learning with his ideas on innativism and universal grammar which was translated into the foreign language learning field by Krashen (1982, 1988, 1998), among others. Krashen (ibid) emphasised the importance of continuously practising a foreign language in order to truly acquire it: "Production ability emerges. It is not taught directly" (Krashen, 1982:21-22). This moved the focus in FLL away from something that is taught by the teacher towards the idea that it had to be internalised by the student. Functionalism saw FLL as a communication system and thus it must be taught in real life scenarios to be fully understood. This idea began to be fully developed by Halliday (1961) arguing that language cannot be understood in isolation, it had to be learnt in the context in which it arises: "Learning language is learning how to mean" (Halliday, 1973:345). Also, TortMoloney (1997:1) stated that "[...] no one learns what is taught, and no one teaches what you learn." This inevitably leads to the discussion in Chapter 3 on autonomous language learning. The shift in focus from the teacher to the learner also occurred because of the trend towards a more individual philosophy in a changing western society. In addition, a more mentalist view of learning began to emerge: cognitive psychology critiqued the mechanical stimulus-response way of learning and highlighted the importance of the individual and their internal, mental processes on behaviour.

Constructivism, studied by Bruner (1960) and Gange (1970), shifted the focus of knowledge as a product to knowing as a process. Vygotsky (1978), who also wrote about the learning process as a cognitive activity, thought that social environments, significantly peers and the More Knowledgeable Other, were fundamental to successful learning. Krashen (1981) also noted the significance of the context in which the language is being learnt. Peterson and Coltrane (2003) note that "[...] in order for communication to be successful, language use must be associated with other culturally appropriate behaviour". In order to explore these features two further areas had to be explored, 
autonomy skills in FLL and the importance of the cultural context in which a language develops and is used. Chapter 3 explores the rapidly growing body of work in autonomous learning specifically in FLL, while Chapter 4 explores intercultural communication and how language develops together with, and is affected by, culture. In Chapter 3 the term autonomy is fully detailed within the context of FLL.

During the course given for the experimental phase of this thesis the psychological and emotional attachment the students formed with the course process and content was a result of their self-directed learning abilities and opportunities to determine their own learning process (Little 1991). These skills were supported and encouraged by the peer interaction students were exposed to during the Google Hangouts sessions. Bobb-Wolf's (2002) emphasis placed on the social aspect of FLL proved to be an important aspect for the results of this thesis and that area is also explored in depth. Bobb-Wolf (ibid) believes that when the learner realises that they can learn from and be motivated by peers the learning process becomes more autonomous. Dam (1994) also focuses on the social dimension to the concept of learner autonomy: "Learner autonomy is characterized by a readiness to take charge of one's own learning in the service of one's own needs and purposes. This entails a capacity and willingness to act independently and in cooperation with others, as a socially responsible person" (Dam, Ericksson, Little, Millander \& Trebbi, 1990:102). Esch (2009) and Dickinson and Ushioda $(2001,2008)$ highlight the important link between autonomous language learning and motivation. Gardner and Lambert's (1972) studies into motivation and language learning is thoroughly explored, including how the relevance of what students are learning is important in continuing with their studies and retention in education courses. According to Dörnyei (2001) and Ushioda (1996) the natural tendency of all learners, in all fields, is to lose sight of established objectives or give way to distractions. So maintaining view of the relevance of what learners are learning is of high importance. The relevance of culture in FLL is the theme for Chapter 4. It begins with a review on von Humboldt (1999) and linguistic relativity. Later, the Sapir-Whorf hypothesis (1956), which also explains the relationship between language and culture, is exposed. Although it is a concept that fell out of popularity during the $70 \mathrm{~s}$, it has been recently recovered by researchers such as 
Boroditsky (2010) and Deutscher (2010). This chapter moves on to review the work by anthropologist Hall (1959) who creates a framework for a theory of culture considered in its entirety as a form of communication and who categorises the term culture in order to facilitate its study and analysis. These different categories serve as items that can be compared, reflected on and analysed and were part of the basis units for the English and Spanish for Special Purposes ICC course developed for this thesis. Hains and Meyer (1991) believe that intercultural competence gives people the ability to act appropriately and flexibly when confronted with the behaviours of people from other cultures which facilitates communication and thus understanding cultural significance of a people's discourse enables the language learning process.

The last chapter in the first, theoretical part of the thesis focuses on online and distance language learning. First, the history of distance education and learning is exposed and the different approaches that exist for it: Autonomy and independence theory, industrialisation theory and the communication and interaction theories along with important authors in this area of study (Bath 1979; Delling 1987; Holmberg 1983; Peters 1983; Wedmemeyer 1981). A comparative study of online learning follows through the construction of a framework of the evolution of technological tools used in distance learning using Wang and Sun's (2001) four generational model and Garrison's (1985) three key stages in the history of distance education to shape its evolution. The section then focuses on the relatively new concepts of connectivism (Downes 2006; Siemens 2005) and MOOCs (Conole 2013; Daniel 2012). The main issues that occur in distance and online learning, such as feelings of isolation and lack of motivation (Lake 1999; Lorenzetti 2005; Wegner 1999) are thoroughly explored because they must be addressed in order to ensure learner success in online learning environments. Although distance, online learning is a rapidly growing phenomena for many reasons (it is more affordable and it is more accessible, among others) it is actually an area that has extremely high abandonment percentages. This could be because some learners who enrol in courses are merely curious about the subject matter and have no real intention of completing the course (the tourist learner) but as abandonment percentages are also high in traditional distance learning, during the literature review done into this area it 
became evident that there was a lack of research into how this could be addressed. Knowing that there was already a substantial body of work on the importance of autonomy, peer support and the relevance of ICC in FLL, the author wished to explore this discourse type further but in an online and distance education context which included investigating how motivational aspects of learning within these non-traditional settings might eventually be of practical value. While conducting the experimental course, it rapidly became evident that autonomy, peer support and the relevance of ICC was important for motivation in online language learning courses and that those concepts ensured students continued to be motivated throughout the course.

The first intention at the outset of this research was to identify the norms and practices of successful online foreign language learning. From the literature review, because of previous research results into motivation in traditional classroom, and due to the reasons of high abandonment rates of distance and online learning, the author hypothesised that non-abandonment in online language learning classes would be closely linked to students' perception of relevance of the course they were studying to both their professional and personal lives; close interaction with their peers and autonomous learning behaviours. An online language learning course was developed to observe students' motivational factors unfolding within the course and test the hypothesis put forward regarding their decisions to abandon or see the course through to completion. If the three areas above proved to be sufficient - and visible during the course - to encourage students to continue with their chosen online foreign language learning course they will not abandon this course of study. If the hypothesis is proved correct, these practices will need to be analysed and examined so that the patterns motivating students to continue learning and those implicated in the construction of successful learning outcomes are exposed for the purposes of this thesis and for future foreign language learning curriculum planning; developing and then applying these findings to useful language learning programmes, in particular by raising awareness of ways in which students are sufficiently motivated to not abandon their course of language studies.

Thus, the specific research objectives of this thesis are: 
To explore the co-existence and interconnectedness between peers, students' indications of autonomous behaviour and the significance of relevance for continuity within a distant / online learning environment and how these issues relate to motivation.

On this basis, three research questions were formulated:

1. The motivational influences of autonomous behaviour on continuity in online language courses and distance language learning.

2. The importance of course relevance as a motivational influence in online language courses and distance language learning

3. The motivational influences of peer support and interaction on the continuity in online language courses and distance language learning

In order to answer these research questions, the methodology chapter was designed to describe the methods and instruments used to gather data to reach conclusions which would support or negate the thesis questions. The ICC course used was partly based on Hall's (1959, 1966, 1983) work analysing the implicit patterns differing cultures, Hofstede's framework $(1984,1991)$ categorising cultural aspects into dimensions and partly adapted from the University of the Pacific's 'What's Up With Culture?" online cultural training resource for study abroad resource website. Permission was requested to translate and modify resources from this website and it was communicated that the 'What's Up With Culture?' project was originally funded by a Foundation for the Improvement of Post-Secondary Education (FIPSE) grant through the US Department of Education and as such, "[...] the website is considered public domain and its creators encourage educators to use it in whatever way they think would benefit their students (so long as the institution is a non-profit educational entity)" (quote from reply to the original email requesting permission to use and translate resources on the website; see Annex 1 - Email communications regarding course). The Intercultural Communication course was located purely online and the learning content delivery method used was the Blackboard platform. 
The participants were located in many different countries around the world, residing in the UK, Spain and Costa Rica. Students were foreign language learners, specifically native English speakers learning Spanish and native Spanish speakers learning English. The platform used for the linguistic and cultural exchanges was Google Hangouts. The methodology used to fully explore these three questions was first, to develop the aforementioned English and Spanish Special Purposes ICC course that was relevant to the students and that could serve to record examples of motivation through peer interaction and autonomous learning skills. Second, a principle of organisation had to be found for the ensuing analysis. Each of the three thesis questions demanded a slightly different analytical focus but in order to gather the results necessary the author used the same qualitative data analysis methodology as proposed by Huberman \& Miles (1994) and Dörnyei (2007) for all of them. Third, pre- and post-course questionnaires were written up so as to be able to fully gauge from a personal perspective the students' perception and opinions of these areas. The questions in these surveys were organised into the same categories so that the pre- and post-course questionnaires' perspectives could be easily compared.

The methodological design for the data collection is then explained and the next section examined the profile of the students who participated in the course. The electronic platform used for the course is explored in greater detail in the following section before moving onto discussing Google Hangouts used for the linguistic and cultural exchanges, exposing the ICC course content and tools used within the course platform. The next chapter provides the results of the data analysis made from the data collected including with the participants' reflection on learning foreign languages and the role technology plays in that process and most importantly the motivating factors for their participation. This analysis followed an inductive method because it "develops a framework of the underlying structure of experiences or processes that are evident in the raw data" and "provides an easily used and systematic set of procedures for analyzing qualitative data that can produce reliable and valid findings" (Thomas, 2006:237).

The steps suggested by Miles and Huberman (1994) were used as a guide: data collection, processing, categorising and treatment of data and finally, obtaining results 
and drawing conclusions. First the data was gathered through the systematic recording of the discussions during the exchange sessions and from the results from the pre- and post-course questionnaires in addition to the theoretical framework established from the literature review. Next the data was processed into a categories and analysis unit so it could be more easily analysed (Silverman, 2010). Open coding (Strauss \& Corbin, 1990) was used as it is a process that determines concepts and identifies patterns from the data, it was chosen for the coding process because, although the general area of study had already been determined, the specific research questions were not clear before the data collection took place. Unlike the deductive approach, where the researcher adapts data to existing categories, this approach allowed the categories to emerge through patterns in the data analysis, establishing the thesis questions. After the data was analysed again for each thesis question, the conclusions reached are discussed in detail in the final chapter, which also includes the limitations of the study and future lines to research in order to build off this work. 


\section{FOREIGN LANGUAGE LEARNING}

This chapter will describe the evolution of foreign language education and learning during the $20^{\text {th }}$ century up until today. It begins by describing the paradigm shift that has taken place in recent decades, especially in matters to the psychology and cognitive forms of learning and education. It also discusses briefly the educational mainstream approaches that have been popular throughout the second half of the twentieth century until now. Constructivism will be focused on in some depth, emphasising some of the different variants which arise from it, notably psychological constructivism and social constructivism. Finally this section explores the principals and influence of Vygotsky on second language learning.

Language teaching has undergone a significant paradigm shift since the $1980 \mathrm{~s}$. The changes in the way learners acquire knowledge and the way teachers teach and instruct, combined with the introduction of new technologies into the language learning classroom have resulted in dramatic changes in the approaches devoted to language learning processes that have been considered since the end of the Second World War when there was a push towards foreign language learning as a tool for global integration. This movement was led by changes in philosophy, psychology and education and learning theories.

Exposed below are the principal schools of how learners learn, almost following a chronological order, although some overlap to some extent. These are approaches to learning and not techniques or methodologies, which can vary widely among the different approaches. 


\subsection{Approaches to foreign language acquisition}

The language learning methods used today are a result of experimentation and development of other approaches which will be explained briefly in this section. Behavioural approaches to learning include two main schools: classical conditioning, researched by the physiologist, Pavlov (1927), and operant conditioning. The main idea in classical conditioning is association: if two stimuli are repeatedly experienced together they will become associated and automatic. The classic Pavlov experiment used as an example for this idea takes place when Pavlov was studying salivation in digestion; his team weighed how much saliva dogs produced when fed. He noticed that the dogs would salivate as soon as they saw the meat, before they ate it. Pavlov began to do further experiments; he would ring a bell before feeding the laboratory dogs and the dogs would then salivate upon hearing the bell, associating the bell with food. A stimulus is an occurrence that manifests context which can force the subject or learner to respond or can control them to perform a behavioural response, an action or behaviour. Such a stimulus is anything that can directly influence behaviours, producing a response. Proponents of behaviourism believe that when any complex behaviour or performance pattern is analysed, it can be found that to be made up of conditioned reflexes. When a response is conditioned by stimuli it is referred to as conditioned response in classical conditioning.

On the other hand, operant or instrumental conditioning is a type of learning where the impacts of behaviour result in changes in the expectation that the new behaviour will occur: 'Behaviour that brings about a satisfying effect (reinforcement) is apt to be performed again, whereas behaviour that brings about negative effect (punishment) is apt to be suppressed' is implied from the 'Law of Effect' developed by Thorndike (1911). Reinforcement is a result that increases the probability that behaviour will occur and punishment is the opposite. There is both negative and positive reinforcement and punishment. They correspondingly increase or decrease the probability that behaviour will be repeated. Skinner based his work on these experiments. Skinner $(1938,1957)$ 
argued that not all human learning is as automatic and deliberate as suggested by classical conditioning. Most behaviour is not caused by stimuli, but produced at will. The learner interacts with their surroundings and environment to actively produce different consequences. Skinner (1938) believed that the response which is connected to a new stimulus is not a reflex. The idea was to reinforce or reward the correct behaviour that the learner produces spontaneously and not to reinforce bad or incorrect behaviour. Behaviour operates on the environment; the learner's correct response is the product or reward.

As can be noted, core to all behaviourism is the assumption that human learning is determined by behaviour and that behaviour can be modified by reward, punishment and reinforcement. So it follows that foreign language acquisition could be achieved with forming habits through a process of stimulus, response and reinforcement. Students receive linguistic input and their understanding is strengthened by repetition, learners' imitate and repeat what they hear, and by imitating responses automatically, the language is used naturally and freely and learning has then occurred. In this way humans acquire new skills, and these skills have an effect on the environment, and in turn it is the environment which supports and affects learning. If an action proves to have a positive outcome, if the target language being learnt is understood by a speaker of that language, the learner will be more likely to repeat that action. However, if the outcome is negative, if the target language being learnt is not understood by a speaker of that language, it is less likely the learner will repeat the behaviour (or incomprehensible utterance) (Skinner, 1957). A behaviourist approach to foreign language acquisition focuses on repetition, continuous practice, and habit formation and the stimulus, response and reinforcement methodology. Here, second language learning also bases itself on that there will be transfer in learning, a transfer of the native language into the target. Techniques that were used in this approach included memorisation of phrases and entire conversations, question and answer practice, drills, guided speaking and mastery of grammar rules and structures (Richards, 2006). This is simply the habit formation of translating or transferring a grammar structure, it is helpful (or positive) when the structure is similar in both the target and source language but interference occurs 
when the source or native structure is used inappropriately in the target language (i.e. adding an 's' to plural adjectives in English because of the native Spanish structure). This is known as negative transfer. This learning system is today seen as insufficient to what the complexity of second language learning entails as it emphasises observable, measurable behaviour and ignores mental behaviour and meaning; important when addressing cultural implications of language. It also leaves the question open as to how students know more than what they have heard or have seen in language classes.

Structuralism assumes that for every linguistic process there are underlying rules governing that action, the system is arbitrary, but as they exist they can be broken down into parts which can then be analysed. This approach was applied to teaching English in various ways. The most well-known was the audio-lingual which emphasised spoken language skills. Learners would hear phrases in their target language and would repeat those phrases, they could move on to the next stage after correctly imitating the phrase. The phrases they were repeating were translated into their native language so that they would know what they were imitating. Another structuralist method of teaching English is grammar translation. Learners were presented with a text, a list of vocabulary words and grammar rules used in that piece of written text for their target language. Students work their way through the text, vocabulary and grammar, learning the appropriate language with help and explanations from the teacher, thus the target language was broken into the chunk of grammar rules and translated so that they could be directly compared. Following from this Contrastive Analysis (CA) based itself on a comparison of the native language and foreign language. Lado (1957) believed that the way to teach languages was through a deep comprehension of the native language and comparing its phonetics, syntax and vocabulary structures one level at a time; discourse or conversation received relatively little attention.

Rationalism takes an internal stance, it argues that knowledge is innate and something that humans are born with. The learning process is simply a process where the learner reveals what they already know to themselves which occurs through a process of logical deduction and internal speech. The approach of Rationalism to language learning states 
that cognitive functioning is the main actor in the language learning process. While Behaviourism focuses on the results rather than how these results happen, rationalism tries to understand learning at its source, that is, the mental processes. It has been described by Carroll as follows:

\begin{abstract}
According to this theory, learning a language is a process of acquiring conscious control of the phonological, grammatical, and lexical patterns of a second language, largely through study and analysis of these patterns as a body of knowledge. The theory attaches more importance to the learner's understanding of the structure of the foreign language than to his facility in using that structure, since it is believed that provided the student has a proper degree of cognitive control over the structures of the language, facility will develop automatically with use of the language in meaningful situations. (Carroll, 1966:102)
\end{abstract}

During the 60s Chomsky (1957) developed his theory of first language acquisition. He suggested that language learning is an innate capacity - children are 'mentally configured' to acquire language because of their existing capacity of a Universal Grammar (UG). He thought that children were born with a language structure which meant that when babies learnt their first language they were not learning it completely from a 'blank slate' but simply building on a system of linguistic knowledge that they brought with them to the learning process. The theory underlying UG assumes that language consists of a set of abstract principles that characterise core grammars of all natural languages and that this $U G$ also assists learners when learning a second language. UG thus guides the learner who has to simply 'fill in the gaps'. One of the most influential theories for second language acquisition that argues second language acquisition is innate was developed by Krashen (1982). It heavily influenced communicative language teaching, which is explored below.

While the above 'innate capacity' focuses on internal abilities to explain creative aspects of linguistic ability, functionalism contributes to an external focus. It emphasises the content of language and believes that language is mainly a communication system. The focus here is on both how the language is used in realistic situations and what knowledge the learner has of the language, the purpose of language for functionalists is communicative and to attain linguistic knowledge the learner must use the language. It is associated with the Prague school of linguists established in the 1930s and focuses on 
how elements in various languages serve to achieve various communicative functions (Tomlin, 1990), including non-verbal communication and the context of language. It organises language around different communicative functions, themes and situations, so that the learner has to analyse and understand the language in order to create their own codes of communication. By focusing on the individual learning process, this paradigm places the learner, rather than the process, in the centre of learning (Eckman, 1995).

Systems linguistics within the functional approach was elaborated by Halliday (1961); he explored language based on the different ways meaning can be expressed. Drawing on inspiration from work by anthropologist Malinowski, Halliday explored language structures and states that they cannot be analysed in isolation, without a physical and social context:

[...] language acquisition ... needs to be seen as the mastery of linguistic functions. Learning one's mother tongue is learning the uses of language, and the meanings, or rather the meaning potential, associated with them. The structures, the words and the sounds are the realization of this meaning potential. Learning language is learning how to mean. (Halliday, 1973:345)

He used the term as the purposeful nature of communication and outlined seven functions of language: (as classified by Richards \& Rogers (1986:70-71): instrumental, using language to get things done (goals, expressing needs); regulatory, to control the behaviour of others (commands, request); interactional, to create interaction with others (forming relationships); personal, to express meaning (feelings, opinions, individual identity); heuristic, to learn and discover (exploration, knowledge); imaginative, to create other worlds/realities (stories); representational, to communicate information (facts).

This is also relevant when considering the reasons why culture must be understood when the objective is to understand a foreign language. Linguistic structures are reflections of the task that language is trying to carry out; language is seen as a tool for carrying out cultural functions. "In attempting to convey a meaning, people do not only create utterances involving grammatical structures and words, they also carry out actions via those utterances. Austin (1962) introduced Speech Act Theory but Searle (1969) developed and popularised the idea. The fundamental concept of it is that language is 
used to carry out actions. It is not within the scope of this paper to enter into the philosophy of language and language use, however Austin and Searle's Speech Act Theory outlines how language also functions as actions, they build on the philosopher Wittgenstien's (1922) famous theory of language as a cultural tool. This will be further investigated in the chapter on the importance of cultural knowledge in language learning. Functional language teaching differs from communicative language teaching, which will be explored below, in that functionalism focuses on the functional use of English, to accomplish a particular purpose. Functionalism also serves to shift the focus from the teacher to the learner. Learning rather than teaching is emphasised in the learning process as learning now takes place inside the learner; they must learn to use the functions of the language. The learner's accumulation of past experiences, needs, interests, expectations and learning potential are now all considered and the teacher must necessarily take all of those into account and adapt to it.

This paradigm shift regarding the role the teacher performs in the learning process is significant. Approaches until now have placed the teacher as the main source of information, in the case of language learning, on the structure of the target language. The methodologies mentioned above, especially the 'grammar-translation' and the 'audio lingual' methodologies meant that the teacher's work was focused on using materials to bring the language to the learners, in a teaching model where the learner was thought to be immediately able to internalise and reproduce or imitate the target language that was presented in a specific sequence. Thus, in the synthetic paradigm, in addition to guiding the student through the material, the teacher also had the responsibility of evaluating the learner to ensure they had adequately retained the information that had been presented in the materials. However, this method failed to realise that mere repetition was no guarantee of learning. Through research in language acquisition, it is now known that interaction plays a crucial role in learning (Long, 1985; Pica, 1989; Porter, 1985, 1986). It is now also known that a variety of input (the foreign language material and content to which students are exposed) must exist in order for the acquisition process to happen in a more natural way (Long, 1991; Krashen, 1982, 1988). Today's classroom tries to include these concepts by setting up real-life communication situations in which the 
learner can practice. There is a discussion about whether communicative language teaching is an approach or a method but, regardless of this, the theory of communicative language teaching is that real learning comes from practicing in real life situations (or as real as possible in the language classroom). It follows the theories of Universal Grammar and Innativism as it believes that learners' natural language knowledge will allow them to use natural strategies to achieve foreign language acquisition. In the classroom, this translates into using materials that place the learner in authentic situations such as roleplaying, so that conversation and foreign language practice are as natural as possible.

During the 1970s, as the focus on grammar began to be questioned and a new mainstream trend began to emerge, people began to believe that communicating in foreign languages needed much more than a grasp of the grammatical structure. There was a shift towards using language for different and practical purposes and being understood in real life, natural situations: communicative competence. The term communicative competence was coined by Hymes who wanted to go further than Chomsky's 'rule governed creativity' (Hymes, 1967) because it did not account for the social rules and working of language. These are the aspects of language that allow us to convey meaning in different and within specific contexts. Savignon (1983:9) noted that "[...] communicative competence is relative, not absolute, and depends on the cooperation of all the participants involved". Language communication was a dynamic interpersonal activity and not the intrapersonal construct that Chomsky had focused on.

The approach developed from the linguistic sub-discipline of socio-linguistics and the curriculum that arose from this area of study was the study of language in its social context. This curriculum had to:

[...] identify the following aspects of language use in order to develop learner's communicative competence:

1. As detailed a consideration as possible of the purposes for which the learner wishes to acquire the target language; for example, using English for business purposes, in the hotel industry, or for travel

2. Some idea of the setting in which they will want to use the target language; for example, in an office, on an airplane, or in a store

3. The socially defined role the learners will assume in the target language, as well as the role of their interlocutors; for example, as a traveler, as a salesperson talking to clients, or as a student in a school

4. The communicative events in which the learners will participate: everyday situations, 
vocational or professional situations, academic situations, and so on; for example, making telephone calls, engaging in casual conversation, or taking part in a meeting

5. The language functions involved in those events, or what the learner will be able to do with or through the language; for example, making introductions, giving explanations, or describing plans

6. The notions or concepts involved, or what the learner will need to be able to talk about; for example, leisure, finance, history, religion

7. The skills involved in the 'knitting together' of discourse: discourse and rhetorical skills; for example, storytelling, giving an effective business presentation

8. The variety or varieties of the target language that will be needed, such as American, Australian, or British English, and the levels in the spoken and written language which the learners will need to reach

9. The grammatical content that will be needed

10. The lexical content, or vocabulary, that will be needed. (Van Ek \& Alexander, 1980:58-60)

As there was a genuine interest in making language learning authentic, Clarke and Silberstein (1977) stated that: "Classroom activities should parallel the 'real world' as closely as possible. Since language is a tool of communication, methods and materials should concentrate on the message and not the medium. The purposes of reading should be the same in class as they are in real life" (Clarke \& Silberstein, 1977:51).

Canale and Swain (1980) analysed communicative competence and identified four dimensions to it: grammatical competence, sociolinguistic competence, strategic competence and discourse competence. According to them, the goals of communicative language teaching are to be able to use language for a range of different reasons and purposes, inferring a difference between the use of language according to the context and people who interact together (e.g. when to use polite language in formal situations), knowing how to produce and understand different types of texts (e.g., stories, letters, business writing, small talk), knowing how to express oneself even though there are limitations in language knowledge - using different kinds of communicative strategies or explaining what you do not know how to say. 


\subsection{Developments in the field of foreign language education}

This paradigm shift throughout the last decades of the twentieth century is reflected in the emergence and development of various streams of learning. Besides appearing as psychological and philosophical currents, these changes also affected different educational theories and teaching methodologies in foreign language learning. The changes that take place during the 60 s and 70 s developed from an intellectual shift that marks a departure from behaviourist ideas to cognitive theories and other areas of study, such as discourse analysis, pragmatics, sociolinguistics and developing specific areas in the functional approach. These new areas of study favour a focus on communicative approaches to language teaching, emphasising contextualisation as opposed to what had hitherto been a decontextualised acquisition of target language (Candlin, 1980; Littlewood, 1981). The idea that the foreign language learning process should be a communicative process placed the learner in the centre of the learning processes for the first time, it was now the learner who learnt, not the teacher who taught (Nunan, 1988; Yule, 1989), as learning was something that took place inside the individual and because of the learner's efforts, rather than as a reaction or an external behaviour change to what was taught to them. Communicative approaches, quickly gave way to a more emphasis on independent learning. Similarly, changes in educational systems and foreign language teaching were indicative of other changes in other social, political, philosophical and economic fields and how that knowledge was constructed and exchanged. These changes meant that the successful learner was increasingly seen as a person who was able to build knowledge directly from their experiences of the world and not so much a person who simply responded to specific training properly. This introduces not only the idea that will be explored in chapter 2 on the autonomous learner, but also a new way of looking at learning as a constructed knowledge.

Current trends in language learning during the twentieth century, which mainly include constructivism and cognitive learning theories, put an emphasis on the learner. "Knowledge is not passively received, but is actively built up by the cognising subject. 
That is, ideas are not placed inside learners' heads, they will and must construct their own meanings" (Wheatley, 1991:10). The constructivist approach to learning is summarised in that teachers cannot transmit knowledge to the learner, they have to use the learner's existing knowledge to construct further, new knowledge. Throughout the twentieth century there have been three major currents in education and the learning process, which are: behaviourism, cognitivism and constructivism. The fundamental distinction between them is their way of how a learner acquires knowledge. As noted above, behaviourism extends along the first half of the twentieth century, Watson (1919, 1928) defines psychology as a science of behaviour. For Watson, psychology, rather than consciousness as it had been until then, was only a matter of behaviour, what subjects said and what was observable. Watson believed that psychology was a natural science, having as its purpose the prediction and control of behaviour which can be measured, trained and changed (Watson, 1919, 1928, 1930). Behavioural psychology's purpose was "To predict, given the stimulus, what reaction will take place; or, given the reaction, state what the situation or stimulus is that which has caused the reaction." (Watson 1930:11). Watson also stated that the individual is the result of their experiences and interaction with the environment, their behaviour was the result of their adaptation to their context after a period of exposure to a given stimulus, when someone is born their mind is a 'table rasa', a blank slate, and behaviour is learnt from the environment. New behaviour is learnt through classical or operant behaviour. He summarises this idea in the following quote: "Give me a dozen healthy infants, wellformed, and my own specified world to bring them up in and I'll guarantee to take any one at random and train him to become any type of specialist I might select - doctor, lawyer, artist, merchant-chief, and, yes, even beggarman and thief - regardless of his talents, penchants, tendencies, abilities, vocations, and race of his ancestors. I am going beyond my facts and I admit it, but so have the advocates of the contrary and they have been doing it for many thousands of years." (Watson, 1930:82). Watson had based himself on writings by Pavlov and Skinner (see above). According to the experiments conducted by these researchers, learning occurs when there is a change in an observable behaviour: the individual has adapted to the conditioning context. However, during the mid-twentieth century, a new approach to learning developed which put the 
spotlight on the importance of the subject, it was a cognitive revolution, an intellectual movement that begun in the 1950s with the cognitive sciences: psychology, anthropology and linguistics, developed within the (very young) field of neuroscience. In this new trend that tried to understand the brain better, cognitive psychology sought to understand what mental processes happened to the learner, what changed throughout the learning process. Thus knowledge becomes a symbolic mental conception in the mind of the learner. Learning, therefore, is defined as the process by which the learner puts this knowledge or symbolic representation into their memory and into the mind. Learning takes place when the new information is stored in a meaningful and organised manner. The learner learns new content by organising and categorising the information and then storing it correctly in their mind so that they can then easily and successfully access it for future use and reference. All types of new knowledge are mental models, organised in such a way that the learner can transfer this information to different contexts. Cognitive psychology critiques the mechanical stimulus-response way of learning. It highlights the importance of the individual and their internal, mental processes on behaviour. The individual interprets reality and acts on that interpretation and experience. Cognitivism considers knowledge as a representation in the mind of the individual. Not unlike cognitive psychology, the development of learning in constructivism requires that the learner engages in meaning-making. In contrast to behaviourism, constructivists believe that "[...] knowledge is not passively received but built up by the cognizing subject" (Glasersfeld, 1995:18). Thus, constructivists shift the focus from knowledge as a product to knowing as a process. Knowledge is 'construction' carried out by the learner, it is not a copy of reality or their environment as knowledge is known and learnt in a personal and subjective way (Tippins, 1993), it does not exist outside of the learner. Constructivism believes that learners can best understand knowledge that they themselves have constructed. Learning involves real world situations and interaction among other learners and teachers; the learners are central in the process as what is learnt is heavily affected by their experiences and context and mental state. When the learner feels they are prepared, they collect selective information, consider it until they understand it, use it and draw conclusions (form opinions) about it. Constructivism was considered an approach 
that would turn classrooms into a space where knowledge creation takes place and where information could be learnt through use and by absorbing it and knowledge built (and constructed on) by the learner. Unlike traditional classrooms, in these spaces the teacher becomes a facilitator and their role and function is to guide learners and rather than teach, serve as sign posts for them to find their own way through the learning process; these learners ask questions and discuss the subject matter with the teacher and other learners in order to learn and situate the new knowledge. It would be through this interaction that learners would learn as they are accountable for their own learning. The teacher supports the learner by means of suggestions that arise out of ordinary activities, by challenging them to reinforce ideas and trying to inspire creativity and in turn discussions. Teachers are encouraged to create classroom projects that encourage and make spaces for independent thinking and which facilitate the development of information. Students work in groups where problems and new knowledge are discussed with the assumption that this would result in the creation of practical solutions in real life situations.

A major proponent of the constructivist theory is Bruner. In The Process of Education (Bruner, 1960) he states that learning involves the learner building or constructing concepts based on their current knowledge. The purpose of education is therefore to build on the learner's knowledge, using their own thinking strategies, problem solving skills and cognitive abilities which are different to each individual because of their different experiences, education and upbringing. These skills can then be transferred to any situation that arises. He also introduces the idea of the 'Spiral Curriculum' which is where complex ideas are introduced in a simple manner, with simple ideas that follow logically on from knowledge that is already attained, education is taught at increasing levels of difficulty, always starting from the level the learner already has. Like Bruner, the Russian psychologist Vygotsky thought that social environments help learners learn. Context and the instructor facilitates the learning process by providing them with knowledge that is based at their level, while at the same time helping them develop the skills they needed to learn. Put in other words social learning is a precursor to cognitive development. In fact, he went as far as to write that higher mental processes could only 
be achieved in a social context. The two main principles of Vygostky's work are the More Knowledgeable Other (MKO) and the Zone of Proximal Development (ZPD). The MOK refers to a person who is more knowledgeable and has higher thinking skills than the learner, they do not have to be an adult or traditional teacher; they can be a peer. The MKO is related to the second principle which is the ZPD. This principle is important in helping the learner achieve higher level cognitive skills with the help of someone who has the knowledge, and leads to the child learning the concept faster than if they were to try to figure it out on their own (Vygotsky, 1962, 1978). Vygotsky and these concepts will be explored below.

Gagne $(1970,1977)$ defined constructivism by outlining five major categories of learning: verbal information, intellectual skills, cognitive strategies, motor skills, and attitudes. For each category there exist different conditions needed to achieve learning, which can be external or internal conditions. His position on constructivist learning was that there are hierarchies for intellectual skills to be learned based on complexity and that higher levels of complexity build off lower ones.

Establishing a clear division between the different forms of constructivism is a difficult task, as they are all based on the same approach to the development of learning in the mind of the individual and other psychological processes, that "[...] knowledge is constructed in the mind of the learner" (Bodner, 1986). However they can be separated into two main and important fields: cognitive constructivism and social constructivism.

Both Piaget $(1953,1959,1964,1969)$ and Vygotsky $(1978,1986)$ based their contributions to the development of intelligence and its social construction. But whereas Social Constructivism believes that learning is a collaborative activity and that learners develop in the context of socialisation and their environment, cognitive constructivism places the focus on learners constructing knowledge themselves. Piaget explains the learning process through schemes, which are qualitative as well as quantitative. These schemes and structures are acquired when moving from one level to the next. Piaget's cognitive theory has three main components. The first of these components is schemas: considered units of understanding or linked mental representations used to understand 
situations. These units of understanding are stored and applied when needed. They can build on each other in a hierarchy or they can be formed into complex relationships. In order to build upon the existing schemas, these existing schemas need to be brought to the conscious level. The second is adaptation: a process of adaptation to the world through assimilation and accommodation, adapting the existing schema when it does not work with the new knowledge or situation. Equilibrium is achieved when the learner is able to accept the new information. The final one is stages of development, which refer to 4 stages of children's development and are not relevant to foreign or second language learning (it may be to first language learning but that does not enter this scope either). Piaget's developmental theory of learning and constructivism are based on discovery by the learner's themselves. According to his constructivist theory, the best learning environment that can exist is one where the learner can construct knowledge that is meaningful for them.

Bruner $(1990,1996)$ believed that the most important principles to cognitive constructivism were learnt through discovery - learners are presented with examples and they work with them until they discover interrelationships or the core of the examples. His studies in teaching approaches encouraged concept learning and development of thinking. Bruner's work focused on understanding the context of a subject being studied or the subject structure - the fundamental ideas, relationships or patterns in the field that connect all essential information - he thought learning would be more useful and memorable if learners focus on understanding the structure being studied. Active learning is a base for real understanding as well as inductive reasoning (Bruner, 1960, 1966, 1973, 1985).

Social constructivism also holds that knowledge is not transferred from teacher to student but constructed in the learner's mind. However what makes this theory different is that for this approach, environment and context is the focus. Social constructivism emphasises the social, educational and historical contexts of learning and how that knowledge is built and constructed as a group (Horowitz, 2005). Meaning is construed through social interaction and knowledge arises through that interaction, that knowledge is then constructed in the learner's mind. So knowledge exists and its contents are 
located in the social and physical environment, everything and everyone contributes to learners' knowledge. (Rust, 2005).

Four tools help the learning process in this approach; scaffolding, cognitive apprenticeship, tutoring, and cooperative learning. Scaffolding builds on the learner's knowledge level, always pushing the current level up further and ensuring it is suitable for that particular learner. As the learners' competence or knowledge increases, the instructor scaffolds off that level to a higher one. Cognitive apprenticeship "[...] supports learning in a domain by enabling students to acquire, develop, and use cognitive tools in authentic domain activity." (Brown, 1989:123). Furthermore, "Cognitive apprenticeship methods try to enculturate students into authentic practices through activity and social interaction" (Brown, 1989:123). So the emphasis is that learning must take place in real world environments, that learners watch experts carrying out those tasks. Tutoring is a more personal way to mentor and give support to learners; it takes place between the learner and a more-skilled person. The final tool is cooperative learning; it focuses on group learning through experience and discussion. Proponents believe that learners should be encouraged to work cooperatively with other learners. Working in a group means that the learners who have knowledge can easily transfer that knowledge to those who do not, ensuring the group's success (Johnson, 1991; Kagan, 1985, 1989, 1990; Slavin, 1983).

Vygotsky meanwhile, states that knowledge is a product of social interaction and culture. One of Vygotsky's fundamental pillars of the learning process is that the higher psychological processes are acquired in a social context and then internalised. This internalisation "[...] is a product of a particular use of cognitive behaviour in a social context" (Carter, 1993:129). The approaches developed by Vygotsky are based on the idea that what an individual learns depends on their individual activity. So cognitive constructivism believes that learners' most important source is the learner themselves and social constructivism believes that the social environment can help develop the learner's cognitive development. 


\subsection{Foreign language learning in the classroom}

Learning theories and approaches in foreign language learning are most visible in the classroom. The relationship between second language acquisition and learning theories applied to the classroom needs to be explained in order to understand the process and how acquisition itself happens. Modern approaches to the study of foreign language acquisition focused on the learner's creative ability to construct language and their performance in terms of the cognitive processes they used when consciously recognising or decoding the input they receive from their target language. Error analysis suggested that the errors made by language learners when speaking the target language should be analysed so as to provide an insight into how those learners experienced the second language acquisition process. Keshavarz (1997) divided the field of error analysis into two parts: theoretical and applied. Theoretical error analysis focuses on the language learning process and a comparison of the similarities of first language acquisition and the learner's cognitive language learning process. It then tries to decode learning strategies such as over-generalisation and simplification, to finally draw any conclusions on the universals of the foreign language learning process - proponents wanted to answer the question of whether an internal methodology to learning a second language existed. If so, could it be theorised? Applied error analysis focuses more on the practical side of learning, planning corrective language classes, creating appropriate foreign language classroom materials and content, teaching strategies to teachers based on error analysis theories and the studies and analysis that have been conducted into error patterns. Behaviourism began to fall out of fashion with such new approaches and because of the emergence of the Chomskian revolution on transformative grammar. As mentioned, there began to be a move towards explaining how language is acquired through mental processes while the traditional automatic, stimulus-response process to acquisition began to be rejected. The focus now fell on the language student's internal cognitive learning processes rather than external contexts and influences. Chomsky argued that all languages have a limited number of fundamental rules which make up their grammar and basic sentence structures, in addition to a limited set of modification rules which 
existed to amend these structures (by eliminating, adding and replacing words and modifying word order in sentences). According to Chomsky, babies are born with an internal, mental, language acquisition tool which each individual simply uses or 'fills in' with their native language structures that they infer when they are exposed to their native language. The finite number of basic rules and modifications that can be made in any language results in an infinite number of possible phrases. Speaking or 'knowing' a language is actually a matter of innately and naturally reproducing these rules rather than memorising the superficial structures. It seems logical to conclude that when babies learn how to speak they cannot be simply imitating what they have heard others say as those specific structures and the phrases they utter have not been spoken to them before, so they must be applying those fundamental norms to create new constructions. Chomsky was referring to first language acquisition when he developed his theory but this was thought to be equally true of foreign language acquisition, many times learners put together phrases that they have not heard nor been exposed to before. Language learning was now seen as rule governed behaviour. So the communicative approach seen above and error analysis sought to understand language learning by breaking a foreign language down into its parts.

Functional and communicative based approaches which have been mentioned above were then explored. The focus now fell on the individual and how context and environment can also influence language learning. Language was understood to be communication rather than only a strictly rule based phenomena and meaning and interpretation (cultural or otherwise) began to be seen as a key part of the foreign language acquisition process. It was believed that language structures could not be studied without considering the context of their use including the social context in which they are uttered. As mentioned above, drawing on work and research by the anthropologist Malinowski, Halliday (1961) developed the systemic linguistic approach in the 1960s: "[...] language acquisition [...] needs to be seen as the mastery of linguistic functions. Learning one's mother tongue is learning the uses of language, and the meanings, or rather the meaning potential, associated with them. The structures, the 
words and the sounds are the realization of this meaning potential. Learning language is learning how to mean" (Halliday, 1973:345).

As mentioned before, cognitive and personal constructivism sees the fundamental bases of learning as the internal process of the learner based on discovery. Social constructivism sees learning as a result of cultural, historical and social interaction rather than individual construction. But they both believe that people create physiological tools from these contexts in order to operate in them and one of those tools is language. Each different language is a different tool for their specific environment, which is why context cannot be taken out of the tool; that is, language cannot be understood (or learnt) outside of the cultural context in which it was originally created. According to Hoover, in constructivism, learners construct knowledge through building on what they already know, in the case of foreign language learning, learners can use their universal grammar or innate language skills and build off their first language. He also believes that learning is active, not passive, that learners should participate in the learning process, they must negotiate and assimilate any new information they receive and change according to these new experiences. Thus each learner brings different experiences to the classroom, they must infer the correct information for themselves but the teacher must assist in bringing them the correct knowledge at a level that is appropriate for their current knowledge. Krashen's $(1982,1988)$ Monitor Model also has an internal focus and states that the learner will innately absorb and learn from the material or input given to them if that input is at a level that is equal or close to their ideal level. This ideal level is input that builds off the learner's existing knowledge, obliging them to use the knowledge they already have. So if the level is too difficult for the learner to assimilate they will not be able to absorb it, however if the level is too low it will not teach the learner anything new, so the level must be one above the learner's current level, which Krashen calls +1 . Krashen's approach is made up of five hypotheses about how a foreign language is learnt. The first is the acquisition-learning hypothesis. Here he states that there is an important difference between acquisition and learning. Acquisition is absorbed subconsciously, and is assisted by humans' innate language acquisition device (as was seen with Chomsky, this device also accounts for learning first languages). Learning is 
conscious, one example of learning is calculations in the Mathematics classroom and another example of learning is foreign language learning. The second is the monitor hypothesis. When foreign language skills are learnt, these skills serve as a monitor, their role is to edit or modify language that is being or has been produced. The third is the natural order hypothesis. According to Krashen, learners acquire the rules of their first and second language in a predictable order. The fourth is the input hypothesis. Language acquisition takes place when learners are exposed to comprehensible input that is at their right level. If the information which learners are exposed to is properly comprehended by them, and if there is a sufficient amount of it, grammar will be produced and structured naturally; it will be automatically assimilated and in turn later produced through the language acquisition device. The final one is the affective filter hypothesis. It is possible that input cannot be produced when the affective filter is up, that is if the learner is too conscious of their learning and/or if the learner feels inhibited.

The popularity and logic of functional, communicative learning and the monitor theory meant that grammar structures in language learning were often ignored, as the tendency was to encourage learners to practice the foreign language in real-life situations. Even though the tendency today is to once again give grammar a focus in the language classroom, a communicative approach remains a priority for many teachers and this necessarily requires a focus on the cultural influence in foreign language learning at a personal level. But, how can a learner internalise content and develop the psychological tools necessary to communicate in their culture with language? If a language learner first internalises a language before communicating it, how is the transition from the interpersonal to the intrapersonal made? The ZPD developed by Vygotsky (1978) mentioned above responds to these two questions by defining an interactive area which includes a support structure created by the learner, MKOs and the cultural tools appropriate for a situation, allowing the learner to go beyond and build on their current competence (Cole, 1984; Newman, 1989). Vygotsky's often quoted definition of the ZPD is:

...the distance between the actual developmental level as determined by independent problem solving and the level of potential development as determined through problem 
solving under adult guidance, or in collaboration with more capable peers. (Vygostsky, 1980:86)

The ZPD is the area where the mental function 'matures', it is where the transition from interphyscology to intrapsycology takes place:

\begin{abstract}
Every function in the child's cultural development appears twice: first, on the social level, and later, on the individual level; first, between people (interpsychological) and then inside the child (intrapsychological). This applies equally to voluntary attention, to logical memory, and to the formation of concepts. All the higher functions originate as actual relationships between individuals. (Vygotsky, 1978:57)
\end{abstract}

Social interaction is also significant because if two learners have the same knowledge level the learner who is guided through the ZDP will attain a higher level than the one who is not. The ZDP is an area which learners move through in order to reach another level of knowledge; this level of development is attained by the learner's complete participation in the learning process, assisted with guidance from the MKO in that space. Therefore the learning process necessarily includes participation in socially mediated activities (mediation). Learning is a collaborative achievement and the tools for this learning come from culture: cultural artefacts such as the language and its history. Vygotsky argued that humans do not act directly on the physical world but use intermediary and indirect tools to interact with it. These tools can be symbolic or physical and they are produced by humans in specific cultural and historical conditions from which they evolve. They influence the individuals who use them because they result in previously unknown situations, activities and manners. They also go through changes as they are passed from one generation to the next; each generation adapts them to their and their communities' needs and aspiration. These tools are used in the ZDP to support the learning processes. They need to be internalised and once they are learnt they become automatic, thus the learner has moved onto the next level, their development potential. The MKO mediates the learner through the ZPD and that move from one level to the next is known as scaffolding, working off the learner's knowledge in order to internalise more complex knowledge. The two most significant aspects of the ZPD are firstly, that cognitive development is fostered by social and interpersonal activity, which is then used as the platform for functioning within society, and secondly that this process 
must necessarily include internalisation. Internalisation is a process whereby cultural products, such as language, take on a psychological function. The process, along with mediation, is one of the core concepts of Vygotsky's Sociocultural theory developed in the 1920s. As Kozulin (Kozulin, 1990:116) states, "[...] the essential element in the formation of higher mental functions is the process of internalization". Internalisation is a process whereby the relationship of the individual and their social environment is consolidated and it, as a result, is carried into future behaviours (Kozulin, 2003). Internalisation can also be explained as the biological connection between social communication and cognitive activity; it is the process used by learners to arrange knowledge and information and, according to Yaroshevsky (1989), it is the biological organ of cognitive thought. Vygotsky explores the interconnections created and consolidated by internalisation in his studies on genetic development: "Any function in the child's cultural development appears twice or on two planes. First it appears on the social plane, and then on the psychological plane. First it appears between people as an interpsychological category, and then within the child as an intrapsychological category" (Vygotsky, 1981:163). Vygotsky's Sociocultural Theory states that a large chunk of language learning happens casually, through its socio-cultural and functional use. In foreign language learning what matters are the smaller steps that learners take in order to learn their target language so as to reach the larger goal. Looking up a word in a dictionary, using relative pronouns to describe a word they do not know, or trying to figure out the meaning of a word they do not understand in a text may not seem like the fastest or best way learn a foreign language but these steps in themselves are not the primary goal. The learner reads, writes, talks, and listens in order to reach larger goals in order to understand or converse with people. To reach these larger goals the learner takes smaller steps towards them along the way. This process explains the function of language as a tool - using language to achieve specific goals. What is understood to be incidental learning is not that at all, the activities that are carried out are intentional, goal oriented and meaningful. Socio-cultural theory argues that learners do not learn passively or through incidental learning.

The points developed above are seen to be fundamental to acquiring second languages. 
Although it seems outdated, the teacher still places themselves in front of the classroom to teach a foreign language, to mediate and guide the learner. It is still important to remember that "[...] there is a teacher in control of what happens in the classroom."; "[...] students have to be taught in order for them to learn..."; "[...] students learn through class attendance, reading books..." and "[...] there is something that is the object of learning/teaching which must be transmitted through the teacher in class [...]" (TortMoloney, 1997). There is a subject to be learnt and the teacher performs teaching tasks using the tools and methodologies they have at their disposal, either according to established practice or what was seen as the most appropriate method at that time (grammar-translation, audio lingual method, communicative approaches). It is believed that a language is taught or learnt by finding and using the appropriate method specific to the learner. But as was explored in the section on Krashen's approach and the sociocultural theory, it is also believed that simple exposure to a language can also help in the teaching process, as long as the learner uses that exposure appropriately. The learner sometimes uses complicated structures that they have not been taught in an academic situation. Tort-Moloney (1997:1) states, "[...] no one learns what is taught, and no one teaches what you learn." The difference between what has been officially presented to the learner and the output the learner produces is sometimes very different, and this is even more prominent in foreign language learning. So according to Tort-Moloney, among others, the key to applying the Vygotsky model and developing the steps for teaching/learning objectives is recognising the central role of the learner and teacher autonomy, with a focus on the crucial concepts of internalisation and mediation of knowledge for the development of both learner and teacher autonomy in the foreign language learning classroom. The definition of autonomy given by Tort-Moloney (1997:3) is "[...] the state of being liberated within the learning process from obstacles which could operate inside or outside the learning process to significantly and unnecessarily retard the ability to impart understanding". Chapter 3 will explore other definitions and look into this concept from a foreign language learning perspective in more detail.

Within the theory developed by Vygotsky it is noted that what makes humans unique compared to other beings is their ability to develop higher mental functions, as well as 
elementary ones, and that this depends on the fusing of two very genetic different abilities: thought and speech. Once these two abilities have merged, speech plays a very important role in focusing thinking while performing tasks. Piaget (1959) calls this speech egocentric speech and states that it has a role in the process of socialisation and development of cognitive skills. Piaget's study on egocentric speech is Vygotsky's platform to identify and further his idea on the dual use of discourse as a tool for interaction and intra-action. He argues that egocentric speech is internalised and becomes inner speech, the adult develops this until they enter into conversation with themselves and as such inner speech in adults is still a function of cognitive assimilation and appropriation. According to Tort-Moloney (1997), an interactive perspective on cognition appears as a central focus of the psychological development of scaffolding. The process of scaffolding can lead to responsibility, understanding and a consolidation of skills between the child and the MKO. This is done at a rate that corresponds to the development of learning autonomy with regard to the skills that are being learnt. Wood, Bruner and Ross (1976) identified six functions that the tutor makes to aid the learner's performance: stimulation of the learner's interest in the task; simplification of the task; signalling significant or critical elements and discrepancies between what was done and the ideal solution; controlling degrees of frustration; risk to solve the task and showing a perfect version of the task. This scaffolding process leads to advancement in shared activities through interaction and learning occurs through the performance of those tasks.

Progress through the ZPD occurs when the learner responds to those challenges with the support of the MKO who provides the learner with those activities that are within their ZPD. In terms of Vygotsky's studies, the fusion between what can be learned and is taught within the classroom is where the learner's individual needs are satisfied interactively. The underlying importance of the process of scaffolding in second language acquisition is highlighted by the definition given by Little:

Essentially, autonomy is a capacity - for detachment, critical reflection, decision-making, and independent action. It presupposes, but also entails, that the learner will develop a particular kind of psychological relation to the process and content of his learning. The capacity for autonomy will be displayed both in the way the learner learns and in the way he or she transfers what has been learned to wider contexts (Little, 1991:4). 
For Little, the importance of the scaffolding process will continue until the support of scaffold itself can be removed and replaced by the internalisation of knowledge by the learner:

The developmental learning that unimpaired small children undergo takes place in interaction with parents, brothers and sisters, grandparents, family friends, neighbours and so on. Education, whether institutionalised or not, is likewise an interactive, social process. For most of us, important learning experiences are likely to be remembered at least partly in terms of our relationship either with one or more other learners or with a teacher. What is more, our capacity for self-instruction probably develops out of our experience of learning in interaction with others: in order to teach ourselves, we must create an internal substitute for the interaction of home or classroom. (Little, 1991:5).

When Dam refers to learner autonomy (Dam, 1991), he explores this scaffolding structure by focusing on the learner/teacher relationship:

- The change of focus from teaching to learning;

- The change in the role of the teacher;

- The change in the role of the learner;

- The role of assessment and how learning is assessed;

- The language classroom as an optimal environment for learning.

With these changes, the learning process becomes more tangible: learning is not motivated by activities but by objectives. Tasks and techniques are not presented to the learner to carry out, decisions are taken together with the teacher, within the workgroup, or by the learner themselves. The word 'responsibility' appears repeatedly in the literature on learning autonomy. This concept embodies a principle that is fundamental to meaningful activities which lead to linguistic proficiency in the target language.

So the objective is an environment that is sufficiently transparent for the learner to understand the connection between what they do, how they do it, why they do it, and what they have learned. Little argues that learner autonomy entails collaboration; the assumption of learning responsibility involves sharing the responsibility of other learners' learning (Little, 2001a). In the field of learner autonomy different tools are used to guide the aspects mentioned so far. For example, blogs are suggested as a way to channel the learner's internal discourse, which aim to support the internalisation of what is learned. 
Other elements, such as individual and/or group planning and/or assessments assist in the development of a ZPD, in the process of cognition and higher mental functions.

The objective of this thesis is to show that this type of learning motivates foreign language learners to internalise the language learning process both from a cultural and technical perspective, ensuring a thorough and successful learning experience. Learners have the opportunity to choose from a number of actions to deal with a difficult situation in the learning process, which means they are personally involved in it. The situation inevitably makes them enter into dialogue with themselves, the teacher, their classmates and the classroom environment. This situation occurs at the time of stress, Vygotsky identifies it as the point when the learner turns to external speech to facilitate learning (Vygotsky, 1986).

Another key element in the second language is autonomous classroom is group work and peer support as well as interaction. According to Tort-Moloney (1997) in this environment the group is a fundamental part of the individual learning process. Learning from a 'peer' is considered an active agent in the learning process, as it serves as a layer during the scaffolding process for each learner.

This section concludes with Little and his idea that the transfer of control to the learner over learning is more than just a psychological phenomenon. The student must gradually take control of social interaction and their context too, and thus give shape and substance to the learning process and as Little suggests:

[...] Gradual handing over of control to the learner - in other words, the deliberate fostering of learner autonomy - is not an option that the tutor may or may not adopt according to ideological preference: it is essential to the success of the tutoring process. [...] The handing over of control to the learner is more than a psychological phenomenon. In order to gain the psychological benefits of successful learning, the learner must gradually assume control of the social interaction that gives outward form and substance to the learning process. (Little, 1995:7) 


\section{AUTONOMY IN LANGUAGE LEARNING}

This chapter focuses on the concept of learner autonomy. It explores how autonomy in language learning has become an indispensable factor in current pedagogical approaches, especially with the rise of online learning and the spread of communicative technology. This chapter begins by explaining the origins of learner autonomy and what is meant by this term. For this, a review of the studies and definitions provided by different authors is carried out, emphasising the various aspects that have been focused on most over the literature. A review of the literature on learning autonomy led to the realisations that there was an added complication: the wide variety of terms that are used to refer to what is seemingly the same thing. Some of the more common terms are: selfinstruction, self-direction, self-management, learning to learn, and independent learning, to name only a few. After focusing on the definitions and terminology, the following section delves into the pedagogical implications that emerge as a consequence of adopting a methodological approach based on learning autonomy and how important this concept is to online and distance learning. It starts off from a general vision of autonomous teaching/learning where the focus is no longer on teaching but has shifted to learning and how to learn. This entails the development of shared responsibility and new ways of understanding the role of the student and the teacher, feedback in the classroom, relationships, and participation. This chapter also explores the critical aspects of motivation and its significance in foreign language learning. Although, at first sight, they seem to be an entirely different concept, the two are closely related: according to Dickinson (1992) both autonomy and motivation are related to the learner's active engagement and therefore success in the language learning process. Also, autonomous work process helps to foster and maintain motivation and in turn learner's motivation further encourages autonomous work processes (Ushioda 1996). After looking at how these two concepts overlap significantly the term is defined in detail. This last section explores the role of motivation in the language learning process and the success or failure thereof, the conditional factors that affect the motivational processes for learners, the importance of maintaining motivation and its practical application, including the 
operational characteristics of motivation, and ends with a section on peer interaction, specifically how support and feedback from peers can influence the motivational aspects of learning. 


\subsection{Definition of the term 'learner autonomy'}

Before defining the term learner autonomy, a brief description of the origins of the concept is made. Autonomy is an individual's ability to self-govern. Self-determination was discussed by both Plato and Aristotle many centuries ago. In philosophy, autonomy is a truth that is regulated by its own law, independent from other laws, but not necessarily incompatible with them. A moral law is autonomous when it has a basis and its own legal reasons. The father of the development of the idea of autonomy was Kant (Wicks, 2014). According to Kant rational human will is autonomous. As stated in Rousseau's writings, freedom does not consist of being free of laws, but by abiding by laws that are of the individual's own creation. The idea of autonomy is thus more than simply being free from laws; it is about following the laws and rules made by oneself and, in turn, laws that have a truly decisive authority over oneself. This is where Kant's categorical imperative (evaluating motivations for actions) becomes possible. In his 1785 work 'Grounding for the Metaphysics of Morals', he outlines that autonomy of thinking is when a person is free because they are bound by their own will and not by one that is externally imposed by another and where for will to be free it must operate by responding to reason, noting that if an act is determined by something beyond control, it is attributed consequently to external coercion and is not conceived as moral (Wicks, 2014). With the decrease of religious authority and an increase of focus on political liberty and the individual, the concept of autonomy began to take centre stage (Gremmo \& Riley, 1995).

During the 1960s, Holec and Châlon pick up the changing political ideals of autonomy in regard to language learning and while researching this new field are asked by the Council of Europe to develop a language learning project that focused on the social and ideological description of emerging ideas about learning autonomy. This was done under the field of foreign language teaching through the Modern Languages Project of the Council of Europe: the Centre de Recherches et d'Applications Pédagogiques en Langues (CRAPEL), established in 1971. In these early stages, autonomy is defined by the objectives, progress and evaluation determined at all times by students themselves as it is believed that they can and will have the ability to take responsibility for their own 
learning (self-learning) and they are offered access to a large volume of foreign language material, so that they can experiment and learn on their own. These self-access centres often had the drawback of not offering any strong pedagogical rationale, it was assumed that self-access would automatically lead to autonomy. Also, because self-access centres used new and modern electronic equipment, autonomy also became to be identified with technology-based learning; and in this emerging field of computer-assisted language learning, autonomy has become an important issue. As will be explained, autonomy is not an automatic follow-on to technology use; much has to do with how that technology is used and who it is used with. During this same time, research in the United States focused on the definition of a 'good language learner' demonstrating that there are different ways to achieve learning languages successfully and good learner characteristics (Rubin, 1975; Stern, 1975). The Good Language Learner (Naiman, 1978) study researched many of the issues and questions that foreign language acquisition researchers were investigating during the 1980s. In their studies the authors found that "[...] attitude and motivation were, in many instances, the best overall predictors of success in second language learning" (Naiman, 1978:66). This led to a surge of research into language learners' cognitive traits and individual characteristics. Foreign language learning was the process which individual learners used to internalise the language being studied, tying autonomy to individualisation. Riley believes that:

[...] it is the teacher who tries to adapt his methodology and materials to the learner, like a doctor writing out a prescription. That is, the majority of the relevant decisions are made for the learner, not by him. It is in fact individualised TEACHING: it aims at the most efficient use of the teacher and at the most effective result, but in terms of what the teacher wants the learner to achieve (Riley, 1982:32).

The linkage of these two concepts could be interpreted as suggesting that autonomy implies acquiring knowledge without teacher support, when in reality autonomy depends on instructors, peer collaboration and interdependence.

Subsequently, during the 1980s, there was more of a focus to develop the practical aspects of autonomous learning, aiming to make learners develop strategies and techniques that could encourage them to learn independently outside the classroom 
(which Benson called technical autonomy). Benson (2001) explains the changes in perspective towards the concept of autonomy, evolving from a 'situational' idea of the term with the structural conditions necessary for autonomy, to a perspective which is centred on the psychological aspects emphasising the learner's responsibility for their own learning: individual responsibility. He also highlights the change that occurred from shifting towards the methods used for learning from a focus on the objectives and content.

Focusing on the different definitions given to the term autonomy in the field of language learning, one of the first definitions that emerges and is still used as the basis for many authors, was given by Holec (1981). In his definition he describes the term autonomy as the "[...] ability to take responsibility for one's own learning" (Holec, 1981:3). He furthers that definition by adding that with this new responsibility, autonomous learners now set their own short and long term learning goals, decide on the content and progression, monitor themselves and evaluate their own progress. They decide what materials and methods are used in the course as well as how it is structured, organised and implemented in addition to what the performance evaluation criteria and the learning process will be. Holec (1981) also stated that this ability to take control of one's learning was not innate to the learner but that it must be learnt naturally or systematically. It is interesting to note here this idea that autonomy is a skill the learner develops; it is not an attribute of the learning situation. The assumption is that autonomy is not developed simply because the learner is put into a completely unsupported learning environment; the learning objective still exists (Dickinson, 1978). Little (1991) argues that freedom in learning is not that same thing as autonomy and should always be constrained. He regards autonomy as an ability to detach oneself and engage in critical reflection, decision-making, and independent action that presupposes, and also implies, that the learner will develop a psychological relationship to the process and content of their own learning. The capacity for autonomy will be reflected in the way the learner learns and in the way they transfer the new knowledge they have acquired to wider contexts. Little (1991) continues to deepen his definitions and further complements the definition given by Holec (1981) by incorporating the psychological dimension to it. 
Basing themselves on the definition given by Holec (1981), Benson and Voller (1997) offer five different situations where the term autonomy has been used in the context of language learning. These situations are similar to those Little (1991) uses to define what learning autonomy is not, and which is explored below. These five situations refer to:

1. when the learner has absolutely no support in the learning situation;

2. a number of skills related to self-directed learning, which can be learnt and applied to this type of learning;

3. an innate ability that has been suppressed by institutional education;

4. the practice of learners exercising responsibility for their own learning;

5. learners' right to determine the direction of their own learning.

The term 'self-learning' can include every aspect or situation in the five situations described above.

Benson (1996), in turn, suggests that learner autonomy has three main versions in the field of language learning: technical, psychological and a third called political. These three versions correspond roughly to three approaches to learning and knowledge within the field of social sciences and humanities, positivism, constructivism and critical theory. It must be noted that even if these approaches are not specifically treated as theories, they help to associate approaches to the issues of knowledge and learning in this area:

1. In what is known as the technical versions (positivism) the concept of autonomy is defined as the act of learning a language outside the framework of an educational institution - in addition to the fact that learning occurs without the intervention of the teacher - but still places a significant value on attributes that are found within that learning environment. It aims for learners to acquire those values and the skills they need in order to be able to organise their own learning independently from a formal setting; the term autonomy is found in situations where the learner is forced to take charge of their own learning. Positivism is associated with technical autonomy because, and according to Benson, it is normally about rule following and drill practising.

2. The psychological versions (constructivism) define autonomy as a capacity, a set 
of attitudes and skills that enables the learner to become more responsible for their own learning. The development of psychological autonomy is usually perceived to be "an internal transformation within the individual" (Benson, 2001:17), which is why it is associated with constructivism, the construction of knowledge and the valuing of independent, individual thought construction as well as individual's taking responsibility for their own learning (Halliday, 1973). Within this framework, autonomous learning is seen to be an internal evolution within the individual; this transformation can be supported by - but not dependent on autonomous self-development.

3. Finally, the political version (critical theory) of autonomy is characterised by learners' control of the content and process of learning, focusing on both individual control and control in the institutional context where learning takes place. Learners will be able to control the structures that allow them to master key aspects which have a significant impact on their learning. A main view of this version "is that of authoring one's own world without being subject to the will of others" (Young, 1986:19).

After analysing the different views, Benson concludes with three possible definitions when talking about learner autonomy in the field of language learning:

"We are dealing with three basic definitions of autonomy in language learning: Autonomy as the act of learning on one's own and the technical ability to do so; Autonomy as the internal psychological capacity to self-direct one's own learning; Autonomy as control over the content and processes of one's own learning" (Benson, 2001:25).

Little (1995) considers that the basis of learning autonomy lies in the learner's acceptance of their responsibility acquired during learning. The development of learner autonomy depends on learner's exercising that responsibility which will result in the learner making a constant effort to understand what they are learning, why they are learning it, how they are learning it and to what degree of success they are learning it. $\mathrm{He}$ also adds that an effect of learning autonomy is the removal of barriers that are so easily built up between formal education and the broader learning context in which the learner is immersed: their life in general. According to Little, autonomy is effective for three reasons. First, learners inadvertently conduct their own learning. By directing 
themselves, they do not only understand better, but they are also more motivated and more linked to the learning process. Second because when this occurs, learning is more effective as learners are critically aware of their own objectives and methods. Finally, it is because of and with this critical consciousness that the learner feels able to push the limits of their learning context (Little, 1995). Little (1995) also highlights that the liberties made available by this approach are never absolute; they are always limited and conditioned. As humans are social beings, there is a balance between dependence and independence: the resulting condition is interdependence. It has been stated that autonomy is associated with individualism, however this assertion can sometimes prove confusing as the learner does not develop by working alone and unsupported, they flourish in group relationships with other learners, learning together and from each-other, in interaction and interdependence (as explained in peer motivation). In this vein, as explored in the first chapter, the MKO also plays an important supporting role.

Similarly, in his experimental studies, Esch (1997) tries to confirm that learner's commitment to their own language learning can be carried out successfully within an institutional context, through frequent meetings that do not compromise their autonomy. During his research study with a group of independent learners at the French Language University of Cambridge, the participants largely decided the content and methods of the training themselves. Each week the group met for an hour to carry out an activity they had planned the previous week and discussed work they had carried out individually. Esch (ibid) defined the success of the training through three requirements necessary for any institution that intends to bring this to fruition:

The students were self-selected; the feedback was essentially given during the course conversation sessions but always seemed to the point because it was a conversational topic shared by the whole group; the syllabus was selected by the members of the group from the second week onwards (Esch, 1997:165).

The definition given by Little (1997) complements that given by Holec (1981) by incorporating a psychological dimension to it. From here, Benson (2001) argues that the ability to take responsibility for one's own learning is described in terms of control over the cognitive processes involved in the self-regulation of effective learning. Later Bobb- 
Wolff (2002:3) basing herself on those definitions given by Holec (1981) and Little (1997) defines the term 'autonomy' through five negatives. She asserts that these negations are based on misconceptions about what the term 'autonomy' means. Both Little (ibid) and Bobb-Wolff (ibid) define the term from what is not. Thus they state that:

1. Autonomy is not synonymous with being self-taught, that is, it is not confined to the fact that the learner 'learns without a teacher', although largely all learners perform much of their learning without teacher intervention.

2. It is not about the student learning on their own, without interaction with other learners. The moment the learner recognises that they are able to learn from and be motivated by their peers is when their learning process becomes a more independent process. Autonomy has often been associated with individualisation or differentiation.

3. Autonomy in a formal institutional context or in the classroom does not imply that the teacher completely abandons their responsibilities, it is not about abandoning the learners and letting them fend for themselves. The teachers continue to orientate and guide but their function is not the same as what it has been until now. So, autonomy cannot be equated with independent learning without a teacher.

4. Autonomy is not something that teachers do to learners, it is not a teaching method and it is not a new methodology.

Aoki and Smith (Aoki, 1999) also support this idea. Learners need the stimulus and orientation of the teacher, but of course learners cannot immediately disengage from a traditional dependence on teachers, it is not something that can be programmed in a number of sessions. Aoki and Smith (ibid) delve into this negation and reformulate three misconceptions that have frequently emerged around the term autonomy. First that autonomy is a (new) methodology; autonomy is not an applied approach to a particular form of learning. It is, as stated by Holec (1981) an educational purpose. Second, that autonomy implies individualism; within different fields, it is claimed that autonomy does not involve a total independence. Here, Holec (1985:175) emphasises the fact learners can take responsibility of their own learning "[...] together with other learners [...] or with 
outside help". Finally, the legitimacy of autonomy depends on psychological/cultural considerations. The decision for or against the development of learning autonomy has often been described as psychologically or culturally inappropriate, when in reality these are political objections. According to Benson (1996), taking control of one's own learning, accepting that responsibility, requires a change in the traditional teacher - student power structures. Consequently it has been argued in different contexts that autonomy is a democratic /liberal-democratic, imported (and thus) imposed learning ideal and that is inappropriate in terms of learning styles (Aoki, 1999; Little, 1999). Therefore autonomy is not a single behaviour that is simple in its description, the autonomous learner is often recognised by their behaviour, but that does not always manifest in the same way. Much depends on the needs and objectives of the moment the learner is learning, the evolution in their own learning, etc. Furthermore, autonomy is not a state that learners are striving for. This feature is related to the concept that autonomy cannot be guaranteed once acquired. So, when a learner develops this ability it does not mean that they will retain it permanently. Similarly, a student who is highly autonomous in an area is not at all autonomous in another. Little (2008) gives an overview of the evolution of the concept of autonomy by analysing his own interpretation which has evolved significantly since his first publications. He describes his contribution as focusing on the psychological processes of learning, taking a broad view of constructivism, based on Piaget (1959), Vygotsky (1978) and Bruner (1985) (see chapter 2), who claim that autonomy is primarily a human characteristic as is the capacity that we use to become autonomous beings. This makes his earlier work clearer where he proposes that autonomy can be found in any form of human behaviour:

Human beings are autonomous in relation to a particular task when they are able to perform that task (1) without assistance, (2) beyond the immediate context in which they acquired the knowledge and skills, and (3) flexibly, taking account of the special requirements of particular circumstances (Little, 1997:94).

Consequently, autonomy becomes an objective for all learning development including formal learning, whether in formal or informal educational settings. Along the same vein of the many parallels with the statement Little (1997) makes about what autonomy is not, 
Waterhouse (1990) refers to various mistakes or erroneous interpretations of what constitutes autonomy. They mainly relate to the fact that autonomy is often confused with learners working in isolation and where the teacher's role is relegated to the background. Thus, the teacher would provide less support to the learner perhaps considering that such support is a contradiction to autonomous learning.

There is therefore consensus among authors on the phenomenon of learning autonomy. This consensus is based on sharing the same opinion about misinterpretations that have been made of the term, misinterpretations that in many cases have led some to believe that an autonomous learner is one who works alone, a learner who is thrown in at the deep end of the pool. The various definitions have a great similarity to each other, being perhaps Holec's aforementioned definition that is most representative in addition to being the most used throughout the literature.

Dam (1994) introduces the social dimension to the concept of learner autonomy. He understands the development of learner autonomy as the development of learner's awareness of both being a learner and their learning process. According to him, this process can only occur through contact and cooperation between students and teachers on the hand, and between learners themselves. Thus we see that not only teachers but also learners come to the classroom with knowledge about what to learn and how to learn it. In both cases: "It is a question of taking small steps towards the shared responsibility for the teaching/learning situation. The aim is learner autonomy - learner autonomy is the only means possible" (Dam, 1994:526). He further elaborates on this: "Learner autonomy is characterized by a readiness to take charge of one's own learning in the service of one's own needs and purposes. This entails a capacity and willingness to act independently and in co-operation with others, as a socially responsible person." (Dam, 1995:44)

Dickinson (1987), meanwhile, states that to be responsible for something does not necessarily mean accepting it completely or assuming it without support or advice. For Dickinson, being responsible is being capable, as a learner, of making decisions about the type of support needed and reaching agreements with the teacher, who facilitates learning. Widdowson (1990) argues along the same line about the need for a foreign 
language learner to develop under the guidance and support of the appropriate teacher. Van Esch and St. John (2003) restate this idea that learner autonomy can be developed to the extent that the control, management and responsibility for learning pass from teacher to learner. This highlights the different aspects that are characteristic of learning autonomy which allow this transfer to take place. According to them, these features are:

\begin{abstract}
A solid framework created by teacher and learner, this framework will be modified according to relevant learning needs and progress accomplished. A desire for the learner to invest in both the learning process and end product, using what they have learnt to redefine the objectives throughout that process. Learner commitment to agree to and carry out actions arising from their obligations as a learner (Van Esch \& St. John, 2003:17).
\end{abstract}

These aspects allow students to develop their autonomy while they gain more freedom, having control over their decisions, choices and consequences which allow them to evaluate both the process and the end product of learning. According to Benson and Voller (1997), the focus of learning autonomy appears as a learner-centred approach, which is anti-authoritarian. Its implementation is often characterised by ambiguities that arise from two basic tensions: on the one hand the tension between responsibility and no limitations and on the other, the tension created between the individual and the social context. From this it can be deduced that learners have the capacity to govern themselves in the learning process. This ability means learners are able to discern when particular information is new or already known and perform activities as intrinsically human as explaining, predicting and becoming aware; activities that lead learners to selfregulation of their learning process according to the objectives to be achieved.

Hall and Beggs (1998) present a different argument from that described so far. These authors criticise previous definitions as they believe they are 'asocial', i.e. they lack the element of doing something else with acquired knowledge besides simply being consumers of what they learn. For them, the element of interdependence defended by authors like Holec or Little simply exist as an element that is internal to the learner, a condition of the individual mind. Thus they argue in favour of an existing interaction that is characteristic of the use of foreign languages being used. Until now, learners are not given a real opportunity to generate knowledge. Learners are not free to choose what 
they want. Their options, for example, are constrained by other people (publishing houses which create language learning materials, content in self-learning centres, etc.) as Pennycook (1997:53) argues:

Promoting autonomy in language learning, therefore, needs to take into account the contexts of the language learners, to open up spaces for those learners to deal differently with the world, to become authors of their own worlds. If language educators take up the notion of autonomy in language learning merely in terms of developing strategies for self-directed learning, or, in its most reductionist version, sending students to a self-access centre to study on their own, they may be denying their responsibilities as language educators to help students to find the alternatives they deserve.

Sinclair (2000) also provides his description of the concept of autonomy, based on both the aforementioned definitions and further research in this area:

- Autonomy is a construct of capacity.

- Autonomy involves a willingness on the part of the learners to take responsibility for their own learning.

- The capacity and willingness of learners to take such responsibility is not necessarily innate.

- Complete autonomy is an idealistic goal.

- There are different degrees of autonomy.

- The degrees of autonomy are variable and unstable.

- Autonomy is not simply a matter of placing learners in situations where they have to be independent.

- Developing autonomy requires conscious awareness of the learning process, i.e. a conscious reflection and decision making.

- Promoting autonomy is not simply a matter of teaching strategies.

- Autonomy can take place both inside and outside the classroom.

- Autonomy has a social as well as an individual dimension.

- The promotion of learner autonomy has a political as well as a psychological dimension.

- Different cultures give different interpretations to the concept of autonomy (Sinclair, 2000:7-12).

Jiménez Raya, Lamb and Vieira (2007:1) define autonomy in the following terms: "[...] the competence to develop as a self-determined, socially responsible and critically aware participant in (and beyond) educational environments, within a vision of education as (inter)personal empowerment and social transformation". When furthering their definition they base themselves on a number of assumptions that are developed below. Some of these assumptions are consistent with several of those given by Sinclair (2000) and discussed above. Jiménez Raya, Lamb and Vieira (2007) define autonomy according to them in the following manner:

- It is considered a competency: by describing it as a competency, this first 
characterisation of the term tries to expand its vision, referring to it as more than just skill. The term competency fuses aspects that are included in responsibility, implying the ability to use knowledge, understanding, thinking skills and selfregulatory skills to carry out effective learning. So, this notion of competency denotes positive connotations and includes the desire and ability to grow as a person and learner.

- It is not an absolute concept: Autonomy is not conceived as something that a learner has or does not have. It is considered as a continuum where there are varying degrees of self-management and self-regulation that can be developed at different moments during the learning process.

- It implies self-determination: Self-determination involves encouraging the actions of people who have a high level of reflection. When promoting autonomy, conditions for the development of intrinsic motivation are encouraged: active engagement in learning, power of discourse, initiative and decision making, self-control, and persistence in learning.

- It involves social responsibility: In this regard the social dimension of autonomy must be emphasised. One of the myths already mentioned is the fact that autonomy develops in solitude, but in reality the social aspect of autonomy must always be taken into account. The development of social responsibility involves being aware of the needs of the group and interdependent relationships. Being socially responsible means using that awareness to improve the group's ability to live and work together. The development of this meaning of social responsibility requires a range of social skills such as communication, cooperation, negotiation, problem solving and perspective.

- It necessarily involves critical awareness: even if this feature can be derived from those described above, it is necessary to emphasise the idea that people both as individuals and the group live in contexts of power and are subject to ideological influences that may lead them to seem autonomous when in fact they are not. In such contexts, autonomy requires a special development of critical consciousness towards these influences and the ability to resist them if 
necessary.

- Denotes a proactive and interactive role: The autonomy of learning, as we have seen, includes a social area that involves the ability to interact with others and learn from them, assuming that learning occurs through interaction with others. This reinforces the idea of social interaction, which emphasises the dynamic nature of the relationship between teachers, learners and tasks.

- It is possible and desirable in educational settings: Significantly, any context can be educational as long as learners can learn in and from it. The degree of the learner's involvement in the construction of educational environments will have direct implications for the development of autonomy as a competency for learning throughout life.

Oxford (2003), based on the ideas by Benson (1996) and as mentioned above, presents a theoretical model that unites four different perspectives. One is a technical perspective, which emphasises the physical situation; the second is the psychological perspective, emphasising learners' characteristics; a socio-cultural perspective emphasising mediated learning, and finally a critical political perspective centred on ideologies, access and power structures. Thus, Oxford (2003) abandons a single view of autonomy and argues instead for an integrated model where the four perspectives mentioned above are interdependent: "No single perspective should be considered antithetical to any other perspective, although some theorists would have us believe that antagonism is inevitable" (Oxford, 2003:90).

Martínez (2008) states that learning autonomy seems to refer to the concept of capability that integrates different perspectives which are interdependent: they reflect a vision of a constructive learning process, socio-interactive and reflective. In research conducted by Martínez (2008) with future teachers on the concept of autonomy and its interpretations, it is seen that his ideas may not correspond with what objective theories of autonomy reflect. Martínez emphasises the apparent improvisation in most cases when defining autonomy spontaneously. These interpretations evoke several design errors pointed out in the literature (Aoki, 1999; Esch, 1997; Little 1991;) when autonomy is equated to individualisation or differentiation; independent learning without a teacher; a new 
methodology or an absolute.

Ellis and Sinclair (1989) have stated that helping students take responsibility for their own learning can be beneficial to them, because: learning can be more effective when learners take control of what they are learning; they will learn when they are ready to learn; those learners who take responsibility for their learning continue learning outside the classroom and those learners who know how to learn may transfer that knowledge and strategies to other areas (Ellis \& Sinclair, 1989).

The definitions that are most relevant for this thesis are those highlighting the social and motivational aspects of autonomy. During the ICC course students' autonomous working skills proved to be one of the reasons they continued working on their foreign language and newly learnt ICC skills. As mentioned above, the psychological and emotional attachment the students formed with the course process and content was a result of their self-directed learning abilities and opportunities to determine their own learning process (Little 1991). Again, according to Little (1991), autonomy is effective for three reasons. First, learners inadvertently conduct their own learning; by directing themselves, they not only understand better, but they are also more motivated and more linked to the learning process. These skills were supported and encouraged by the peer interaction students were exposed to during the Google Hangouts. Bobb-Wolf's (2002), emphasis placed on the social aspect of autonomy is also important for this thesis. She believes that when the learner realises that they can learn from and be motivated by peers the learning process becomes more autonomous. Dam (1994) also focuses on the social dimension to the concept of learner autonomy: "Learner autonomy is characterized by a readiness to take charge of one's own learning in the service of one's own needs and purposes. This entails a capacity and willingness to act independently and in co-operation with others, as a socially responsible person." The importance of the social aspect for Hall and Beggs (1998) and Pennycook (1997) comes from their belief that knowledge of foreign languages needs to be used to be strengthened, so that learners are not simply absorbing newly learned knowledge but also practising and perfecting it by using it.

Within the literature, there are disagreements with regard to the focus on the different 
interpretations seen so far. It could be concluded that one of the aims of education over the last 60 years is the development of learner autonomy, with some degree of agreement on the need to be more independent in terms of how to learn, think and behave. Within the constructivist paradigm, the learning process itself is perceived as autonomous, requiring self-regulation, reflection and abstraction in order to build necessary conceptual structures for knowledge. However, even when this objective is broadly agreed upon, there are discrepancies as the main methodological discourse of autonomy lies in the field of language teaching, rather than in practice itself (Jiménez Raya, 2007). This author suggests that there are different reasons generating tensions that lead to this situation, including: tensions between freedom and responsibility, limitations-control in institutional contexts where education systems limit the possibilities of autonomous development; difficulty in agreeing on a definition of the practice of autonomy; difficulties in defining its role in the classroom today and ways to foster or encourage its development and policies and practices within initial (and subsequent) teacher training may not adequately cover issues related to autonomy. Thus, as already stated above, one of the fundamental objectives of education today is the development of autonomy, but the term 'autonomy' itself has led to many controversies between different sectors, educators, linguists, teachers, etc. who have been unable to agree on a single definition. This uncertainty has led to various interpretations and notions, 'independence', 'self-regulation', 'self-management', 'self-direction', 'self-instruction', 'learner development', 'learning to learn' (Jiménez Raya, 2007:28). One of the biggest difficulties that often surrounds the term autonomy is to offer a global definition that considers everything autonomy carries implicit because so many aspects surround the term and it has been subject to so many interpretations. Dickinson (1987) also mentions the aforementioned different terminologies 'self-instruction', 'self-direction', 'self-access learning' and 'individualisation'.

Upon reviewing the different terminology, it seems that the terms defining autonomy can be categorised into two different groups. The first is a way to refer to a learning modality, how learning is carried out, thus included in this group are the terms 'self-instruction', 'self-direction' and 'self-directed learning' which could be called autonomous learning and 
whose degree of self-direction may be more or less depending on the decisions taken by the learner during the learning process. In the second group, the term autonomy refers more to competence as what the term implies is an ability that gradually manifests in skills or actions. Because this ability is not innate the learner must undergo a training process in these skills to acquire them.

The vast majority of references to the term autonomy found in the literature seem to point to the significant change in the field of language learning over the past half century or more. As mentioned before, this shift of focus from 'teaching' to 'learning' can be a result of the interest that is now seen in the learning process rather than simply the end product. This direction highlights references to the term autonomy that can be seen in the following two definitions:

1. "The ability to take responsibility for one's own learning", as stated by Holec (1981:3), as seen above, and:

2. [learner autonomy is] "[...] essentially a matter of the learner's psychological relation to the process and content of learning - a capacity for detachment, critical reflection, decision-making, and independent action" as stated by Little (1991:4).

There are many other definitions which highlight the importance of issues such as the learner's responsibility, ability and willingness during their learning process experiences. For Dam (1994:4) "Autonomy is characterised by the learner's willingness to take charge of their own learning and thus servicing their own needs and purposes". In this definition, the word 'willingness' is key in that it carries a high degree of involvement by the learner. This willingness to take charge of their own learning entails a capacity and willingness to act independently and in cooperation with others as a social responsible person. Dam's definition includes the definition offered by Holec (1981) where capability plays an essential role and also uses the word 'willingness' which shares a meaning with the term 'attitude' resembling the one offered by Dickinson (1987:11) referring to the term selfdirection: "[...] the term self-direction describes a particular attitude towards the learning task in which the learner accepts responsibility for all decisions that have to do with learning but does not necessarily undertake the implementation of these decisions". 
It seems obvious that the definitions of autonomy is the action of an autonomous learner who is able to take charge of their own learning process with all that it implies, this learner is the only person responsible for decisions taken in terms of objectives, interests, needs, materials, pace and place of learning. It is also accepted that this skill is not innate, but something the learner must learn, known in the literature as learner training, equipping the learner with the skills necessary to take charge of their own learning process, which many authors consider necessary for a learner to be autonomous (Dickinson, 1987; Ellis, 1989; Holec, 1980; Little, 1997). However, Kumaravadivelu (2003), considering the objective of learning autonomy, sees a double perspective in the current literature: one which he calls a 'narrow view' and the other a 'broad view'. The narrow view aims to enable the learner to learn how to learn. From this stance it is a short-term perspective. This perspective has academic learning through enabling strategies as its main focus. The end goal is academic learning, academic autonomy. The ultimate objective of the broad view is that students learn to liberate themselves, their goals are long-term goals and they look towards alternative aspects and contexts, liberating autonomy. It aims to create critical thinkers who can realise their potentials as individuals (Kumaravadivelu, 2003). Breen and Mann do not consider autonomy to be "[...] a process that can be learned just as if it were a set of rules and skills" and as they themselves state, they disagree with Holec by proposing that autonomy is not an aptitude or skill that must be learned, but should be seen as "a way of living in this world; a position from which to engage with the world" (Breen \& Mann, 1997:134). The search for a uniform definition of the concept of autonomy has not been free of criticism. Breen and Mann wonder if it really is necessary to have a unified theory of autonomy to strengthen the term: "Do we need some unified theory of autonomy to protect the concept from dilution, trivialization or commodification in the wider language learning industry?" (Breen \& Mann, 1997:149). For them it is much more convenient to have different interpretations of the term in order to enrich and consolidate it. They suggest that teachers interpret the concept into their teaching in formal learning settings as an extension and statement of their beliefs. They continue by stating that not providing specific definitions is preferable to a unification of interpretation, even if that were possible, as this situation would permit more innovation in the learning process and 
teaching methodologies which in turn would reflect the different cultural interpretations and classroom practices there are around the world and in each different educational setting, thus, generating many alternative concepts and possibilities. 


\subsection{Pedagogical implications derived from the concept of learner autonomy}

From the different perspectives identified so far, we can deduce that learning autonomy involves the implementation of elements that were not considered until now. Elements such as: decision making, teacher-learner negotiation, peer cooperation and teacherlearner cooperation, participation and the actual learning progress. Elements like these lead learners to develop a shared responsibility both within the classroom and throughout the different moments and spaces that shape their learning process. Thus we see that there are various changes within the current structure of learning. One of the most important is the changing role of the teacher and the implications for the concept of learner autonomy with the rise of online learning in addition to those that are mentioned below. Little (1997) notes that every person is autonomous when they are able to perform a specific task without assistance; when they are able to complete it in another context that is entirely different to that in which they acquired the knowledge and skills they need to successfully perform the task; when the person is able to perform the task in a flexible manner, taking into account the specific characteristics and needs of each particular circumstance. Thus, by using this definition of what it means to be an autonomous learner it can be seen that autonomy implies two concepts. On the one hand, the ability to apply knowledge and skills acquired in the classroom in appropriate contexts that go beyond the scope of the classroom. On the other, it shows the necessity of keeping such knowledge and skills up-to-date, in order to meet the demands that come from continuing change of situations and circumstances. After defining autonomy as an objective in formal learning contexts, Little (1997) highlights the fact that the learner's achievement is a matter of learning as well as the learning how to learn. Conscious reflection also appears as crucial from the beginning of the learning process as all formal learning is a consequence of intentional motivation. In this sense, when studying competence in a second language it must be remembered that learning a language has common elements with learning other subjects, but also significant differences. Different because, unlike in subjects such as chemistry, mathematics or history, language learning occurs spontaneously and implicitly: it is the result of a series 
of evolutionary processes that take place unconsciously. However, it is like other subjects in that they all have their own scientific concepts. This dual nature of second language learning in formal contexts explains why the learning autonomy development has two, albeit ultimately inseparable, objectives: autonomy in the use of language and autonomy in language learning. This also explains why the teacher can intervene on two different levels, which are also inseparable. This support must exist in language learners' efforts in using the target language, but must also exist when supporting their efforts in orienting their learning and practice of their target language. If the development of autonomy were to be established as one of second language pedagogical objectives learners could be fully involved in the planning, implementation, monitoring and evaluation of the teaching process. A successful implementation of a pedagogy oriented towards learning autonomy is not a matter of following a strict set of guidelines, but implies responding appropriately to the needs of a particular group of students in a specific socio-cultural context. That response must necessarily consider aspects that relate to strategies, guiding the learner and cultural difference (Benson, 2001; Benson \& Voller, 1997; Dam, 1994, 1995; Little 1991, 1997, 1999).

One implication that emerges from this is the need for a shared responsibility in regard to addressing learning. This requires creating an environment where learners are able to take responsibility for their own learning and look forward to it. This shift towards a teaching-learning context that lies in an exclusive one-way teaching standard set by the teacher and one set exclusively by the learner ensures that shared responsibility. An intermediate context between those two possibilities ensures that cooperation and negotiation have their own space in the context of teaching and learning, as stated by Dam (1995). According to him, this approach implies a change in the way we view foreign language teaching as well as its acquisition, emphasising five main differences:

1. A change in a focus on teaching to focus on learning: there will be a move from focusing on teaching to focusing on learning. This change means that the 'what' and 'how' you learn will be central concerns for both teacher and learner. 
2. A change in the role of the teacher: instead of the teacher teaching a subject in a sequence that he predetermines, he will have to take different aspects into account. He will focus on the learner and their learning process, rather than focusing exclusively on one teaching system; he will be open to ideas and suggestions from the learners; he will design working methods to assess learners' progress; he will act as tutor as well as a participant in the learning process.

3. A change in the role of the learner: The starting point for the creation of an autonomous learning environment is the idea that learners have in regard to language learning and the skills they need for it. This will also make learners aware of the various factors that contribute to the learning process. The learner is asked to define their own goals, to choose relevant materials and activities both inside and outside the classroom, and to evaluate the result of their learning process.

4. A change in the role of assessment: A fundamental aspect of the learning process. Assessments will play a dual function. On the one hand they ensure that the work carried out has been reviewed and discussed. On the other hand assessments establish an experimental basis and an awareness that can be used in further learning.

5. A change in the vision of the classroom - the classroom as a learning environment: The classroom is seen as a workshop or laboratory where knowledge is researched and tested, the classroom is not seen as an artificial environment.

Process and content are interdependent. Authors like Holec (1981) also mention these changes and give importance to the value of assessment and its role. The concept of assessment is linked to the needs of the learner, as well as their objectives. Assessment is the operation that determines whether the results agree with the stated objectives and, therefore, whether they have been achieved. After analysing the results, the learner can see if their goals were initially defined properly or even if their own needs have been properly analysed. Assessment is understood to give an element of support, not 
reproach, and are a fundamental contribution to the learning process and the development of learner autonomy. Assessment includes teacher and peer feedback.

No two learners learn the same way and likewise, no two teachers address their responsibilities in the classroom in the same way. The approach described above, particularly with regard to decision-making and negotiation, can be a bit confusing when put into practice. Dam and Gabrielsen (1988) suggest a framework for collaborative decision making. This framework could be understood as the basic framework for the organisation and development of activities in the classroom. Thus, according to them, the process would ideally be as follows: teachers and learners discuss and decide the objective to be achieved in the next class session and the best way to work to achieve those goals; learners choose the materials and decide the method, work organisation and schedule; the teacher takes part in developing the programme; the teacher uses their observation to make suggestions for the session; the teacher and learner evaluate and assess the completed tasks; each learner identifies his next objective; learners and teachers plan the next session. As Sturtridge (1997) suggests, self-learning models involve a reassessment of the roles of the teacher and learner as well as the relationship between them and their relationship with learning institutions. These roles and relationships can be complex and cannot be reduced to simple behavioural expectations or distribution of power. For learning autonomy projects to work, it is essential that both learners and teachers know each other, what to expect from each other and what their attitudes towards institutional and social learning are. The different models of autonomous learning are embraced within the group in addition to the diversity of interests, styles and objectives that these learners have (Linder, 1982).

Van Esch, Schalkwijk, Elsen and Setz (1999) also focus on this point but emphasise the starting point of teacher training. It is clear that when implementing autonomy-based learning the teacher's role changes from total control to playing a supporting role The teacher no longer leads the learning process as their role shifts from leading to tutoring or advising; implementing to planning: this change will encourage the teacher to dedicate more resources to the preparation, development and adjustments to the learning tasks; 
there will consequently be a greater dedication to the preparation and management of classes, exclusively assessing the final product to an assessment of both the product and process: the teacher is no longer solely concerned with what students should learn, they begin to also focus on how they should learn it, emphasising learning strategies in addition to any strategies that are necessary for improvement. (van Esch, Schalkwijk, Elsen, \& Setz, 1999). Regarding these three changes in the teacher's role, the authors assert that "the teacher's role will not be less prominent but will definitely be different" (van Esch, et al., 1999:28).

Learner autonomy or 'strategic learning', a name which they consider to be more accurate and less prone to misunderstanding, implies a change in the focus of learning and resulting in self-regulation. Self-regulation in the field of teaching is arousing increasing interest and is gradually becoming an integral part of teaching and learning. Self-regulation has been defined as all learning where learners are active participants in their own learning process (Schunk \& Zimmerman, 1998). They refer to participants as being active in a metacognitive, motivational and behavioural manner. In any process that occurs in this way, there is self-oriented informational feedback that allows the learner to control the process. From this definition it follows that awareness, control, and interaction are the building blocks of self-regulation. Baker and Brown (1980) consider that the processes of self-regulation may involve different degrees of activation of consciousness. They present awareness as a continuum in which there are four different scales:

1. Implicit regulations, integrated into cognitive functioning, without being conscious of the subject and which are inaccessible.

2. Regulations that are accessible to consciousness and made explicit if the task or other item thus demands it.

3. Explicit regulations, on which the subject intentionality operates in speech.

4. Implemented regulations relying on support that is external to the thought of the subject. This support may be the learner or the teacher provided he does not take control the instrument.

Along the same lines, they state that in order to reach that self-regulation a progressive 
shift in the exercise of control is needed, as mentioned above. Control moves to the learners so that they can use it independently. The transfer must be done emphasising the importance of the critical moments of the new resolution; of the alternative options that exist; of a justified reason to why the solution appears to be, in each particular case, the best choice and on what occasions would the rejected solutions have been preferable. Thus there is a shift from an external and teacher-centred control to an internal self-regulation on behalf of the learner. Control is regulated by the learner but guided, by teacher control assuming a new role as facilitator (Baker \& Brown, 1980).

In short, autonomy can be defined in a very general way: it is the ability to take control of one's own learning. By contrast, it is not described in terms of method, but as an approach, a way in which the learner approaches the learning process. With this idea in mind autonomy becomes a desirable and legitimate objective in learning foreign languages. According to the above review, all learners can be autonomous and there is a natural tendency for learners to take responsibility for their own learning process, although it is unique to each participant and each situation (Nunan, 1995). Those learners who lack autonomy are also able to develop it, provided they have the appropriate preparation and conditions available to them. Many authors have reflected on this concept and the influence the practice of teaching and learning has exerted on learners' development (Kelly 1996, Pemberton, 2001). Finally, it could be argued that autonomous learning is more effective than non-autonomous learning and that developing autonomy implies better language learning (Benson 2003; Legenhausen, 1999, 2003). 


\subsection{Autonomy and motivation}

With the shift towards learner-centred learning, a body of literature began to emerge on the connections between autonomy and motivation. Dickinson $(1978,1992)$ heavily researched this new field of study based on cognitive theories of motivation in education and one of her conclusions was that both autonomy and motivation are concerned with learners' active engagement in the foreign language learning process. Ushioda (1996) described autonomy as being involved and taking responsibility for one's learning and believes that self-motivation implies taking charge of and controlling emotional aspects of that process. Autonomy, or the perception of personal control, helps to maintain motivation, in other words, the degree of self-control of the learning process determines the motivational potential. Therefore, the methodology of language teaching should promote the development of feelings of control and efficacy regarding the ability to perform tasks. It is important here that learners have materials and resources at the correct foreign language level as if the level is too simple they will not learn and if the material is too complex they will lose motivation. Experimental studies conducted by Noels, Clément and Pelletier (2001) and Carrió Pastor (2013) showed that the learners' involvement in the design of learning goals and methods is extremely motivational and fosters autonomous learning. Influenced by the aforementioned self-determination theory, autonomy is closely linked to language learning motivation; there is much evidence to show that when learners take control of their learning they feel more motivated to learn (Lamb, 2001; Sakui, 2002; Ushioda, 2001, 2008). In the study conducted by Carrió Pastor (2013) students and teachers worked collaboratively to design exercises which used authentic materials from specific content websites; the results of a motivation questionnaire given to those students after the course showed that learning using material they designed was more successful because the content was relevant to their learning objectives, and this in turn stimulated the language learning process for them.

As explored in the section on autonomy, its association with complete independence from teachers and/or instructors is not entirely correct. Current trends in autonomy 
studies believe that autonomy is more socially situated and that the learners' ability to learn a foreign language is supported by their participation in social life and membership of learning and target culture communities. The autonomous learner is a creative product but also a producer of his social context (Esc, 2009). From a motivational perspective, this means that strategies that enable the learner to exercise a certain degree of choice and freedom in the course content and learning methodologies and share responsibility, function not only to motivate and promote autonomy but also as socialising strategies. Through them, personal goals may become aligned with curriculum goals, and through which the learners regulate their own motivation. According to Ushioda (2003:90) "[...] like learners' capacity for autonomy, their motivation must be viewed as an intrinsic part of human nature, yet one which needs supportive interpersonal interactions and an optimal learning environment in order to grow in positive ways". Although it is learners who must "[...] do the wanting, they need to be brought to understand what it is good to want and why. This is achieved not by progressive attempts to regulate their behaviour from outside, but by supportive interpersonal processes which foster the development of autonomy and the growth and regulation of motivation from inside".

Another aspect that seems to significantly increase motivation in the sphere of autonomy is the availability of a variety of possibilities or options as well as resources and materials. A variety of options can lead to a sense of autonomy because the learner feels they are developing their own learning methods and using materials they have chosen, it defines learner motivation due to control which manifests in positive effects on learning and performance. Instructors, MKOs or peers should clarify intentions, stress the importance of the task and properly present the different activities in order to establish optimal motivating conditions as well as to ensure a correct learning process. Any learning process involves a challenge that can bring about a state of uncertainty, as the learner does not know if the process will be successful or not, thus feedback is another key aspect of motivation. 


\subsection{Motivation}

The language learning process involves the need for active participation by the learner. This participation is encouraged by learner motivation. But the term motivation is difficult to define as it is viewed by researchers in this field as complex, multidimensional, situated and dynamic (Dörnyei, 1997; Williams \& Burden, 1999). Gardner (2010) quotes Keller (1983:389) when he defines motivation as: "Motivation refers to the choices people make as to what experiences or goals they will approach or avoid and the degree of effort they will exert in this respect". But he then explains in the same article that because this definition does not include all the aspects that characterise motivation, it is not accurate. Gardner and Lambert (1972) define motivation as a desire to achieve a goal, combined with the energy to work towards that goal. They believe that motivation can be interpreted as the influence of mental processes that lead to a conscious decision to act. Motivation also refers to the manifestation of a number of psychological processes involved in the activation and carrying out of certain behaviour. This state of cognitive and emotional activity is a result of the desire to learn a foreign language either out of curiosity, communicative necessity, in order to identify with the culture of its speakers or to ensure the achievement of established objective or external goals, whether academic or other types. It mainly consists of an inner strength that comes from the bodily sensations or instincts, as Brown (1987:114) notes "[...] an inner drive, impulse, emotion, or desire that moves one to a particular action." It has been conceived as a combination of effort and a desire to achieve a learning goal as well as favourable attitudes towards learning the language (Gardner, 1985) which takes the learner through a period of intellectual and sustained effort. Certain psychological perspectives specify that the essence of motivation is performed through the development of certain 'action-reaction' theories, characterising it as the impulse to release internal stress and meet needs.

It has been proven that the greater the motivation, the better learning that occurs as learners thus engage more in tasks and necessarily improve their linguistic capabilities (Richards \& Schmidt, 2002). For that reason, one of the most important psychological factors in determining the success or failure of linguistic performance can be found in 
learner motivation, according to Richards and Schmidt (2002:344): "Motivation is generally considered to be one of the primary causes of success and failure in second language learning". In addition, the responsibility of teachers in motivating the student used to be indisputable, as they could modify the resources, methods and subjects according to the interests and needs of students when they were in total control of the lessons, whether that be online or in a traditional classroom. In the case of distance learning, this role would be taken up by the course designers, as they direct the learning process by choosing the materials to be used. Autonomy here plays a very important role as the student must choose their own learning methods and motivate themselves. Masgoret and Gardner state that motivation is "[...] responsible for achievement in second language learning." (Masgoret \& Gardner, 2003:170). Results in a study carried out by Masgoret and Gardner in 2003 evidenced the link between motivation and language achievement and proved that they are closely related. During this study the variables of their socio-educational model (integrativeness, attitudes toward the learning situation, motivation, integrative motivation and instrumental orientation) were analysed to show a correlation between motivation and language learning success. They concluded that "[...] the correlation of the attitude, motivation and orientation variables with achievement were consistently positive and motivation correlated more highly with achievement than the other variables" (Masgoret \& Gardner, 2003:193). They also described each item of their socio-educational model of second language learning as being significant but believed that motivation is more so because it has a direct impact on language learning achievements. Dörnyei agrees: "My personal experience is that 99 per cent of language learners who really want to learn a foreign language $[\ldots]$ will be able to master a reasonable working knowledge of it as a minimum, regardless of their language aptitude." (Dörnyei, 2001:3). Motivation analysis highlights the importance of two dimensions or key components: firstly the energy component which refers to the characteristics of intensive and persistent behaviour such as, for example, drive and secondly the directional or structural component of variable behaviour: the means or mechanisms available to the energy or motivation to focus on a specific behaviour. Regarding the factors involved in language acquisition motivation, the stimulus or 
impulse to learn is subject to a number of factors, examples of which include social integration, either as immigrants or visitors to another country, communication needs, the different attitudes adopted towards the target language and culture, education or academic success, among others. Gardner calls this the integrative model. He studied Canadian students learning French and found that students who wanted to feel part of the French social community were more motivated to learn the language. Also, variables such as interest, curiosity and the desire to achieve significantly shape the nature of motivation (Gardner 1983, 1985).

Motivational processes are conditioned by a number of characteristics related to the learner, their history, environment and context. The motivational potential is also determined by the influence of certain situational factors (Dörnyei, 1994). Gardner and Tremblay (1994) also highlight that motivation is a dynamic process which includes many variables that must be considered. Within the context of acquiring a foreign language, motivation could be seen as a compendium of the following variables, including but not limited to, specific attitudes, nature of the language programme, frequency of training or learning sessions, availability of teaching resources, organisation of work, desire for learning, need for learning, direct contact with the target culture and/or language, participation, age, etc. Therefore, it can be said that motivation brings together a set of short and medium-term variables that activate human behaviour and move in a certain direction towards achieving a goal (Ho, 1998). All these factors can strengthen and, in turn, hinder the connection between motivation and learning of a foreign language. This impulse or psychological 'need-to-know' or 'need-to-learn' implies a certain behaviour that can be deduced from the learner's needs and goals. For these reasons, the study of motivation cannot take a simplistic view as it requires consideration of cognitive, affective, emotional, contextual and social variables. Certainly, social and psychological variables are relevant for the understanding of linguistic motivation. Motivation arouses positive social attitudes and every learner is motivated differently as they have their own personal meaning for external influences and circumstances that arise from their own personal history. The psychological constructivism approach has shown that students construct their own learning experiences from these influences and circumstances 
(Bruner, 1986, 1990). The aforementioned Canadian psychologists, Gardner and Lambert contributed significantly to the study of the nature and potential of motivation. These scholars have established their own typology for motivation factors: inclusive motivation, generated intrinsically by a positive view of learning a foreign language as well as towards the cultural identification and integration of the target culture; and instrumental motivation, prompted by the influence of external forces such as passing an exam or communicating within the target culture for employment (Gardner \& Lambert, 1972). This second type of motivation views learning a language as a mere tool which results in a reward. Instrumental motivation pursues an essentially pragmatic purpose. Gardner and Lambert's studies on the influence of motivation on the process of learning a foreign language are significant when considering the psychological factor of attitude. It has been shown that inclusive or intrinsic motivation leads to the achievement of higher levels of proficiency (Spolsky, 1969). Therefore, we could say that this type of motivation is absolutely necessary for an optimum learning process. This type of motivation also seems to favour the retention of information in long-term memory (Brown, 1987), confirming its functional value. However, this theory received conflicting interpretations that refuted its validity as it also suggested that instrumental motivation could better encourage linguistic performance (Lukmani, 1972). Extrinsic motivation may have negative characteristics as the desire to achieve a goal, driven by an external incentive may dominate the entire language learning process and long-term learning is not achieved, only temporary learning. In addition, extrinsic reinforcement may reduce intrinsic motivation or achievement motivation. This argument has been criticised. This lack of overall consensus caused Au (1988) and Gardner (1992) to take a neutral position and Gardner began exploring the idea that contextual diversity could determine the nature of a specific attitude. In other words, a specific context could encourage or manifest a particular type of motivation. Brown states that both types of motivation can exist simultaneously and that this is the ideal situation for achieving communicative competence, regardless of the influence of the contextual framework. Indeed, according to Brown, both types of motivation (integrative and instrumental) can lead to or ensure success in the learning of a foreign language (Brown, 1994). Gardner and Lambert 
(1972) also highlight the differentiation between manipulative or intellectual motives. Along the same vein, cognitive psychology defines a clear distinction between intrinsic motivation and extrinsic motivation. Self-determination theory (SDT) (Dörnyei, 2009; Noels, 2005, 2009; Noels, et al., 2000, 2001;) highlights intrinsic motivation in language learning and autonomy of learning in the learning process (Deci \& Flaste, 1995; Deci \& Ryan, 2002). This type of motivation seems to favour learning autonomy and contributes to fostering independence. Learning when intrinsically motivated is a rewarding activity. In contrast, extrinsic motivation results in an over-reliance on external support when solving problems. When the learner is extrinsically motivated, their learning process has the aim of achieving previously established objectives. Extrinsic motivation has the purpose of attainment of positive feedback or a reward of some sort or because they are subject to some sort of pressure. Intrinsic motivation arises out of curiosity or an instinct to explore which in turn encourages certain feelings of competence and selfdetermination. It prompts the learner to perform a certain task. Curiosity promotes activation of motivation. This motivating variable awakens the inclination to explore the unknown. Deci and Ryan (1985:245) state that: "Intrinsic motivation is in evidence whenever students' natural curiosity and interest energize their learning. When the educational environment provides optimal challenges, rich sources of stimulation, and a context of autonomy, this motivational wellspring is likely to flourish". They consider an interaction between the two types ideal as an attitude towards achieving goals contributes significantly to maintaining motivation.

Learning can suppose an inner satisfaction for the learner. Continuously low linguistic performance can seriously hamper any further development of skills and competencies because that inner satisfaction will be compromised, so to further refine the essence of motivation, the motivational value of self-confidence and a sense of efficacy must be explored. There are studies that show that self-confidence is positively related to successful performance in the target language ( $\mathrm{Au}, 1988$ ). The process of selfconfidence has also been shown to determine the attitude and effort dedicated to the process of learning a second language (Clément, Dörnyei, \& Noels, 1994). This effort is interpreted as a direct indicator of motivation since it reflects the intensity of persistence 
in achieving a given task. The self-efficacy theory was developed by Bandura. This theory refers to people's perception of their own ability to perform specific tasks and, accordingly, their sense of efficacy influences the activities they chose to carry out during the learning process in addition to the level of those activities, the effort dedicated to them and persistence in finishing them. People with a low sense of self-efficacy view difficult tasks as personal threats; they refer to their own personal weaknesses and the obstacles they encounter rather than focus on getting the task done. As a consequence, they do not trust themselves enough to successfully complete the task and they abandon the process. In contrast, a strong sense of self-efficacy motivates learners' achievement behaviour by supporting them in their approach and they then focus on the task rather than their ability to complete it or not, heightening and sustaining effort and motivation. Bandura states that:

Unless people believe that they can produce desired results and forestall detrimental ones by their actions, they have little incentive to act or to persevere in the face of difficulties. Whatever other factors may operate as guides and motivators, they are rooted in the core belief that one has the power to produce effects by one's actions (Bandura, 2001:10).

These beliefs are only indirectly related to learners' real abilities because they can result from a process that comes from the learner's personal history and external sources such as feedback, part experiences, opinions, stereotypes among other experiences. Once again, we see motivation as a socially distributed process. 


\subsection{Motivational components}

The contextual influences on motivation in language learning have been briefly explored throughout his section. The two areas that have most significant in the literature are 'instructional context' - such as materials and tasks used in the classroom, course design, how assessment is made, etc. (Pintrich \& Schunk, 2002) and the psychological state of learners when they engage in a task and either realise their individual interest or experiences and interest in the situation (Hidi \& Ainley, 2008; Krapp, 2002) - and social and cultural influences - peers, social and cultural pressures, family, how the learner views the target language and culture, etc. (Wentzel, 1999). There are psychologists who relate motivation to the influence of certain needs or impulses. Ausubel distinguished six types of needs: the need for exploration, manipulation and physical and mental activity; the need for stimulation, knowledge and finally the need for acceptance or approval from the learner's environment or context (Ausubel, 1968). The term motivation has also been described by some psychologists in terms of human needs such as identity, autonomy, safety, and self-worth. Williams and Burden distinguish several internal and external factors involved in the mental process of motivation: curiosity, challenge, feelings of competence and self-efficacy, the perceived value of the activity, trust, anxiety, fear, interaction, the learning context, cultural norms and social attitudes (Williams \& Burden, 1997).

Generally, society tends to attribute success to the learner's personal skills and this in turn increases their motivational potential and persistence in achieving their established goals. However, failure is attributed to the lack of immediate effort or personal ability, consequently generating inhibitions or a retreat from the learning process. For learners who have a low achievement motivation or performance level, success can be attributed to certain external causes such as the level (ease/difficulty) of the task. Attribution theory concerns itself with the learners' view of the reasons for their successes and failures. There are four types of attributes given to success/failure: ability, task difficulty, effort and luck (Dickinson, 1992). According to Weiner, stability of these attributes is key to motivation (Weiner, 1983). Dickinson further argues that when learners believe they have 
control over their learning and when learners attribute success to the stability of factors, they are more likely to take on more challenging tasks, be more motivated and thus increase their ability to perform (Dickinson, 1992).

It has been shown that the value placed on the final goal and activities performed to achieve these goals seem to determine the influence of motivation. Therefore, the perceived value of the objectives and the activities carried out during the learning process is a significant variable to consider in the study of motivation. The psychological notion of motivation could be characterised by the influence of three key attributes: global, situational and task-oriented. The total or partial presence of these three aspects can determine the dynamics of the process of foreign language learning, thus the cohesion of these three factors can affect to a greater or lesser extent, the nature of language learning.

Physical factors and aspects such as learners' surroundings and support (or lack of it) from their peers also have an effect on the learner's motivation. Thus the learner's context should provide an incentive for action and must adequately reward their efforts. In addition, learners' motives or desires to learn must be correctly organised and prioritised, so that certain needs must be covered for the learner to be logically interested in the following needs. In the case of foreign language learning, the level of the tasks must be appropriate to the learner's level to ensure their attention is maintained. Also, a distinction is made between primary motivations - innate, universal and physiological: hunger, emotional, etc. - and secondary motivations - not universal and acquired. Interest and effort shown by learners towards the learning process vary according to age, past experiences, immediate needs and long-term goals and the sociocultural context of the subjects. An example that is often cited in the literature is an immigrant's need or desire to learn the language of their new host country. Another example is the social status of the target language in the country where learning that language is taking place in. The language learning process depends on what the learner wants to learn, what they already know, to what extent they practice what they are learning and how much they want to learn: these are the basic and indispensable personal conditions that enable or 
facilitate the acquisition and application of new linguistic knowledge.

During the process of learning a foreign language there are many barriers to motivation as the need to communicate is not normally extremely urgent or desperate. It is reasonable to say that the dynamic nature of motivation during the process of learning a foreign language behaves asymmetrically as the degree of influence or development of motivation occurs during learning when the learner reaches high levels of linguistic performance and fluency or when the tasks are fulfilled. However, sometimes failure can also lead to motivation but in general motivation seems to be a short-term event that does not guarantee a permanent status. According to Dörnyei and Ushioda the natural tendency of all learners, in all fields, is to lose sight of established objectives or give way to distractions. Thus they believe that continuous motivation should be maintained throughout the learning process.

Although the spectrum of executive motivational strategies is broad (since ongoing human behaviour can be modified in so many different ways), the following areas appear to be particularly relevant for motivation:

- making learning stimulating and enjoyable;

- presenting tasks in a motivating way;

- setting specific learner goals;

- protecting the learners' self-esteem and increasing their self-confidence;

- allowing learners to maintain a positive social image;

- promoting cooperation among the learners;

- creating learner autonomy;

- promoting self-motivating learner strategies (Dörnyei \& Ushioda, 2013:118).

The points that are relevant to this thesis are maintaining motivation by promoting cooperation among the learners and creating learner autonomy, in addition to ensuring students maintain an awareness of why they are studying their chosen target language and perceive its relevance - understanding the target culture better can help maintain that initial interest or curiosity. Learners can be interested in that target language for reasons that could be either intrinsic (they saw an interesting documentary on the target country when they were young) or extrinsic (distant family is from that country); thus that interest could be deepened by further learning. Ellis reasons that individuals who are motivated to integrate both linguistic (target language) and non-linguistic (cultural studies 
about the target language country) aspects of language learning will attain more motivation and a higher degree of linguistic proficiency (Ellis, 1997).

Making a sustained effort and thus fostering a motivational styled learning - for present objectives but also for future learning - as well as the achievement of results, should be a priority objective in the learning process. At the same time, errors and failures provide valuable information for successive stages of learning. Thus the motivational aspect involves not only interest in a given task but also sustaining that interest, a continuing dedication and mental effort. The motivational process requires significant mental concentration and conscious awareness (Keller, 1984).

Motivation as a socially distributed process was also investigated by Bandura who developed a social learning theory that describes language learning in terms of the interrelationships between personal, behavioural and environmental or social factors (Bandura, 1986). Bandura extends the notion of self-efficacy to the collective efficacy of groups working together towards a common goal, thus exposing the importance of peer support in motivation as a socially distributed process (Bandura, 2000, 2001). Williams and Burden also focused on a social constructivist model in the field of motivation highlighting the idea that each learner is motivated in different ways but that this motivation is subject to social and contextual influences, "[...] these will include the whole culture and context and the social situation, as well as significant other people and the individual's interaction with these people" (Williams \& Burden, 1997:121).

Peer groups exert a powerful influence on individual motivation. Peer influence in learner motivation can be seen in a negative light when social comparisons are made and when stakes are high in regard to the self-consciousness of performing in front of peers. Feelings or fear of underachievement in regard to the peer group culture (McCaslin \& Good, 1996) can also be a problem as can be more serious behavioural consequences such as disaffection, group countercultures and social rejection (Hymel, Comfort, Schonert-Reichl, \& McDougall, 1996). However, according to Wigfield \& Wagner (2007) there is ample research that suggests that peers are often attracted to similar individuals or individuals with similar interests and goals and that they strengthen one another's 
motivational orientations, and if these motivational orientations are directed towards a learning or achievement focus, the effects of peer and/ social influences can be very positive.

Information feedback is appropriate and even invaluable in all teaching-learning process (Williams \& Burden, 1997), but more so when the feedback comes from someone the learner trusts. Many learners seek the satisfaction that comes with successfully achieving their tasks or end goals and the positive feedback that comes from it. This positive feedback results in higher motivation and even performance. At the other extreme lies fear of failure, but sometimes negative feedback can result in motivation too if the learner decides to use that feedback to improve. Peer feedback and support of the learning process strongly encouraged motivation during the ICC course. It is important for motivation that the MKO or peers give feedback and try to encourage present and future learning processes so as to boost motivation. However, any excess praise and reward or negative feedback maybe counter-productive as it has been shown that overreliance on rewards and praise can cause a loss in motivation and effort making and negative feedback may cause negative views of the learning process and result in abandonment. As has been seen in the group experiment conducted, peer motivation is very important in terms of encouraging each other to continue with and participate in activities and tasks (see Results and Conclusions chapters). Group participation and collaboration in the exchanges ensured learners continued studying in the course and that each learner was able to practise their target language. This collaborative learning has its basis in sociocultural theories which suggest that a learner's development happens on two levels. One is social; the other is psychological. Thus this learning process takes place first between people and develops as an inter-psychological experience between those players and subsequent to that as an intra-psychological experience (Ge, et al., 2000; Vygotsky, 1978). In the ICC course developed for this thesis, given in a learner-centred collaborative environment, learners worked together to construct knowledge and negotiate meanings through group based exchanges on Google Hangouts and activities designed to foster understanding of the themes. From here assumptions were drawn about collaborative learning and knowledge building, in 
regard to motivation as these tasks and processes require communication, collaboration and negotiation based on a platform of shared ideas, values and beliefs (Johnson \& Johnson, 1996). Harasim (1990:54) emphasises that "teamwork enhances connectivity and socio-emotional engagement in the learning process, as well as creating an intellectual climate that encourages participation". In other words, a well-designed online environment is conducive to both learners' affective and cognitive development and their motivation to participate because emotional links are created when this type of learning takes place. The online ICC course provided a structured environment where learners could talk about what they had learnt and ask about any misunderstandings while practising their target language by talking with their peers. By working together to better understand new concepts and practising their foreign language skills, learners in turn create an even more cooperative learning environment that emphasised learning as groups in that online environment (Kalman, et al., 2010; Turpen \& Finkelstein, 2010). Research studies suggested that this type of group collaboration and learning environment can help foster a more long-term learning as well as generate further motivation (Cross, 1998; Keiner \& Burns, 2010; Simon \& Cutts, 2012). The aforementioned emotional ties also influence in learners' responsibilities in that they have to participate in terms of being available for other students, in the case of the experimental ICC course, to both construct knowledge within the group and practise their target language. 


\section{LANGUAGE AND CULTURE}

Intercultural communication (ICC) aims to understand the impact of culture on communication and to develop the capacity and the ability to perceive and consider alternative viewpoints in intercultural contexts. ICC is the process of communicative interaction between individuals and groups who have cultural differences. These cultural differences are principally differences in perceptions, interpretations, values and behaviours; ICC studies how these variations significantly affect the shape and the outcome of the communicative event. When participants interact in intercultural encounters, they rely on assumptions that have been developed within their own culture; these assumptions and in some cases interpretations, act as perceptual screens or filters for the messages that are being exchanged.

The first section in this chapter introduces the concept of linguistic relativity as the idea that language shapes thought and moves on to an exploration of the relationship between language and culture and how those assumptions and interpretations are developed through that relationship. Although culture has traditionally been investigated from an anthropological perspective, this section further defines culture and communication from an ICC basis. It explores how the concept of culture can be categorised so as to make it comprehensible for foreign language learning within the ICC sphere and explains why ICC is necessary for successful foreign language learning before ending with Hofstede's different dimensions to culture, which are analysed from a communicative perspective as these formed the basis for the ICC course. 


\subsection{Linguistic relativity and how language shapes culture}

As a general framework, this section is based on the traditional theory which argues that linguistic patterns determine the way the individual perceives their world and way of thinking. One source this theory of linguistic relativity springs from is the $19^{\text {th }}$ Century German philosopher and linguist Wilhelm von Humboldt (1836) for whom language expresses and shapes the spirit of the people; he believed it has its own internal form, which organises the world of a people:

The mental individuality of a people and the shape of its language are so intimately fused with one another that if one were given, the other would have to be completely derivable from it. For intellectuality and language allow and further only forms that are mutually congenial to one another. Language is, as it were, the outer appearance of the spirit of a people; the language is their spirit and the spirit their language; we can never think of them as sufficiently identical. (Humboldt, 1999:46)

In the first half of the twentieth century American anthropologist and linguist Boas (1887) began to further explore this idea by studying the relationship between language and culture. By studying native Amerindian languages and analysing their grammars Boas began to develop the idea that he was not only faced with different linguistic forms, but rather a different way of interpreting and classifying the world. He began to develop the theory of cultural relativism by studying the relations between language and their influences on culture, as he states that: "[...] civilization is not something absolute, it is relative [...] our ideas and conceptions are true only so far as our civilization goes". (Boas, 1887:1-4). During this time, he had been employed to study phonetics in different languages but what began to interest him were the interpretations of his peers - Englishspeaking researchers - and the discourse about what they were studying. After transcribing and translating Amerindian texts, Boas noted that those cultures need to be understood within their own terms rather than from a dominant European language like English because he had become aware of different ways of classifying the world and human experience. Thus, according to him, cultural relativity affects individuals' perception towards everything, including language; he believed that cultural awareness is necessary in understanding how individuals classify the world and their experiences. 
Sapir (1921), a student of Boas, re-visited cultural relativism and noted that language classifies experiences in a different manner, and that this classification is governed by three areas: language, thought and culture. In studying several Native American languages, Sapir (1921) began to believe that it was not grammatical structures, semantics or pragmatics that were most significant, but that it was actually the formal organisation of meaning construction or the categorising of mental representations that determined thought. Sapir's student, Whorf (1956) furthered his observations by giving the example of how language can be deceiving when acting as a vehicle of thought based on experience and perception, proposing that languages refer to experiences which are formally categorised into groups which are in turn assembled into specific, coherent systems of reference.

\begin{abstract}
We are thus introduced to a new principle of relativity, which holds that all observers are not led by the same physical evidence to the same picture of the universe, unless their linguistic backgrounds are similar, or can in some way be calibrated. [...] the relativity of all conceptual systems, ours included, and their dependence upon language stand revealed. We dissect nature along lines laid down by our native languages. The categories and types that we isolate from the world of phenomena we do not find there because they stare every observer in the face; on the contrary, the world is presented in a kaleidoscopic flux of impressions which has to be organized by our minds - and this means largely by the linguistic systems in our minds. This fact is very significant for modern science, for it means that no individual is free to describe nature with absolute impartiality but is constrained to certain modes of interpretation even while he thinks himself most free. (Whorf, 1956: 213-214)
\end{abstract}

Linguistic relativity explores the idea that differences in thought emerge from differences among languages. This form of relativism views language as a predisposition to thought rather than a limitation of it. In the words of Whorf (1956:221), the principle of linguistic relativity involves "[...] users of markedly different grammars [being] pointed by the grammars toward different types of observations and different evaluations of extremely different acts of observation, and hence are not equivalent as observers but must arrive at somewhat different views of the world". This is now known as the Sapir-Whorf hypothesis because although they never published any work together the idea was initially introduced by Sapir (1921) but became popular during the 50s with the work of Whorf (1956).

Whorf differed from his linguistic and anthropologist predecessors because he used an approach to observe differences between languages and their meaning that was more 
focused on structure (Lucy, 1997). Whorf (1956) compared the language of the Hopi Indians of Arizona to a number of European languages. Using temporal marking, Whorf's structural comparison of those languages led him to believe that the Hopi have a fundamentally different concept of time than Europeans do. This presumption led to one of Whorf's most famous statements in regard to how languages may shape thoughts and thus culture. He stated that European cultures arrange and perceive their world in terms of time and space, while the Hopi cultures focused on events. In addition, the Hopi has no words or expressions referring directly to the abstract concept of time; none for the past, present or future. According to Whorf, the Hopi emphasised change and processes, instead of viewing the chronology and patterns of days, months, years, decades, as a continuous, homogenous, formless abstract notion (Pinker, 1997).

Lucy (1992) thus summarised Whorf's argument that specific linguistic patterns influence people's thoughts, which in turn shapes both cultural and behavioural norms:

Large-scale linguistic patterns

(integrated fashions of speaking)

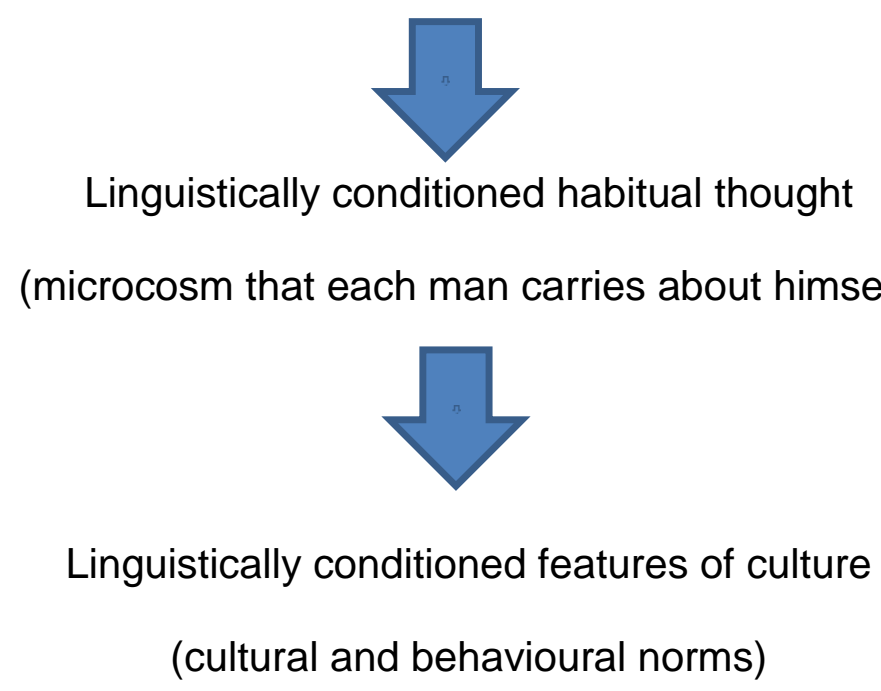


Figure 1: Structures of Whorf's agument linking language, the individual and culture (Lucy, 1992b)

According to Whorf (1956), language is thus the means by which humans create their conception, understanding and values of objective reality, it acts as an intermediary between subjects and objects. Similarly, the words we hear or pronounce shape our semantic environment or verbal context, an environment that influences how people think, and these words have an intentional significance that are shaped by that which emerges from minds and thoughts. Language comes from a coexistence that is established between us and the world created within our society in interaction with other people. It has emerged as a way to describe and interact with the environment and it is not surprising that much of it is consciously or unconsciously modeled according to the habits and behaviours of each social group.

However, there was an issue with these new ideas: a near complete lack of evidence to support claims. Psychologists Brown and Lenneberg (1954) criticised the fact that Whorf had not himself physically gone to any Native American areas to study the language or people, he never contacted nor spoke with an Apache or Hopi, Whorf's psychological assertions seemed to be based solely on grammatical terms: the language is different to English and so they think differently. Whorf also used glossaries to show evidence of the differences in grammar, unfortunately direct translations often lose much meaning.

So by the 1970s the Sapir-Whorf hypothesis theory (1956) seemed to have been completely rejected, especially because the theories claiming that language and thought are universal were so readily accepted. However, recently there has been a resurgence of these ideas. Boroditsky (2010) considers that "[...] language is a human quality, creation or tool, which mankind invented and is continually honed to suit our needs". (Boroditsky, 2010:1). She believes that there is a steadily growing body of empirical evidence proving that languages shape thinking: "[...] a flurry of new cognitive science research is showing that, in fact, language does profoundly influence how we see the world" (Boroditsky, 2010:1). She also conducts experiments to prove this. Her research studies involving language and thought seem to evidence that language does make people behave differently by indicating differences in human nature depending on the languages that we speak. However, she also notes that "Simply showing that speakers 
of different languages think differently doesn't tell us whether it's language that shapes thought or the other way round. To demonstrate the causal role of language, what's needed are studies that directly manipulate language and look for effects in cognition". (Boroditsky, 2010). Deutscher (2010) has recently been researching what he calls the new linguistic relativism. He notes that language affects thought through areas such as spatial perception, gender, time and colour. Deutscher criticises anthropological linguists including Whorf who he says never had any actual evidence to support his own claims and argues that the most solid evidence for language influencing thought and perception comes from the study of geographic references or deixis in different groups of people, such as the experiments conducted by Boroditsky (2000) of the Pormpuraawans tribe in Australia (Deutscher, 2010). The most significant finding to come from this study is that this is the first model of language found to date that uses cardinal points instead of the traditional notions of space: left, right, up and down. Rather than saying: 'I have an ant on my left leg', the Pormpuraawans say: 'I have an ant on the southwest of my leg'. Boroditsky states that this way of conceptualising space influences the conceptualisation of time. She showed the Pormpuraawans sets of photographs of a man at different ages, the growth of a crocodile and a banana in the process of being eaten. The people being studied placed the photographs reflecting the chronological order of the events shown. The photographs were shown to each participant in two different locations and each time facing a different cardinal point. English speakers always order the events from left to right. Hebrew speakers placed them from right to left (because Hebrew is written from right to left). Boroditsky found that speakers of the Pormpuraawan language ordered events from east to west (Boroditsky 2000). According to her, and as we saw above in the Sapir-Wharf hypothesis, this different grammar or syntax of a language influence aspects of thinking (Boroditsky 2000).

Another study into the idea that language shapes thought and thus culture was again carried out by Boroditsky (2001) and uses the notion of causality. English speakers tend to describe events in terms of agents that do things, even if the event was accidental. So an English speaker might say 'John broke the vase' even in the case of an accident, when it was not John who directly broke the vase on purpose or not. In similar 
circumstances, speakers of Spanish and Japanese say: 'The vase broke'. Boroditsky believes that these intra-linguistic differences have profound consequences on how speakers understand events, construct notions of causality and agentivity and what they remember as witnesses (Boroditsky, 2001). Along the same vein, Fausey (2010) studied these ideas in her research. She asked speakers of English, Spanish and Japanese to watch videos where two people burst balloons, broke eggs and spilled drinks, either intentionally or accidentally. The speakers then took memory tests for each event and were asked if they remembered who had broken the items. She believes that her results showed a significant difference in how each person interpreted the events. The speakers of Japanese and Spanish did not remember who had broken the items in the accidental events as well as the English speakers did (Fausey, 2010). In 2002, Boroditsky, Schmidt and Phillips (Boroditsky, 2003) compared the word 'bridge' in Spanish and German and asked native speakers of those languages to state adjectives for it. The word 'bridge' is feminine in German and masculine in Spanish. German speakers described bridges with 'feminine' adjectives such as beautiful, elegant, fragile, pretty, and slender and Spanish speakers described them with 'masculine' adjectives such as big, dangerous, strong, sturdy, and towering. They did this with several other nouns and object gender continuously influenced the participants' judgments. This is despite the fact that the testing was performed in English, a language without grammatical gender designations. 


\subsection{Relationship between language and culture}

Continuing work researched within the school of North American linguistics, American anthropologist Edward Hall borrowed Benjamin Lee Whorf's idea of language conceived not just as a medium of expressing thought, but as a major element in the formation of thought and applied those studies to all human behaviour and their cultures. In one of his most famous books, The Silent Language, Hall (1959) attempts to lay the foundations for a theory of culture considered in its entirety as a form of communication, and therefore susceptible to analysis and structuring. According to Hall, language was one of culture's main features and was present at all levels of his research and analysis. Hall stated that when a foreigner interacts with a new culture, they are "[...] faced with a different way of organizing life, of thinking and of conceiving the underlying assumptions about the family and the state, the economic system, and the man himself." (Hall, 1959:26). If culture is understood to be the behaviours, values and beliefs of the people of a country (as will be explored below) it seems logical to make direct parallels between language and culture. Hall emphasised the fact that culture is heavily acquired through language and communication and that it controls individuals' lives to such an extent that the members of that culture are not even aware they are internalising it. Hall noted that:

[...] we must never assume that we are fully aware of what we communicate to someone else. There exists in the world today tremendous distortions in meaning as men try to communicate with one another. The job of achieving understanding and insight into mental processes of others is much more difficult and the situation more serious that most of us care to admit. (Hall, 1959:28-29).

Hall believed that culture exists at two levels: an explicit culture, one which people speak about, such as the laws of a particular country; and implicit culture, where the 'rules' are assumed or unspoken, which exists outside people's consciousness, such as the customs and traditions of a society or 'presuppositions' about values and how to behave. Hall then separates these two levels into three categories: Firstly, formal learning occurs 
through precept and advice. Adults shape younger people's thoughts by giving them guidelines that cannot be put into questions through such phrases as: it is not done that way. These philosophies are often universal, such as running away from a large animal. Secondly, in informal learning, behaviours are imitated, but no explanations of why those behaviours are done are given, there are systems of behaviour that are passed from one generation to another without anybody shaping the rules (Hall, 1966). It is precisely these systems that vary from one culture to another. Communicative examples of these include different forms of greeting, ways of starting conversations, turn taking and many other different 'hidden' features of culture. Thirdly, technical learning is knowledge that the learner learns in formal situations, such as through reading or through teacher transmission to the student, for example, when learning to drive a car. These three types of learning give rise to three types of consciousness. All the rules and traditions that correspond to a culture fall into the first, formal consciousness; the second, informal consciousness is made up of the activities and behaviours that the people of the culture learn unconsciously and which they do automatically. Finally, people are completely aware of technical consciousness, it can be registered, explained and taught. It is important to note the affective component underlying the first two types of consciousness. People grow up in a community and the informal rules of behaviour and 'good' and 'bad' values they learn are internalised to such a point that when they are faced with a violation or breach of any of these guidelines they can feel uncomfortable or offended. Hall $(1959,1966,1983)$ devoted much of his work to analysing the implicit patterns differing cultures and categorising them. He believed that this would facilitate communication between groups or cultures because groups could then understand and analyse their interpretation of a category and compare it with another group's interpretation. Using tools from different fields, including anthropology, biology, psychology and sociology, he developed extremely useful and practical theories about the function and use of time, space, senses (sight, hearing, smell, touch) in different cultures. As an example, in his book The Hidden Dimension, (Hall, 1966) he develops the idea of space as a communication system. He studied people's perception and use of personal (Latin cultures tend to talk in closer proximity than Germanic cultures) social, architectural, and urban spaces (Arab cultures tend to use public space more than 
northern European cultures). 'Proxemics' is the term he coined for the interrelated observations and theories of the use of space as a specialised elaboration of culture. According to Hall (1966) people from different cultures inhabit different sensory worlds, so the experiences perceived through one set of culturally patterned sensory screens is quite different from the experiences perceived through another. Hall attempts to make his reader aware of those patterns. He analyses culture using defining units of culture or building blocks which he terms 'isolates' (Hall, 1959) and then moves on to associate these isolates with a biological base so as to compare them among different cultures, gradually building a unified theory of culture. As an example of one of these isolates, he believed that time is one of the key elements of culture. He gave the example of Americans thinking that time is something fixed in nature, it is characterised by discreteness, linearity, there is a need to programme and head forward, towards the future. Time is categorised formally into days, hours, minutes, weeks, months, seasons, years, celebrations etc. This culture tends to arrange time, for example putting months into a year, emphasising cycles and giving it a high value: 'time is money', and 'don't waste my time', it is tangible (a commodity), it has duration and depth. Many of these isolates put together are the building blocks that create the values of a culture. The example of the isolate 'time' shows how unconscious implicit patterns work in a culture, and how strongly each member of that culture holds on to them. They exist without most people being aware of them, if the foreign language learner is taught how these isolates are part of the communicative culture of the target language they are learning, it could facilitate their meaning making and comprehension in that language. 


\subsection{Definition of culture and communication in terms of ICC}

Culture has been defined in many ways; it is a concept that has been addressed from multiple perspectives. The definitions of the extremely complex concept of culture stretch across multiple disciplines and scientific fields including psychology, linguistics, sociolinguistics, anthropology, philosophy and ethnography. Despite the wealth that this multiplicity provides, it can also be a liability: conceptual ambiguity. Culture has traditionally, mainly been studied from an anthropological perspective, but within Intercultural Communication (ICC), culture does not take on that purely anthropological definition; it also requires a symbolic perspective that accounts for the diverse and complex universe of meanings and symbols contained within. ICC occurs in interaction, in a particular communicative situation. So rather than addressing culture from a strictly anthropological base, this thesis explores the concept of culture from a social phenomenon perspective, favouring the process, interaction itself, and where explanations provided by social-historical conditions function as a kind of sociological framework of that condition, but do not determine the direction of the interaction in order to facilitate language learners' use and comprehension of the target (and thus unfamiliar) language and cultural meanings.

Vívelo (1987) states that the anthropological perspective, which he calls totalistic, defines culture as a mechanism of adaptation: the totality of tools, actions, thoughts and institutions through which a population is maintained. He believes that the complex totality of culture includes knowledge, beliefs, morals, values, laws, traditions and all the capabilities and habits acquired by the individual as a member of that specific society. He defines culture as a conceptual system: a system of shared knowledge and beliefs with which people organise their perceptions, experiences, make decisions and act. According to this definition, culture is a type of conceptual code that people use to recognise and understand the world and interact.

González (1986) defines culture as the organising principle of human experience, the place where individuals and groups are positioned, formed, defined and relate. Cultural studies explain culture as an effective context where hegemony is built, and in which 
various ideological currents recreate different points of union, establishing culture in ways that historical dominant relationships influence the forming of individuals and the identities of social groups. The concept of culture proposed by Comaroff and Comaroff (1992) can be understood as the dialectical relationship between structure and practice that reproduces and transforms the character of the social order. When studying culture a constructive sense of culture must be emphasised because culture is what underlies the structure of each individual's world, the models they use to make sense of the world, its cognitive and communicative character, its pragmatic and dialectical status and the common knowledge that allows the right amount of interaction necessary to implement the notion of symbolic territory, which is where intersubjective constructions are built and the context of appropriation, and interpretation.

Bodlye (1994) believes that culture is something that is passed from generation to generation through learning. Thus an individual is not born with a culture but acquires it by learning the shared meanings that exist in it, which in turn allows them to belong to it and gives them an identity. In this sense, culture is closely linked with the process of socialisation that takes place through interactions with the family, at school, through religion and mass media, among other situations. So culture is acquired, learned and shared. It is also dynamic and changing. It is important to note that Bodlye's definition does not imply that there are no individual differences, he simply emphasises that it is the shared concepts that allow individuals to communicate and generate relationships of belonging beyond biological or historical identities. The interesting thing about this definition is that it incorporates a communicative element: culture needs communication not only so that it is passed on from generation to generation, but because the very existence of culture, objectified in social practices and interactions, and internalised by subjects, is mediated by the communication processes.

Triandis (1972) states that culture is closely related to cultural identity. Cultural identity is the common reference that provides a basis for understanding the world and how it functions and facilitates interaction with other people. This framework is built through social and cultural dynamics that depend on power and ideology, but it emerges from, 
and is part of, community traditions and practices, whose meanings are negotiated. Brislin (1980) gives another definition of subjective culture that is similar to the cultural identity concept proposed by Triandis. Subjective culture is the individuals' response to parts of their environment that have been created by man, or the characteristic ways a group perceives their social environment. This definition is similar to Bourdieu's (1984) concept of habitus: "A structuring structure, which organises practices and the perception of practices." (Bourdieu, 1984:170). Habitus encompasses the values and beliefs that social groups form and internalise by performing their everyday activities subconsciously. Habitus is the structure of each individual's mind in that society which is formed by what Bourdieu calls 'schemata': the internal representations of external structure which lead individuals to think, perceive, act and behave in a determined way. Thus habitus is in an internalised form that determines how individuals act according to a series of symbolic internalisations acquired throughout their life (Bourdieu, 1990).

As mentioned above, culture was first explored from the field of anthropology. Poyatos (1994:25) provides an adequate definition of totalistic in the context culture:

Culture can be defined as a series of habits, shared by the members of a group living in a geographical space, that are learned but biologically conditioned, such as means of communication, social relations at different levels, different daily activities, artefacts created by this group and how they are used, typical manifestations of personalities and individuals' ideas about their own existence and other members (Author's translation) (Poyatos, 1994:25).

Goodenough (1957) comments on culture from a mentalist perspective:

In my opinion the culture of a society is what people [members of this society] need to know or believe in order to operate in a manner that is acceptable to its all its members... Culture refers to what people have to learn and differs from their biological heritage. This definition emphasises that culture is not a material phenomenon. [...] It refers to models that people use to relate, perceive and interpret all these things. As such, what people say and do, their social organisation, their events all are product or a result of their culture to the extent that they apply them to the task of perceiving and responding to their circumstances. (Goodenough, 1957:167)

For Keesing (1997), culture is a shared system of ideas, a type of conceptual code that people use to understand the world and how to act; it does not include tools, actions or institutions, only thoughts. Within this mentalist dimension of the concept of culture sociologist Vander Zanden (1996) defines it as the social heritage of the people; a 
learned way of thinking, feeling and acting that characterises a society. For the psychologist Robert Feldman culture is the configuration of learned behaviour and of the results of behaviour whose elements are shared and transmitted by the members of a society and for the sociologists Horton, Hunt and Cohen (1972) culture refers to a mode life that members of a society learn, share and transmit across generations.

Combining all these perspectives of the meaning of culture, it can be defined as the set of learned behaviours, or from the field of social psychology as that expressed by Hofstede:

[...] the collective programming of the mind that distinguishes one group of humans from another. It is transmitted from one generation to another; it changes shape continuously and gradually and includes a value system that shapes the basis on which it is built (Hofstede, 1984:51).

He also states that most people belong to several different groups and as a result, carry within them various levels of mental programming, which correspond to different levels of culture. Vívelo (1987:10) also distinguishes between these different levels, cultural and social contexts:

When I refer to culture, I am referring to conceptual codes, something that exists in people's minds. When I refer to social, I mean the behaviour patterns of society, the interaction between individuals as members of society. Therefore, the terms 'social organisation' or 'social system' I refer to are the descriptions of people interacting, while 'culture' refers to a set of ideas according to which people act. (Vívelo, 1987:10)

Kluckhohn notes that:

The patterns and themes (configurations, motivations or beliefs) that a culture consists of vary from explicit or manifest to implicit or hidden. Patterns generally belong to explicit culture in the sense that they can be easily abstracted from behaviour and the verbalisation of the participants of that culture. Topics (configurations, motivations or beliefs) tend to be implicit... Participants of the culture often find it difficult to verbalise those themes which tend to operate on a subconscious level (Kluckhohn, 1973:75).

It is important to briefly note that because culture is only one category or dimension of human behaviour, it must be situated in context and in comparison with two other equally important dimensions: the universal and the personal. Universal is the way people throughout all cultures react in the same way (for example the way every person in all 
cultures nurture their children), and personal refers to the ways in which individuals are different from other people, including those people in their own cultural group. Universal values and behaviours means that not everything about people from a different cultural group will inevitably be different, and personal behaviour, emerging from an individual's personal history, means that not every way they react or behave will apply to other individuals from that culture.

Culture provides the values that give communication the basis for the interpretation of symbols and meaning, and the survival of culture depends on communication for its initiation, learning, maintenance, exchange and transmission. Thus culture itself is a communication system. The complex interconnections of cultural events transmit information to its members. As Hall (1966) noted, culture is communication and culture is evidenced in the intercultural communication process.

Communication, like culture, is a very broad concept. There are many definitions for human interactions. Generally speaking communication is the process of transmitting messages and sharing meanings through symbols. These symbols can be linguistic, non-verbal, pictorial, or other random annotations which two or more people agree have a specific meaning. Alone or in combination, they carry or convey messages. The processes of selection, arrangement and interpretation of symbols are included in the transmission of messages (Leach, 1976). Interpretation is critical to the process of communication. Interpretation is extremely significant because the way in which a message is interpreted varies depending on the culture of the person as well as their individual experience, and according to the context and situation in which the communicative event occurs. Meaning can often be inferred from situational and contextual cues. Cultural, situational and contextual rules can be more important than actual words when delivering messages in communicative acts. Because there is obviously a breakdown in communication if the receiver does not understand the message being sent, feedback is another important aspect of the communication process. Feedback is one of the best ways for the transmitter to ensure their interlocutor is correctly receiving the message. The response sent by the receiver can shape the transmitter's delivery and language as they will try to ensure that this message is being 
correctly received. If the transmitter has no way of verifying that the message is being received, problems may arise in the communicative process, as serious as if the receiver has simply not understood the message being sent. This circular communication process allows for successful understanding, which in turn facilitates the development of a pleasant interpersonal relationship (Mehrabian, 1972). Messages can be transmitted through multiple channels. During face-to-face interaction the people communicating tend to use the primary channels of sight, hearing, smell, touch and taste. Messages can also be transmitted by using devices such as telephones, computers, mass-media and other technological mechanisms. Humans are social creatures who use symbols and transmit social knowledge without even realising they do it. This knowledge reflects a collective perception of reality which differs between cultures. There is always the danger that one culture's conception of the world or reality clashes with another culture's way of perceiving the world or reality. History and common events prove that this is something that can and does happen. Foreign language learners who practise intercultural communication believe that successful communication in intercultural contexts requires recognition and understanding of the impact of culture on communicative behaviour, interpretation of meaning and perception of values and the world. 


\subsection{The importance of ICC in foreign language learning}

The definition of intercultural competence in a language given by Hains, Lynch, and Winton (2000) emphasises the ability of individuals to relate and communicate effectively with other people who do not share the same culture, ethnicity, language or other important variables. According to Meyer intercultural competence - as part of the foreign language learner's broad competence of speaking another language - identifies the ability of a person to act appropriately and flexibly when confronted with actions, attitudes and expectations of people from other cultures (Meyer, 1991). Oliveras' definition is also worth noting, "[...] the ability for language learners to stabilise their own identity in the process of mediation between cultures and help others to stabilise theirs." (Oliveras, 2000:38). One of the reasons why intercultural competence is so important to language learners is because much of people's culturally motivated behaviour occurs at a subconscious level; learners need to be aware of this is because it will help them better understand the messages members of those cultures are sending which are not verbalised or obvious and the many meanings that may be hidden from them. Recent studies that have researched reasons why learning about culture is thought to be an important part of the foreign language learning experience have proved that it is a relevant issue in the applied linguistics field and consequently that the two should be taught simultaneously. These studies have also highlighted the importance of the sociocultural context when learning a foreign language, and consequently the social interactions needed to develop intercultural communicative competence in foreign language learners. Theoretical research into foreign language learning often uses terms such as 'cultural competence', 'the intercultural dimension', 'intercultural communicative competence' and there are continuous references to the significance of understanding cultures and learning about cultural communication during the foreign language learning process. Byram (1997), Buttjes (1991), Kramsch (1998), Morgan (1994) and Sercu $(2004,2005)$ stand out as relevant figures in this field. They have all served as a reference for the document 'The Common European Framework of Reference for Languages: Learning, teaching, assessment' developed by the Council of Europe on 
language learning and the importance of ICC during this process. This publication states that: "Knowledge of the shared values and beliefs held by social groups in other countries and regions, such as religious beliefs, taboos, assumed common history, etc., are essential to ICC." (European Council, 2002:11) and that "The linguistic and cultural competences in respect of each language are modified by knowledge of the other and contribute to intercultural awareness, skills and know-how. They enable the individual to develop an enriched, more complex personality and an enhanced capacity for further language learning and greater openness to new cultural experiences." (European Council, 2002:43). This framework was developed by exploring the relationship between language and culture and using the resulting conclusions to guide research into the significance of addressing ICC in foreign language education.

Sercu (2005) states that incorporating intercultural objectives into a foreign language curriculum should not be unique to language teaching as it affects a wide variety of issues. She also believes that foreign language learning is, by definition, intercultural as two cultures are meeting during the learning process and needs to be negotiated, a foreign language in the classroom puts learners into contact with a world that is culturally different from their own. As Nichols and Stevens (2001) point out, teachers of languages often agree that target languages should be taught alongside their cultures. If the foreigner would like to become familiar with a new culture, often the culture of the foreign language they are studying, they must go through a learning process, which is usually long and arduous, as, although exactly the same categories exist in their culture, the content and interpretation of these categories (and thus reactions and behaviours towards them) is completely different; for a member of another group to understand the same concept in a different way or to view them from a different perspective is not easy, which is why the learner should be taught the different possible ways of interpreting them or at least be made aware of them and that there are many ways of reacting to them, that they exist on a continuum with two extreme points.

Culture used to be taught in language learning class as the literature, facts and geography of the target language, this was a simplification of culture, what Kramsch 
(1993) calls the fours Fs; food, fairs, folklore and statistical facts. When anthropology began to study culture in the 1960s the idea that culture did not only exist as facts and information began to take root and began to be seen as something that is shared between members of a group and as more deep rooted. Brooks (1960) wrote about 'Culture with a capital $C$ ' and 'culture with a small c' in language learning. The former refers to those traditional ideas of culture (the four Fs), and the latter to the behavioural patterns and lifestyles of everyday people and he stressed that although this culture was less visible he thought that it was either equally or more significant. Kramsch (2003) believes that foreign language education should include teaching about how to understand differences between cultures through teaching culture with a small c. Also according to Brooks, it is not possible to teach learners how to internalise the culture of the language they are learning but they can understand the differences between cultures, by learning about the different cultural dimensions, which can eventually result in a deeper understanding of that culture when those learners then go on to experience and live in or interact with that culture. Hofstede and Pedersen (2002) noted that intercultural misunderstandings are underestimated problems. They believe an awareness of cultural differences and knowledge of basic and general cultural variables would facilitate the art of communicating effectively across boundaries. 


\subsection{Categorising cultures for ICC}

Learning a foreign language necessarily includes learning about the culture of that target language not only because of the theories that interrelate language and culture but because of the inevitable exposure learners will have with native speakers (and consequently natives) from that culture. However, learners do not face these new cultures with a blank slate, all learners have prior experiences and prior knowledge which they use to learn languages and about those new cultures; this experience and knowledge is normally taken from their own culture. The decoding process and the process of negotiation with another culture involves establishing comparisons between what is similar and what is different from the learner's own culture. As Neuner and Zarate stated:

Learning about the foreign world and learning to use the foreign language is more than just 'habit formation' or imitation and reproduction of speech patterns. It comprises a cognitive dimension of learning that is realised in procedures of comparing, inferring, interpreting, discussing and similar discursive forms of negotiating the meaning of phenomena in the foreign world. (Neuner and Zarate, 1997:75)

A lack of understanding at this level can lead to misinterpretation of the behaviour and meanings of the native language speakers as non-native learners can interpret them incorrectly because their true (and hidden) meanings can only be found within the totality of the culture, which is acquired socially and through formative experiences within that culture. Therefore, the same way isolated words heard out of context can express several possible meanings, when people observe behaviours isolated from their cultural context, they are usually interpreted from the perspective of the non-native culture of origin. If language learners do not have intercultural competence they might interpret other cultures from their own cultural perspectives, which, because it is conditioned by their own cultural beliefs, can be incorrect. Making learners aware of this idea is important when learning a foreign language and thus acquiring intercultural competence: how behaviours and perceptions develop from cultural values. This idea is explored in a separate section below. 
One method that has proven to be productive when explaining and learning about cultural differences is to teach learners about the categorisation of general cultural features into dimensions of cultures that will be explored in the following section: categorising fundamental issues that exist in all cultures and then analysing and explaining the different ways each culture deals with them. Because each of these dimensions or categories exist in every culture Gudykunst and Kim (1996) note that learners can easily understand them if they are first aware of their own culture's perspectives of them. Once this is understood they can then compare their culture with that of their target language culture, understand the differences and finally accept and internalise the target culture's perspective of them. Each culture's perception of a dimension is located along a continuum. According to Gudykunst and Mody (2002), there is no one perspective that can be found at one end of the continuum. All cultures have parts of both the opposite ends of the dimensions but they generally tend to belong mostly to one of the opposites.

Categorising dimensions of culture can be defined as the process of grouping phenomena that are discriminately different into categories. Lakoff (1985) writes about this cognitive process:

\begin{abstract}
Without the ability to categorize, we could not function at all, either in the physical world or in our social and intellectual lives. An understanding of how we categorize is central to any understanding of how we think and how we function, and therefore central to an understanding of what makes us human. Most categorization is automatic and unconscious, and if we become aware of it at all, it is only in problematic cases. In moving about the world, we automatically categorize people, animals, and physical objects, both natural and manmade. This sometimes leads to the impression that we just categorize things as they are, that things come in natural kinds, and that our categories of mind naturally fit the kinds of things there are in the world. But a large proportion of our categories are not categories of things; they are categories of abstract entities. We categorize events, actions, emotions, spatial relationships, social relationships, and abstract entities of an enormous range: governments, illnesses, and entities in both scientific and folk theories, like electrons and colds. Any adequate account of human thought must provide an accurate theory for all our categories, both concrete and abstract. (Lakoff, 1985:6)
\end{abstract}

As an interactive process, it is communication that allows interculturalism to take place; it makes it tangible and objectifies it. Intercultural competence contributes to ICC by fostering understanding among individuals. Understanding intercultural relations in a communicative situation means understanding both cultures that come into contact. ICC 
is performed where there is contact between two or more meanings and significance structures, and when one of the members of one of those structures begins to understand - in the sense of internalising - the meaning and value of symbols, signs and objects that belong to the structures or culture of the other. This does not mean that these meanings and significance structures are completely accepted, it refers to an understanding of them which in turn fosters or facilitates a comprehension that can help overcome the differences or boundaries that exists when two groups have different meanings and interpretations of those signs (what they say). It is, above all, about creating the conditions for a shared, common, accessible context, through comprehension and negotiating, where differences can enrich human interaction because of the different ideas both groups can learn. To paraphrase Casmir (1997), the construction of a third culture from two initial cultures is not simply the sum of the two, it is the creation of a different one where connecting exchanges are structured and objectified. A third culture is the intercultural perimeter where intercultural exchanges, interaction and communication take place between two cultures.

Communicative effectiveness necessarily faces a challenge in such a communicative encounter. As communication between different cultural parties does not recognise nor share given codes or common signals, there is a breakdown in the understanding of the messages that are exchanged. Communication is effective if an acceptable degree of understanding exists between the parties or in other words: if they adequately share the meanings of what they say. The pursuit of effective ICC is thus achieved with a communicative competence through the establishment of guidelines that shape communicative interaction into a 'shared' experience. Participants who engage in communicative interaction rely on their cultural assumptions to interpret messages: they are (unintentionally) used to filter the messages that are exchanged. When these participants engage in intercultural communicative interaction the cultural framework in which each of those participants interprets messages may vary. Therefore, the success or failure of the interaction depends largely on participants' familiarity with the cultural meaning given to the messages of their interlocutor as well as their awareness of the differences between them. This is how a communicative interaction experience can 
move from an individual experience to a 'shared' experience. Thus following from this idea, the limits of ICC are found in the lack of knowledge participants have of their interlocutor's culture, the particular representations and cultural meanings each individual refers to during the intercultural interaction, the places from where their values, beliefs and meanings have been created. These limits result in a mental boundary from which individuals are defined and perceived and from which they define and perceive their interlocutor's messages. 


\subsection{Dimensions of culture - content included in the thesis ICC course}

One of the most important parts in the ICC course was explaining to foreign-language students how the cultural aspects of a communicative system affects how people of that culture act and interpret the world. How the values of a culture affect perceptions and behaviour is an important concept because the values of a culture are developed alongside the culture itself. The actions of every person are a result of a system of values and a learned attitude that deeply affects their perception and behaviour. McLaren (McLaren, 1998:14) writes that:

Culture is a human phenomenon and is who we are, both physically and mentally. It is both a state in which each of us exists and a process which changes according to the individual, time and the place. This combined state and process called culture affects us all as we respond to others, to events and to the environment.

Values are the basis of the vast and diverse world of selective behaviour. They can be defined as a relatively permanent belief that a specific mode of conduct is socially preferable. It is a prescriptive belief according to which some means or end is judged to be desirable or not, and has cognitive, affective and behavioural components. A value system can be defined as an organisation of beliefs about preferred modes of behaviour, and that each of these has a value of relative importance (Rokeach, 1973). In regard to the functions of values, they serve as standards or criteria to guide the conduct of individuals, to justify and rationalise certain beliefs, attitudes and actions. They also determine the image that individuals chose to present to others and they justify judgements. Thus value systems help individuals choose between alternatives in order to resolve conflicts and make decisions.

Cultures are composed of different sociocultural groups and they each manifest specific cultural values that are appropriate for each group, but together they make up the value system of one culture. An example of how behaviour or communication can be affected by the values of culture is directness and indirectness. Directness as a value is easily seen in North American society in the forthright and blunt way people often speak to one 
another, 'telling it like it is', or in the way the educational system rewards speaking out and encourages students to volunteer their answers and opinions in the classroom. In much of Asia, it is indirectness which is valued, this can be seen in how people are often much more discreet and reserved in academic settings and everyday social interaction. This leads to a related issue in the study of communication in general which is perception, what an individual from one culture interprets can often be entirely different from how another individual interprets it. In the sense of ICC this can be generalised to be understood as that the perception of something is often cultural because it is interpreted and that interpretation is usually shaped through culturally formed judgements and pre-established values. Wellros (1999) states that language can function as a cultural marker, she believes that it facilitates communication within the group and makes it easier to recognise and interpret situations.

In addition, language can be used to create boundaries and exclude other communities from the group. A cultural group may note a common history, a regional affiliation or a family community, giving people roots and making them feel as though they are part of something. This would emphasise an in-group and out-group feeling. Implicit in ethnocentric perspectives is the belief that if one culture is inherently better and that all others must compare unfavourably or lack some essential quality that one's own culture possesses. Wanguri (1996:456) notes that: "We tend to like people who are similar to us and to not like people who are different." Because people are born into a culture and are brought up to believe the values of that culture they become naturally ethnocentric. The concepts of that culture seem natural to them and individuals are not aware that those concepts and values are actually culturally determined. Like culture, ethnocentrism is learned and usually subconscious. (McLaren, 1998). When foreign-language students are aware of this common perspective they not only better understand what native speakers of their target language are saying to them as they can understand meanings that are either hidden or would otherwise seem strange to them because they are wrapped in unspoken cultural interpretations and perspectives but they can also learn to respect other cultural perspectives; being more accommodating to different views facilitates ICC and cross-cultural interaction. It is important for learners to change the 
'glasses' they look through (the perspective of their culture) to the 'glasses' of another culture. When a foreign language learner tries to understand a foreign language without being aware of the very different meanings each word, phrase, conversation or context might have in another culture, it is possible that they can misunderstand meanings. They may understand the sentence that is uttered to them, but they may understand it according to their culture, while it could have a very different semantic meaning in another culture. The learner must first be conscious of the different unfamiliar situations that may arise - or at least that the possibility that they can exist - and then be aware that all persons act, speak and interpret under the influence of their cultures. Once this understanding has been grasped, learners can then move on to learning about the general different categories or dimensions that exist in each culture in order to then specify them further. It is important to note here that not all behaviours, values and actions are carried out solely because of cultural traits; the history and personal motivations of the individual also heavily influence their choices. Sereno and Bodaken (1975) note that perception is a subjective, creative and active process by which the individual creates meaning as a result of mixing certain external stimuli (verbal and nonverbal) with certain internal stimuli (elements of their attitude, personality, motivation, needs, beliefs, values, etc.) They distinguish three stages in the process of perception: the selection, organisation and interpretation of external and internal stimuli. Selection refers to the process of eliminating certain external and internal stimuli and emphasising others. After that is done, perceptions are organised, thus forming categories based on incomplete information. The last stage of perception involves the formation of judgements or inferences about the selected stimuli.

As communication is a field that deals with meanings of messages at an expository and receptive level it has been a great ally of cultural studies: it is understood as an organised system where social interactions take place following a set of unconscious rules and patterns that are developed as symbols specifically within the scope of the power of the symbolic. Watzlawick (1977) believes that not communicating is impossible; every gesture, every action, every sociocultural practice is interpreted by others and sometimes even understood as intentional by others: it is understood to be a statement, 
a communicative message, because it follows the interactional dynamics of communication, the dynamic exchange of information which occurs in social and communicative situations. This meta-communicative axiom creates links between culture and communication; it clarifies the interplay between interaction as the basis of social organisation and interaction as the basis of communication. Based on these conceptual assumptions, ICC, as a branch of the study of communication, expresses more than simply a name relationship with culture. It is a communication where data are meanings which are exchanged, evaluated and interpreted from two or more culturally different fields.

Another important feature of the intercultural dimension that needed to be included in the ICC course is that culture is often not seen as something that is concrete and homogeneous, but as something dynamic, constantly changing and characterised by internal diversity itself. Also, and as explored in other chapters in this thesis, the teacher's role is no longer to simply transmit a body of knowledge on culture or the country where the target language is spoken that is more or less closed, but is to promote students' autonomous learning so that they can adapt to the fast moving changes in cultural learning. The teacher's role is that of mediator between learners and the foreign culture of their target language. Abdallah-Pretceille (1998) notes that education on cultures has moved from being presented as normative and descriptive knowledge to learning about comprehensive and interpretative know-how. Pedagogically this means the end of the lectures and mastering techniques in favour of active learning methods where learners study authentic documents and analyse different communication situations. Byram, Nichols and Stevens (2001) state that the role of teachers is not to provide comprehensive information for students but to bring the foreign culture to the classroom so that students learn vicariously. Their real task is to facilitate learners' interaction with differences in other cultures and societies by teaching them about the subject in general so they can be aware of them, which is actually teaching them to understand and the categories of cultural values, beliefs and behaviours and to encourage them to research into their target language specifically while being aware that everything they learn can change so that they can adapt when something does. Risager 
(2006, 2007) pin points the 80 s as when the foreign language teaching begins to be influenced by an intercultural perspective, when interaction between cultures increased, as well as their attempts to get to know, understand and recognise each-other. According to her, the intercultural approach considers both the target culture and the learners' culture, it compares the students' country and target country, inviting the learner to analyse both cultures while being aware that the target culture changes as much as their own culture. The ultimate aim is to develop an intercultural communicative competence that allows the student to act as mediator between the two cultures.

Hofstede's (1991) framework categorising cultural aspects into dimensions was used for this thesis' ICC course and is the most commonly used in the communication, cultural studies, psychology, sociology, marketing, business and management studies fields. He used 116,000 questionnaires from over 60,000 respondents in seventy countries in his empirical studies (Hofstede 1984, 1991, 2001). He created five dimensions, assigned indices on each for all nations, and linked the dimensions with demographic, geographic, economic, and political aspects of a society. This study remains the most thorough to date and is the most comprehensive and robust in terms of the number of national culture samples. The dimensions are useful in ICC and cultural competence studies and were included in the ICC experimental course used for this thesis. These dimensions include:

- Non-verbal communication

- Proxemics

- Time

- Individual and collective societies

- High and low cultures

Within these dimensions Gudykunst and Ting-Toomey (1988) and Gudykunst (2004) outlined different communication styles which are also relevant to this area and the course developed for this thesis. These are furthered below.

Non-verbal communication refers to everything that contributes to the meaning of the message that is not words, it is the contextual stimuli in communication situations. These 
non-verbal aspects are often culturally interpreted because of their cultural categorisation. It refers to gestures and body movements, eye-contact, facial expressions, gaze and touch. Ekman and Friesen (1969) note that certain gestures, which they call 'emblems' are nonverbal substitutes for words. Other body movement functions are supporting signs (signs that accompanying and reinforce the verbal message); affection (facial expressions that reflect the emotional state of the listener, they can reinforce or contradict the message); adaptation (body movements and facial gestures that communicate messages unintentionally) and control (movements and gestures that monitor and control the other person's communication). They provide the necessary feedback that allows the other person to know whether the message has been understood or if clarification is needed or when to stop talking, etc.

Proxemics studies the use of space and is concerned with analysing the way in which people perceive structures and use their personal and public spaces, as well as the influence of certain spaces and the way people respond to them (Knapp, 1972). Research into proxemics emphasises the relationship between human behaviour and structure, interpersonal space and territory. In regard to interpersonal space, this area of research assumes that people regard the distance or space that is kept between them as one that defines their interpersonal relationship. Interpersonal space is often described as a bubble that protects the individual or shows respect. The concept of territory is an extension of interpersonal space and refers to the identification of a person or a group from a given space or territory and their declaration of ownership of it and their willingness to defend it (Knapp, 1972).

Time or chronemics studies the meaning, use and communication of time. Use and management of time or 'patterns of time' is a hidden aspect of culture which cause misunderstandings between people from different cultures. Every culture has its unique patterns with which they manage time and different attitudes towards it. Hall highlights several concepts in the study of chronemics: activity, variety and urgency, referring to the impression that the time passes fast or slow and most importantly, monochronism and polichronicsm which are useful expressions to explain cultural differences in the meaning and perceptions of time (Hall, 1959, 1976, 1983). Monochronism refers to cultures where 
time is the absolute and people are the variable. Where the needs of people are adjusted to suit the demands of time, there are schedules and deadlines to be considered and met. In monocronic cultures, time is quantifiable and completely limited; it can run out. People from monocronic cultures usually do one thing at a time and finish one task before starting another task. In polychronic cultures time is a tool for the people of that culture; it is adjusted to suit their needs. Time does not run out and is therefore always available. People from polychronic cultures often have do several things at the same time, they do not feel as though they have to finish one task before starting another.

Individualism and collectivism is another dimension to culture that refers to the individual's relationships to the groups which form culture. People live and interact together and while doing so they develop a method or system of relating to other individuals. Cultures differ in the extent to which the individual prefers being part of a group (including family, social or work groups). Hofstede (1984) refers to these variations as individualism and collectivism. Highly individualistic cultures - cultures given as examples are Belgium and the United States - believe that the individuals of a country must look after only themselves and also their immediate families; the autonomy of the individual is fundamental. Decisions are based on what is good for the individual, not for the group or society at large, as being self-sufficient will guarantee the well-being of the group. Independence and self-reliance are highly valued. Similarly, judgements and values about what is morally correct or corrupt can be made only from the perspective of the individual. Hall (1983) believes that collectivist cultures require an absolute loyalty to the group, where the 'group' may be considered the nuclear family, the extended family, a caste or a work group. Here, decisions should be made to benefit the group, not the individual. In turn, that individual's security is ensured and needs are met because the group and its members look after that individual. The identity of the individual is in large part a function their membership and role within a group. Harmony and the interdependence of group members are stressed and valued. Group members are relatively close psychologically and emotionally, but distant towards non-group members. Huge cultural differences and thus barriers to ICC can be explained by 
misunderstandings due to perspectives of the individualism-collectivism dimension. As mentioned above, collective cultures are group oriented, which results in members of this group placing a large psychological distance between the fellow members of their group (the in-group) and those who are not (the out-group). In-group members often have (or are required to have) an unquestioning loyalty to the group and prioritise it over any other group or individual and consequently out-group members are perceived to be not as important. Conversely, members of individualist cultures do not place such as a large chasm between in-group and out-group members; in-group members are not as close (for example family), but out-group members are not as distant. Triandis (1995) believes that the individualism-collectivism dimension is by far the most important attribute that distinguishes one culture from another. Another aspect that is important in this dimension is that individualist cultures encourage their members to 'speak their minds'. As an example, students from individualistic cultures are likely to ask questions about what they are studying; students from collectivistic cultures are not. Lustig and Koester (1999:123) also add that, "[...] people from individualistic cultures are more likely than those from collectivistic cultures to use confrontational strategies when dealing with interpersonal problems; those with a collectivistic orientation are likely to use avoidance, third-party intermediaries, or other face-saving techniques." Lack of knowledge of this dimension can cause many issues when communicating because of its interpretations as being 'rude' and 'offensive'.

The final dimension to culture which was included in the ICC course was high- and lowcontext cultures. Hall (1966) believes that cultures imply information through settings or the context the communicative interaction takes place. He notes that every individual experiences so many perceptual stimuli - visual, odours, tastes, and bodily sensations that it would be impossible for the individual to consider them all simultaneously. Thus, one of culture's functions is to provide the members of that group with a 'screen' between the individual and those stimuli to assist them with prioritising and interpreting them. This dimension is different from the others outlined because it emphasises the role of context. High-context cultures prefer to use high-context messages where the meaning is either implied by the physical setting or presumed to be part of the individual's internalised 
beliefs, values, norms, and social practices; very little is provided in the words included in the message. In high-context cultures, individuals tend to speak one after another in a linear way, so the speaker is seldom interrupted. Communication is, according to Gudykunst and Ting-Toomey (1988:110), "[...] indirect, ambiguous, harmonious, reserved and understated." In high context cultures, communication style is influenced by the closeness of human relationships, well-structured social hierarchy, and strong behavioural norms. An example given of high-context communication are the interactions that take place between two people who have been in a relationship for a long time and are thus able to interpret their partner's gestures or even a short comment. The message does not need to be explicitly said because that message is carried in a shared understanding they have developed in their relationship over time. Low-context cultures prefer to use low-context messages, which means the majority of the information that is being passed on is included in the words themselves. In low-context cultures, meanings are explicitly stated through language. People communicating usually expect further verbal descriptions and explanations when something remains unclear. As Hall (1966) explains, most information is expected to be in the verbally spoken message in order to make up for what is missing in the context (both internal and external). A low-context culture is characterised by direct communication, the constant and continuous use of words and is direct and often emotional (Gudykunst \& Ting-Toomey, 1988). An example Hall gives of low-context communication is the instructions that are given by a manager to his subordinate who is not familiar with a process. The instructions must be extremely explicit and clear for the subordinate to fully understand them.

The different communication styles defined by Gudykunst and Ting-Toomey are not included in Hofestede's cultural dimensions but extremely important when exploring communicative differences between cultures and necessarily includes all the other dimensions included above. The identified different styles of verbal communication within the cultural dimensions and ICC frame are: direct/indirect, elaborate/succinct, personal, or person- centred/contextual and instrumental/affective. These styles exist in all cultures and the difference depends on the context as well as in the cultural perspective which results in one particular style being considered more appropriate than another. 


\section{ONLINE AND DISTANCE EDUCATION}

This chapter begins with an exploration of the theoretical foundations of distance education through a historical exploration of different theories that have been put forward. These include the theories of autonomy and independence, industrialisation and communication and interaction. This first section considers these theories to give a basis to the following section which explores the development of distance and online learning in regard to technological advancements such as the World Wide Web, the internet, ICT (Information and Communications Technology) and CMC (Computer Mediated Communication). The historical theories put forward during the $20^{\text {th }}$ century seen in the first section are still relevant for both distance and online learning despite the rapid growth in new technological tools and processes; these emerging platforms for learning at a distance and online are not simply additions to traditional distance learning, they are changing the way students learn completely, and thus scholars are still struggling to respond to the theoretical basis of this type of learning. It has been suggested that Connectivism may be an appropriate learning theory for $21^{\text {st }}$ century learning styles because of its emphasis on networked and connected creation of knowledge. This theory also complements the needs for interaction in both distance learning courses and for online foreign language learning and practice. The following section explores the emerging phenomenon of Massive Open Online Courses (MOOCs). Many well-know and prestigious higher education institutions have begun to offer courses online to large numbers of students as a response to its rapid growth in popularity. The $5^{\text {th }}$ section explores historical and current issues with distance and online learning which is especially relevant as this thesis attempts to respond to those problems. Finally a history of online collaborative projects that are similar to the project that is the subject of this thesis is explored. Telecollaboration mainly focuses on exchanges between foreignlanguage students so they can learn about their target culture and language through interaction with native people, and was thus used as a basis for the experimental course in this thesis. 


\subsection{Theoretical basis of distance education}

Distance Education (DE) theories have been revisited lately with the introduction of online learning and courses which include MOOCs and Small Private Online Courses (SPOC). Despite this development, its theoretical basis continues to be somewhat fragile (Holmberg, 1985). According to Baath (1979) and Keegan (1990) there is a need for a theoretical analysis and an intellectual debate on DE. Moore states that:

As we continue to develop various non-traditional methods for reaching the growing numbers of people who cannot, or will not attend conventional institutions but who choose to learn apart from their teachers, we should divert some of our resources to the macro factors: describing and defining the field, discriminating between the various components of this field, identifying the critical elements of the various forms of learning and teaching, in short, building a theoretical framework which will embrace this whole area of education (Moore, 1973:661).

In another article, he continues along the same lines by noting that although researchers have tried to create a theory for the field, DE is nonetheless "chaotic and confused. There is no national policy, nor anything approaching a consensus among educators of the value, the methodology or even the concept of DE" (Moore, 1993:3). Various contributions do try to formulate a theoretical basis for distance learning and have even suggested that DE should be considered a separate discipline of study all together (Holmberg, 1986). But the establishment of a clearly defined theory has not yet been achieved whose purpose would be a platform for decisions about methods, resources used, organisational structure, financing, research and organisation. However, the most significant theoretical ideas that have been put forward are explored in this section, classified into three categories. The main contributors to these theories are Rudolf Delling, Charles Wedemeyer and Michael Moore and their theories of autonomy and independence stemming from the late 60s and 70s; Otto Peters and his theory of industrialisation and thirdly Börje Holmberg, John Baath, David Sewart and John Daniel with their theories of Communication and Interaction. These researchers tried to build a sufficiently broad general theory to explain the phenomena of DE satisfactorily.

Delling (1987) considers DE to be a multi-dimensional system that includes learning and 
communication processes. His definition of DE is:

[...] a systematic activity, made up of the selection, educational preparation and presentation of instructional materials, as well as the supervision and support of student learning, which is achieved by use of the appropriate technical resources that allow communication between student and teacher (Delling, 1987:21).

Moore (1977) focuses on three features in this Autonomy and Independence theory: one is the separation of teaching and learning behaviours and patterns i.e. the way learners learn and teachers teach; the use of technology and the communicative tools available and finally the importance of two-way, free flowing communication between the student and the teacher. For Moore (1977) the distance learning institution should facilitate communication between the student and the teacher. Building on Moore's definition, in the introduction to the book 'Distance Education' (Rao, 2003), Rune Flinck proposed another, more complex definition:

Distance education is a learning system where the teaching behaviours are separate from the learning behaviours. The learner works - alone or in a group - guided by study material arranged by the instructor who together with the tutors is in a location apart from the students, who however have the opportunity to communicate with a tutor/tutors with the aid of one or more media such as correspondence, telephone, television, radio. Distance education may be combined with various forms of face-to-face meetings. (Flinck, 2003).

This definition also outlines the idea that students can enjoy different learning situations with independent and autonomous learning methods. It has long been agreed that distance learning necessarily supposes independent working and autonomous learning. This idea has been explored in Chapter 2 with regard to foreign language learning and more in depth in Chapter 3 in its own right, but is now explored as a concept of distance learning. Delling (1987) distinguished eight dimensions that highlight student's autonomy in DE: the learner, society (including legislation, public administrations and family), the institutional organisation with which the learner enrols or registers, the learning objectives, the content to be learnt, learning outcomes and physical (and in some cases temporal) distance, feedback and communication. He emphasised the essential difference between one-way learning opportunities (books, newspapers, films, selfinstructional courses) and two-way opportunities (classroom instruction, discussions, correspondence, distance learning with feedback). He believes that the phrase 'Distance 
Education' does not reveal much about the characteristics of teaching, because in general there is no teacher in that system; student learning is carried out through a variety of technical resources, people and materials. Thus Delling sees the role of teachers and institutional organisations reduced to a minimum and emphasises the autonomy and independence of the learner. Distance learners tend to reject the conventional teacher-student relationship, so the role of the institution is to provide students with resources that allow them to become more autonomous. This view tends to industrialise the educational process, making the institution simply a resource. The idea that learning can actually reside outside the institution and even the learners themselves is an idea will be further explored with the concept of connectivism in another section in this chapter. Keegan (1990) notes that within this position Delling seems to place DE outside the field of educational theory, in a communicative sphere, characterising it as a process that is carried out through dialogue and communication.

The term 'independent study' was first used by Wedemeyer in 1968 in his journal article 'With whom will you dance? The new educational technology' who later elaborates on it to describe DE for higher education:

Independent learning is learning that changes behaviour and which results from the activities carried out by students in space and time, and whose environment is different from a traditional educational institution; students who are guided by teachers, but do not depend on them, students who accepted degrees of freedom and responsibility to initiate and conduct activities conducive to learning (Wedemeyer, 1981:73).

He continues by providing the following conceptual structure for an ideal system: The system should be able to:

1. Operate wherever the student is.

2. Increase it responsibility for student learning.

3. Free teachers from custodial duties, in order to pursue other more significant, educational tasks.

4. Offer students more opportunities in courses, methodologies, etc.

5. Use all the resources that have proven to be effective.

6. Combine the resources and methodologies available so that each student can be taught in the best way.

7. Redesign and develop courses so they are suitable for the resources being used and the specific student. 
8. Maintain and foster opportunities to suit individual differences.

9. Assess student achievement in an un-complex way in order to ensure barriers are not introduced, while the student learns at their pace.

10. Allow the student to start and stop their studies according to their own rhythm (Wedemeyer, 1981:328-336).

Kaye and Rumble (1981) believe that the only way to bring down the space-time barriers is by separating teaching and learning. Planning courses according to an approach that emphasises the separation of teaching and learning led Wedemeyer (1973) to postulate six characteristics of distance learning as an independent system, ensuring they are able to operate anywhere, whether with the participation of teachers or not in the same place and at the same time:

1. The student and teacher are separated.

2. The normal process of teaching and learning are carried out through written materials or other means.

3. Instruction is individualised.

4. Learning occurs through student activity.

5. Learning fits the student's own environment.

6. The student assumes responsibility for their progress, with sufficient freedom to start and stop their learning at any time, setting their own pace (Wedemeyer, 1973:76).

The concept of distance involves more than physical distance in both distance and online learning. Other barriers exist such as time barriers (the learner cannot attend those classes at that time) physical barriers (the learner cannot leave the house for some reason) or social and cultural distance. If the objective of distance learning is a system that works at any place and time, for one or many students, Wedemeyer (1973) argues that the traditional classroom should be restructured. This restructuring will result in more freedom for the learner as following that learning will take place at the student's own pace and according to their needs and circumstances; learning will be individualised, ensuring the student has sufficient freedom to enroll in the courses they chose and the learner will have enough freedom to choose their objectives and activities.

If resources such as a computer and the telephone are used to replicate regular classes without expanding opportunities, and without giving freedom and responsibility to the student, the system cannot be called independent study or autonomous learning. This 
idea was put forward by another author whose contribution to the theory of autonomous and independent learning has been significant: Michael Moore. Among his contributions to $\mathrm{DE}$, are the concepts of autonomy and distance. The author begins with the idea that education has been through a 'Copernican Revolution': the transfer of gravity of thought and educational research, the move from a teacher-centred mentality to a focus on the student's learning process (Moore, 1973). This mentalist shift is based on three basic principles he has developed:

1. A recognition that each individual learns concepts and skills at a different pace so if learning is idiosyncratic, the concept of standard group disappears.

2. Effective learning can include 'experience', interpreted within a behavioural or phenomenological framework. This idea also means that everyone can learn through experience.

3. Learning in today's world changes continuously and rapidly, and learning occurs throughout life. Thus learning need not take place only during formal education years.

For Moore, teaching should focus on the learner, the teacher should ensure they have opportunities to learn and thus support them in their decision-making and assuming responsibilities. This is facilitated by new educational and communication technologies and thus students who make better use of technological resources are more independent physically, as they do not depend on the need to reside in a particular physical place and from the continuous presence of a teacher or tutor. Like Wedemeyer, Moore believes that student autonomy must refer to learners setting their own objectives, choosing their own learning methodologies and extensive feedback and evaluation (Moore, 1973).

The main representative of the Industrialisation theory is Otto Peters who argues that an analytical and comparative approach to studying DE has allowed him to develop a theoretical structure of the field. Peters rejected the traditional categories of educational research as he believed they have proved inadequate for an educational analysis of distance study systems, he states that the structure of DE systems is so far removed from traditional education that new models and tools need to be used to analyse them. His puts forward the following definition: "DE is a form of indirect instruction. It is 
imparted by technical media such as correspondence, printed materials, teaching and learning aids, audiovisual aids, radio, television..." (Peters, 1973:104). This description includes two features that are also part of other distance learning theories, the separation of the teacher and the learner, and the use of technology. Peters' analysis goes even further though and he concludes that this structure is best understood if they are compared to concepts from the industrialisation of society, specifically those of productivity, categorisation and delegation of labour and mass production. The mechanisation and automation of teaching methodologies and models and the fact that learning success depends on pre-prepared courses and not on teaching ability are also part of his argument. Peters justifies his search for a new theoretical framework based on that fact that he considers DE a new form of education, one that is now industrialised and more technological. He establishes this from his analysis of conventional oral and group education, which he believes have changed little in structure since the 17th century, given that the rhetoric of universities in the Middle Ages was simply replaced by classes, seminars and lectures (which he calls pre-industrial study), and became the typical characteristics of mainstream education, a parallel which is often drawn by proponents of MOOCs, Coursera director Daphne Koller and the Khan academy creator, Salman Khan. A humanistic influence brought about the addition of tutorial classes and a discussion based tutorial system where few students attended so that they could have a more personalised understanding of the course seems to have been perfected in the $19^{\text {th }}$ century, when teachers began to have more contact with the student and play a significantly larger part of the whole teaching process (Moore, 1968). According to Peters, because the traditional concepts of education are insufficient analytical categories to explore this industrialised form of education, new categories must be used, and he believed that what was most appropriate was to use categories that analysed industrial processes. Peters (1983) believed that all forms of human behaviour were strongly influenced by the industrial revolution except traditional educational methods in schools and universities. Peters $(1983 ; 1989)$ uses other comparisons between DE and the industrial production of goods: rationalisation, division of labour, automation, assembly line, mass production, preparatory work, formalising, standardisation, operational change, objectification, concentration and centralisation. He believed that the 
practical implications of his theory are somewhat difficult to accept given the weight of the tradition of conventional educational processes. Also, teachers' adaptation to distance learning systems is usually slow and there will be inevitable clashes with traditional methodologies because in $\mathrm{DE}$, teaching units are divided into subunits that are executed by different people and different elements of the educational system. In this industrialised model of education, the student finds that instruction is available at the moment and place they wish, so they chose their own methodology to use. Because instruction is not structured into times, places and people, new responsibilities are placed on the student which did not exist in pre-industrialised education systems.

Among the exponents of the Communication and Interaction theories are John Baath whose main contribution was his two-way communication concept, Börje Holmberg and his Guided Didactic Conversation and John Daniel and his concept of Interaction and Independence. Baath (1979) researched the two-way communication concept in DE during the 70 s by exploring how teaching models developed by educational theorists such as Skinner, Bruner and Gagné could be applied to DE. He believed that open communication between the student and their teacher (and vice-versa, hence 'two-way') is fundamental to successful DE learning. Later, Baath incorporated empirical research into his developing theoretical analysis which studied the relationship between the frequency of delivering tasks during a course and its corresponding communication, the substitution of tasks being corrected by the teacher with student self-assessments and correcting tasks with computers (Baath, 1980). Similar to this theory, is Garrison's theory of communication in distance learning. He believes education is "based upon seeking understanding and knowledge through dialogue and debate" (Garrison, 1989:12), also emphasising that two-way and free-flowing communication from the teacher to the student is extremely important. He argues that because the student does not have easy access to the teacher in distance learning, technology can bridge the gap in communication between them. He further states that they are inseparable and sees the evolution of distance learning and educational technology occurring together. Baath's concept of two-way communication assigns a central role to that two-way communication and to feedback provided by the teacher, who should not only correct errors and assess 
students' work, but should also ensure materials and content are relevant to how they are being learnt. Holmberg (1983) developed the Guided Didactic Conversation (GDC) concept of DE based on a philosophy that gives importance to learners' independence and autonomy and the teacher's guidance towards it. Rather than focusing on the structure of DE he emphasises more the communicative relationships the learner has with their teacher and how it refers to the teaching process when learning is done in a distant setting. According to him, management, guiding, group teaching and assessment are effective only if they support individual learning and only if the learner has the freedom to make decisions and a personal relationship is established with their teacher. In this regard, DE was considered particularly suitable to individual learning, because it is based on the learner choosing their preferred learning method and content, while the teacher still guides, mainly towards achieving complete autonomy. Holmberg describes distance study as self-study, but not only as individual learning as students are still able to benefit from the course and their interaction with their teachers and other elements that make-up the structure. This concept of communication, emotional involvement and autonomous learning was the basis of GDC and the application of these ideas and especially the relationship between the student and the educational structure are the development of the GDC. If the course content is produced according to these principles, communication would flow more freely between the learner and the creators of that content (usually the teachers), ensuring students are more interested and engaged than if they are presented with content that is used in face-to-face classrooms. Holmberg believes that the personal relationship between the learner and teacher fosters motivation, which can also be encouraged by good self-study materials that are adapted to positive two-way communication (Holmberg, 1983; 1985; 1989a).

There is constant interaction (conversation) between the supporting organisation (authors, tutors, counsellors), simulated through the students' interaction with the preproduced courses and real through the written and/or telephone interaction with their tutors and counsellors. (Holmberg, 1983:1).

He also listed recommendations on how materials for a course should be developed, stating that they should:

- Be easy, accessible and relevant to the subject being studied: clear, use colloquial 
language and the information should not be presented in a dense matter.

- Have explicit instructions that ensure the student knows what to do, what to avoid, what to pay attention to and what their next step is.

- Ensure there is a constant exchange of views and questions regarding what is accepted and what is rejected are asked.

- Emotionally involve the student so that they have a personal interest in the subject.

- Personalise the content and use possessive pronouns.

The final theory to explore is the theory of interaction and independence. For Daniel (1982), DE systems emerge from three sources: a long tradition of independent study; modern development of educational technology and a new, theoretical interest in open learning. The fusion of these elements has produced new educational systems that support distance learning and satisfy societies' economic and political needs. Daniel believes that DE systems should include activities where students work both alone and with other people. The chosen balance between interactive and independent activities has implications on the administration and economics of the educational system. An increase in the proportion of interactive activities improves student performance, but it has additional costs in terms of economic and time resources. The cost of interactive activities is proportional to the number of students enrolled in them. Therefore, independent activities favour economies of scale, contrary to interactive activities as the cost increases proportionally to the number of students. He also considers that courses should not be designed to be completely independent: socialisation and feedback are principle interactive activities that are fundamental. Because distance learners are only partially integrated into the education system and they feel little obligation towards it, interactive activities play an important role in ensuring learners reach their objectives. Daniel believes that the more freedom the student possesses, the less likely it is they complete the course, such that DE systems can be positive or negative in regard to learners setting their own pace. This position is contrary to that of Holmberg who notes that students should be free to choose their own paths (content, set objectives, pace etc.) without pressure. While Moore (1973) and Wedemeyer (1973) emphasise autonomy and independence for distance students, Daniel tries to strike a balance between interaction and independence within the system's structure, and shows how this affects students' retention and cost structures. 
When these theories are bought together and compared, there are two common points that can be found in each of them: a primary focus on the student and a common trend of emphasising communication. The focus of this section has been the way theory in distance learning has evolved. Analysing these suggested theories can serve as a platform on which to base the evolution of a common theory and teaching and learning practice. A trend that seems significant is the decreased importance placed on temporal and spatial distance or separation. Although the idea of distance will inevitably be central to $D E$, its meaning varies enormously with technological developments, especially in regard to ICT tools and consequently with learners' direct relationship to the type of learning desired. This change in meaning will also have an impact on the role of the teaching, the course content and materials that will be used, methods of instruction and learner expectations and behaviours, all of which will be explored in the next section. 


\subsection{Developments in technological resources in distance education}

The use of Information and Communication Technologies (ICTs) as well as Computer Mediated Communication (CMC) in distance and online learning are important and necessary to support modern and current learning and teaching theories. This section explores the evolution of Distance Education (DE) in regard to foreign language learning and the development of technological tools to assist this learning.

The literature in the field of distance language learning uses classic concepts that come from the more extended concept of DE for its definition, usually emphasising organisational or technological structures instead of more educational perspectives or experiences from within the field. Keegan (1990) offers the definition that is most widely cited which outlines the structural characteristics of the more general area of distance learning: a space and temporal distance between teacher and learners with importance given to two-way communication, the use of technology, and the influence of an educational organisation that sets it apart from traditional, face-to-face learning. Another more current definition is given by Hiple \& Fleming (2002) who focus on the changing evolution of distance learning definitions. They use two features of Keegan's 1990 definition to differentiate more recent distance language education models: teachers and students and students within the class now communicate using internet-based tools and that communication is two-way. According to him, the underlying characteristic of the evolution of $D E$ is the increasing interaction students have with not only their teachers, but with their peers as well. The amount of research into distance language learning published under the rubric of DE seems to show that the concept is more complex than it seems at first sight (Fleming, 2002). The field of technological education has changed dramatically since the appearance of the first distance education courses designed to learn foreign languages from the late nineteenth century (Simonson, 2000) and since the first computer-assisted instruction (CAI) models of the 70s. The methods and means used have changed and been replaced by different tools as they have emerged, such as the telephone, television, the Internet, etc. The first part of this section explores the 
history of DE and differs from the above section because, rather than exploring the theoretical aspects of DE, it focuses on the technological development of each of these stages. The technological tools used in distance and online education radically changed the way DE was structured. The most emphasised concept of DE is based on the communication between teacher and student, which was initially very slow and only since the major technological advances of the last century have students and teachers been able to be in contact comfortably (Holmberg, 2005). Although this is now seen as an essential part of $D E$, as well as foreign language learning, Holmberg states that the main purpose of this development was so that students can learn through receiving critical and productive feedback (Holmberg, 1995) and Garrison (1989) defends collaboration in foreign language learning between teacher and student based on the communicative approach - free-flowing communication has not always been possible, in addition to the fact that it was not seen as a priority to learning.

However, and fortunately for language learners, ever since the appearance of the first distance learning language course in the late nineteenth century, not only have teaching and learning approaches and methodologies changed continuously and radically (see Chapter 2) but so have the means and resources, which have been replaced by different tools as they have emerged, both because of ideological changes in how to teach foreign languages and because of those technological developments (Simonson, 1999).

Wang \& Sun's (2001) four generational mode outlines the evolution of the technical tools used in DE.

\begin{tabular}{|l|l|}
\hline Generation & Technology \\
\hline First (prior to 1970) & $\begin{array}{l}\text { Correspondence courses delivers printed material using the } \\
\text { postal service, which is how the student and teacher } \\
\text { communicate }\end{array}$ \\
\hline Second (1970-80) & $\begin{array}{l}\text { Old media: Printed materials, postal service. } \\
\text { New media: television, radio, telephone, audio cassettes, cable } \\
\text { TV. }\end{array}$ \\
\hline Third (1980-90) & Old media: television, radio, telephone, audio cassettes, cable \\
\hline
\end{tabular}




\begin{tabular}{|l|l|}
\hline & TV. \\
& $\begin{array}{l}\text { New media: word processor, multimedia packets, e-mail, the } \\
\text { internet. }\end{array}$ \\
\hline Fourth (1990-2000) & $\begin{array}{l}\text { Old media: print, postal system, radio, television, telephone, } \\
\text { audiocassette, cable television, word processors, multimedia } \\
\text { packets, e-mail, the Internet. } \\
\text { New Media: Internet based technologies real time technology, } \\
\text { VolP (e.g. Skype), chats (e.g. messenger) real time resources, } \\
\text { virtual reality. }\end{array}$ \\
\hline
\end{tabular}

Figure 2: Stages of distance language learning - Wang and Sun's Four Generational Model (Wang \& Sun, 2001:541)

Garrison (1985) identifies three key stages in the history of DE: correspondence or the postal service; teleconferencing, including use of television and telephones and computer-based learning. There have been many different suggestions on how to categorise the various stages of development and disagreements about how to differentiate the generations of DE, figure 2, Wang \& Sun's (2001) four generational model, succinctly describes them: The first generation courses were written correspondence courses that used the postal service as the main communication and delivery methods until the 70s; the second generation used technologies that broadcast courses (used together with print materials) such as radio and television as well as audio and VCRs (Innes, 1982); the third began to use ICTs, CD-Roms (Rothenberg, 1998), computer mediated communication technologies and posting content and material on websites (Stanley, 2001); finally the fourth generation models used Internet applications and tools in real time as well as taking advantage of Web 2.0, a more interactive form of the Internet. Unlike Garrison, Wang and Sun believed that the coexistence of existing media with other emerging tools at each stage was efficient and relevant. Some such as printed material are still heavily relied upon but others, such as the telephone is being gradually replaced by chat, social messaging resources and other online communication 
tools, especially in the case where distances are international. An important differentiation between the third and fourth generations is that the third generation used technology to simply distribute and present the course materials, fourth generation use of technology was much more interactive and advanced, especially in terms of communication tools that worked with applications such as Voice over Internet Protocol (VolP).

Because a new awareness of social equality arose following the Second World War (see Chapters 2 and 3), debate about access to education began to grow, accelerating government and social support for DE. Distance learning models were seen as a way to reach groups that were previously unable to access education. Open access to education continues to be a driving force in the development of distance learning and there is also a growing focus on lifelong learning (Tuijnman, 1999). The teaching philosophy of the first generation of DE coincided with an initial stage of distance language learning outlined by Garrison (1989); at this early stage foreign language teaching still followed traditional methodological approaches to language learning, such as those based on translation or structuralism (see Chapter 2) and so although only written and printed material was seen as sufficient to assist language learning it was actually not very compatible to oral proficiency and communicative tasks. However because of changes in ideology, teaching methodologies and technological evolutions mentioned above, correspondence course material began to be accompanied with audio material, making language learning more relevant. The introduction of audio elements made it possible to develop learners' skills in listening, presented through recorded audio tapes and broadcasts on radio or television. Innes describes the first distance foreign language course made available to the public by BBC (Innes, 1982): The course was first broadcast in 1975; it combined printed course material with radio and TV broadcasts and also offered face-to-face classes in different locations in the United Kingdom; in addition there was a final evaluation exam offered by the University of Cambridge. These new ideas and advances along with the arrival of cable TV and the parabolic antenna were another a major step towards the autonomous learning of students; because of the introduction of these new DE technologies courses began to develop focusing on 
projects and action, described by White as:

[...] aimed to encourage learners to move beyond the prescribed subject matter of the course to engage with language resources in their environment; it involved them in making decisions about the content and goals of their learning and provided support through the establishment of learner networks (White, 2007:99)

This methodology seemed to be specially designed for students' autonomous study; there was now a different approach that included listening activities accompanied by a set of recommended guidelines so the student could make better use of the course. However, although autonomous learning began to be emphasised because of a shift in ideology, the introduction of computers did not revolutionise distance language learning as was expected as the methodologies and approaches to teaching remained the same. Computer-assisted language learning, also known as Computer-Assisted language Instruction (CAI), reached its peak during the 1990s and 2000s. According to Levy (1990) this approach required a high degree of commitment and organisation by students and teachers for the successful achievement of foreign language fluency, still more commitment and motivation than that of traditional classroom and face-to-face based courses. This stage is also characterised by the inclusion of multimedia packages installed on computers with CDs that complimented the courses' pedagogical material. This material focused on students' autonomous learning and required little intervention by the teacher (Levy, 1990). This use of new technology was also the preferred instruction method during the $70 \mathrm{~s}$ and $80 \mathrm{~s}$ in traditional face-to-face classrooms, but it still mainly focused on grammar and ignored natural, oral competencies. All exercises were completed off-line, such that the information flowed between the student and the computer, the student did not interact with other people who spoke that language outside their course and rarely interacted with their teacher. This type of CAI is still used today for the practice of the mechanical parts of the language, such as learning vocabulary, acquisition of word order, grammar rules, reading comprehension, etc. however these activities are usually no longer presented through disks or CDs and are stored on web pages. Drawing on Skinner's programmed instruction (Skinner, 1954; 1958b) who thought that learning content should be delivered in small, manageable packets and that 
the learning pace should be set by the learner, CAI programs were usually designed by a course developer and were usually simply a reproduction of language exercises resulting in classes that were very similar to traditional face-to-face classes given with tape recorders and text books. In its most sophisticated forms CAI courses were meant to simulate the subject's cognitive processing and help them with operations and exercises (Felder, 1988). This was seen as efficient because it taught only and exactly what should be taught. As seen in Chapter 2, this lack of natural linguistic teaching was not conducive to language development. It was not until the next stage in distance learning that the Internet was introduced, and with it came email, fora and other Web 1.0 based tools which enormously improved communication between students and teachers. Online environments approached language learning very differently: students now had an immeasurable amount of information available to them and interaction with their teachers and other students was much easier and faster. An inter-institutional distance language learning project that emerged as a result and which continues today as a methodology is the 'Tandem learning programme' (Appel, 2002; Warschauer, 1996). This language learning system is based on the principles of bilingualism, reciprocity and autonomous learning to connect native language speakers with learners of that language (Schwienhorst, 2010) through traditional communication methods but also through email, messenger and other initial Internet-based tools. Tandem was different from the pen-pal system because communication was much faster and could now be done in groups more easily. It is explored in more detail below. Thus during the $90 \mathrm{~s}$, the introduction of the World Wide Web made it possible for the user to navigate an endless amount of knowledge, at their own free will. The idea that this context could be applied to learning situations was almost immediate. The new emerging learning model was based on discovery because the learner did not have fixed objectives or content and was an extension of learning proposals that had emerged some years ago with the appearance of hypertext-multimedia in the classroom during the 80 s and $90 \mathrm{~s}$, even before the advent of the Internet. Different authors such as (Beeman, 1987 and Conklin, 1987) had researched into these new technologies and noted that they facilitated learners' freedom to move around in an environment that they called an exploratory or discovery learning environment. Moreover, by requiring that students use non-linear thinking, they could 
stimulate integration and contextualisation in a way that conventional learning systems, linear by nature, could not. Talyor (1995) calls the fourth and current stage in distance learning the 'flexible learning model'. This fourth stage coincides with the stage of 'integrative computer-assisted language learning' (late twentieth century to the present), the computer begins to be seen as a tool that can help users learn and acquire a limitless amount of knowledge. It is now used for task-based work and collaborative projects. It introduces synchronous collaboration in distance language learning and allows for real-time learning. VolP, with or without webcam, hugely advanced the development of oral proficiency skills as oral language could be practiced with speakers whether native or not - of the foreign language being learnt. From this moment, each student would have the opportunity to practice all four basic language skills (oral, reading, written, grammar) from home. This stage also represents an important advance for autonomous learning and the costs associated with learning a foreign language as the student no longer had to be physically present in a classroom or location to practise their target language nor did they have to travel to a country where their target language is spoken to communicate naturally with speakers of that language (Hampel, 2004). Although this stage also saw advances in speech recognition technology which could be applied to language learning, these types of software programs are focused on the more superficial aspects of language, such as pronunciation or grammar, and ignore the real meaning of what a learner is saying. It cannot understand creative or cultural use of language which is something that can only be acquired through direct contact with people (see Chapter 4). This fourth stage emerges at the same time as Web 2.0, which refers to the second generation of the Internet where user-generated applications, tools and content are developed by users for themselves and their online communities and not by a network administrator. Some examples of these tools are wikis, blogs and most importantly for this thesis, social networks. Web 2.0 is an improvement on conventional analogue media and on Web 1.0 because the Internet can now be modified and interacted with, resulting in the creation of new user-created content and relationships. Tools such as blogs, wikis and social networks facilitate dialogue between students and collaborative learning. Although decentralisation and a more freely available education 
have been attributed to the appearance of the Internet and Web 1.0, these concepts now take on a new meaning with Web 2.0 (Thomas, 2010). Different technological and communicative tools are introduced at a rapid pace. This is rapidly absorbed into learning platforms and methodologies which in turn become much more collaborative, inter-connected and student-centred; students begin to take advantage of these advances and enhance their autonomous learning through the use of Computer Mediated Communication (CMC) (Hurd, 2001). CMC not only brings about a revolution for distance language learning, but also for foreign language learning in traditional classrooms: students who are unable to travel to a foreign country can engage in written and real-time conversations with natives of the foreign language they are learning (Belz, 2002; Kern, 2004; Kern \& Warschauer, 2000).

Another concept in DE that is furthered by the use of technology to support learning is individualisation, autonomous learning and personalisation. As seen in Chapter 3, the terms individualisation and autonomous learning are not used in the sense of isolating the individual during the learning process, but rather the opposite. The online and distance learning approach of individualisation in education will allow students, through the use of resources that technology provides such as networking and socialisation, to gain a more personalised and complete reality of the world that surrounds them, based on their preferences and representations, which are characteristics of their cognitive scaffolding, so that from it and because of their role in it, they acquire new knowledge. An analogy to this is the algorithm Google searches use to provide us with personalised results: it uses and process large amounts of information, the history of the individual's use of the web browser to guide and filter its search and then guide the results. It is not only that Google's search algorithm that uses a lot of information; the search is also guided by the information history held by the individual and their preferences.

Computer Mediated Communication (CMC) is communication between humans that is facilitated by technological tools. It has become an effective communication resource that has had significant impacts on many areas of communication (Beatty, 2004). Warschauer (1996) calls it a revolution in the knowledge production process and believes that it is blurring the line between written and oral communication because it is 
often used together with other Internet based communication tools. Hiltz and Turoff (1978) defined CMC as "[...] the process by which people create, exchange, and perceive information using networked telecommunications systems that facilitate encoding, transmitting, and decoding messages". Luppicini (2007) states that CMC is "[...] communications, mediated by interconnected computers, between individuals or groups separated in space and/or time" (Luppicini, 2007:142). Warschauer (2000) noted that $\mathrm{CMC}$ is communication that takes places through tools provided by computers. The application of sociocultural theory into the study of CMC was first explored by Warschauer (2000) and is extremely relevant to this thesis. CMC with a sociocultural perspective is defined by Jones as:

[...] not just a tool. It is at once technology, medium, and engine of social interactions. It not only structures social relations, it is the space within which the relations occur and the tool that individuals use to enter that space (Jones, 1995:16).

Jones does not only refer to an educational setting in this definition, his work also tries to highlight the intercultural interaction opportunities that CMC provides through making communicative tools easy to use and access. However CMC in online learning is also significant as it allows students to interact more freely with their teachers and their peers in their target language. These new tools can also be interpreted as facilitating learning or creating a new type of learning all together. Telephones and other traditional media continue to be used, but as the use of CMC begins to rapidly expand for the first time, peers from different geographical locations begin to interact more easily and thus more frequently and there is a much more direct communication between the teacher and their students. It has also served to facilitate authentic interaction with people who natively speak the foreign language students are studying, so that they can practice their target language and allow first-hand learning of their target culture.

Tudini (2003) uses CMC tools in his distance language courses so that intermediate foreign-language students of Italian can chat with native Italian speakers in chat rooms. In his research Tudini found that students spoke freely with native speakers, participating actively in open-ended tasks, just as students of this ICC course were able to practise their target language and learn about their target culture. An important conclusion from 
both these courses is that native speakers provide "[...] an authentic and purposeful cross-cultural experience which is otherwise limited to the language teacher, members of the local community or other learners" (Tudini, 2003:157). Further literature on intercultural online exchanges (Kramsch \& Thorne, 2002) state that research into distance language education should always include programmes about intercultural competence and online interactions with native speakers, which could be done in the form of telecollaborative exchanges between language learners in different countries (O'Dowd, 2006, 2012) such as during the course carried out for this thesis. Because changes have taken place at such a fast pace Thorpe states that:

CMC enables distance learners to engage in collaborative learning and discursive interaction with peers and tutors in a variety of communicative settings. However the potential of the technology to deliver a more discursive and collaborative learning process has not always been achieved (Thorpe, 1998:265).

Thus Thorpe believes that the potential these new technologies has brought the distance language learning field have not been completely exploited, he would like to analyse and monitor this new way of learning, which continues to evolve and remain innovative even ten years later. They also need to be considered in terms of creating a suitable learning theory in order to arrange and unify all the new possibilities. As McLoughlin and Lee state:

Theories that underpin technology based learning designs need to be carefully examined. It is imperative that educational technologies are conceptualized within theoretical models that relate how pedagogy can be transformed to harness the potential of social software tools for learning (McLoughlin \& Lee, 2008:642) 


\subsection{Connectivism}

Connectivism has been put forward as a possible learning theory to articulate the instructional possibilities of online learning. Driscoll (2005) analysed the three most popular psychological learning models in the context of teaching models, which are different from the distance learning theories described in the previous section as they relate specifically to how students learn rather than a more general framework that encompasses education. The traditional models are behaviourism, cognitivism and constructivism. These theories have been explored in regard to language learning in Chapter 2. In behaviourism, reality is external and objective, and learning happens through experience so that teaching adapts environmental factors to suit students and their learning behaviours. Cognitivism states that reality is created through the learner's cognitive representations and that knowledge is thus gained through experience and consideration. As learning includes both, teaching should focus on helping learners to develop symbolic mental building blocks that will be the platform for their newly acquired knowledge and skills. The third model, constructivism states that knowledge is constructed from what the learner already knows and teaching should thus focus on helping students to create personal meaning from their experiences. The fourth and newest learning model is the connectivist learning model. The neuropsychological connectionist model and the distributed knowledge theory have been combined to create what is known as this connected network learning theory. According to George Siemens, knowledge is distributed throughout the brain and exists in the connections of different nodes (Siemens, 2005). The connectionist approach tries to explain knowledge formation from a cognitive perspective. According to connectionism, the brain is made up of connections and when those connections recognise patterns, by linking together information through nodes, learning takes place. These nodes are strengthened through use and other connections that are created, the stronger those connections are the easier it is for the brain to associate them with other information nodes. Learning is conducted through training the nodes to connect and associate information, not through 
the creation or construction of new knowledge (Plunkett, 1998). The process is not governed by any rules (chaos theory) and the brain will automatically and naturally look for associations between concepts to create those links. According to Dempsey and Van Eck (2007) as long as the brain has a certain amount of input it will find associations and create networks of connections, strengthening the links from already existing information to new information, resulting in learning. Siemens (2006) draws parallels with this learning theory and online learning by stating that social and technological knowledge created exists through the connections made by people between individuals, communities and machines. Like other similar terms (e-learning, online learning or webbased learning) and emphasising more on their social perspective, networked learning environments and learning networks are those where technology promotes connections between everyone in the group to foster a discussion about the subject being learnt and the learning process. These connections allow multiple interactions between content and people (Dirckinck-Holmfeld, 2009; Ryberg, 2008). Although parallels of this networked learning have been drawn with the traditional concept of working groups, they differ enormously not only because they are geographically dispersed, but also because these connections may be made between people or groups who are not working within the same field or even towards the same outcome (Garriso, 2003). Virtual communities (not working groups) are communities of people who share values or common interests that are communicated through the various communication tools that these networks provide. When the main role of these networks is the acquisition of knowledge, they become virtual learning communities. Derived from the model proposed by Seely Brown and Collins (1989) and the concepts developed by Wenger (1998), learning communities provide learning networks with a solid link between their components (DirckinckHolmfeld, 2009). Connectivism stems from a fusion of this connectionist model, learning networks, virtual communities and chaos and autonomy theories, whose main idea arises from connections that are established in this digital network:

[...] we break from our insistence of complicated explanations to complex phenomenon and collapse down to connections as the basic unit for understanding knowledge and the process of learning (Siemens, 2010b:online).

So connectivism is often associated with online learning because of the connectedness 
(through ICT tools, social networks, fora etc.) and the interaction that entails. Connectivism differs from other learning theories and models because its fundamental principle supposes that knowledge and learning does not only reside in a person, they can also occur outside a person. It usually occurs in networks, which are, according to Downes, fluid and changing, "[...] because without change, growth and adaptation are not possible... It is through this process of change that new knowledge is discovered, where the creation of connections is a core function" (Downes, 2009:16). Advocates of connectivism (e.g. George Siemens and Stephen Downes) state that traditional learning theories also ignore other issues such as the fact that (and according to connectivism) learning can be stored and manipulated by technology, knowledge can be created between groups and they are unable to describe how learning happens within organisations. Moreover, unlike constructivism, which states that students try to attain understanding through tasks that give meaning, connectivism believes that meaning already exists and the learner needs to recognise the patterns that allow it to emerge. Deciding these meanings and forming connections between communities are the core activities of learning (Siemens, 2005). In addition, connectivism also states that connections that are formed naturally, without too much effort on the part of the learner, and sometimes not even fully under the control of those same individuals (Siemens, 2006). Therefore there is no transfer or construction of knowledge (Downes, 2008). Siemens summarises his proposal on the following principles:

- Learning and knowledge reside in the diversity of opinions.

- Learning is a process of connecting specialised nodes or information sources.

- Learning may reside in non-human appliances.

- The ability to know more is greater than what is currently known.

- Promoting and maintaining connections are needed to facilitate continual learning.

- The ability to see connections between fields, ideas and concepts is a core skill.

- Updated knowledge is the purpose of all connectivist learning activities.

- Decision-making is itself a learning process. (Siemens, 2005:online)

He emphasises that knowledge is changing so quickly that an affirmation made today may be incorrect tomorrow because of changes in the context of the information that 
affects that decision. This is especially relevant in the case of foreign language learning as language is continuously changing. Within this new learning theory, other new learning models emerge (McLoughlin \& Lee, 2008) such as the e-learning 2.0 model developed by Stephen Downes to acknowledge the application of technological tools in education and the online learning structures that have exponentially grown since one of Downes' courses was first offered online, now known as massive, open, online courses: MOOCs. 


\subsection{The emergence of MOOCs}

The acronym MOOC refers to Massive Open Online Courses. This learning structure is understood as an approach to teaching, however it is more well-known because of its acronyms: a course that is open to any student, and tries to attract large numbers and which is accessible via the Internet. John Daniel states that the definition of MOOCs is evolving continuously and gives as an example of this the changes in its definition in the website Wikipedia from the $16^{\text {th }}$ September 2012 to $20^{\text {th }}$ September 2012 (Daniel, 2012). Conole defines MOOCs as "online courses that harness the potential for learning in a large-scale, distributed community of peers, through open practices" (Conole, 2013:6). MOOCs have been split into two different categories called cMOOCs and XMOOCs. cMOOCs are more associated with connectivism and networked learning while xMOOCs are associated with courses offered by established universities and are thus more behaviourist in teaching nature, based on lectures videos and texts where cMOOCs encourage large quantities to join so as to foster more interaction and networking between peers (Daniel, 2012). Nkuyubwatsi (2013) states that MOOCs are praised for the fact they have developed as a suitable learning structure for the current knowledge society and that they create opportunities for learners the interact with course material and content as well as their peers in order to create personalised learning environments (PLEs). Whether this phenomenon has developed as an answer to today's technological context because there was a gap or whether it has arisen because of the phenomenon itself is still being debated.

Technologically advanced societies are experiencing rapid and dramatic change because of the continuous technological advances that are taking place and MOOCs have arrived at a time when education would like to make use of those advancements in order to improve and make learning more accessible and easier for everyone. It has also been behind a resurging interest in DE. It seems MOOCs have been so readily embraced because they reflect a relevant characteristic of emerging society's characteristics and an easily comprehensible comparison, they offer open and 
unmediated access to knowledge resources through technology. deWaard, Abajian, Gallagher, Hogue, Keskin, Koutropoulos, and Rodriguez (2011) state that one of the main characteristics of MOOCs is openness: a flow of knowledge and information in a networked system that organises itself and its participants which is continuously transforming. MOOC courses fall under the open and distance learning umbrellas, which have traditionally made the most of technology advances by using free and open software for educational purposes. The course content, educational resources and material used in MOOCs are free and open and usually published under a Creative Commons License. The knowledge that is transmitted by learners and teachers is openly shared (Fini, 2009).

Kop, Fournier and Mak (2011) believe that openness also refers to communication and participation in networked contexts. Registration is usually available to anyone, the course structure is often quite flexible, and the final evaluation process, as well as the tasks to be done during the course are freely accessible. However, the $\mathrm{xMOOC}$ model is known to be slightly more structured and the learner autonomy developed in terms of learning and teaching methodology can be more limited. One of the philosophical foundations of MOOCs according to proponents of them has been to completely alter the way in which learning outcomes are assessed. For example, in their online learning programme LAK12 (Analytics, 2012) Siemens states:

You are NOT expected to read and watch everything. Even we, the facilitators, cannot do that. Instead, what you should do is PICK AND CHOOSE content that looks interesting to you and is appropriate for you. If it sounds too complicated, do not read. If it looks boring, move on to the next item. Learning outcomes, therefore, will be different for each person. (Learning Analytics 2012 MOOC course) (Analytics, 2012:online)

However, the result of this approach is that any learning of course content cannot be assessed. Many MOOCs use other students in the class to review learners' work, known as peer-review. This however has been criticised as those students do not have the knowledge necessary to give appropriate feedback and help students understand the work fully. It does foster interaction though, which to Siemens is fundamental in creating those connections that ensure learning. Interaction is considered to be an immediate response to questions, demands, dialogues and interventions that occur in the learning platform and outside of it and the development of course topics. 
Traditionally, in distance learning and later in e-learning, the different types of technological support offered to the learner have had a common denominator, they have meant dealing with barriers to education, not only temporal and space barriers but also other barriers that may prevent or hinder the student's (or teacher's) attendance of class. They were also a response to overcoming personal deficiencies and disabilities. These solutions or methodological environments and approaches were considered to have similar values that were fundamental to furthering distance learning and that were different to those that currently existed and could also be extended to other areas.

These values of the democratisation of education are the origins and the essential parts of today's different and new approaches to education which have given rise to new situations and which are not accidental but a result of the new attitudes to teaching and learning that stem from the technological advances and the connected environment society has become. So words such as 'interactive' and 'interactivity' in education and these technologically advanced learning platforms are vital. According to Berge (2002) and Muirhead (2000) these methodologies are characterised by new elements that facilitate learning.

Traditional distance learning that existed before technological advances, such as the postal service and the telephone, was learning that took place over a much longer period of time because of the delay in communication and the physical and psychological distance, to such an extent that the power to learn was lost in the slow transmission of knowledge; communication in those contexts had very low interactive potential despite the emphasis placed on two-way communication. This can still be seen in some distance learning platforms today, even those that are offered online. This lack of teacher-student interaction is sometimes, but not always, made up for with student-student interaction in groups that may or may not be part of the course itself according to learning objectives. Many proponents of MOOCs will argue that there is an increased interaction between students and teachers through technological and virtual tools such as social networking, fora, chats, email, which in turn increases dialogue, autonomy and self-assessment which all foster learning. The result is that technologically supported education is 
becoming much more interactive. This interaction is extremely important not only in foreign language learning, but in distance learning too. The role of teachers has radically changed because of today's increased interaction, they are now not only imparting knowledge - even if that is through uploading pre-existing content in videos and reading materials or other media - but are also now mediators and facilitators of educational and interactive activity. This also influences teachers' content and resource creation (learning and support materials) which students will use to aid and guide their learning; the activities teachers give the students to learn with and assessments which should include learning progress references and indicators, will guide students' decisions for their next steps throughout the learning experience.

It also increases their flexibility and ability to change according to needs and signals they identify and detect. Thus the role of the teacher in learning methodologies that are based on networks is now characterised by their potential to organise resources (create opportunities, establish networks, links and dialogue between learners). In addition, the resources that are developed under these conditions integrate elements that promote self-learning fostered by interaction through the resources of 'sharing' and 'adding'. This type of interaction leads to self-assessment as it includes elements that integrate interventions by others. MOOCs suppose these networks and self-assessment activities arise naturally, that is to say, without a structured or pre-designed environment. Consequently course design will need to ensure the functions of the programme guide the way to learning objectives.

As mentioned above the initial model that MOOCs adopted was the connectivist model. However the success of MOOCs has led educators to try to adapt it to postsecondary online education and developed the $\mathrm{XMOOC}$ model, designed as a more conservative and traditionally teacher-led, although still open, online and using advanced technologies of the Internet and computers. The differences between these two models have been explored above, the main differences being that in XMOOCs the course structure is less flexible in terms of what resources and methods learners can use to find information and the role of evaluation and assessment tasks carried out during the course. Also, cMOOCs are distributed and tend to use a more networked platform (Daniel, 2012). 


\subsection{Issues with distance and online learning}

Bates (2012) believes that calling MOOCs a new pedagogy is erroneous. He writes that "[its] teaching methods are based on very old and out-dated behaviourist pedagogy, relying primarily on information transmission, computer-marked assignments and peer assessment". He continues by stating that the MOOCs movement did not discover the concept of online learning and that learners have been learning at a distance for many years. Apart from this issue, there are several others that appear often in the literature review that was carried out. One of those issued raised by some researchers is that the free and open access principles of the MOOC acronym are not respected. Accreditation is sometimes only offered when students pay for it (Mangan, 2012; Young, 2012b), so students may take the course and do the work in it, but they are not recognised for doing so. In many cases the course is not massive either and when there are high volumes of students enrolled a large percentage are merely curious students who have no intention of completing the course or doing any of the work and tasks assigned to them, they would simply like to have some information regarding the subject of the course. David Wiley (2012) offers a definition that highlights the inconsistency of the concept:

There are a number of reasons why the term MOOC is a misnomer.

- Many MOOCs are massive but not open (e.g., http://www.udacity.com/legal/)

- Many MOOCs are open but not massive (e.g.,http://learninganalytics.net/syllabus.html)

- Many MOOCs try very hard not to be courses (e.g., http://cck11.mooc.ca/how.htm).

Well, at least all MOOCs offered to date have been online - so at least there's one thing we can agree on. I hate this term. Almost every so-called MOOC violates at least one letter in the acronym. Why are we using this word that doesn't describe the things we attach it to? (Wiley, 2012:blog post).

Retaining and motivating students for any learning course, whether distance learning or traditional face-to-face classes, has always been a primary concern for educational systems (Baath, 1984b; Holmberg, 1995; Kember, 1990). Retention rates seem to be particularly low in distance learning and within distance learning especially low for online courses such as MOOCs. According to Tinto's model of student retention, the 
percentage of students who drop-out of traditional, face-to-face courses has historically been at the same percentage rate of about $40-45 \%$ for the past 100 years (Tinto, 1982). In the online and DE context, retention rates appear to be about 10 to 20 percentage points higher (Carr, 2000; Diaz, 2002; Moody, 2004) and MOOC rates are even higher.

The definition of retention, in the context of something as complex as education, is not straight-forward. Research into retention usually refers to completion of an entire course or degree (Institutional Research and Planning, 2003) but ignore the 'tourist' student or learner who wishes to simply get an understanding of the course subject or practice their target language, without the need for a formal qualification or official assessment, thus retention in terms completion of the course is only relevant for some learners. For others, learning success refers to achieving their objectives which may include simply participating (Berge, 2004). Defining retention is also made difficult because of the different ways educational institutions assess learning. When this thesis uses the concept retention it refers to continued learner participation in an educational course until completion, which includes face-to-face and distance learning course programmes, institution, or system and the persistence and motivation the learners show and manifest to continue their participation in that learning context by either completing work, participating in the course, interacting with other students or assessing their knowledge of it. While retention in DE has been studied extensively, there is a gap in the study of elearning and MOOC retention, probably because they are such new concepts. Research into the wide variety of variables related to retention in face-to-face and distance learning by Sarkar (1993) highlights the fact that it is a variable and complex issue which includes a multitude of aspects that are sometimes very personal, including family support, socioeconomic levels and the academic and social integration of students in general as well as teaching methodologies used, institutional resources and services and current trends. However the most widely cited criticism of distance learning is that students feel isolated due to no contact with teachers and other students (Carr, 2000; Garland, 1993a; Martinez, 2003; Moody, 2004; Rovai, 2005). When student feel they are completely unsupported it is more difficult to stay focused on objectives. Research by many scholars, such as Lake (1999), Wegner (1999) and Lorenzetti (2005) among others has 
found that a high percentage of distance learners believe the feeling of isolation is a threat to continuing with their studies and mention that teacher-student and studentstudent interaction plays a large role in motivating them to learn. This feeling of isolation can stem from both physical distance and a difference in time zones (Lake, 1999; Lorenzetti, 2005; Wegner, 1999). According to Hill the concern that is most often raised by students enrolled in distance learning courses is this feeling of un-connectedness (Hill, 1996). Thus Moore and Kearsley (1996) propose increasing the degree of interaction that is available in DE courses and encouraging students to interact with each-other to try to ensure that learners continue with their studies. They also believe this can be compatible with the atomisation and systemisation of education. 


\subsection{Telecollaborative exchanges and being connected for foreign language learning interaction}

Telecollaboration is the collaboration between people who use online and ICT tools to work together. Telecollaboration in foreign language education is collaboration between people who use online and ICT tools to carry out intercultural and multilingual exchanges between groups of students in different countries for the purpose of learning foreign languages (Dooly, 2008). According to Guth and Helm (2010) telecollaboration is:

[...] internet-based intercultural exchange between people of different cultural/national backgrounds set up in an institutional context with the aim of developing both language skills and intercultural communicative competence (as defined by Byram (1997)) through structured tasks. (Guth \& Helm, 2010:14)

Kern, Ware and Warschauer (2008) believe it is form of network-based language and cultural learning; it has been defined by Belz and Thorne (2007) as Internet based mediated intercultural foreign language education and as online intercultural exchanges by O'Dowd (2007).

The origins of intercultural exchanges stem back many years. One of the first well-known projects is one developed by Célestin Freinet in 1920s France (Cummins, 1995). Freinet asked his students to write articles about his town and region in the north of France and created newspapers to exchange them, together with what he called 'cultural packages' of flowers, fossils and pictures, with schools in other parts of France. Another early model of intercultural exchanges and collaboration on cultural projects are tandem learning' (Kötter, 2003; O'Rourke, 2005) projects organised by secondary schools which would pair together two foreign language learners in different countries so that they could communicate and participate in bilingual exchanges. These learners are usually native speakers of the language their partner is learning. They communicated through letter writing, email or other communication tools. In this broad sense tandem learning probably began with intercultural projects carried out in schools, such as those where students write letters to peers in different countries, the difference being they now rely heavily on ICTs.

An early example of online based telecollaboration is the Cultura project developed in 
1997 by MIT researchers Furstenberg and Levet: “... a Web-based, intercultural project situated in a language class that connects American students with other students in different countries" (Furstenberg, Levet, English \& Maillet, 2001:59). Its first documented purpose was to bring together French students studying English at the University of Institut National des Télécommunications in Evry, France with English students studying French at the Massachusetts Institute of Technology in Cambridge, USA by developing a web-based course that studied cultural issues from both countries so that students could practice their target language while contemplating and learning about their target language's culture. In many similar telecollaboration projects reported in the literature, teachers develop the content and materials to be used, monitor interaction and try to generally be very involved in the course, especially through providing support and advice to the students, but learners normally communicate with one another with no intervention from tutors or anyone else that are part of the group.

Traditionally in these types of projects students would communicate through hand-written letters and report on the communication only to their classes, however today, because of technological advances, many more communication tools are available such as VolP, social networks, blogs, wikis and more importantly video-conferencing tools (Develotte, 2010; Dooly, 2008) including Google Hangouts. Since this method has begun to be integrated into online language learning courses it has quickly become a respected model for computer-assisted language learning (CALL) and its contribution to intercultural communication competence in foreign language learning has become a popular area of research (O'Dowd, 2003; Ware, 2005). Telecollaboration structures and models differ widely depending on the project and student objectives. For the purposes of this thesis, the focus in the literature review and research done to develop an appropriate course for foreign language learners has been on the development of language skills and intercultural communicative competence (Dooly, 2008; O'Dowd 2007). Telecollaboration is ideal for the development of ICC, since it establishes a natural context for learners to engage in intercultural communication, overcoming classroom limitations, such as not having the opportunity to talk to native speakers of target languages or having access to authentic cultural conversation situations (Belz, 
2007). The definition of intercultural communicative competence that has been accepted by most of the telecollaboration literature is based on Byram's (1997) ICC model which was explored in Chapter 3. In the context of foreign language education, the purpose of telecollaboration is to use online communication tools to bring foreign language learners in different countries closer together to practise their target language while learning about their target cultures, sometimes through carrying out joint projects (Thorne, 2006) or in the case of the ICC course that has been developed for this thesis, to discuss their new knowledge in ICC. Telecollaboration is seen as extremely helpful in foreign language learning as it allows students to engage in communication with native speakers of their target language and culture and it provides an opportunity for them to participate in such authentic intercultural exchanges within the structured and educational context of their foreign language classroom. In the words of Kern et al. (Kern, 2004), telecollaboration offers teachers the opportunity to:

[...] use online resources not to teach the same thing in a different way, but to help students enter into a new realm of collaborative enquiry and construction of knowledge, viewing their expanding repertoire of identities and communication strategies as resources in the process (Kern, 2004:21). 


\section{METHODOLOGY}

There are two Chapters to the methodology section. The first, Chapter 6, describes the design of the course. This chapter is in turn structured into six parts. The first part describes how the course was designed. The second exposes the participants in the course and those students who enrolled. The next section, 'course tools' outlines the tools visible to the participants in order to study in the Blackboard online learning platform. These tools are shown on the platforms as headings and contain materials and resources that correspond to the specific title given to them. The following section describes Google Hangouts, the second pillar to the ICC course. Section five explains the actual steps participants needed to make to begin and during the course. It details what information was given to participants prior to the start of the course so that they could know what to expect when they began the course through communication with them and what steps were to be followed when the actual course began. Finally, the last part to Chapter 6 explains what tools were available on the course to the participants to further understand the course materials students had interacted with and how these tools were to be used by them. 


\subsection{Course design}

The Intercultural Communication (ICC) course was designed partly based on Hall's (1959, 1966, 1983) work analysing the implicit patterns differing cultures, Hofstede's framework $(1984,1991)$ categorising cultural aspects into dimensions and partly adapted from the University of the Pacific's 'What's Up With Culture?' online cultural training resource for study abroad website. Permission to translate and modify resources from this website was granted as the 'What's Up With Culture?' project was originally funded by a FIPSE (Foundation for the Improvement of Post-Secondary Education) grant through the US Department of Education and as such, "the website is considered public domain and its creators encourage educators to use it in whatever way they think would benefit their students (so long as the institution is a non-profit educational entity)" (quote from reply to the author's original email requesting permission to use and translate resources on the website, see Annex 1 - email communications regarding course). The interactive exercises were created by the author and her team of foreign language teaching specialist from ESIC Business School and the recordings were written and recorded by the same team. The supporting exercise were created using various resources from the Internet and based on work by Hofstede \& Pedersen (2002), Utley (2004) and Tomalin \& Stempleski (1993) among others. 


\subsection{Participants}

The participants were located in many different countries around the world and were aged between 19 and 45 years old and were mainly Engineering or Philology university students - specifically native English speakers learning Spanish and native Spanish speakers learning English. The only limitation for involvement in the study was that participants must be at a European Framework of Reference for Language levels of B1 and B2 which is an intermediate and upper-intermediate level in their target languages, that is, Spanish or English. Participants were sourced from Universities in different countries, in the Spanish Department in English speaking countries and the English Department in Spanish speaking country. These departments were contacted through email (see Annex 1 - email communications regarding course). Five universities replied in the affirmative, see table below. The instructor sent an announcement (see Annex $1-$ email communications regarding course) with instructions so that the Head of the relevant Language Departments could notify their students of the course and inform possible participants of its content. They were to only notify students at a B1 or B2 level. The notification included instructions on how to enrol should the student be interested in participating in the course.

\begin{tabular}{|c|c|c|c|}
\hline $\begin{array}{l}\text { a. Enrolled } \\
\text { participant name } \\
\text { and username }\end{array}$ & $\begin{array}{l}\text { b. Different } \\
\text { universities } \\
\text { involved in the } \\
\text { course }\end{array}$ & $\begin{array}{l}\text { c. Countries where } \\
\text { the enrolled } \\
\text { participants } \\
\text { resided }\end{array}$ & $\begin{array}{l}\text { d. Participant } \\
\text { professions }\end{array}$ \\
\hline $\begin{array}{ll}\begin{array}{l}\text { Benzal, } \\
\text { (jobenmo) }\end{array} & \text { Jose }\end{array}$ & $\begin{array}{l}\text { Auckland, New } \\
\text { Zealand }\end{array}$ & United Kingdom & $\begin{array}{l}\text { Student studying } \\
\text { English Philology }\end{array}$ \\
\hline Bontoft, Eve (emb) & Sydney, Australia & Spain & $\begin{array}{l}\text { Student studying } \\
\text { foreign languages }\end{array}$ \\
\hline $\begin{array}{l}\text { Bridge, } \\
\text { (bluescar) }\end{array}$ & $\begin{array}{l}\text { Cambridge, United } \\
\text { Kingdom }\end{array}$ & Costa Rica & $\begin{array}{l}\text { Student studying } \\
\text { Engineering }\end{array}$ \\
\hline $\begin{array}{l}\text { CUENCA, } \\
\text { (ananita) }\end{array}$ & $\begin{array}{l}\text { Manchester City, } \\
\text { United Kingdom }\end{array}$ & Australia & Teacher \\
\hline $\begin{array}{ll}\text { Castillo, } & \text { Claudia } \\
\text { (cldacastle) }\end{array}$ & $\begin{array}{l}\text { Durham, } \\
\text { Kingdom }\end{array}$ & New Zealand & Unemployed \\
\hline
\end{tabular}




\begin{tabular}{|c|c|c|c|}
\hline $\begin{array}{ll}\text { Chan, } & \text { Jennifer } \\
\text { (jennchan) } & \\
\end{array}$ & Valencia; Spain & & \\
\hline $\begin{array}{l}\text { Correa Arias, Diana } \\
\text { Carolina } \\
\text { (diacaroarias) }\end{array}$ & $\begin{array}{ll}\text { Polytechnic } & \text { Of } \\
\text { Valencia, Spain } & \end{array}$ & & \\
\hline $\begin{array}{l}\text { Cortes Granell, Ana } \\
\text { Maria (acorgra) }\end{array}$ & Salamanca, Spain & & \\
\hline $\begin{array}{l}\text { D'Arcy, Liza } \\
\text { (interculturalcommu } \\
\text { nication) }\end{array}$ & & & \\
\hline $\begin{array}{l}\text { Delgado, Rebeca } \\
\text { (rebecamdf) }\end{array}$ & & & \\
\hline $\begin{array}{lr}\begin{array}{l}\text { Fernández } \\
\text { Campo, }\end{array} & \text { del } \\
\text { (ladymcbell) } & \text { Isabel }\end{array}$ & & & \\
\hline $\begin{array}{l}\text { García Heras, } \\
\text { Victoria } \\
\text { (victoriagarcia) }\end{array}$ & & & \\
\hline $\begin{array}{l}\text { Gonzalez, } \\
\text { (luisglezrodero) }\end{array}$ & & & \\
\hline $\begin{array}{l}\text { Gormley, } \\
\text { (frances29) }\end{array}$ & & & \\
\hline $\begin{array}{l}\text { HERNANDEZ, } \\
\text { CRUZ (preciosa) }\end{array}$ & & & \\
\hline $\begin{array}{l}\text { HRAIRA, } \\
\text { (nabilhraira) }\end{array}$ & & & \\
\hline $\begin{array}{l}\text { Harriss, Alasdair } \\
\text { (amcharriss) }\end{array}$ & & & \\
\hline $\begin{array}{ll}\begin{array}{l}\text { Hillier, } \\
\text { (rhillier) }\end{array} & \text { Rebecca } \\
\end{array}$ & & & \\
\hline Iron, Lucy (lucyiron) & & & \\
\hline $\begin{array}{ll}\text { Jimenez, } & \text { Rebeca } \\
\text { (rebecajr) } & \end{array}$ & & & \\
\hline $\begin{array}{l}\text { Llzarazo, } \\
\text { (felipelz) }\end{array}$ & & & \\
\hline $\begin{array}{l}\text { Lamb, } \\
\text { (nlam022) }\end{array}$ & & & \\
\hline $\begin{array}{l}\text { Ma, Yingying Myra } \\
\text { (myramyy) }\end{array}$ & & & \\
\hline
\end{tabular}




\begin{tabular}{|c|c|c|c|}
\hline \multicolumn{4}{|l|}{$\begin{array}{ll}\begin{array}{l}\text { Martinez, } \\
\text { (arianamr) }\end{array} & \text { Ariana } \\
\end{array}$} \\
\hline \multicolumn{4}{|l|}{$\begin{array}{l}\text { Martínez, Carlos } \\
\text { (carloscourse) }\end{array}$} \\
\hline \multicolumn{4}{|l|}{$\begin{array}{l}\text { Matthews, Joanna } \\
\text { (jomatthews27) }\end{array}$} \\
\hline \multicolumn{4}{|l|}{$\begin{array}{ll}\text { Miguel, } \\
\text { (markony) }\end{array}$} \\
\hline \multicolumn{4}{|l|}{$\begin{array}{l}\text { Mistry, } \\
(\text { km05) }\end{array}$} \\
\hline \multicolumn{4}{|l|}{$\begin{array}{ll}\text { Murphy, } \\
\text { (murphsup93) }\end{array}$} \\
\hline \multicolumn{4}{|l|}{$\begin{array}{ll}\text { Myers, } \\
\text { (myerha21) }\end{array}$} \\
\hline \multirow{2}{*}{\multicolumn{4}{|c|}{$\begin{array}{l}\text { Neill, Chris } \\
\text { (chrisneill) } \\
\text { OB, Jefftheinstructor } \\
\text { (jeobinstructor2) }\end{array}$}} \\
\hline & & & \\
\hline \multicolumn{4}{|l|}{$\begin{array}{l}\text { Perez, Ignacio } \\
\text { (ignacioperez) }\end{array}$} \\
\hline \multicolumn{4}{|l|}{$\begin{array}{l}\text { Pitarch, } \\
\text { (glopi) }\end{array}$} \\
\hline \multicolumn{4}{|l|}{$\begin{array}{l}\text { Saiz, German } \\
\text { (campoalbillo) }\end{array}$} \\
\hline \multicolumn{4}{|l|}{ 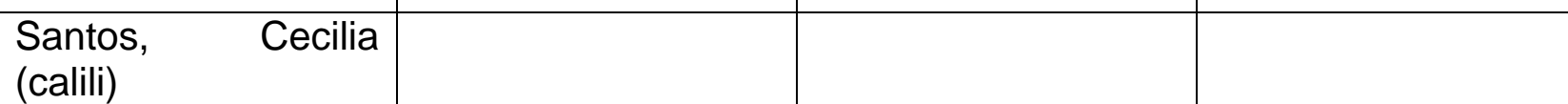 } \\
\hline \multicolumn{4}{|l|}{$\begin{array}{l}\text { Sunderland, Megan } \\
\text { (meganesunderland }\end{array}$} \\
\hline \multicolumn{4}{|l|}{$\begin{array}{ll}\text { Suárez, } & \text { Andrea } \\
\text { (ansufon) } & \end{array}$} \\
\hline \multicolumn{4}{|l|}{$\begin{array}{ll}\begin{array}{l}\text { Vicente, } \\
\text { (lunavich) }\end{array} & \text { Lucía } \\
\end{array}$} \\
\hline \multicolumn{4}{|l|}{$\begin{array}{ll}\text { Wade, } \\
\text { (katiewade) }\end{array}$} \\
\hline $\begin{array}{ll}\text { Whelan, } \\
\text { (kloereese) }\end{array}$ & & & \\
\hline
\end{tabular}




\begin{tabular}{|l|l|l|l|}
\hline $\begin{array}{l}\text { Witt, Georgia } \\
\text { (georgiawittxo) }\end{array}$ & & \\
\hline $\begin{array}{l}\text { Wyde, Rebecca } \\
\text { (beckywyde) }\end{array}$ & & & \\
\hline $\begin{array}{l}\text { peter, katharina } \\
\text { (kpet456) }\end{array}$ & & & \\
\hline $\begin{array}{l}\text { pyne, madelyn } \\
\text { (mpyn323) }\end{array}$ & & & \\
\hline
\end{tabular}

Table 1: Participants and General Information about Students who Enrolled 


\subsection{Course tools}

The platform chosen to deliver the course was the Blackboard Learning Management System (LMS). It was chosen over the other LMS available because of two main reasons: the instructor's familiarity with the platform and the support and help the platform offered for both instructors and students. Each major tool had a 3-7 minute "how to' videos, there is a live chat available to ask Blackboard experts specific questions as well as help documents, tutorials, previously resolved issues page and fora. Courselnfo LCC and Blackboard LCC were created in 1997, both had the stated objective of designing software that provides training and which uses all the possibilities the Internet can offer. A few months later they two merge to form Blackboard Inc. Blackboard works on the web and its documented aim is to improve education by providing different forms of personalised and immediate communication between teachers and students and providing delivery methods for work, participation and collaboration among students and teachers across different platforms. Blackboard is closed source software, Blackboard Learn LMS licences are sold and adapted for different environments and is offered as cloud solution from Blackboard servers. The licence this course used was a free and open licence.

Blackboard offers three options for creating a new course: Import a course. Create a new course. Create a test course. The instructor created a new course. The first step was to sign up to the platform as an instructor, this was done by simply entering the information required, which included personal and contact information. The next step was to create the course. The instructor entered the name of the course, an ID code for it and a description. The instructor was then prompted to choose the course structure and theme. There was written documentation, webinars and video tutorials explaining the different themes and structures. The different structures related to the aesthetic and physical appearance and layout of the course. The final step was to invite students to enrol. Student enrolment could be done either manually by the instructor or by the student through self-enrolment; the instructor chose self-enrolment so that the students would 
have to enrol themselves, however this did not eliminate the manual enrolment option, but it was never used. An internet address was generated for the announcement email sent to students who could simply click on this link and be taken to the registration page to register for a Blackboard Course site account and from within that account, enrol in the course. The home page is fully configurable, the instructor was able to add new modules and configure, modify, move or delete the default modules that appear, ensuring that only most important information or only those modules and tools that were needed for the course were available to students.

The different steps and sections in the course will now be described and some figures are shown to exemplify the characteristics of the course designed for this research.

Creating and / or adding content to the course. Once inside the course site, on the left hand side there is a content menu which includes the default folders and tools, the instructor also had the option to add content folders or sections on the site. This is done through the option 'Create content area'. The areas could also be subdivided - in the case of this Intercultural Communication course the instructor subdivided the areas into course information, different week content, tools, communication tools and other tools. The information in this content area can be made available at the date and time chosen by the instructor and according to individual students or groups. Each weekly content was made available on Sunday evening at midnight. Within the Content the user can again create different sections or folders. The Intercultural Communication Course included the sections outlined below. In all cases except the 'Homepage and what's new' section the content was always posted in both English and Spanish. There were many more tools available than the ones which the instructor decided to use. The instructor wanted to keep the course as simple as possible as the focus was on the linguistic exchanges and practising the target language rather than on completion of exercises. The course tools and different sections are explained below. The headings can be seen in the screenshot on the left hand side of the webpage. These content headings for each section are shown on the main screen and the access links to these sections remained on the left hand side. When one of these sections was clicked two folders appeared Spanish or English - when one of those language folders was chosen the content 
material from that section was displayed in that chosen target language.

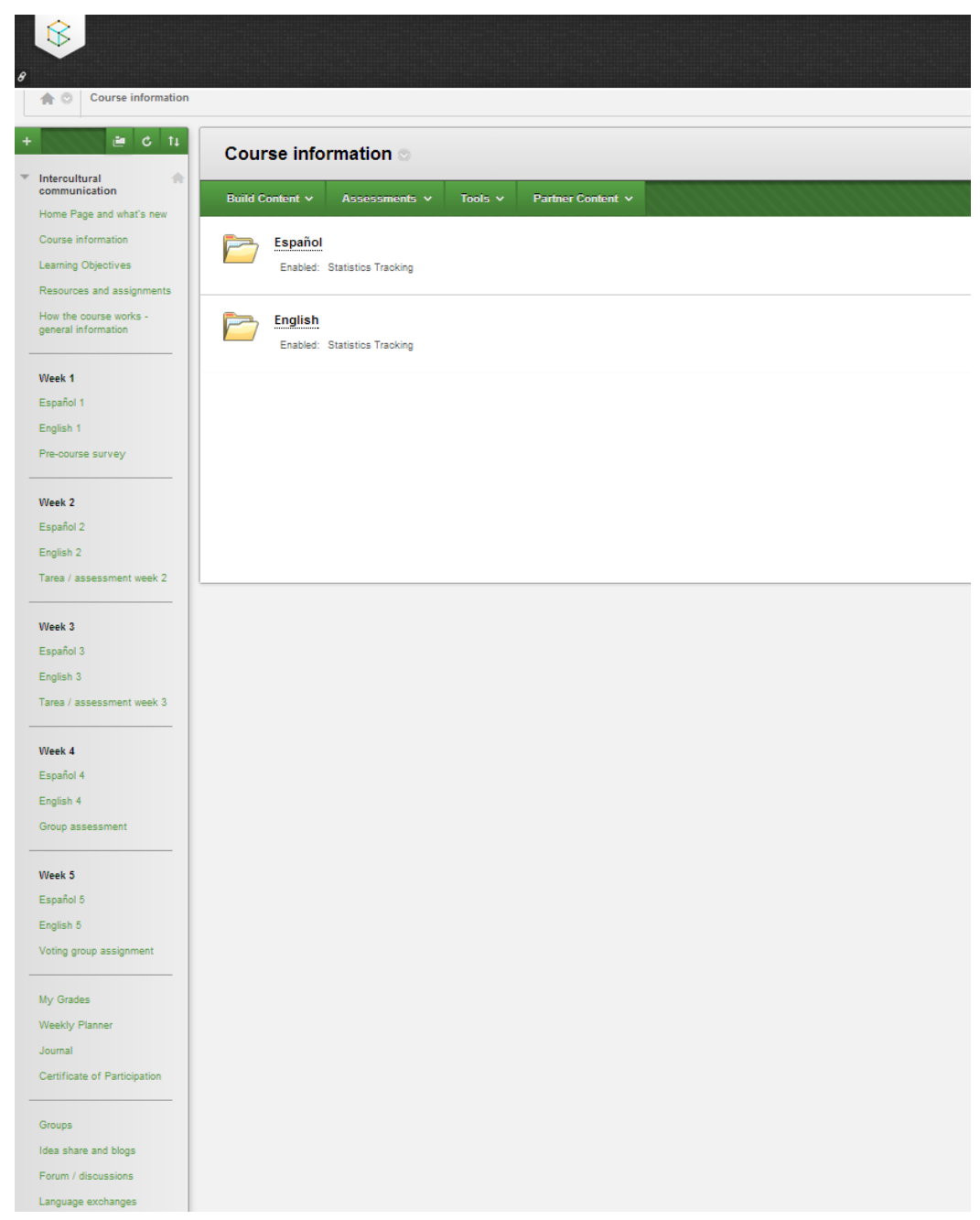

Figure 3: Content folders

\section{Section 1}

1.a - Home page and what's new

Announcements were placed in the 'announcement' section. Students could either visit this section for announcements and communications or could configure their account to receive emails of these announcements throughout the course. The first announcement 
was titled 'Welcome' and served to inform students of where to find any information on the course and what to do in the case they were unsure about any aspect of the course (in the sections 'content', 'what to do next' etc.). The second was titled 'European time' and referred to the different time zones that would be circulating throughout the course, ensuring students were aware that not all times would be in local times. The third gave information about the recordings and the final announcement informed students on the pre-course questionnaire they were required to complete. Throughout the 5-week course an average of 5 announcements were posted every week to inform students about course issues. Other examples were instructions on how to join the Google Hangouts, how students could find their groups, information on the assignments and certificate of participation information. Annex 2 - Structure and information for students, includes the most important announcements and instructions that were sent. This page also included the task that needed to be completed by the participants. Such as finding their group and making contact with them or starting work on an assignment. This page also notifies participants of any blog or discussion board activities. Participants are able to customise the page. They can include any task they set themselves regarding the course and have a calendar available to remind themselves of what needs to be done and when. This is the only section that is only in English. All other sections are in both English and Spanish. 


\section{Home Page and what's new}

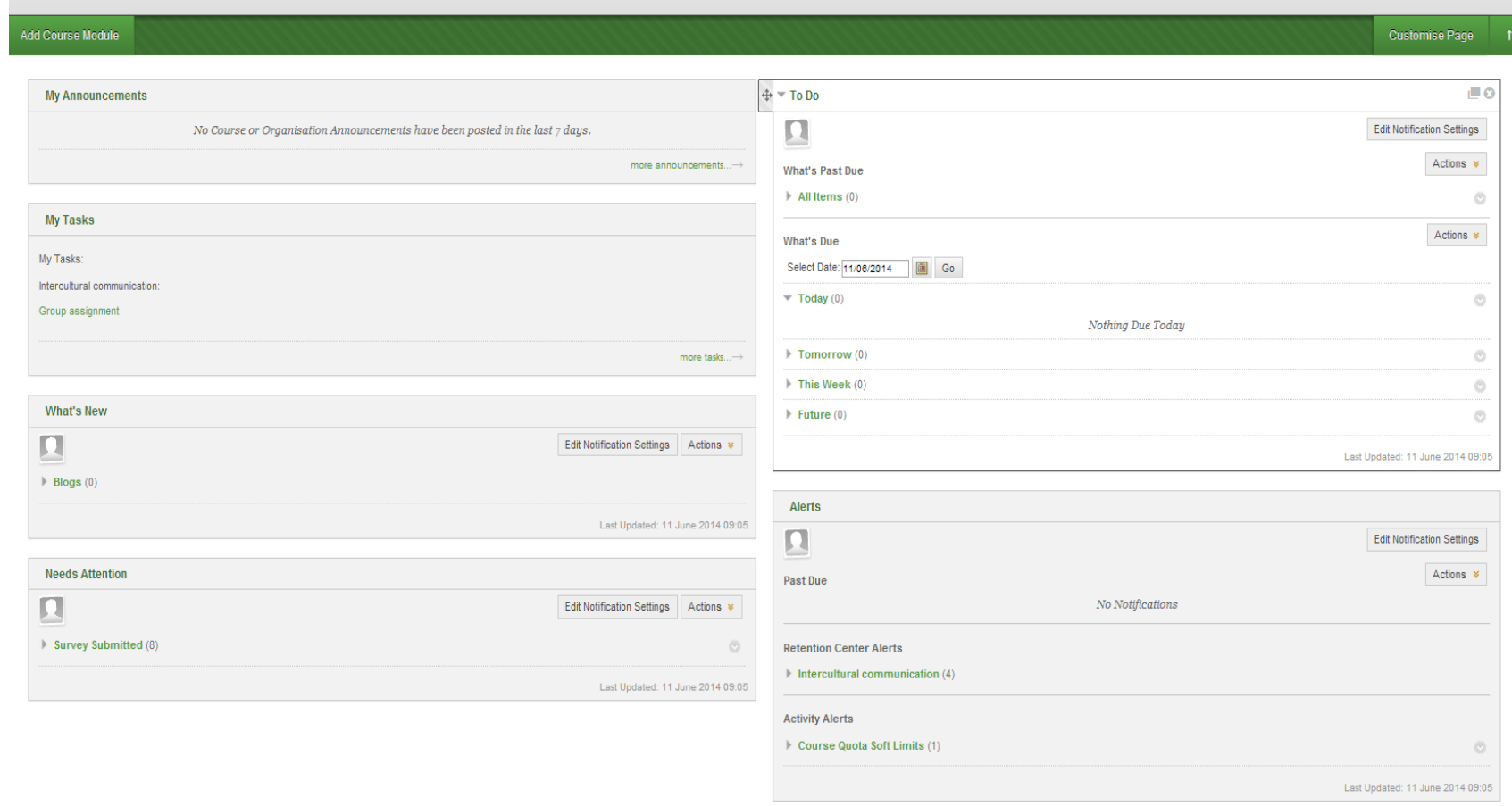

\section{Figure 4: Home page and What's new}

1.b - Course information

There were two sections in the 'Course information' section. The first was entitled 'Course description and objectives'. It briefly explained what the objectives of the course were and what content to expect as well as a welcome message. It described in general terms how participants were to proceed throughout the course. The second section 'Course structure' included a table which outlined what steps participants were meant to take each week. The table showed five headings for each week; 'To read', 'To listen to', 'To do', 'Assignment' and 'Language exchange'. 


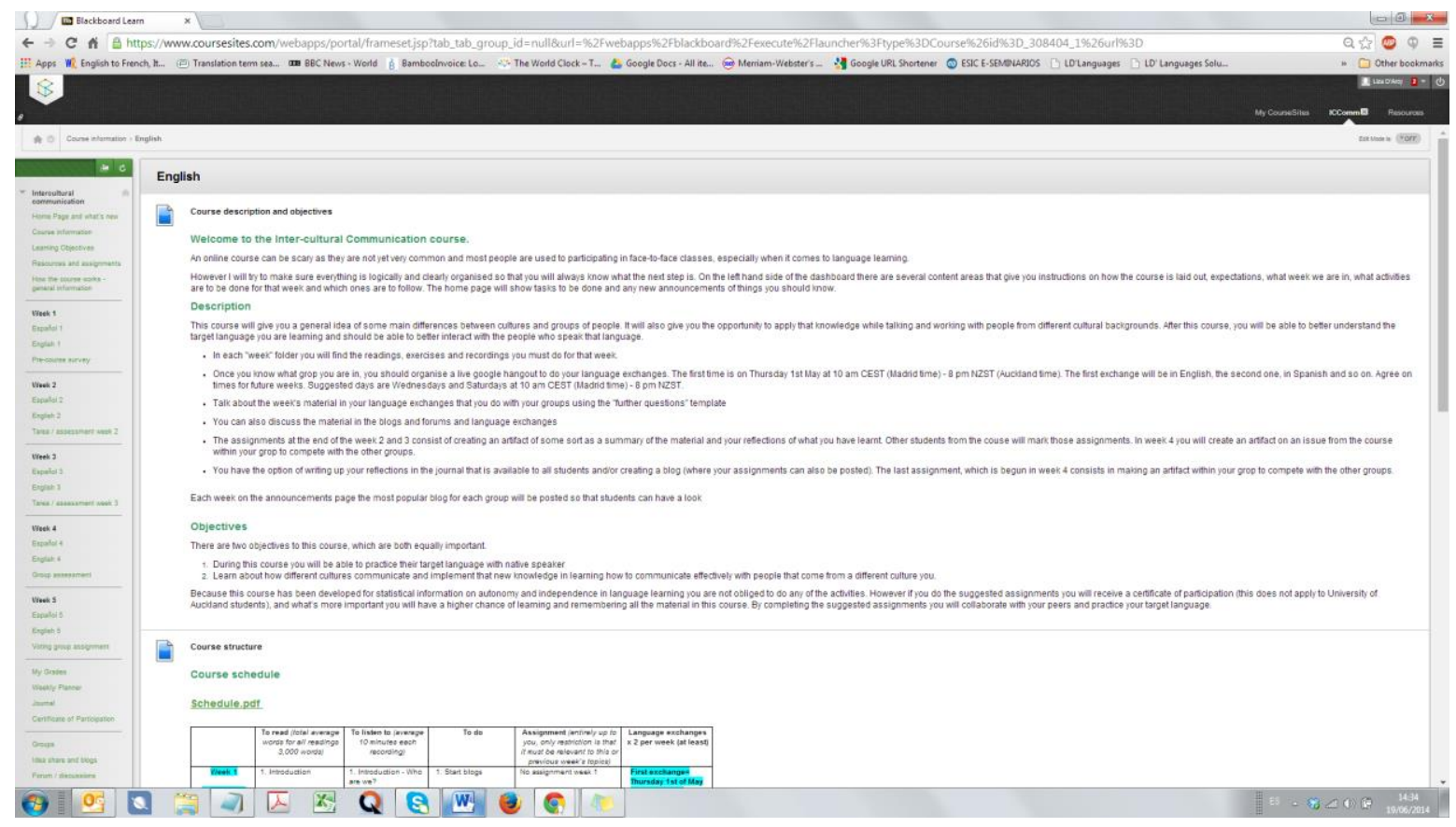

Figure 5: Course information

\section{1.c - Learning Objectives}

There were two sections in the 'Learning objectives' section. The first was entitled 'Objectives' and explained in depth what the two main objectives of the course were. The second section was entitled 'Assignments' and briefly explained the assignment structure for the course. See Annex 2 - Structure and information for students, for detailed content.

\section{1.d - Resources and Assignments}

There were five sections in the 'Resources and Assignments' section. The first was entitled 'Course schedule' and was a downloadable PDF file of the weekly schedule that had five headings: 'To read', 'To listen to', 'To do', 'Assignment' and 'Language exchange'. The second was entitled 'Resources for course material' and explained where all the resources (readings, recordings and language exchange exercises and templates) could be found in the course site. The third section was entitled 'Google 
Hangouts' and included instructions on how to participate and set up the linguistic exchanges on Google Hangouts. The fourth section was entitled 'Resources for language exchange' and included downloadable files called 'Week 1', 'Week 2', 'Week 3', 'Week 4', and 'Week 5'. Each file corresponded to one of the weeks in the course and contained open ended questions regarding that week's content. It served to stimulate conversation and reflection on that week's material. The files also had exercises to do in groups which reinforced the concepts learnt from that week. For example, one of the content subjects for week 2 was 'Linking values to behaviour'. One of the Linguistic exchanges resource templates available for that exchange was called 'sayings from around the world'. The document has a list of sayings and participants had to decided where the sayings came from, what messages were being communicated and therefore what value this message supported and how that could be transferred to behaviours. The fifth section was called 'Assignments' and explained more in depth the assignments for the course, what was expected and how they could be delivered. It also explained the peer grading section and the use of rubrics for grading. The peer grading section was deleted after the first assignment because it was not used.

1.e - How the course works - general information

This section was broken down into a further 3 sections: 'Instructions', 'Google Hangouts' and 'What do I do today?' The 'Instructions' section explained how the course is structured and what is expected of the students and when. One paragraph was entitled 'Steps to follow'. These instructions were repeated throughout the Course Content Area so that students could identify them easily. The 'Google Hangouts' section explained how to carry out linguistic exchanges using this tool and where they could find supporting material for those exchanges to encourage communicative interaction. 'What do I do today?' was a table that showed students exactly what they should be doing for that specific week.

Section 2 
The following section included the content for each week, the course content, materials, readings and recordings. The entire course in Spanish and English can be found as Annex 3 - Course.

2.a - Week 1. Reading and recording for week 1

2.b - English Folder

2.c - Spanish folder

2.d - Pre-course questionnaire

2.e - Week 2. Reading and recording for week 2

2.f - English Folder

2.g - Spanish folder

2.h - Tarea/assessment week 2

2.i - Week 3. Reading and recording for week 3

2.j - English Folder

2.k - Spanish folder

2.I - Tarea/assessment week 3

2.m - Week 4. Reading and recording for week 4

2.n - English Folder

2.o - Spanish folder

2.p - Group assessment

2.q - Week 5. Reading and recording for week 5

2.r - English Folder

2.s - Spanish folder

2.t - Voting group assessment/post-course questionnaire

Section 3

The next content area was the section entitled 'Tools'. 
3.a - My grades

In this section students could view any grades that they were given.

3.b - Weekly Planner

This section is similar to the 'Home Page' with a focus on the calendar announcing any events or coming up or tasks to do as well as deadlines and when assignments are due.

3.c - Journal

In this section students were able to create their own individual journal. Journals are functionally identical to blogs but differ only in that blogs are also offered as a group project. Students can also leave comments but it is more a tool for reflection rather than discussion. 


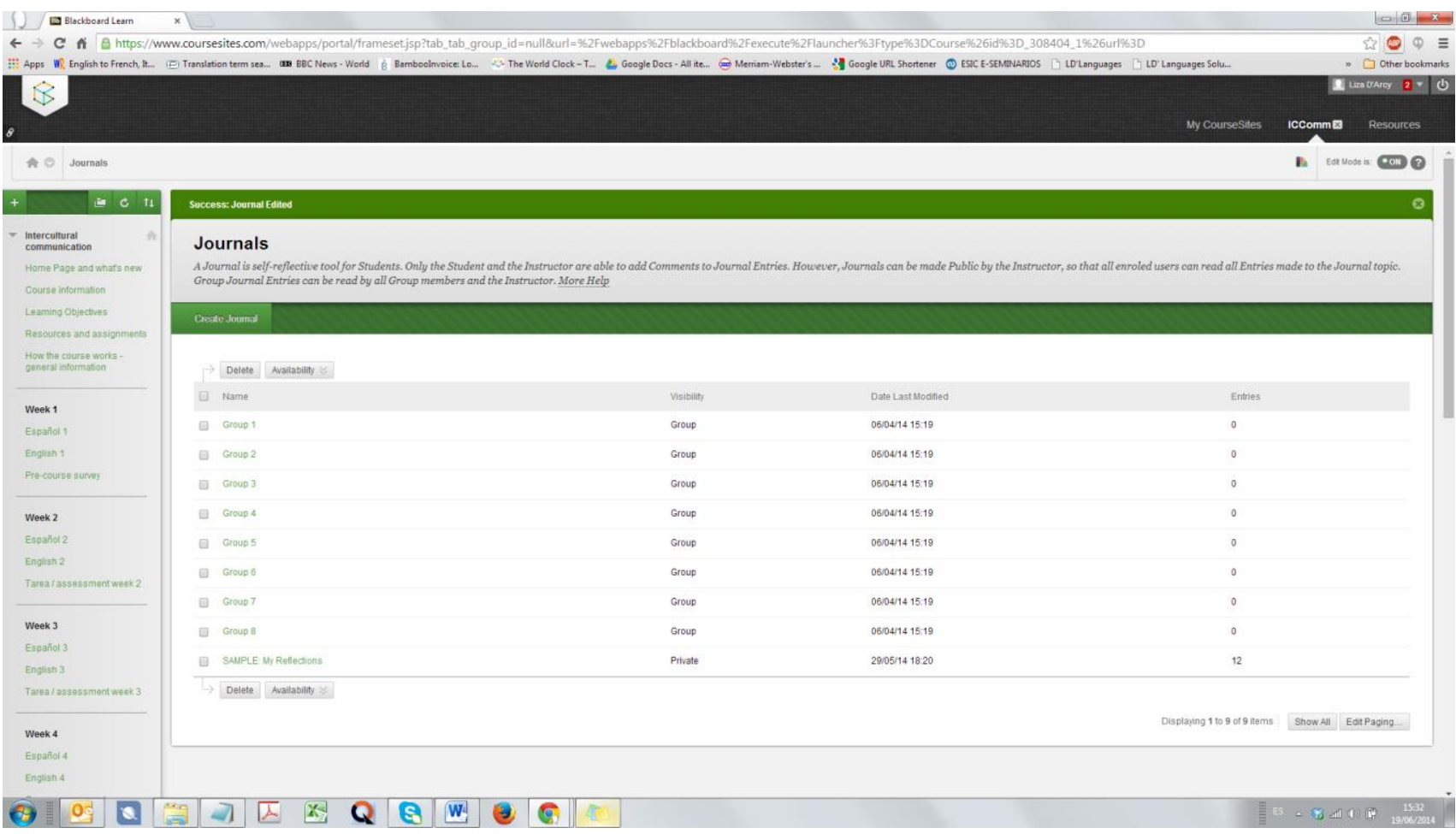

Figure 6: Journals

\section{3.d - Certificate of participation}

Achievements may be used to motivate students. There were several options to give recognition to students which are automatically generated depending on different triggers based on one or more rules created by the instructor. These can be based on how much the student participates, grades or even attempts at assignments. Achievements can also include badges which are beginning to take on recognition outside of the Blackboard course site. The idea is similar to those used by other platforms or video games as they exist to encourage users to achieve objectives (they can also be published on social networks to foster competitiveness). In this course the instructor offered a 'Certificate of Participation'. This section explained to the students what they needed to do in order to receive their certificate of participation. The instructor was able to configure the triggers that would automatically generate a certificate of participation if the student completed them. They were: Complete the Pre- and post-course questionnaires and deliver the 
week 2 and 3 individual assignment. The instructor also included that participation in the linguistic exchanges and group assignment was highly valued but as they could not be quantified in the course site they could not be configured as parameters. This is because the linguistic exchanges were done outside the Blackboard course site and the group assignment was not handed in via the Blackboard course site - it was posted on the 'General' forum.

\section{Section 4}

The following content area was entitled 'Communication tools'.

\section{4.a - Groups}

This section includes the groups. A total of 46 students enrolled (23 native Spanish speakers and 23 native English speakers) and were put into 5 groups of 6 (3 native English speakers and 3 native Spanish speakers) and 2 groups of 8 (4 native English speakers and 4 native Spanish speakers). This section outlined the groups; students could see what groups they were in and who their fellow group members were. From here they could email members of their group. The section description read:

In this group you will

- Discuss the course material

- Carry out language exchanges

- Ask any questions you have about the course content

- Create a group artefact

4.b - Ideas share and blogs

This section allowed students to create and maintain an individual blog. The instructor created a Group blog for each group to collaborate in so when students opened up this 
section they found the 8 different Group blogs (one for each group and a general blog) and at the bottom of the list an option to create an individual blog. When students made entries to the blog, other students from the group and the instructor were notified of this entry on their home page and were invited to comment on it. Blogs on Blackboard cannot be personalised much as far as design goes but it certainly serves its purpose and is extremely user-friendly. The individual blog is editable by only the individual student and the group and general blogs can be edited by anybody enrolled in the course. Students' participation in blogs can be graded or evaluated by the instructor or peers. Students are notified of new entries to blogs on their Home page.

\section{4.b - Forum / discussion area}

This area existed specifically for students to have informal chats within their group, organise times for the linguistic exchange, comment on course material, ask questions or raise doubts and collaborate on group or even individual assignments. Unfortunately the structure was a bit outdated and took a while to open up. A social network 'wall' structure may have facilitated communication. This tool was not used much. The instructor created 7 different discussion boards for the 7 different groups and a general discussion board where all students, regardless of group, could interact. When the forum is created it gives you various options which includes options to grade the students on their contributions, for students to edit their own or other students' posts, on how the threads are viewed and who can start threads and discussions. For this course there were no restrictions added except editing other students' posts which was not allowed.

\section{4.d - Voice tools (including Instant Messaging).}

Unlike the other tools, this tool was not available as a default and needed to be downloaded onto the user's computer or device. It is a new feature in Blackboard Learn 9.1 called 'Live Classroom' and is used by the instructor to interact with students in a live, online classroom featuring text chat, two-way audio, videoconferencing, interactive whiteboard, application and desktop screen-sharing and breakout rooms. As this course 
was focusing on autonomy and instructor support was kept to a minimum this tool was not used. However the Instant Messaging (IM) part of it was used with some students to provide support when their peers could not provide specific answers. This IM tool also includes the option to make a voice call between participants who are signed in. This option was never used by the instructor as the need did not arise.

\section{4.e - Language exchanges}

This section had several different content folders: 'How to carry out language exchanges', 'Google Hangouts', 'Week 1 Resources for language exchanges', 'Week 2 Resources for language exchanges', 'Week 3 Resources for language exchanges', 'Week 4 Resources for language exchanges', 'Week 5 Resources for language exchanges', 'General Resources for language exchanges'. This content section outlined the linguistic exchange objectives and instructions and provided templates and activities that could be done during the linguistic exchange sessions (see Annex 3 - Course).

\section{Section 5}

Another content area that was visible to students was the 'Other tools' area,

\section{5.a - Tools}

This section explained all the tools students had available to them and provided quick links to access them directly. This section was provided by Blackboard and was not modifiable. It was only available in English 


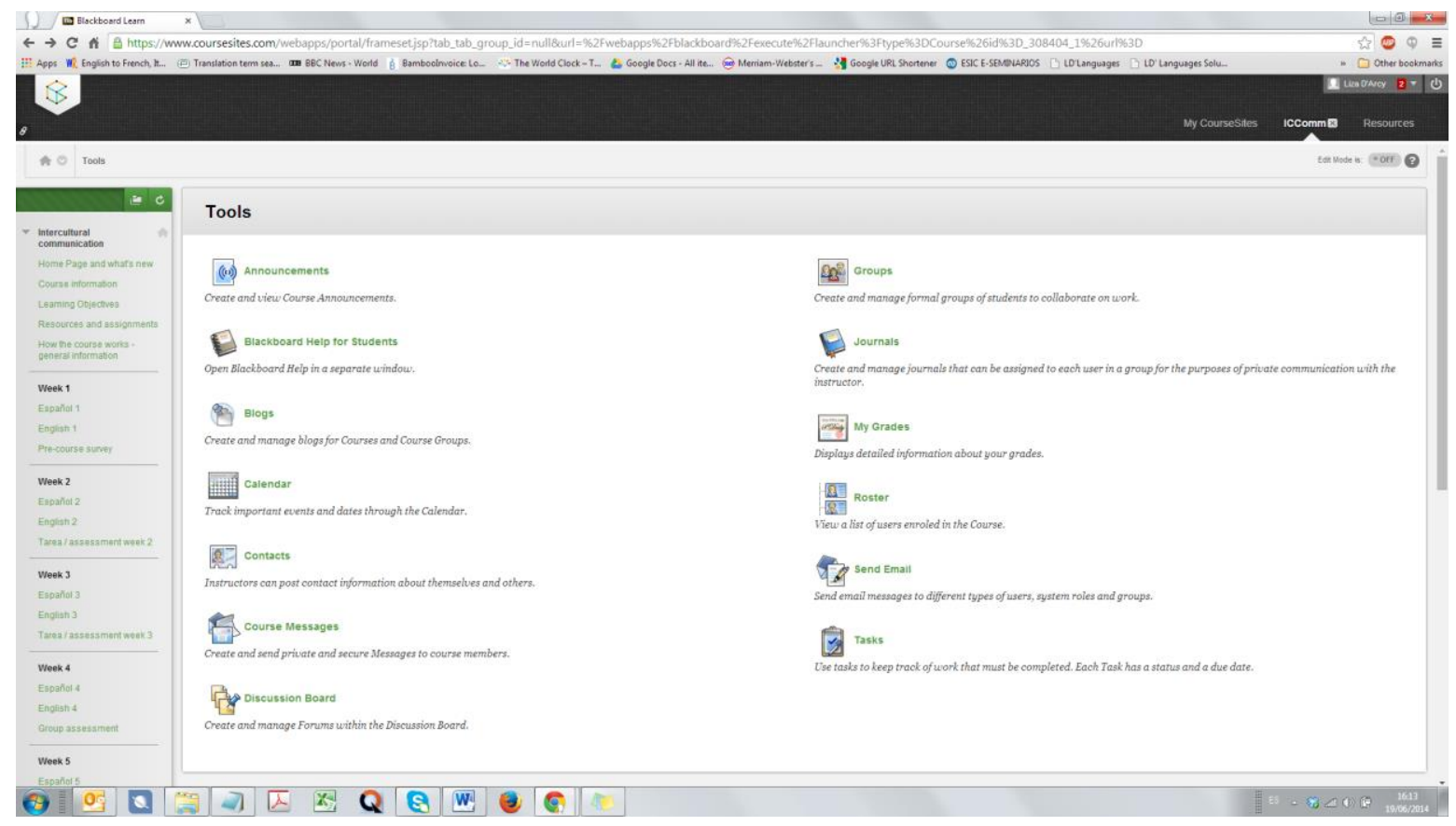

Figure 7: Tools

5.b - Help

Clicking on the 'Help' section opened another window in the student's browser to the Blackboard help webpage. This page included tutorials and FAQs and is very thorough, covering most doubts and questions, both technical and related to the course tools themselves. 


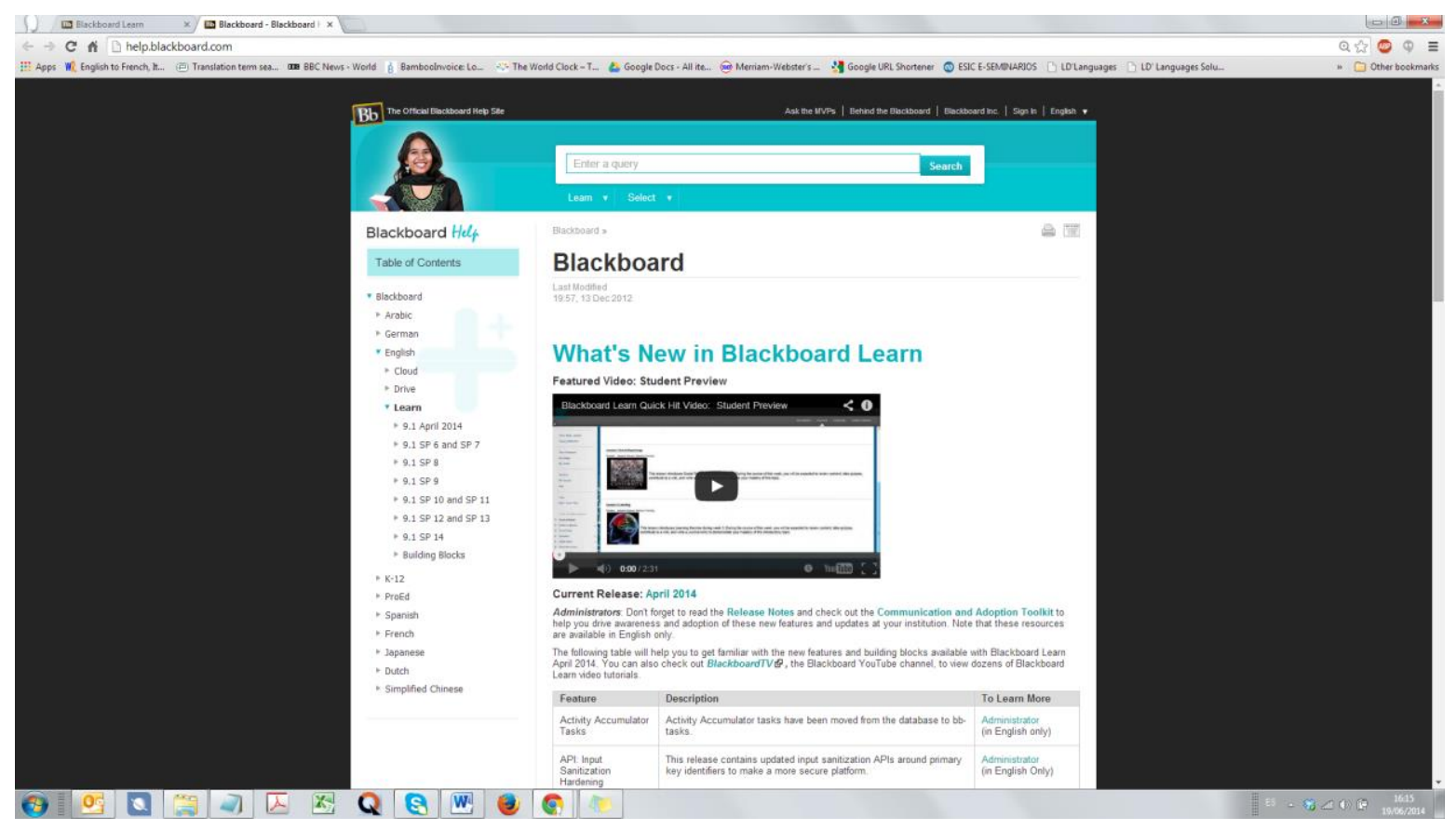

Figure 8: Help

5.c - Contact

The 'Contact' section referred to how students were able to contact the instructor and what time frame they should expect a reply in. 


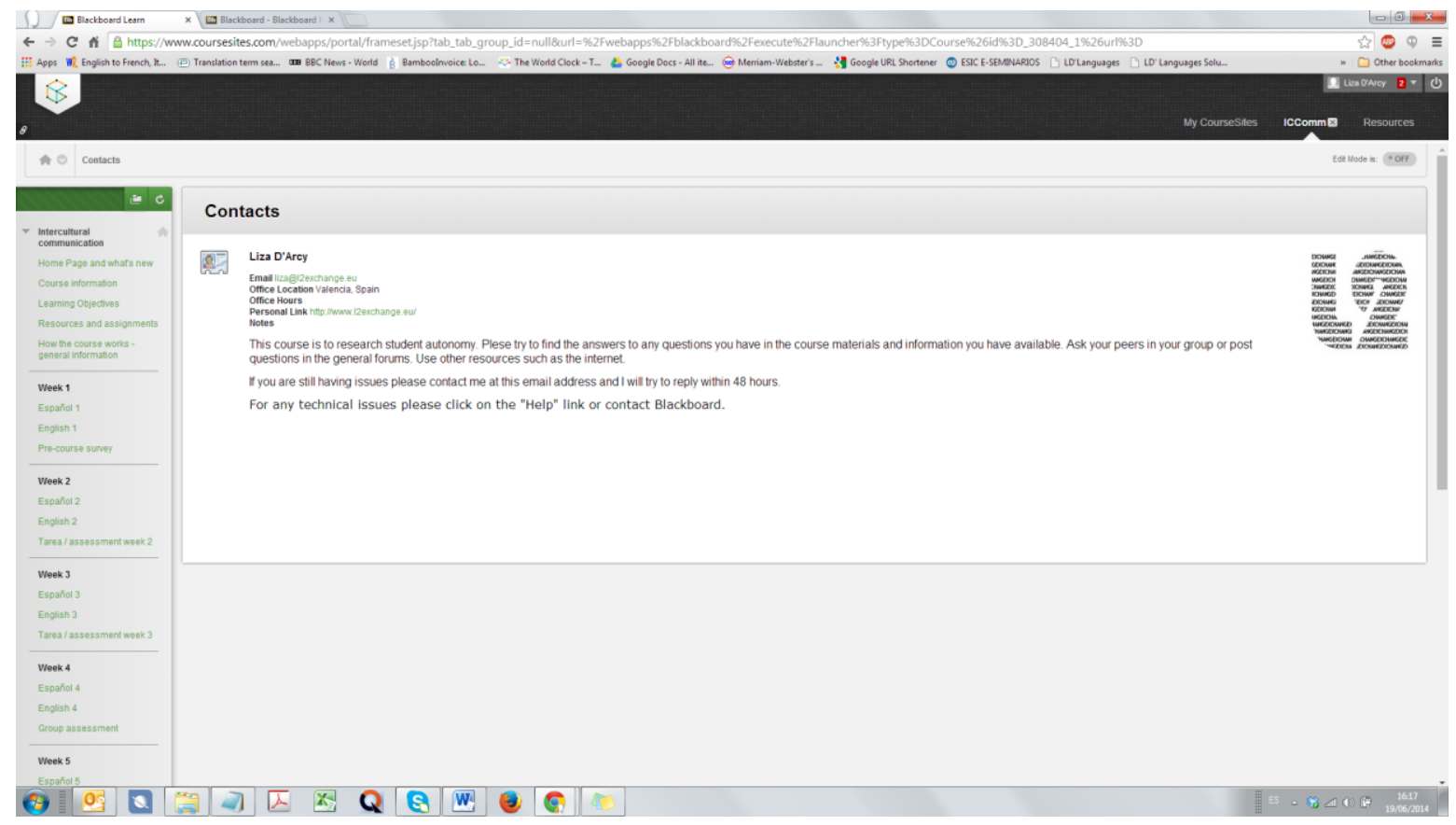

Figure 9: Contact

The above tools were those available to the students for the Intercultural Communication course and were edited using a WYSIWYG editor for Blackboard. It is fairly complete as far as basic editing tools are concerned; the instructor was able to use standard formatting tools (bold, italic, underline, strikethrough, paragraph types, fonts, font sizes, colours, lists, and paragraph alignments). There was also an option to attach external files, images and videos which could then be edited on the platform itself. The course tools are managed similarly to the content tools. They are basic to the course, some of them were made invisible so that they students did not have to worry about them but they cannot be eliminated. They can also be made available or not to students depending on dates, times, groups and previously reviewed content, and can also be organised into folders.

\section{Section 6}

The final content area used in the course was entitled 'Managing users and groups'. 
This was another section that was available to the instructor for creating groups and managing them within the course. This area was not visible to students. Once users were enrolled they were put into groups by the instructor. Students then have access to the tools within their groups in addition to individual access. There are three ways to put users into groups: Self registration: Users can register or apply for registration into a group. The instructor had the option to limit the number of students per group. Random registration: The instructor specifies the size of each group then chooses the option for the system to randomly place each student in groups according to that number. Manual registration: The instructor creates the necessary groups and allocates each student correspondingly. This was the option chosen by the instructor of the Intercultural Communication course. There needed to be an even number of Spanish and English native speakers in each course and the other two options could not guarantee an equal distribution of native speakers. 


\subsection{Google Hangouts}

The second main part of the course was the linguistic and cultural exchanges carried out using Google Hangouts. As seen above, the Blackboard platform provides several ways for instructors and students to communicate, but despite their availability, the most significant communication and interaction tool in the course was the linguistic exchange practiced twice per week through Google Hangouts. These linguistic exchanges really set this course apart from any other online language learning or Spanish/English for Special Purposes course because it offered students a natural, real context in which to interact with native speakers of the target language they were learning, sometimes that is not easy to do when students are living in a country where the language they are studying is not widely spoken. It also served for students to motivate one another. Nobody in any of the groups knew each-other, except for Groups 1 and 4, where there were two participants from the same university who had studied together for one semester, so all students were on the same level. Students mentioned being 'nervous', 'scared' and 'apprehensive' about starting a course with people they had never encountered before. Only $22 \%$ of participants had done an online course before and only $50 \%$ of participants felt confident in an online course. Also, the linguistic exchanges were new to all students so this apprehension and equal footing meant that students were able to create a closer bond and meant that students would feel more obliged to continue with the exchanges as they would be letting their peers down if they did not. These linguistic exchanges used support exercises specially developed for the course that supported that week's course core subjects or concepts that had been taught (Hofstede \& Pedersen, 2002) (Utley, 2004) (Tomalin \& Stempleski, 1993). The first exchange was scheduled for $1^{\text {st }}$ May.

Google Hangouts is a videoconferencing program offered by Google where up to 10 people can videoconference simultaneously. The camera focuses on the person speaking and the other people involved in the video conference can be seen in smaller 'boxes' at the bottom of the screen. 


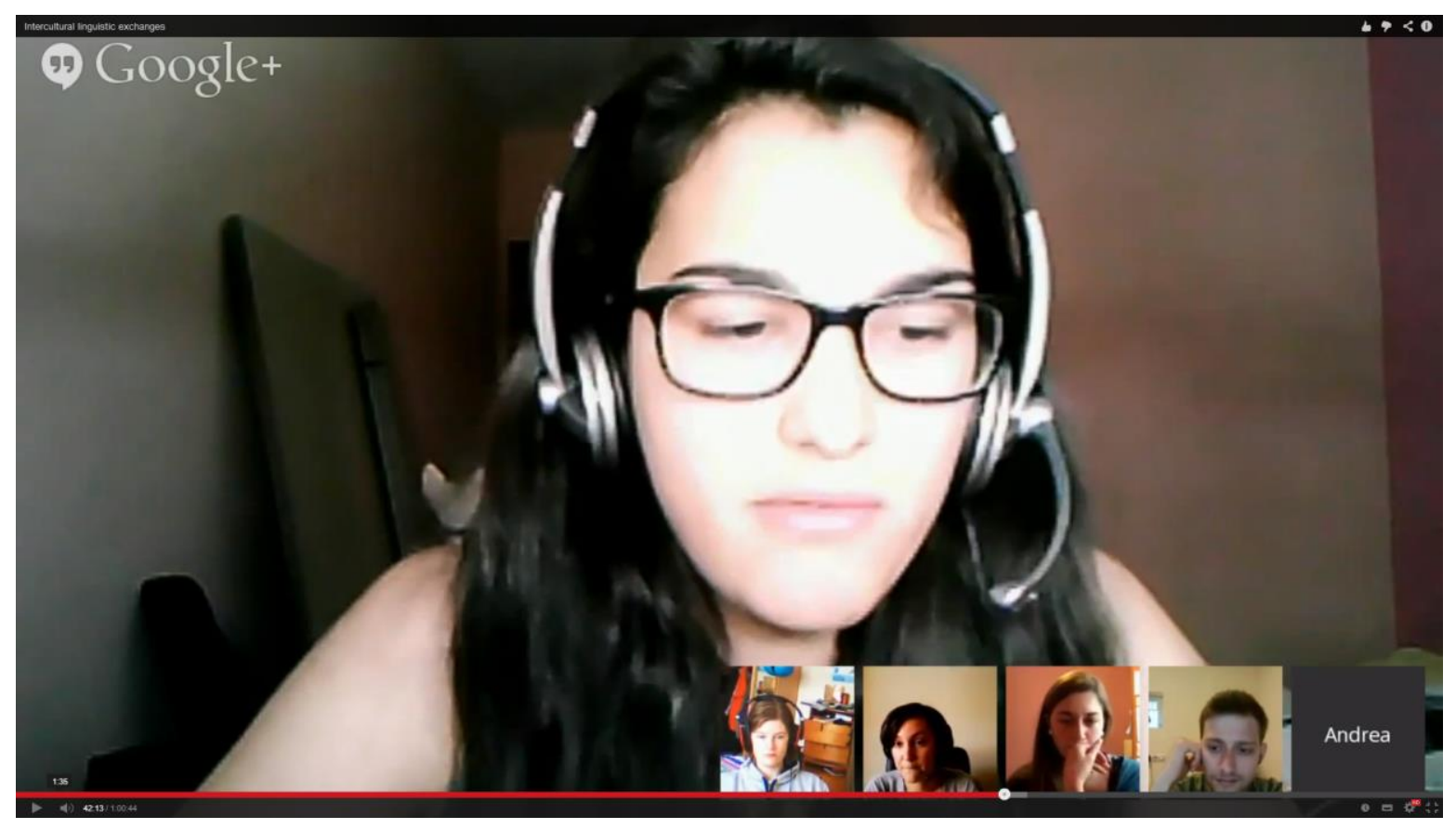

Figure 10: A Google Hangout session

Each person can interact with the group completely naturally as the noise sensor is very sensitive so when someone is talking the 'group' focuses on them. The tool is ideal for a distant, online exchange scenario.

In order to use the tool you must have a Google+ account and be invited to join the Hangout by the owner of the account who created the Hangout. For the purposes of the study the Hangout had to be 'live' which means the Hangout was available to the public however other people who were not invited to the Hangout, that is people from outside the group and the study - and once the session was finished it was posted on the account's YouTube channel. It was necessary to record the session so that it could be transcribed and analysed. Normal Google Hangouts that are not done 'live' are not recorded.

Students were put in groups before the start of the course by the instructor who used a tool that was available for this purpose on the Blackboard platform. Students could then 
see what group they were in by accessing the 'Groups' section in the course site. The instructor set up each Google+ account for each group (Group 1, Group 2, Group 3, Group 4, Group 5, Group 6, Group 7) after seeing that this step had not been done by any members of the group even though it was outlined in the 'To do' tasks on the homepages and in the 'What do I do next?' section and course outline section. The instructor then assigned one person for each group to initiate the Hangout and invite other members of their group to participate. The first Google Hangout was scheduled to start on $1^{\text {st }}$ May. Members from Groups 1, 3, 4, 5 and 7 'arrived' to the Hangout. In Group 3 and 7 there were only 1 and 2 students respectively so they were invited to join other groups in order to balance out the number of students. This meant that for the other exchanges there were 5 participants in Group 1, 4 participants in Group 4 and 4 participants in Group 5, which was the control group and included the instructor. 3 other students tried to access the Hangout but were not able to successfully do so. Several emails were exchanged with these students explaining how to access the Hangout but they were unsuccessful and these students did not participate in any exchange.

Once the exchange had begun (by hitting the 'Broadcast' button) participants used the 'further exercises' templates available in the 'Language Exchange' section to stimulate discussion and practise their target language. These documents had exercises and open ended questions relating to the course content for that week. The first exchange included introductory exercises to get to know each-other and was carried out in English, the second session was conducted in Spanish and so on. Students decided at the end of the session on what day and at which time the next session would be held. Examples of these exchanges can be seen in Annex 4 - Examples of Google exchange hangouts. 


\subsection{How the course unfolded}

Once students were enrolled in the course the instructor could contact them either individually or through the 'announcement' tool. When an announcement was created all students were automatically sent an email containing that announcement which was also posted on each students' 'Home page' under 'Announcements'. The Course Content sections (Home page and What's new, Course information, Learning Objectives and Resources and Assignments) and Tools sections were made accessible one week before the course was launched so that they could become familiar with the course structure, what was expected of them, find out what group they were in and make contact with their group members should they want to. Following that, the content for the first week was released on Sunday $27^{\text {th }}$ April at midnight CEST when students could then access the readings and recordings from that week.

The 'To do' list for that week included: Start blogs, write a journal entry of your reflections, see what linguistic exchange group you are in, create a Google+ account for your group (discuss on the discussion boards who will do this) and carry out your first exchange on Google Hangouts. There were no assignments at this stage. As mentioned before, during this week no participants created a Google+ account for their group to conduct the Google Hangout so the instructor created these groups. The instructor then posted the information on each individual Group's discussion board. The Google+ accounts were: iccommgroup1@gmail.com password: linguisticexchange, iccommgroup2@gmail.com password: linguisticexchange, iccommgroup3@gmail.com password: linguisticexchange, iccommgroup4@gmail.com password: linguisticexchange, iccommgroup5@gmail.com password: linguisticexchange, iccommgroup6@gmail.com password: linguisticexchange, iccommgroup7@gmail.com password: linguisticexchange. In the 'Language exchange', 'How the course works' and 'General Information' section students were instructed that the first exchange would take place on Thursday $1^{\text {st }}$ May at 10 am CEST. This time was chosen because it coincided well with the time zone in New Zealand which is 10 hours ahead of Spain. Any other time would be unpractical for being 
after $8 \mathrm{pm}$ or before 9am, times which many people feel are outside work or school schedules and are more personal times. However as the only students who were eventually active were students residing in European countries, this time was changed to suit their availability. 


\subsection{Tools to foster reflection}

The first step for student reflection is to read the content and listen to the recordings in their target language. This was considered important during the design of the course - to ensure students practised, used and were continuously exposed to their target language. In addition, this content would give them material and ideas to discuss with their peers in the Google Hangouts. For this, Language Templates were made available for them (see Annex 3 - Course) which contained further exercises on the topic they had studied that week for students to further develop their ideas. There were also different tools available to encourage and promote student reflection, in writing, before the Linguistic Exchange sessions which were the fora/discussion boards, blogs and journals. They had the option of posting their reflections individually in journals or more openly through their group's blog which had a different focus, as the nature of blogs invites comments and discussion. Neither the discussion board, fora, blogs nor journals were used much. Almost all the interaction was carried out during the Linguistic sessions in the Google Hangouts, orally, and through social media. Annex 3 - Course contains the above mentioned resources, materials and templates to support the linguistic exchanges on Google Hangouts, they were designed to reinforce the concepts learnt during the week and to encourage conversation between students. They were created based on work by Hofstede \& Pedersen (2002), Tomalin \& Stempleski (1993) and Utley (2004) among other resources. During the week, participants reflected on what they had read and listened to and then had to decide how to proceed forward; what to do with that new information, how and where to direct their learning. They were given the opportunity to further develop this new knowledge with exercises and templates on that subject found in the 'Language exchange' section. Reflection and individual planning was the first step to the Linguistic exchanges. Using these exercises in the Hangouts was not only useful to stimulate conversation between the students, but it was also useful to retain new knowledge that they had studied for that week and prior to the exchanges. The demonstrated importance of using and talking about newly learned knowledge for retention was an motivating 
factor to how the course was structured as even simple retrieval of that knowledge can ensure retention.

Individual and group assignments (sections 2.h 2.I and 2.p). During the course there were two optional tasks to create an assignment. The instructions for these assignments could be found at the end of each week under the 'Assignment' heading:

"Create a product (writing/reflection/multimedia file/music/video anything!) regarding one of this or last week's subjects and upload or post it on your blog (preferably) and/or anywhere on the Internet.

Attach the file or submit the blog/web address here before (due date) and other students will be assigned to review as you will be assigned to review other students' assignments by Monday 11th May."

Initially the course included a section were each participant was to review the assignments handed in by their peers. Unfortunately the peer review option was then eliminated as it did not seem as though many students were going to hand in their assignments. However during the course planning stage this was a very real option as it would further involve group work and peer interaction and is very closely tied to peer motivation and autonomous learning. The option of creating an assignment was offered to keep participants active and so they could further develop their new knowledge on the subject and students were encouraged (through the course instruction sections) to interact with their peers in asking questions and discussing the material. The group assignment was directly related to fostering interaction. During the $4^{\text {th }}$ and $5^{\text {th }}$ weeks students worked in their groups to prepare a product of any sort (multimedia file, PowerPoint presentation, video etc.). The purpose of this task was to have participants negotiating ideas and preferences and thus not only practising their target language and motivating each-other to participate, as it had to include all members of the group, but also allowed for further creation of communication channels, as was seen by one group who decided to create a Facebook page so they could communicate with each other outside the times that had been arranged for their Linguistic Exchanges. This Group assignment involved reflecting on the course content and then deciding together which subject would be represented. 


\section{RESEARCH METHODOLOGY}

The first and second parts of the second Chapter to the methodology section depict the theoretical framework. The third part outlines what methods were used to gather data from the course. That data-set includes the statistics generated from the Blackboard platform the course was delivered on; the results from the pre- and post- course questionnaires given to each participant and the Google Hangouts exchange sessions. The fourth part of Chapter 7 outlines how this collected data was analysed and what methodology was followed for this analysis and the final part is a summary of the statistical analysis run and qualitative research that was done into the experiment. 


\subsection{Theoretical Framework}

A theoretical framework will now be presented in order to better explain how peersupport, relevance and autonomy affect students' motivation to continue studying a foreign language in an online environment.

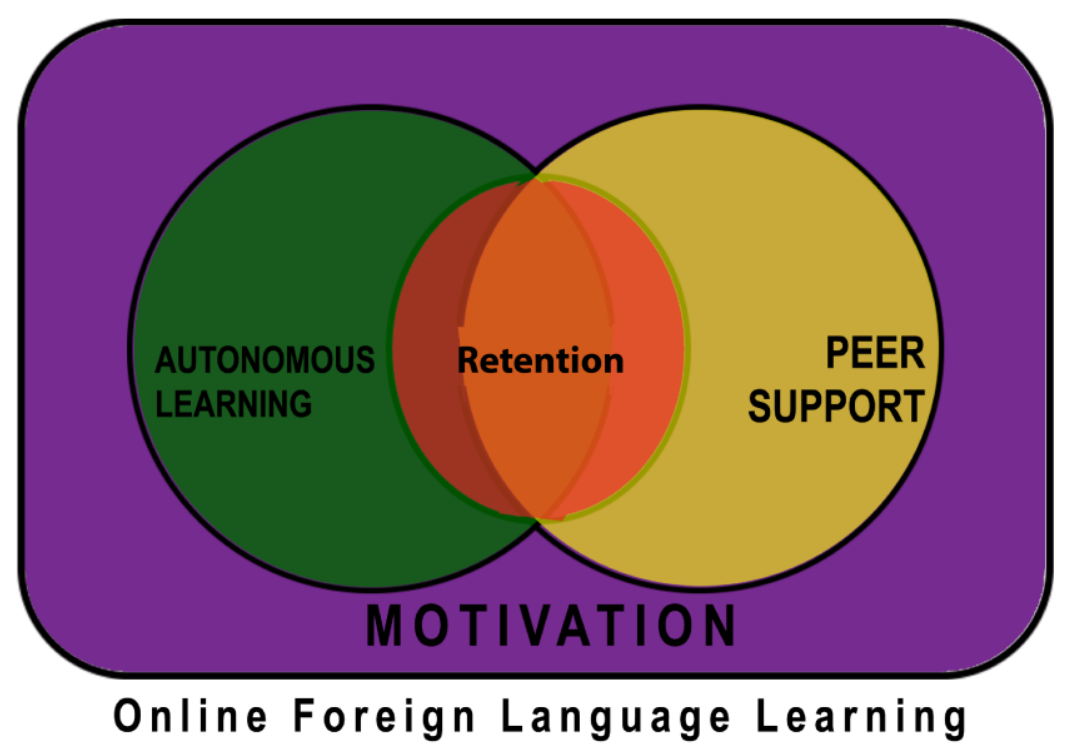

Figure 11: Theoretical framework for online foreign language learning

The first figure shown above depicts the interaction of the different factors needed in an online foreign language learning environment and the interplay of the different areas that must be accounted for so that learning takes place as a result of continuing in the chosen course of study, namely peer-support, autonomous learning and the student's awareness of the relevance of what they are leaning. Motivation occurs through the exchange between the participants, autonomous learning skills and awareness of relevance of the subject.

Figures 12, 13 and 14 show the different areas that must exist in Foreign Language Learning environments. 


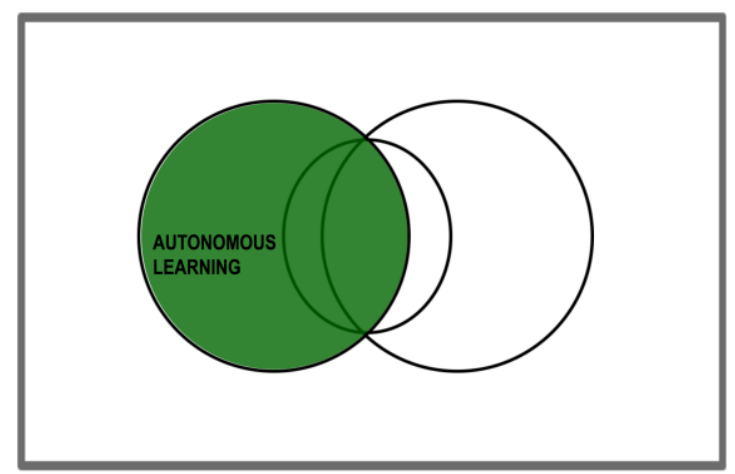

Figure 12: The student's autonomous working skills in the online Foreign Language Learning environment

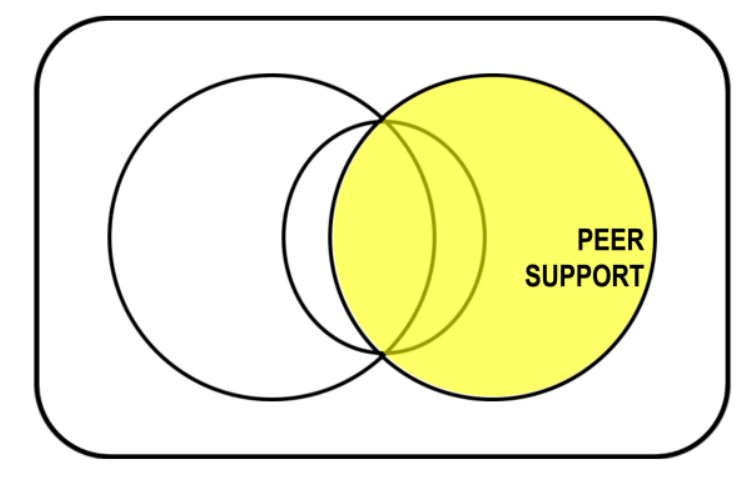

Figure 13: Other learners (peer-support) in the online Foreign Language Learning environment

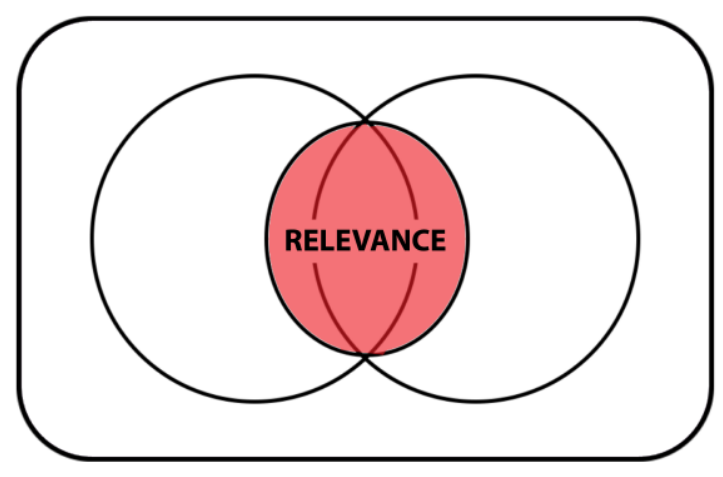

Figure 14: The importance of relevance in the online Foreign Language Learning environment 
Students are motivated when they are aware of the relevance of what students are studying; if this relevance is continuously present it can ensure there is no abandonment of the course being studied.

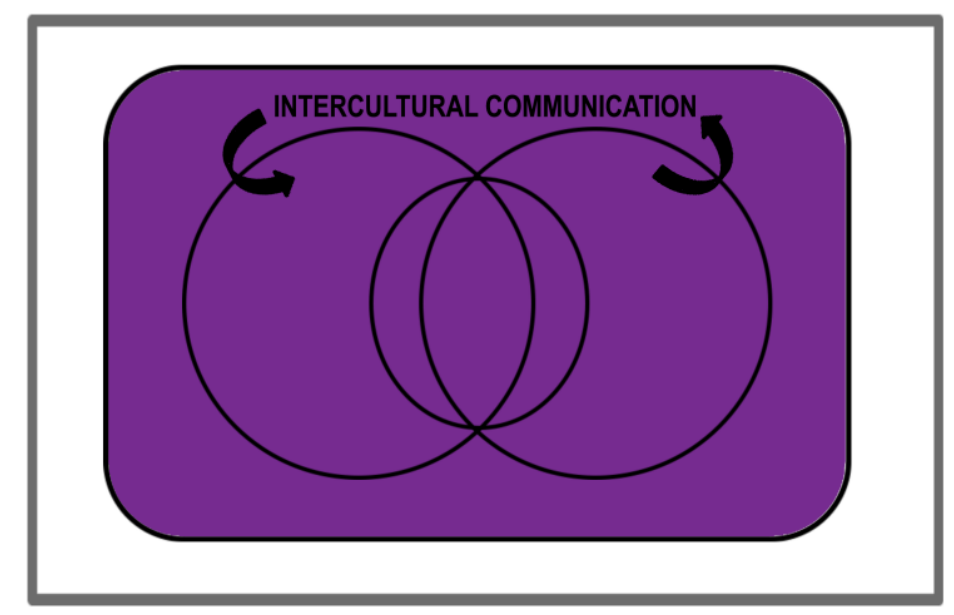

Figure 15: Students' understanding of intercultural communication as being relevant to learning foreign languages

This thesis explores the factor that links the above areas to the language-learner's motivation during an online foreign language learning course, as depicted by the purple shaded area in the middle $(\theta)$. It is hypothesised that when these three areas interact, learning takes place as students do not abandon their course of studies, as shown in graph 16 below. 


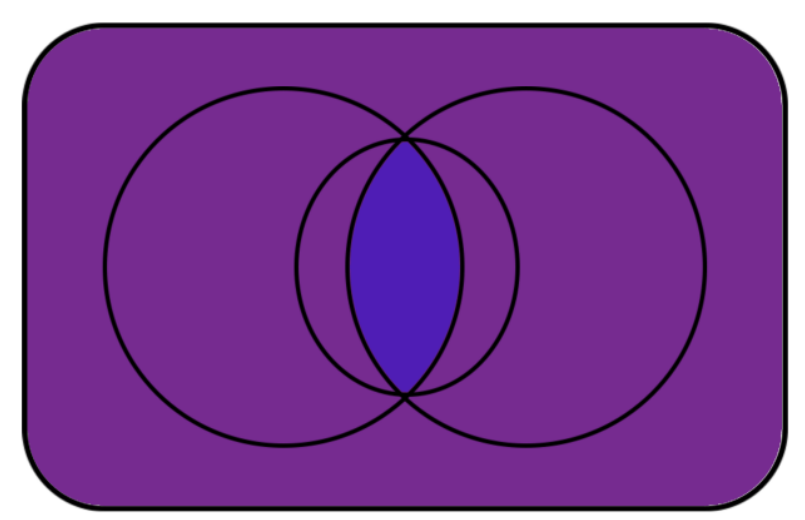

Figure 16: Motivation and thus non-abandonment, retention and continuity in course because of the interaction and presence of these three areas 


\subsection{About the Research Methodology}

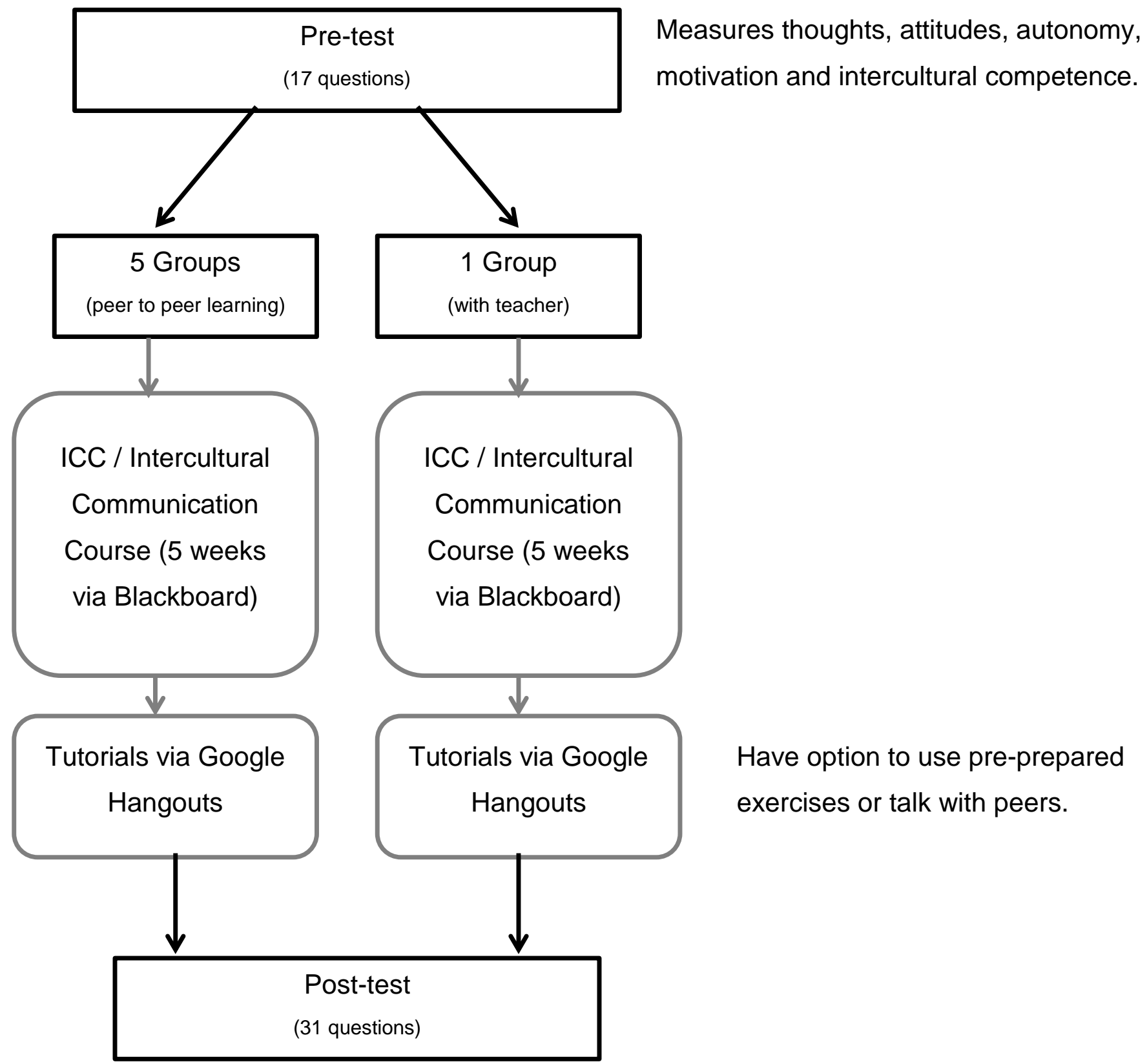

Figure 17: Flow chart of the research methodology 

The study's research methodology consists of pre- and post- questionnaires for participants to answer. The pre-test had 17 total questions measuring thoughts, attitudes, autonomy, and motivation. The post-test had a total of 31 questions with an open question for comments. In between this, participants were grouped into six different mini classes or study groups. Among the six, a total of five were put into peer-to-peer learning situations while the control group had a teacher with them. All groups took part in the Intercultural Communication Course (ICC) for 5 weeks supported by Google Hangout sessions. 


\subsection{Data collection}

The research adopted a case study approach in the form of one course which consists of two distinct parts and two questionnaires. The first part was the delivery of the online Intercultural Communication course which had a duration of five weeks from $28^{\text {th }}$ April 2014 until $1^{\text {st }}$ June 2014. Its aim and purpose was to teach students about the different communication processes between cultures and acquire knowledge that can help them increase their cultural competence so as to better communicate in the foreign language they were learning.

The second part was similar to tutorials in that the voluntary participants were divided into groups who would meet twice a week on Google Hangouts. These tutorials, linguistic exchanges or session as they also referred to throughout the thesis, had been planned for two important reasons. The first reason was that they served to discuss the concepts learnt during the course and so that students could practise their target language with other students who were native speakers of that language. During these tutorials students had the option of using pre-prepared exercises that reinforced issues learnt during the week, or they could simply talk about the subject using pre-prepared questions that focused on those subjects. At the beginning of the week students were able to access that week's materials in the form of readings and recordings. Participants were required to read the texts, complete the exercises included in those texts and listen to the recordings. They then arranged two sessions to interact with the members of their group in the Google Hangouts platform.

These Google Hangout sessions were recorded and transcribed: the second reason was for gathering data for future analysis. The data to be analysed from the sessions was gathered through the systematic recording of these discussions during the exchange session using electronic recordings - the Google Hangouts sessions that were recorded 'live' and automatically posted on a YouTube video channel could be downloaded in digital format. Google Hangouts which are not 'live' are not recorded by Google cannot be downloaded and they are lost after the session finishes. The videos that had been 
recorded were downloaded into mp4 format and could be watched as many times as necessary for the data analysis and transcribed. In addition, the Blackboard platform used to deliver the course automatically gathered statistics and recorded students' movements within the course which would also be used as part of the dataset for the future data analysis.

The pre- and post-questionnaires were prepared to collect further information for the data analysis process and for assessing the participants' profiles in regard to their thoughts and attitudes of online learning, autonomy, motivation and intercultural competence. The sources used for the design of questionnaires were Dörnyei, Z. (2007), Flick (2009) and Sudman, Bradburn and Schwarz (2010). The questions were presented in the questionnaire using the Likert format (1 - Strongly agree, 2 - Agree, 3 - Neither agree nor disagree, 4 - Disagree, 5 - Strongly disagree and 6 - Not applicable). The questionnaires can be found as Annex 5 - Pre- and post-course questionnaires. The final question in the post-questionnaire was an open question where students could leave any comments they thought were appropriate to the course. These questionnaires were uploaded on to the Blackboard platform in the course itself and placed in the course content area. Students were then asked to complete the questionnaires as part of the course itself and was a requirement for the course completion and certificate of participation. The questionnaires were then registered on the Blackboard statistics which could be accessed and analysed by the course creator. Again, the results of the questionnaire were automatically uploaded to the Blackboard statistics area in percentage form. The results were anonymous.

When defining the questionnaires about learner motivation, autonomy in online or distance studying and intercultural competence the considerations mentioned in chapters 2-5 and those extracted from the literature review were taken as a reference and used to shape the questions. The questionnaires were created to cover the basic areas of participants' thoughts on intercultural communication, motivation, autonomous learning for online/distance learning and how their peers will affect their learning and in turn to what extent they thought they could affect their peers' autonomous learning. The precourse questionnaire was launched one week before the course begun, on $21^{\text {st }}$ April, 
and closed 1 week after the course began, $5^{\text {th }}$ May, as the questions would no longer apply because the students would have already been acclimatised to the online course environment and they would have already been in contact with their peers. The results of the pre-course questionnaire would allow the instructor to analyse the student profiles and also assess the differences in attitudes towards online learning after the course had been completed. The pre-course questionnaire consisted of 17 questions. After the course was completed the students were asked to conduct a post-course questionnaire, which contained the section where students would vote for their favourite group assignment to be done towards the end of the course. The post-course questionnaire consisted of 31 questions (including the voting question) and aimed at measuring students' experiences throughout the course, their motivation sources, their thoughts and beliefs on the course and how much they felt they learnt and achieved within the course as well as serving as a comparative tool to the pre-course questionnaire.

Thus the data was gathered mainly through the statistics generated from the course platform itself, the results from the pre- and post-course questionnaire and the Google Hangouts exchange sessions, in addition to the collection of suitable reference material that was structured by the theoretical research and literature review. 


\subsection{Data analysis methodology}

This qualitative research study sought to paint a picture of the motivational aspects of online language learning, and because of this the author believed that it was necessary and more descriptive to refer to the need for authenticity. This resulted in the data analysis process being constructed in such a way that it ensured the data extracted from participant interaction and questionnaires expressed their true thoughts and motivational perspectives. Qualitative data analysis is understood to be the process by which the information gathered by the researcher is organised and treated to establish relationships, interpret, and draw conclusions and meanings (Dörnyei, 2007). It is therefore characterised by its circular nature, as opposed to the linear position assumed by quantitative data analysis as pointed out by Hennink, Hutter \& Bailey (2010). The methodology proposed for this research was a randomised controlled trial. However due to the fact that the groups needed to be reorganised because native speakers needed to be distributed evenly, the empirical research became an quasi-experimental research project as the random assignment for the process no longer existed. Quasi experimental research is similar to experimental research as the course was created based on situations existing in the real world, the online course used a platform whose design and structure was pre-existing. As Seliger and Shohamy claim (1989), quasiexperimental research is conducted under conditions that are very difficult to control as well as research conditions where the participants cannot be reorganised into groups that are especially designed for them. According to Seliger and Shohamy (1989), quasiexperimental research is more likely to have external validity because it is conducted under very similar situations as those found in educational contexts,

The first part to this study and to the analysis of the collected data was to make inferences while establishing the categories for the research findings by identifying patterns across the data collected (the language exchange session, the pre- and postquestionnaires and the theoretical foundations). The analytic inductive method this study followed detected the frequently occurring concepts and motivational aspects of participant continuity based on the data. After collecting the data, the author processed 
them and categories began to emerge as well as relevant aspects that overlapped, resulting in a categorisation framework which also considered theories and results from other research studies and multiple texts (the literature review) (Miles \& Huberman, 1994). There was a large amount of information and many hours of transcripts to analyse, and in addition, during the early stages of the study everything seemed significant to the general research area - as the specific thesis questions had not yet been established - which is the reason the conceptual framework and the thesis questions were so important: they shaped the limits of what information was to be analysed and what information would be left out.

However, this was done simultaneous to forming those questions. As the data were analysed and processed the three areas began to emerge from the emphasis placed by the participants on them. The data collection procedure was a selective process (Miles \& Huberman, 1994), thus this study used an inductive approach to install a base of experiences or processes that emerged from the raw data. However, although the transcripts from the linguistic exchanges provided a descriptive account of the study, they did not provide explanations, thus "[...] all relevant and theoretically salient micro and macro contextual influences that stand in a systematic relationship to the behavior or events one is attempting to explain" (Watson-Gegeo, 1992:54) had to be taken into account in order to be interpreted. Much of the literature on interpretive research (Bogdan \& Biklen 1997; Dörnyei, 2007; Erickson, 2004; Goetz and LeCompte, 1984; Miles and Huberman, 1994) provides different descriptions of the general sequence of qualitative data analysis, but the process given by Miles and Huberman (1994), structured around four key areas: data collection, processing, categorising and treatment of data and finally, obtaining results and drawing conclusions was followed in this doctoral dissertation.

The next part was to process the data. An important stage during this step is to create categories; this categorisation stage was studied from the perspective of content analysis (Sánchez-Algarra \& Anguerra 2003; Silverman, 2010), Silverman suggests creating categories for the data and then separating the data of those categories into 
corresponding units of analysis (autonomous behaviour, peer support and relevance). These categories often have to be interpreted from the data but in the case of this study the categories emerged without much effort as the three areas of motivation were often commented on by the participants and also the author had already tentatively thought about these areas from the literature review carried out as they were reasons that had figured repeatedly as traditional language learning motivational issues. There are different approaches to creating categories (categorisation). As mentioned, the one chosen for this study was the inductive process which consists of creating categories from reading and reviewing the compiled data without having already created them. Some authors call this task 'open coding' (Strauss \& Corbin, 1990); it is a process that stems from determining concepts and identifying patterns from the data. The author chose the open coding process because, although the general area of the study had already been determined, the specific research questions were not clear before the data collection took place. A second approach is called deductive, where, unlike the previous process, categories are established before the research study takes place, it is the researcher's role to adapt data to an existing category. There is also a mixed approach to qualitative data analysis called 'mixed' because the analysis also uses quantitative data. This study also included quantitative data; this data was not statistical as no statistics were relevant but it did use percentages attained from the pre and-post questionnaires filled out by the participants. Thus the data pool was an integration of data collected from the language exchange sessions, the pre- and post-questionnaires in addition to the theoretical foundations of the research carried out.

There are many different inductive methods to coding qualitative data. In this case the interpretive qualitative research combined observations, interpretation, and perspectives based on theory in addition to the dataset mentioned above and the method of analysis chosen was a thematic content analysis which is one of the most commonly used (Ritchie, Spencer \& O'Connor, 2004). It emerges from grounded theory (Glaser \& Strauss, 1967) that provides a way to represent reality; it is a method that draws meaning from what is being studied. This method was chosen because it creates theoretical categories from the data collected and analyses relationships between them 
(Corbin \& Strauss, 2014) when there is not yet an established hypothesis in place. Such that by using analytical procedures, the specific motivational issues to be studied were construed from the data that were gathered. So the first time the data were analysed, those observations were summarised into conceptual categories and further analysed until a theory evolved (in regard to the circular nature of the study) (Glaser \& Strauss 1967; Huberman \& Miles 1994). The relevance of grounded theory for this study is that it makes the procedures and qualitative analysis explicit while guiding the development of useful conceptualisations of data. It grounds the qualitative analysis by ensuring that it is not only dependant on implicit methods and simply the researcher's intuition and talent (Corbin \& Strauss, 2014). In the case of this thesis, the study started with a general view of the area the author wished to study, not with a specific hypothesis. So the characteristics or attributes of what was being studied emerged through an analysis of the data and was not assumed or imposed. Thus grounded theory emphasises discovery and development of theory and is not based on deductive reasoning that completely relies on a previous theoretical framework (Glaser \& Strauss, 1967).

Several interesting aspects emerged from using this method for this study in particular: data collection and analysis occurred almost simultaneously; the data determined the research processes and products, not the predetermined framework idea of motivation; discovery and development emerged from the analytical processes carried out, the data did not serve as a theoretical verification for already known theories; and also the systematic use of analytical procedures led to more abstract levels of analysis, eventually refining the thesis questions (Charmaz, 2005). The coding process serves to fragment the transcripts of the exchange sessions into the separate established categories. This coding process helped in the analysis of the data as the information was determined and identified according to those categories. Once the categories and the research questions were fully elaborated, they were related to each other in order to develop an integrated explanation and comprehensive objective.

The first task after the data are collected, transcribed and categorised is to make sense of it (Bogdan \& Bilken, 1997). The challenge is to simplify it as part of a broader category 
and understand what all the complexity contained in the transcripts meant or refer to (Patton, 2005). It is therefore necessary to use a coding process that creates a manageable classification or coding system (Patton, 2005). Ryan and Bernard (2000) believe this is one of the most important parts of qualitative data analysis: "Coding is the heart and soul of text analysis" (Ryan \& Bernard, 2000:775). The author analysed the exchange content from the established categories, determining what was significant, and from there identified patterns in these qualitative data and turned those patterns into meaning (Patton, 2005). The basic tasks required to conduct coding are separated from the analysis model or the epistemological tradition in which the research is based. In this sense, Ryan and Bernard (2000) point out two essential tasks associated with coding. The first is sampling: after reading the linguistic exchange transcripts several times in order to categorise the data, the analysis units were then selected from those texts by highlighting relevant quotes and examples. The second one is identification of examples and evidence: these issues were abstract constructs that the author identified during the data collection and categorisation process that were then consolidated and turned into comprehensible units upon coding. The literature review also served as a source of inspiration to support this coding process, as did the author's professional experience in the study area and the gaps identified in other studies that were reviewed.

There are different ways to decide upon which analysis units are relevant for each category, but the one common theme for that process is that after completion of the categorisation creation, the researcher identifies the data that serve as evidence for those categories and codifies them so that those categories can be applied to the entire transcription or text corpus. In this regard, Miles and Huberman (1994) point out that the coding process actually supports the data analysis process, as in order to put the units into the established categories the texts must be analysed closely, while ensuring that the relationships between the units stay together. Finally, relationships between the codified units are constructed into concept models.

The next step was to identify how these elements relate to each other within the theoretical model of each category. These models are a group of abstract constructs which are supported by the relationships between them. The encoding process was 
carried out without using software, so as to encourage the cognitive and analysis processes involved at each stage. Software programs for analysing qualitative data such as Atlas.ti and NVivo offer different tools and formats to conduct the coding process, but the principles of analytical processing are the same, starting from the creation of categories from patterns and repetitions, through to the coding process. Patton states that "Qualitative analysis transforms data into findings. No formula exists for that transformation. Guidance, yes. But no recipe. Direction can and will be offered, but the final destination remains unique for each inquirer, known only when-and if-arrived at" (Patton, 2015:521). As mentioned the data was analysed during the categorisation and coding processes, but a further, more detailed analysis was still needed. A detailed analysis of the analysis units that had been coded in the previous step would identify and provide evidence to support the category concepts and thesis questions established.

The tasks involved in this stage were to analyse all the available research material for evidence to concepts that shaped the motivational thesis questions. This was done through theorising - by using abstract thinking - about the motivational concepts found as a common theme throughout the data and by drawing general assumptions using a research model that stemmed from a qualitative paradigm (Cohen \& Manion, 1994) and focusing on the descriptive aspects participants made of these concepts. The evidence that emerged from the participants' discussions during the linguistics exchanges affirmed the thesis questions but the raw material in itself did not serve as evidence or proof of either the affirmation or negation of the thesis questions, the data needed to be put into analysis units, coded and interpreted in order to be understood within the context of the study. For this reason it was important to make clear how the analysis units and interpretation of the data fit together within the structure provided by the research questions.

The analysis bridged the data that had been collected with the theoretical framework outlined by the literature review and the research questions. Interpretive commentary brought together the data being analysed and the conclusions that were drawn from it. The author provided commentary on what the data revealed as support to the affirmation 
and evidence proving the thesis questions. On some occasions a longer interpretive commentary would either explain or further interpret a quote or phrase from the participants and often the situation chosen as examples were included within theoretical perspectives which sometimes alluded to a more general meaning of the assertion or pattern. The interpretations of general assertions then lead to a comprehensive discussion of the overall theory produced by the entire process. The results that were found are discussed in the Results and Conclusions Chapter.

The value of truth and credibility in research studies relates to the credibility and trust that the results provide based on their explanatory capacity and the consistency between the different perspectives and examples chosen to represent the evidence. That is, the isomorphism established between the data collected and reality (Erickson, 2004). Another way to value the credibility of the results is to consider their applicability or ability to transfer; this refers to the possibility of transferring the conclusions drawn in this context to other similar conditions. A situation that has the same conditions as the study could be any online foreign language learning course that includes spaces for peer interaction. This is further commented on in the Conclusions Chapter, referring to the ease of the findings transferability. 


\subsection{Statistical analysis report}

An analysis of the course data was required in an attempt to identify any variables of statistical significance in order to gain further insight into the course, the participation of the students and with the ultimate aim of improving any future course design. No significant results were concluded and this section is an outline of the areas looked into and the methodologies applied. 46 students enrolled in the course and of those only $50 \%$ participated in it and only one edition of the course has conducted. Because of this, a comprehensive analysis was not possible because there was not sufficient data to draw statistical results from individuals on the course or make a comparison with another course. A wide variety of options were looked into in order to identify any statistically significant variables; student retention and abandonment, number of times the course material was accessed (especially comparing the control group with others), access to the course itself by content area, times and days of the week and user activity in fora and groups. A comparison between those studying English and those studying Spanish was also of consideration.

Using SPSS the chi-square test of association, also known as Pearson's chi-square test was employed. This is used to test how likely it is that an observed distribution is due to chance as it measures how well the observed distribution of data fits with the distribution if the variables were independent. When the chi-square value is calculated it is combined with the degrees of freedom so that the p-value can then be determined through use of $=$ chidist (chi-squ,df) in Excel. In order for data to be considered significant a $p$-value of less than 0.05 would be required. 


\section{RESULTS}

The results extracted from the language exchange sessions, pre-course questionnaire and post-course questionnaires described in the previous chapter are outlined below with comments. The statistics generated by the Blackboard Learning platform can be viewed in Annex 6 - Results generated by Blackboard. This chapter has been divided into the results extracted in regard to the three thesis questions outlined in the Introduction Chapter. The results structure follows a mixed methodology approach, first examples are given, they are then explained qualitatively and finally the percentages generated from the relevant pre- and post-course questionnaires are also shown. 


\subsection{Results for research question 1 - Linguistic exchange sessions examples}

In Table 1, the results concerning question 1, the motivational influences of autonomous behaviour positively affecting continuity in online language courses and distance language learning, are shown.

\begin{tabular}{|c|c|c|}
\hline E.g. & Date & Examples from language exchange sessions \\
\hline 1 & 15th May 2015 & Nabil attends a session from the hospital \\
\hline 2 & 20th May 2015 & $\begin{array}{l}\text { Anna attends a session at } 6 \mathrm{pm} \text { even though she has } \\
\text { not yet had lunch }\end{array}$ \\
\hline 3 & 1st May 2015 & Lucy: "I got up especially to come see you guys". \\
\hline 4 & 14th and 19th May 2015 & $\begin{array}{l}\text { Anita: "Yeah you know what? I was quite naïve when I } \\
\text { joined the course... I had so much to do, it was exam } \\
\text { period, corrections, a million things that I had to do, } \\
\text { and that's the truth that I haven't done much... [I now] } \\
\text { read the content but I haven't done much and I wish } \\
\text { that I could do more." } \\
\text { Anita: [in next session] "....yo lo he leído todo y he } \\
\text { tomado notas." [she continues by explaining the } \\
\text { concepts of that week's course content to her peer] }\end{array}$ \\
\hline 5 & 17th May 2014 & $\begin{array}{l}\text { Eve: "I guess it would depend on the position, like, I } \\
\text { think possibly it's also the relative age of the employer } \\
\text { and the employee. Someone might feel uncomfortable } \\
\text { employing someone much younger or employing } \\
\text { someone much older than themselves." } \\
\text { Chris: "Hm, exactly, yeah I think. At the same time I } \\
\text { think it's a bit odd sometimes. I mean, for example in } \\
\text { one of my courses that I did in France at the university. } \\
\text { Um there was a senior, well there was a mature } \\
\text { student there. He was older than the teacher herself, } \\
\text { and it was really odd, the teacher still spoke to her as if } \\
\text { she was a teenager... The whole dynamic just felt } \\
\text { really, really odd to me. That even though the woman }\end{array}$ \\
\hline
\end{tabular}




\begin{tabular}{|c|c|c|}
\hline & & $\begin{array}{l}\text { was older there was still this implicit 'I'm the teacher, } \\
\text { I'm the boss' kind of thing. Not looking at her as a } \\
\text { person, but more like, an ordinary student. Even } \\
\text { though his older woman wasn't going to be, you know, } \\
\text { shouting and disrupting the class." } \\
\text { Eva: "Yeah. I found it quite odd when I was in Spain } \\
\text { and I taught English to, ah, three adults in their place of } \\
\text { work. I found that quite strange for the first few weeks } \\
\text { because they were about twice my age and I think, } \\
\text { being the one, cause we were only speaking in } \\
\text { English, and their level of English was probably } \\
\text { around, between A2 and B2, so um, for me that was } \\
\text { odd because being the person speaking your native } \\
\text { language, kind of puts you as the role of, in a more } \\
\text { authoritative role, and having that with three adults with } \\
\text { who are like, very well experienced engineers or aged } \\
\text { around } 40 \text { I found that very odd for the first few weeks. } \\
\text { I got used to it, but yeah, that was quite strange." } \\
\text { Chris: "Are there many, Ignacio at your uni, are there } \\
\text { many students that are older for example in your } \\
\text { class?" } \\
\text { Ignacio: "Yes, in my class yes, I don't know about any } \\
\text { other career [degree] but in my career [degree] there } \\
\text { are, I don't know, three out of ten are older than me for } \\
\text { example." }\end{array}$ \\
\hline 6 & 20th May 2014 & $\begin{array}{l}\text { Anita: "...their relationship with time is different to our } \\
\text { relationship with time in Europe, they take their time to } \\
\text { have a conversation, and they prolong conversations in } \\
\text { time..." } \\
\text { Anna: "There is a difference between Germany and } \\
\text { Austria as well, for example I wanted to order a hot } \\
\text { dog, a Viennese hotdog, and I said it in my fast } \\
\text { German, and they said 'ah, no, just slow down, take it } \\
\text { easy, say it again, more slowly, what do you want?' } \\
\text { (laughs). So they are more of a slower culture as well } \\
\text { but not in a bad way, because I think slow has a very } \\
\text { negative connotation these days but it doesn't have to. } \\
\text { I think in general life is much too fast paced these } \\
\text { days, because everyone is running around and want to } \\
\text { get everything done in one day." Anita agrees and } \\
\text { continues: "I've had to change and go native in many } \\
\text { ways and I'm so grateful I've done it. Because first of } \\
\text { all... it has helped me to reduce frustration a lot. Going } \\
\text { down" }\end{array}$ \\
\hline 7 & 28th May 2014 & Anna: "But everybody helped each-other out there, \\
\hline
\end{tabular}




\begin{tabular}{|c|c|c|}
\hline & & $\begin{array}{l}\text { cause people who had read it said, uuu this is the topic } \\
\text { and then regardless of whether they had time to read } \\
\text { the things everyone had their own ideas on the topic." }\end{array}$ \\
\hline 8 & 19th May 2015 & $\begin{array}{l}\text { Ana: “Yo creía que eran dos tareas en grupo". } \\
\text { Rebecca: “...group assessment, la fecha de entrega } \\
\text { es el martes } 27 \text { mayo y para la revisión el jueves } 29 ” . \\
\text { Ana: “¿Entonces solo hay un trabajo en grupo?” } \\
\text { Rebecca: "En grupo sí, hay solamente uno”. }\end{array}$ \\
\hline 9 & 28th May 2014 & $\begin{array}{l}\text { Anita: “... I was looking for a Master's degree. I was } \\
\text { thinking about doing a Master's degree online. But I } \\
\text { checked, and I didn't feel as though I wanted to do that } \\
\text { because I'm a quite social person and I didn't, I thought } \\
\text { well, what if I pay that money and I get unmotivated. } \\
\text { I'm not sure about it. And I'm looking for a Master's and } \\
\text { I would like to do one and I don't know where. But the } \\
\text { online option, I didn't see it so clear. Because I } \\
\text { remember studying at the University [in Spain, where } \\
\text { there are no tutorials], well in my year in England, was } \\
\text { absolutely good for me... for me, I worked harder, I } \\
\text { worked even twice the hours I worked in Spain } \\
\text { [because of the tutorial group], because I had to meet } \\
\text { the guys [in the tutorial group], talk to them, be in a } \\
\text { small group, interact and give my opinions." }\end{array}$ \\
\hline 10 & & $\begin{array}{l}\text { Anita: "It's like an unwritten compromise [commitment, } \\
\text { obligation or promise, from compromiso in Spanish], } \\
\text { let's say. The hangouts make that difference. It's the } \\
\text { idea of a seminar, when you're at university, that apart } \\
\text { from the lectures and all that, seminars, I remember for } \\
\text { me being Spanish, we didn't have that, I went to } \\
\text { England and we had that part, and I felt really, really, } \\
\text { good, I felt so motivated. In the case of online course I } \\
\text { didn't know that before... and ah, it's the same kind of } \\
\text { idea of just giving the exercises as if it was a book, but } \\
\text { through the screen and I didn't feel motivated [she was } \\
\text { referring to the fact that she thinks that most online } \\
\text { courses are very similar to traditional courses as they } \\
\text { simply transfer the course content, material and } \\
\text { exercises onto a screen] but in this one [the ICC } \\
\text { course] I felt, yeah it's like a seminar online, you're } \\
\text { going to be talking about it [the course content] you're } \\
\text { going to be interacting with your classmates". }\end{array}$ \\
\hline
\end{tabular}


The results are shown in different columns. The first column numerates the examples, the second presents the date the linguistic exchange session the example was extracted from took place and the third column has the example that is then discussed below the Table.

\section{Table 2: Results and Examples from the Language Sessions Relevant to Research Question 1}

As can be seen in Table 2, in examples 1, 2 and 3 students are fully taking advantage of the opportunities to practise their target language with native speakers of their target language. Their participation in exchange sessions even though they were held at times that were not practical for them, shows responsible learning behaviours that only they are able to negotiate. Lucy attends the exchange session despite the fact that the time her group agrees to meet is not very practical for her because she lives in a different time-zone than the other members of her group.

Example 4 showed that Anita makes an effort to catch up on work after showing disappointment of her own falling behind. She has now fully engaged with the material and is actively taking advantage of the course to both learn and discuss the concepts with her peers.

Examples 5, 6 and 7 showed autonomous learning behaviours - a set of attitudes and beliefs that lead to engagement and persistence in their academic tasks - by working on the course content. These skills area also manifested in the language exchange session when groups discuss the week's content and work on the optional course exercises for that week. In this example, group 1 is discussing the optional course exercises set for the exchange sessions by integrating their own personal experiences and stories on that week's content and concept, further consolidating their new knowledge about it. Here Chris, Eva and Ignacio discuss that week's course exercises: cultural concepts and attitudes towards age in different cultures. The example used was age in the work environment. The specific subject was whether age was a deciding factor when 
employing people. In example 6, Anna is referring to trying to not worry so much about time and that she has noticed that the results of this has been a reduction in her stress levels, she now accepts 'slow living' in Costa Rica. These examples show the students relating the course content and exchange exercises to cultural issues, and also to their own personal experiences and opinions about the issue. The fact that they were exploring the course content concepts and ideas showed that they were perfectly able to 'stay on track' and work without the guidance of a teacher or tutor and still develop the ideas within the course framework at their own pace. Example 7 also exemplifies this concept of students giving their own ideas and inputs regarding the contents and participating fully with the work they had autonomously done.

In example 8 of Table 2 Ana expressed doubts about the details of the group assignment, Rebecca navigated onto the course site and immediately found the information she needed, clarifying the issue. This fluid moving about the course site shows her confidence in the course structure and shows her independence working within it.

In example 9, as has been explored in different areas of this thesis, autonomous learning cannot be done in isolation. For students to explore their new found knowledge in both concepts about ICC and language skills they needed peer interaction to talk about these ideas, which they could also hear about and experience in real life, as their peers were natives of these new cultural concepts. In this example Anita explains this concept of needing peer interaction to foster and support autonomous learning and that the problem with traditional online courses is not that she would have to work autonomously, the problem is that she wouldn't have the peer interaction she finds necessary to motivate her to do so.

In example 10, Anita continued with the idea raised in example 9, at a different point in the exchange session, underlying that the exchange sessions - and working independently to be able to work together with her peers - were an important part of the course and one of the most motivating factors about the course. 


\subsection{Results for research question 1 - Pre-course questionnaire}

In Table 2, the results of the pre-course questionnaire questions relevant to thesis question 1 are shown. The questions are presented in the first column and the percentages generated are presented in the second, following a Likert-type scaling method.

\begin{tabular}{|c|c|}
\hline Pre-course questionnaire questions & Likert scale. Results in percentages \\
\hline \multirow{7}{*}{$\begin{array}{l}1 . \text { I feel confident learning and } \\
\text { navigating in an online course }\end{array}$} & Strongly Agree $\quad 16.667 \%$ \\
\hline & $33.333 \%$ \\
\hline & $\begin{array}{l}\text { Neither Agree nor } 27.778 \% \\
\text { Disagree }\end{array}$ \\
\hline & Disagree \\
\hline & Strongly Disagree $0.00 \%$ \\
\hline & Not Applicable \\
\hline & Unanswered \\
\hline \multirow{7}{*}{$\begin{array}{l}\text { 2. I feel as though I am motivated } \\
\text { enough to complete the course with no } \\
\text { teacher support }\end{array}$} & Strongly Agree \\
\hline & $27.778 \%$ \\
\hline & $\begin{array}{l}\text { Neither Agree nor33.333\% } \\
\text { Disagree }\end{array}$ \\
\hline & Disagree \\
\hline & Strongly Disagree $0.00 \%$ \\
\hline & Not Applicable \\
\hline & Unanswered \\
\hline \multirow{6}{*}{$\begin{array}{l}\text { 4. If I am given the opportunity, I can } \\
\text { learn on my own and make important } \\
\text { academic decisions }\end{array}$} & Strongly Agree \\
\hline & $44.444 \%$ \\
\hline & $\begin{array}{l}\text { Neither Agree nor } 11.111 \% \\
\text { Disagree }\end{array}$ \\
\hline & Disagree \\
\hline & Strongly Disagree $0.00 \%$ \\
\hline & Not Applicable $\quad 0.00 \%$ \\
\hline
\end{tabular}




\begin{tabular}{|l|lr|}
\hline & Unanswered & $11.111 \%$ \\
\hline $\begin{array}{l}\text { 6. I often find ways to practice my target } \\
\text { language outside of academic contexts }\end{array}$ & Strongly Agree & $27.778 \%$ \\
& Agree & $50.00 \%$ \\
& Neither Agree & nor $0.00 \%$ \\
& Disagree & \\
& Disagree & $11.111 \%$ \\
& Strongly Disagree & $0.00 \%$ \\
14. I think I will complete the course & Not Applicable & $0.00 \%$ \\
& Unanswered & $11.111 \%$ \\
& Strongly Agree & $22.222 \%$ \\
Agree & $55.556 \%$ \\
& Neither Agree nor5.556\% \\
& Disagree & \\
& Disagree & $0.00 \%$ \\
& Strongly Disagree & $0.00 \%$ \\
& Not Applicable & $0.00 \%$ \\
& Unanswered & $16.667 \%$ \\
\hline
\end{tabular}

Table 3: Results of the Pre-course Questionnaire for Questions which are Relevant to Research Question 1

In question 2, the results found were relevant because they show that although $69.23 \%$ of people who started the course saw it through to its completion, only $44.45 \%$ initially thought they would. Question 4, however shows that question 2 cannot be interpreted to understand that most students didn't think they could work autonomously.

Continuing with students' autonomous attitude towards learning, the results of question 6 are relevant because they support the fact that the students were autonomous language learners before the course began and thus one reason for their continuity in the course. As the students did not have an instructor coordinating their activities and they did not have any obligations to carry out the course work and assignments, it seemed relatively 
easy for students to either abandon the course or simply use it for interaction with native speakers.

The results in question 14 suggested clearly that students were independent learners. $77.78 \%$ thought believed they would complete the course, and in fact approximately this amount did, $69.23 \%$. 


\subsection{Results for research question 1 - Post-course questionnaire}

In Table 4, the results of the post-course questionnaire questions relevant to question 1 are shown. The questions are presented in the first column and the percentages generated are presented in the second, following a Likert-type scaling method.

\begin{tabular}{|c|c|c|}
\hline \multirow{4}{*}{$\begin{array}{l}\text { Post-course questionnaire questions } \\
\text { 1. I feel more confident learning and } \\
\text { navigating in an online course than I } \\
\text { did before I started this course }\end{array}$} & \multicolumn{2}{|c|}{ Likert scale. Results in percentages } \\
\hline & Strongly Agree & $45.455 \%$ \\
\hline & Agree & $54.545 \%$ \\
\hline & Neither Agree nor Disagree & $0.00 \%$ \\
\hline & Disagree & $0.00 \%$ \\
\hline & Strongly Disagree & $0.00 \%$ \\
\hline & Not Applicable & $0.00 \%$ \\
\hline & Unanswered & $0.00 \%$ \\
\hline \multirow[t]{6}{*}{$\begin{array}{l}\text { 2. I was motivated enough to complete } \\
\text { the course with no teacher support. The } \\
\text { reasons I was motivated were: }\end{array}$} & \multirow{3}{*}{\multicolumn{2}{|c|}{$\begin{array}{l}\text { I was not sufficiently motivated } 0.00 \% \\
\text { to complete the course with no } \\
\text { teacher support } \\
\text { I wanted to learn about the } 72.727 \% \\
\text { course context } \\
\text { I wanted to practise my target } 72.727 \% \\
\text { language }\end{array}$}} \\
\hline & & \\
\hline & & \\
\hline & \multirow{2}{*}{\multicolumn{2}{|c|}{$\begin{array}{l}\text { The course was fun } 72.727 \% \\
\text { I enjoyed being completely } 18.182 \% \\
\text { I knewn the success of my peers } 63.636 \% \\
\text { depended on my participation }\end{array}$}} \\
\hline & & \\
\hline & Other & $9.091 \%$ \\
\hline \multirow[t]{2}{*}{$\begin{array}{l}\text { 4. I was able to learn on my own and } \\
\text { make important academic decisions. } \\
\text { The reason for this was because: }\end{array}$} & \multicolumn{2}{|c|}{$\begin{array}{l}\text { I was not able to learn on my } 0.00 \% \\
\text { own } \\
\text { and make important academic } \\
\text { decisions }\end{array}$} \\
\hline & I was not under pressure & $18.182 \%$ \\
\hline
\end{tabular}




\begin{tabular}{|c|c|c|}
\hline & \multicolumn{2}{|c|}{$\begin{array}{l}\text { I wanted to learn about } 72.727 \% \\
\text { intercultural communication } \\
\text { I wanted to practice my target } 18.182 \% \\
\text { language }\end{array}$} \\
\hline & I enjoyed the course & $90.909 \%$ \\
\hline & Other & $9.091 \%$ \\
\hline \multirow{7}{*}{$\begin{array}{l}\text { 8. I think I will now find ways to practise } \\
\text { my target language outside of academic } \\
\text { contexts }\end{array}$} & Strongly Agree & $54.545 \%$ \\
\hline & Agree & $27.273 \%$ \\
\hline & Neither Agree nor Disagree & $9.091 \%$ \\
\hline & Disagree & $0.00 \%$ \\
\hline & Strongly Disagree & $9.091 \%$ \\
\hline & Not Applicable & $0.00 \%$ \\
\hline & Unanswered & $0.00 \%$ \\
\hline \multirow{7}{*}{$\begin{array}{l}\text { 10. I have learnt autonomous learning } \\
\text { skills and will use them for furthering my } \\
\text { target language learning }\end{array}$} & Strongly Agree & $45.455 \%$ \\
\hline & Agree & $45.455 \%$ \\
\hline & Neither Agree nor Disagree & $9.091 \%$ \\
\hline & Disagree & $0.00 \%$ \\
\hline & Strongly Disagree & $0.00 \%$ \\
\hline & Not Applicable & $0.00 \%$ \\
\hline & Unanswered & $0.00 \%$ \\
\hline \multirow{7}{*}{$\begin{array}{l}\text { 15. I feel more confident about learning } \\
\text { online after taking this course }\end{array}$} & Strongly Agree & $27.273 \%$ \\
\hline & Agree & $63.636 \%$ \\
\hline & Neither Agree nor Disagree & $0.00 \%$ \\
\hline & Disagree & $9.091 \%$ \\
\hline & Strongly Disagree & $0.00 \%$ \\
\hline & Not Applicable & $0.00 \%$ \\
\hline & Unanswered & $0.00 \%$ \\
\hline
\end{tabular}




\begin{tabular}{|l|ll|}
\hline $\begin{array}{l}\text { 19. My personal learning motivated me } \\
\text { to participate }\end{array}$ & Strongly Agree & $36.364 \%$ \\
& Agree & $63.636 \%$ \\
& Neither Agree nor Disagree & $0.00 \%$ \\
& Disagree & $0.00 \%$ \\
& Strongly Disagree & $0.00 \%$ \\
& Not Applicable & $0.00 \%$ \\
& Unanswered & $0.00 \%$ \\
\hline
\end{tabular}

Table 4: Results of the Post-course Questionnaire for Questions which are Relevant to Research Question 1

In question 1, the results of the post-course questionnaire show that the students' autonomous learning skills developed quite a bit during the course.

In question 4, none of the participants thought they were not able to learn on their own and make important academic decisions, once again this highlights the fact that students worked very well autonomously. It was obvious that participants' autonomous learning skills were one of the primary reasons students could continue with the learning process; if students didn't have these skills they would not have done any of the coursework or participated in the exchanges and this in turn would have meant they did not engage either in the course or with their group peers.

In questions 8 and $10,54.54 \%$ strongly agreed and $27.27 \%$ of students who completed the course agreed that they would now actively find ways to practise their target language outside of their traditional classrooms after having studied on the ICC course. Question 10 was also significant in this regard as again; almost all students believed they had "learnt autonomous learning skills and will use them for furthering my target language learning" (only 9.1\% neither agreed nor disagreed, no student disagreed). This shows a development of autonomous learning skills which students found a direct benefit from. This could be interpreted as being exceptionally motivating. 
Question 19 was a very significant question in the post-course questionnaire. A full $100.00 \%$ agreed that their personal learning motivated them to participate. This can be understood from two different perspectives. Firstly, that the learning of ICC was relevant to the students and encouraged them to stay in the course and continue participating in the exchanges. Secondly that this work had to be done on their own so their autonomous learning responsibilities motivated them to continue in the course. 


\subsection{Results for research question 2 - Linguistic exchange sessions examples}

In Table 5, the results extracted from question 2, i.e. the importance of course relevance perceived by students as a motivational influence in online language courses and distance language learning are shown.

The results are shown in different columns. The first column numerates the examples, the second presents the date the Google Hangouts linguistic exchange session the example was extracted from took place and the third column has the example that is then discussed below the Table.

\begin{tabular}{|l|l|l|}
\hline E.g. & Date & Examples from language exchange sessions \\
\hline 1 & 8th May 2015 & $\begin{array}{l}\text { Eve: "Pero, yo no quiero olvidar el español porque } \\
\text { hace 4 meses que estoy aquí [France] que no hablo } \\
\text { español porque no he tenido curso de español ni } \\
\text { nada". }\end{array}$ \\
\hline 2 & 8th May 2015 & $\begin{array}{l}\text { Chris was studying Spanish as a foreign language but } \\
\text { mentions that his end of year project is regarding the } \\
\text { lack of native teachers in foreign language teaching at } \\
\text { Spanish universities. }\end{array}$ \\
\hline 3 & 1 st May 2015 & $\begin{array}{l}\text { Andrea mentions the importance of learning English } \\
\text { for her future career }\end{array}$ \\
\hline 4 & 14 th May 2014 & $\begin{array}{l}\text { Anita: “..estoy aprendiendo muchísimo, estoy } \\
\text { aprendiendo muchísimo. Y más en esta situación } \\
\text { adonde me encuentro en una cultura totalmente ajena } \\
\text { a lo que yo conocía y demás, entonces estoy teniendo } \\
\text { la oportunidad de aprender mucho más rápido lo que } \\
\text { es esta cultura de modo que la entiendo mucho mejor, } \\
\text { la respeto mucho más..." }\end{array}$ \\
\hline 5 & 20th May 2014 & $\begin{array}{l}\text { Eve: "El tiempo tiene un valor muy grande para } \\
\text { nosotros, que es verdad, y es lineal. Así que tenemos } \\
\text { que hacer una cosa a la vez para hacerlos bien. Pero } \\
\text { yo creo que también se valor hacer muchas cosas a la } \\
\text { vez, también, porque es aún más eficaz. Así que el } \\
\text { objetivo, es igual, para hacer, el objetivo es hacer } \\
\text { muchas cosas y si se pueden hacer a la vez, pues }\end{array}$ \\
\hline
\end{tabular}




\begin{tabular}{|c|c|c|}
\hline & & mejor." \\
\hline 6 & 8th May 2014 & $\begin{array}{l}\text { Eve: “... no he escuchado mucha gente hablando de } \\
\text { la religión. Pero para mí es bastante raro ver la } \\
\text { diferencia entre la religión y la política, no solo en } \\
\text { cuanto al ... situación particular en Francia pero yo no } \\
\text { sé si han escuchado alguna vez el consejo de } \\
\text { ingleses de cuando vas alguna vez a la casa de una } \\
\text { persona que no conoces muy bien... que no es } \\
\text { aconsejable hablar de la religión ni de la política. Pero } \\
\text { aquí la gente habla mucho de la política pero no he } \\
\text { notado ninguna conversación acerca de la religión." }\end{array}$ \\
\hline 7 & 14th May 2014 & $\begin{array}{l}\text { Chris: “¿Eres más individualista?" } \\
\text { Andrea: "Yo sí, yo sí." }\end{array}$ \\
\hline 8 & 14th May 2014 & $\begin{array}{l}\text { Anna: There are countries that tend toward } \\
\text { universalism or particularism, for example Germany. } \\
\text { It's a very law-abiding country. People tend to stick to } \\
\text { the law more than in England. For example here l've } \\
\text { seen that if there are no cars coming [on the road] but } \\
\text { the traffic light is on red most Germans still won't go } \\
\text { [cross the road] even though nothing is coming, } \\
\text { because they've learnt that you need to stop at red." }\end{array}$ \\
\hline 9 & 14th May 2014 & $\begin{array}{l}\text { Anita: "I mentioned before about Costa Rica being a } \\
\text { collectivist society. They have got that sense of } \\
\text { community. And their families and communities are so } \\
\text { important as a result of this that for example in this } \\
\text { case [donating blood] I heard that in general people } \\
\text { feel forced to go to hospitals to give blood, just for one } \\
\text { reason: to protect their family. Because in the case of } \\
\text { a huge important surgery, they can receive blood, } \\
\text { transfuse, is that the word? Only in the case that one } \\
\text { of the family are a regular donor. So in this case you } \\
\text { could think the other way around that they are more } \\
\text { individualist, but no, it's because they want to protect } \\
\text { their people. To them in every way family is really, } \\
\text { really important." }\end{array}$ \\
\hline 10 & 14th May 2014 & $\begin{array}{l}\text { Rebecca: "Here with the crisis, it's affected all of } \\
\text { Spain but it's affected my area, Extremadura, a bit } \\
\text { more maybe and you find a lot of people choosing to } \\
\text { stay at home, living with their parents and living with } \\
\text { their families and you have you know, generations that } \\
\text { are still living under the same roof. And I recently did a } \\
\text { questionnaire, a questionnaire cause I did some } \\
\text { research for a project into how the crisis has affected } \\
\text { the community. And people actually turned round and } \\
\text { said, well we're quite happy living at home, it works } \\
\text { really well, you know, we help each-other, you know }\end{array}$ \\
\hline
\end{tabular}




\begin{tabular}{|c|c|c|}
\hline & & and we're just really happy with our situation..." \\
\hline 11 & 19th May 2014 & $\begin{array}{l}\text { Anita: “...lo que veo excitante de este tema [del } \\
\text { curso] es eso, que te das cuenta tratándole, } \\
\text { hablándolo, viviéndolo, que aun ahora que vivimos en } \\
\text { diferentes países entre nosotras. Pero al final todo } \\
\text { está, sabes, no hay nada tan delimitado. No hay tanto } \\
\text { este país es enteramente así, este país es } \\
\text { enteramente así. } \\
\text { Ana: "No, está claro que es a medida del individuo, } \\
\text { hay unas diferencias que más o menos marca una } \\
\text { cultura, pero van cambiando con respecto al individuo } \\
\text { y al círculo familiar o parental. } \\
\text { Anita: "Por ejemplo, Rebeca viviendo en España, } \\
\text { aunque nosotras como españolas que llevamos tantos } \\
\text { años viviendo en España y hemos podido ver los } \\
\text { cambios, de que varía mucho las respuestas de la } \\
\text { gente dependiendo en su edad, de adonde vive, si es } \\
\text { un entorno rural, si es entorno urbano, si es del capital } \\
\text { si se trata de las islas, pero bueno, hay una tendencia } \\
\text { más o menos generalizada, en muchas cosas, pero a } \\
\text { lo mejor no los vemos igual porque somos españolas" } \\
\text { Rebecca: "Sí, sí. Para mí es muy interesante..." }\end{array}$ \\
\hline 12 & 20th May 2014 & $\begin{array}{l}\text { Anita: "...their relationship with time is different to our } \\
\text { relationship with time in Europe, they take their time to } \\
\text { have a conversation, and they prolong conversations } \\
\text { in time..." } \\
\text { Anna: "There is a difference between Germany and } \\
\text { Austria as well, for example I wanted to order a hot } \\
\text { dog, a Viennese hotdog, and I said it in my fast } \\
\text { German, and they said 'ah, no, just slow down, take it } \\
\text { easy, say it again, more slowly, what do you want?' } \\
\text { (laughs). So they are more of a slower culture as well } \\
\text { but not in a bad way, because I think slow has a very } \\
\text { negative connotation these days but it doesn't have to. } \\
\text { I think in general life is much too fast paced these } \\
\text { days, because everyone is running around and wants } \\
\text { to get everything done in one day." } \\
\text { Anita: "I've had to change and go native in many ways } \\
\text { and l'm so grateful l've done it. Because first of all... it } \\
\text { has helped me to reduce frustration a lot. Going down" }\end{array}$ \\
\hline 13 & 28th May 2014 & $\begin{array}{l}\text { Anna: "...because l've noticed that not being in Spain, } \\
\text { but doing this course and talking to my Spanish friends } \\
\text { has helped..." }\end{array}$ \\
\hline 14 & 19th May 2014 & $\begin{array}{l}\text { Nabil: "Translation has a lot to do with culture. } \\
\text { Sometimes when I'm talking about Arabic, it's my }\end{array}$ \\
\hline
\end{tabular}




\begin{tabular}{|l|l|l|}
\hline & & $\begin{array}{l}\text { language and I know how to play with words. But } \\
\text { when I enter or when I'm working with English and } \\
\text { Spanish I find it a little bit more difficult, it's not my } \\
\text { culture". }\end{array}$ \\
\hline 15 & 19th May 2014 & $\begin{array}{l}\text { Nabil: "I have no problem to talk in either language; I } \\
\text { have a desire to meet people from both cultures." Soy } \\
\text { Árabe y estoy aquí estudiando traducción en inglés y } \\
\text { español." }\end{array}$ \\
\hline
\end{tabular}

Table 5: Results and Examples from the Language Sessions Relevant to Research Question 2

In example 1, Eve clearly states that this course is necessary for her to practice her Spanish, otherwise she feels as though she will struggle to maintain it.

In example 2, Chris finds the course very relevant because his end of year project is comparing the lack of native teachers teaching foreign languages at universities in Spain with the fact that there is a requisite for foreign language teachers at universities in England to be native speakers of the language they teach in addition to the absence of the obligatory year abroad study for language learners in Spain. He thinks that interacting with people in this course will help his research because they are language students studying foreign languages at university.

In example 3, Andrea is motivated to enrol and complete the course for professional and academic reasons. This is one example of many, students were extremely motivated by learning about ICC as they thought this topic could help them improve their foreign language skills and in turn they were motivated to practise those skills - both their foreign language skills and their newly acquired ICC skills - because that practice was relevant to them in this case for their university studies and her future chosen career.

In example 4, Anita is motivated by this course because she now better understands a culture that used to be foreign to her with the new knowledge provided to her by the course. This example is similar to example 3 above, but in this case Anita's motivations are purely personal, she is curious about other cultures and has an intellectual motivation to understand them. 
In example 5, by commenting on how people from her own culture view time, Eve is relating the course content to herself and associating that newly learnt knowledge to her personal life.

In example 6, the cultural comparison Eve makes about social taboos shows that the course content is relevant to what she was experiencing in her year abroad at that moment.

In example 7, Group 1 discusses the course content in regard to the subject of individualist or collectivist and each person talks about the results of the test they did to show whether they were more one than the other. Andrea furthers this to tell stories about her childhood and how that is relevant to being an individualist. Here she is directly relating the course content to her personal history.

Examples 8-12 show students comparing directly the new knowledge they have learnt to their host culture. This shows that the relevance of what they are learning is continuously and immediately present. Also, because students were able to relate their host cultures to specific cultural traits and understand the reasons why people from that culture behave that way, they would then be able to apply those concepts and understand them more in depth and it will thus facilitate communication with them - the course has direct relevance for them and that relevance is maintained throughout the course. In addition this showed an in-depth reflection of the course content and an association of the course to their personal life.

In example 13, Anna is commenting about how much the course has helped her practise her Spanish and make her more fluent. It is one example of many where participants commented on the fact that this course and its language exchange sessions with other students was relevant for them because they believed that learning about ICC would help them develop their language learning skills.

In example 14, Nabil comments on how it is important to know the culture of the languages you are translating extremely well in order to be able to translate properly. $\mathrm{He}$ finds that this course is directly relevant to his professional career. 
In example 15, Nabil is already fluent in both Spanish and English so even though he is aware that the course is designed for foreign language learners he is taking the course to learn about intercultural communication and to practise those skills with natives of English and Spanish cultures. 


\subsection{Results for research question 2 - Pre-course questionnaire}

Table 6 shows the results of the pre-course questionnaire questions relevant to thesis question 2. The questions are shown in the first column and the percentages generated are shown in the second, following a Likert-type scaling method.

\begin{tabular}{|c|c|}
\hline \multirow{8}{*}{$\begin{array}{l}\text { Pre-course questionnaire questions } \\
8 . \quad \text { I feel that learning about } \\
\text { intercultural communication can help } \\
\text { me improve my target language }\end{array}$} & Likert scale. Results in percentages \\
\hline & Strongly Agree $\quad 38.889 \%$ \\
\hline & $50.00 \%$ \\
\hline & $\begin{array}{l}\text { Neither Agree nor } 0.00 \% \\
\text { Disaaree }\end{array}$ \\
\hline & Disagree \\
\hline & Strongly Disagree $0.00 \%$ \\
\hline & Not Applicable \\
\hline & Unanswered \\
\hline \multirow{7}{*}{$\begin{array}{l}\text { 9. I feel that learning about intercultural } \\
\text { communication can help me improve } \\
\text { interacting with people from other } \\
\text { cultures in any language }\end{array}$} & Strongly Agree \\
\hline & $44.444 \%$ \\
\hline & $\begin{array}{l}\text { Neither Agree nor } 0.00 \% \\
\text { Disagree }\end{array}$ \\
\hline & Disagree \\
\hline & Strongly Disagree $0.00 \%$ \\
\hline & Not Applicable \\
\hline & Unanswered \\
\hline \multirow{6}{*}{$\begin{array}{l}\text { 10. The subject of intercultural } \\
\text { communication motivates me }\end{array}$} & Strongly Agree \\
\hline & $55.556 \%$ \\
\hline & $\begin{array}{l}\text { Neither Agree nor } 0.00 \% \\
\text { Disagree }\end{array}$ \\
\hline & Disagree \\
\hline & Strongly Disagree $0.00 \%$ \\
\hline & Not Applicable \\
\hline
\end{tabular}




\section{Unanswered $\quad 11.111 \%$}

Table 6: Results of the Pre-course Questionnaire for Questions which are Relevant to Research Question 2

Results from question 8 of the pre-course questionnaire showed that $38.89 \%$ of students strongly agreed and $50.00 \%$ agreed that it was important to learn about intercultural communication in order to improve the foreign language that they were studying. That meant that nearly all of the students who had enrolled in the course saw learning about ICC as relevant to improving their foreign language skills. In addition almost all believed that learning about intercultural communication could help them improve interacting with people from other cultures in any language. Thus it could be stated that students will be motivated to learn if they think what they are studying will help them achieve their objectives, in this case, improve the oral skills of the target language they are learning and being able to more easily interact with native speakers of that language. This is also proven in question 10, when they are asked directly whether studying ICC motivated them. 


\subsection{Result for research question 2 - Post-course questionnaire}

Table 7 shows the results of the post-course questionnaire questions. The questions are shown in the first column and the percentages generated are shown in the second, following a Likert-type scaling method.

\begin{tabular}{|c|c|}
\hline Post-course questionnaire questions & Likert scale. Results in percentages \\
\hline $\begin{array}{l}\text { 2. I was motivated enough to complete } \\
\text { the course with no teacher support. The } \\
\text { reasons I was motivated were: }\end{array}$ & $\begin{array}{l}\text { I was not } 0.00 \% \\
\text { sufficiently } \\
\text { motivated to } \\
\text { complete the } \\
\text { course with no } \\
\text { I wanted to learn72.727\% } \\
\text { I wann whed to } 72.727 \% \\
\text { The course was } 72.727 \% \\
\text { fin enjoyed being } 18.182 \% \\
\text { completely } \\
\text { autonomous } \\
\text { I knew the success } 63.636 \% \\
\text { of my peers } \\
\text { depended on my } \\
\text { participation } \\
\text { Other }\end{array}$ \\
\hline $\begin{array}{l}\text { 7. I was motivated by the interaction I } \\
\text { had with native speakers of the } \\
\text { language I am learning }\end{array}$ & $\begin{array}{lc}\text { Strongly Agree } & 72.727 \% \\
\text { Agree } & 27.273 \% \\
\text { Neither Agree } & \text { nor0.00\% } \\
\text { Disagree } & \\
\text { Disagree } & 0.00 \% \\
\text { Strongly Disagree } & 0.00 \% \\
\text { Not Applicable } & 0.00 \% \\
\text { Unanswered } & 0.00 \%\end{array}$ \\
\hline $\begin{array}{l}\text { 11. I feel as though I now understand } \\
\text { what intercultural communication is }\end{array}$ & Strongly Agree \\
\hline
\end{tabular}




\begin{tabular}{|c|c|c|}
\hline better than before I started the course & $\begin{array}{l}\text { Agree } \\
\text { Neither Agree no } \\
\text { Disagree } \\
\text { Disagree } \\
\text { Strongly Disagree } \\
\text { Not Applicable } \\
\text { Unanswered }\end{array}$ & $\begin{array}{l}27.273 \% \\
r 0.00 \% \\
0.00 \% \\
0.00 \% \\
0.00 \% \\
0.00 \%\end{array}$ \\
\hline $\begin{array}{l}12 . \quad \text { I feel that learning about } \\
\text { intercultural communication has helped } \\
\text { me improve my target language }\end{array}$ & $\begin{array}{l}\text { Strongly Agree } \\
\text { Agree } \\
\text { Neither Agree } \\
\text { Disagree } \\
\text { Disagree } \\
\text { Strongly Disagree } \\
\text { Not Applicable } \\
\text { Unanswered }\end{array}$ & $\begin{array}{c}27.273 \% \\
45.455 \% \\
\text { nor } 27.273 \% \\
\\
0.00 \% \\
0.00 \% \\
0.00 \% \\
0.00 \%\end{array}$ \\
\hline $\begin{array}{l}\text { 13. I feel that having learnt about } \\
\text { intercultural communication can help } \\
\text { me improve interacting with people from } \\
\text { other cultures in any language }\end{array}$ & $\begin{array}{l}\text { Strongly Agree } \\
\text { Agree } \\
\text { Neither Agree } \\
\text { Disagree } \\
\text { Disagree } \\
\text { Strongly Disagree } \\
\text { Not Applicable } \\
\text { Unanswered }\end{array}$ & 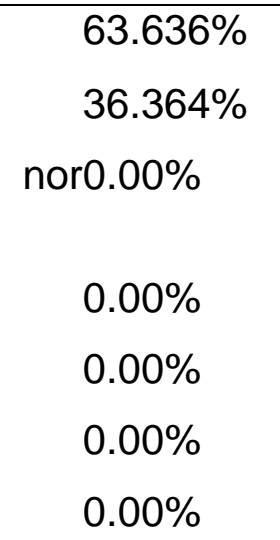 \\
\hline $\begin{array}{l}\text { 14. The subject of intercultural } \\
\text { communication motivated me during the } \\
\text { course }\end{array}$ & $\begin{array}{l}\text { Strongly Agree } \\
\text { Agree } \\
\text { Neither Agree } \\
\text { Disagree } \\
\text { Disagree } \\
\text { Strongly Disagree } \\
\text { Not Applicable } \\
\text { Unanswered }\end{array}$ & $\begin{array}{c}63.636 \% \\
36.364 \% \\
\text { nor0.00\% } \\
\\
0.00 \% \\
0.00 \% \\
0.00 \% \\
0.00 \%\end{array}$ \\
\hline
\end{tabular}




\begin{tabular}{|c|c|}
\hline $\begin{array}{l}\text { 19. My personal learning motivated } \\
\text { me to participate }\end{array}$ & $\begin{array}{lr}\text { Strongly Agree } & 36.364 \% \\
\text { Agree } & 36.636 \% \\
\text { Neither Agree } & \text { nor0.00\% } \\
\text { Disagree } & \\
\text { Disagree } & 0.00 \% \\
\text { Strongly Disagree } & 0.00 \% \\
\text { Not Applicable } & 0.00 \% \\
\text { Unanswered } & 0.00 \%\end{array}$ \\
\hline $\begin{array}{l}\text { 22. The most important part of the } \\
\text { course for me was: }\end{array}$ & $\begin{array}{lc}\text { Learning } & \text { about27.273\% } \\
\text { intercultural } & \\
\text { Ŵmmininination } & \\
\text { Whorking autonomously } & 0.00 \% \\
\text { Interacting with } & \text { other } 72.727 \% \\
\text { students } & \\
\text { Other } & 0.00 \% \\
\text { Unanswered } & 0.00 \%\end{array}$ \\
\hline $\begin{array}{l}\text { 23. The second most important part of } \\
\text { the course for me was: }\end{array}$ & $\begin{array}{lc}\text { Learning } & \text { about63.636\% } \\
\text { intercultural } & \\
\text { Working autonomously } & 18.182 \% \\
\text { Interacting } & \text { with } \\
\text { students } & \text { other } 18.182 \% \\
\text { Other } & 0.00 \% \\
\text { Unanswered } & 0.00 \%\end{array}$ \\
\hline
\end{tabular}

Table 7: Results of the Post-course Questionnaire for Questions which are Relevant to Research Question 2

In question 2, students answered that they were motivated to continue studying because they wanted to learn about ICC and because they wanted to practise their target language. Significantly, no-one disagreed with question 7, evidencing that this opportunity might have been one of the main reasons students continued in the course. An example of how practising their target language with natives was motivating for 
students can be seen in example 13 of Table 4 when Anna speaks about how much the course has helped her practise her Spanish and has helped her become more fluent.

In questions 11, 12 and 14, the results from questions 11 and 12 show that students believed the course was extremely helpful to them and results from question 14 show that the subject of ICC motivated them to continue studying, we can conclude that this is could be because the course was helpful and relevant for them and also because it interested them personally. There are two arguments we could deduce from this. Either students (1) became more motivated (even if they had not initially been) during the course because they began to see the relevance of the subject or improvement in their skills or (2) the students who were not initially motivated by this subject, i.e. those that did not see the relevance in studying ICC for any reason, did not continue with the course. Example 11 in Table 4 is a good example in regard to (1) as conversations such as these during the exchanges clearly show how the students were engaging in the content and saw its relevance directly related to what they are living, experiencing and studying.

Question 19 was a significant question in the post-course questionnaire. These results can be understood from two different perspectives. First that learning ICC was relevant to the students' personal learning goals and those objectives were factors that encouraged them to stay on the course and continue participating in the exchanges. Secondly, as we have seen in the section on autonomous learning, this work had to be done on their own so their autonomous learning motivated them to continue in the course. Focusing on the first part, learning about ICC to achieve personal learning objectives can be understood in terms of learners relating the course content to themselves and their own personal experiences, that is, learners do not only find the course relevant because they could relate all the newly learnt concepts to their target cultures, but also because they could use that knowledge to reflect about their own cultures. Finally, in questions 22 and 23 the most important part of the course for students was learning about ICC and interacting with other students, presumably native speakers of their target language. 


\subsection{Results for research question 3 - Linguistic exchange sessions examples}

Some examples that are relevant to thesis question 3, the motivational influences of peer support and interactions positively affecting continuity in online language courses and distance language learning, are exposed in Table 8.

The results are shown in different columns. The first column numerates the examples, the second presents the date the Google Hangouts linguistic exchange session the example was extracted from took place and the third column has the example that is then discussed below the Table.

\begin{tabular}{|l|l|l|}
\hline E.g. & Date & Examples from language exchange sessions \\
\hline 1 & 8 th May 2015 & $\begin{array}{l}\text { Lucy: [Apologises] "I'm a bit rusty in Spanish." } \\
\text { Nabil: "está muy bien, está bien." }\end{array}$ \\
\hline 2 & 9th May 2015 & $\begin{array}{l}\text { Anna: “... cuando tenemos clase de gramatica... yo } \\
\text { solomante si que es asi, porque yo utilizo esta frase } \\
\text { porque yo lo he aprendido desde la infancia, y las otras en } \\
\text { la clase pueden explicar porque se utiliza este aquí, este } \\
\text { tiempo, este verbo... yo no se". } \\
\text { Ana: "seguro que eres buena....eh" } \\
\text { Anita: "Tengo la sensación que te explicas, y de estar con } \\
\text { otras personas a lo mejor de una manera muy natural. Y } \\
\text { en tu caso tienes expresiones que otros de tus } \\
\text { compañeros no tienen. Pero desconoces el porque ..." }\end{array}$ \\
\hline 3 & 14 th May 2015 & $\begin{array}{l}\text { Ana: “...'m not very proud of my accent" } \\
\text { Anna: "Why not?" } \\
\text { Ana: "My teacher says that eh, this is a bit weird" } \\
\text { Anna: "I don't think it's weird" } \\
\text { Ana: "No?" } \\
\text { Anna: "No" }\end{array}$ \\
\hline 4 & 17 th May 2014 & $\begin{array}{l}\text { Participants in group 1 experimented and laughed with the } \\
\text { Google effects that are available in Google Hangouts. } \\
\text { They put virtual hats and glasses on each-other and role- } \\
\text { played starting a business together. }\end{array}$ \\
\hline 5 & 1st May 2014 & \begin{tabular}{l} 
Students in group 1 introduced themselves and spoke \\
\hline
\end{tabular}
\end{tabular}




\begin{tabular}{|c|c|c|}
\hline & & $\begin{array}{l}\text { about their personal lives: what they were studying; about } \\
\text { themselves, where they lived; where they have visited and } \\
\text { travelled to, they spoke about subjects they are interested } \\
\text { in and subjects they are studying: literature; authors; } \\
\text { engineering. They commented on issues in society and } \\
\text { politics and their future plans: what they will do after } \\
\text { studying. They compared higher education fees in different } \\
\text { countries, spoke about different cultures living in different } \\
\text { countries, about musical instruments they play and how } \\
\text { they are learnt while comparing learning how to play } \\
\text { musical instruments with learning a foreign language. They } \\
\text { discussed online learning, Spanish people living in } \\
\text { England, accents, regional differences within countries and } \\
\text { cultural stereotypes. Towards the end of the exchange } \\
\text { session, which lasted } 1 \text { hour and } 1 \text { minute, there was } \\
\text { already a very relaxed atmosphere and lots of laughing. }\end{array}$ \\
\hline 6 & 8th May 2014 & $\begin{array}{l}\text { Ana and Anna decided to work together and revise each- } \\
\text { other's work (Ana was a native Spanish speaker and } \\
\text { reviewed Anna's work and Anna was a native English } \\
\text { speaker and reviewed Ana's work). } \\
\text { Anna: "...para mi yo pienso que ayuda"” } \\
\text { Ana: "Sí, sí, yo también pienso lo mismo, sin duda... } \\
\text { cuanto más [feedback] recibes, mejor, ¿no? O si no te } \\
\text { queda incompleto, la información". }\end{array}$ \\
\hline 7 & 19th May 2014 & $\begin{array}{l}\text { Ana: "Yo no he llegado a entender muy bien lo de, eh, } \\
\text { pensaba que lo de policronimo era de que se hace varias } \\
\text { cosas al mismo tiempo, o sea que, que quieres abarcar } \\
\text { mucho, mientras, que sería la estresada, ¿no? Sin } \\
\text { embargo aquí dice lo contrario."' } \\
\text { Anita: "No" } \\
\text { Ana: "Exacto, lo he entendido mal." } \\
\text { Anita: "No lo he entendido así. Yo. Monocronico sería con } \\
\text { respeto a una actitud, como el tiempo como algo objetivo. } \\
\text { O sea como que para todo el mundo sería igual el tiempo." } \\
\text { Ana: "Ah, entonces sería como, la universal. En } \\
\text { comparación con lo de la dimensión de cultura de que la } \\
\text { ley es así y las reglas así." } \\
\text { Anita: "Si sería como si no hubiera interpretaciones..." } \\
\text { Rebecca: "Y se dice que la gente monocronica hace solo } \\
\text { una cosa a la vez, terminan un cosa antes de empezar } \\
\text { una nueva cosa, tienen que terminar la cosa que están } \\
\text { haciendo..." }\end{array}$ \\
\hline 8 & 28th May 2014 & $\begin{array}{l}\text { Anna: "I think people really helped each-other out there } \\
\text { because there were people who had read the stuff said, } \\
\text { this is the topic, and then regardless of whether you had } \\
\text { time to read or listen to things everyone had their own idea }\end{array}$ \\
\hline
\end{tabular}




\begin{tabular}{|c|c|c|}
\hline & & on the topic." \\
\hline 9 & 14th May 2014 & $\begin{array}{l}\text { Andrea: “¿Y qué es lo que tenemos que hacer hoy?" } \\
\text { Chris: "A ver, abro los documentos ¿Habéis...? No se } \\
\text { creó que los documentos se relacionan a las lecturas de la } \\
\text { semana. Hay uno aquí. No eso no me gusta. Soy un poco } \\
\text { tikis mikis con eso. Bueno, la idea de, pensáis un poco en } \\
\text { la lectura de, sobre la persona que conducía demasiado } \\
\text { rápido. Y una de las preguntas que hay aquí es que: ¿es } \\
\text { siempre justificado, buena, hay situaciones en las que } \\
\text { justificable mentir o no? ¿Siempre es malo mentir?" }\end{array}$ \\
\hline 10 & 25th May 2014 & $\begin{array}{l}\text { Nabil: "I'm going to devote these two days, these next two } \\
\text { days for the group's video... just to give a good image for } \\
\text { this group. I have a good friends, like Lucy and like Ursula } \\
\text { and I'm so glad to be a friend of yours". } \\
\text { Lucy: "Me too!" } \\
\text { The group then talks about Lucy's hobby of rock climbing } \\
\text { and suggest that the group should get together and go } \\
\text { mountain climbing. } \\
\text { Ursula: "Lucy you're invited to my house. You can come if } \\
\text { you want" [to stay]. } \\
\text { Lucy: "Awesome. Well, I'm moving a bit further south in } \\
\text { September, so maybe we could meet half way. I'll be like } \\
\text { in the middle of France..." }\end{array}$ \\
\hline 11 & 20th May 2014 & Group 1 creates a Facebook page \\
\hline 12 & 20th May 2014 & $\begin{array}{l}\text { Anna: "Can we exchange emails to keep in touch? I get } \\
\text { attached to people and I really liked our group." } \\
\text { Ana: "I feel the same; I think that it is a pity to lose } \\
\text { contact." Anita: "We can carry on practising, why not?" } \\
\text { Ana: "I think that is possible." } \\
\text { Anita: "... if you guys want to practise your Spanish" [you } \\
\text { can contact me]... } \\
\text { Ana: "yes, you can count on me also." } \\
\text { Rebecca: "Thank you... we'll hang out soon. In the near } \\
\text { future." } \\
\text { Anita: "and I wanted to say something extra, Ana, you } \\
\text { have really brought us together." } \\
\text { Ana: "I think we all make it." }\end{array}$ \\
\hline 13 & 28th May 2014 & $\begin{array}{l}\text { Anita: "...like a semi-seminar [tutorials]. An online seminar } \\
\text { online, motivating you and helping you to learn. [At } \\
\text { university] I worked harder having the small tutorials than I } \\
\text { did for the course lectures, like for this course". } \\
\text { Anna: "And I think having the social side makes you more } \\
\text { confident in participating [you are not so shy]". } \\
\text { Ana: "Definitely." }\end{array}$ \\
\hline
\end{tabular}




\begin{tabular}{|l|l|l|}
\hline & & $\begin{array}{l}\text { Anna: "It means you work together with them better. More } \\
\text { personal." } \\
\text { Anita: "It's like knowing each-other..." } \\
\text { Anna: "I think people really helped each-other out there } \\
\text { because there were people who had read the stuff said, } \\
\text { this is the topic, and then regardless of whether you had } \\
\text { time to read or listen to things everyone had their own idea } \\
\text { on the topic". }\end{array}$ \\
\hline 14 & 20th May 2014 & $\begin{array}{l}\text { Ana: [explaining a homophone] Rallar means make } \\
\text { something smaller, a carrot for example. And rayar from } \\
\text { raya. Write under. With 'y'. } \\
\text { Anna: Oh yeah. OK, l'll have to be careful with that one. }\end{array}$ \\
\hline 15 & 17 th May 2014 & $\begin{array}{l}\text { Chris: [after they had done a course exercise] OK, I'm, } \\
\text { just going to look at the other activities we have. The group } \\
\text { does another structured, planned activity that supports the } \\
\text { course content for that week. }\end{array}$ \\
\hline 16 & 15 th May 2014 & $\begin{array}{l}\text { Group 1 does the exchange session exercises on cultural } \\
\text { views towards destiny. } \\
\text { Nabil: This concept of the American dream. Let me ask } \\
\text { you a question: Is it real? } \\
\text { Ursula: My uncle, an American, he is always telling me my } \\
\text { dreams can come true if I work for them, and all those } \\
\text { things. }\end{array}$ \\
\hline
\end{tabular}

Table 8: Results and Examples from the Language Sessions Relevant to Research Question 3

Examples 1,2 and 3, show that forming part of a group also leads to sensations of safety, security and comfort, making students more confident which reflects in their use of their target language. For peer learning and support to flourish, it is important to create an online environment that motivates learners by fostering feelings of safety, respect, capability (through encouragement) and an ability to influence the learning situation. Almost every single time a student expressed either their frustration or lack of confidence in speaking their target language the other students in the group would support or encourage them. Examples 1, 2 and 3 showed how this developed.

Examples 4 and 5 show the group bonding together. During these exchanges, students felt included because they were part of a group and bonded with their peers, they could practise their target language with peers in a relaxed and natural context, which was the 
reason they enrolled in the course. Speaking about these broad subjects, which are extremely relevant to the course content, created bonds between the students because it showed them that they were similar in many regards. These similarities form group cohesion, which is very important if the group is to stay together and learners are going to be motivated to continue participating. These results agree with that stated by Forsyth (2006:118) "Cohesive groups are more unified and morale is higher. Members enjoy interacting with one another, and they remain in the group for more prolonged periods of time."

In example 6, this exchange of review work also served to further strengthen the bond that had already been created as they were very involved in each-other's personal work. The encouragement they gave each other would also give them confidence to further their target language work. In addition peer feedback contributes to developing learners' capacity to self-regulate their own work. If it provides relevant information students can significantly improve their language abilities, and seeing that improvement can motivate students to continue studying. Also, it plays a significant role in the construction of relationships; students will accept and integrate feedback from people they trust, and this in turn will make them more engaged in the learning process and thus more motivated to continue with the course.

In examples 7 and 8 we can see examples of peer-learning. Informal peer-learning is understood to be an exchange of knowledge and ideas and learners providing and offering support and encouragement with participants learning from each-other without immediate intervention from the teacher. This can both encourage student learning and also autonomous behaviour, in turn motivating students in their studies.

Example 9 shows students being motivated to review, learn, and understand learning content when they act in a teaching role. This was very obvious in the case of the students who took the lead in their respective groups. They organised the week's session for Google Hangouts and during the exchanges presented the exercises that were to be carried out to further explore the previous week's content and concepts. A good example of this is Chris taking the group leader role for group 1 in example 9. 
Examples 15 and 16 show the groups talking about the exercises available to support the course content for that week. The exchange exercises for the course were developed based on the belief that peer learning is an effective way of sharing language skills and knowledge with each other and that because of this students will find practising their target language with their peers relevant and helpful and thus be motivated to continue with the course until its completion. In peer learning situations students will learn better because they decide what they need to learn which also compliments the ideas raised in the section of autonomous learning during the exchanges. In these situations students are heavily engaged in the learning process because they collect, analyse, evaluate, understand and apply learning by carrying out the course content exercises during exchanges or relate concepts they learn in the course to their daily lives and interaction with people from their target culture. Students were intellectually, emotionally and socially involved in constructive conversations with their peers and learnt by talking and questioning content and negotiating meaning. The peer learning techniques used resulted in a relaxed and enjoyable language environment during the exchange sessions. Significantly, there was also an increase in the students' sense of responsibility and engagement in reading the course content so they could reflect and explore ideas with their peers during the exchange sessions. It encouraged students to articulate their understanding. 


\subsection{Results for research question 3 - Pre-course questionnaire}

Table 9 shows the results of the pre-course questionnaire questions. The questions are shown in the first column and the percentages generated are shown in the second, following a Likert-type scaling method.

\begin{tabular}{|c|c|}
\hline \multirow{8}{*}{$\begin{array}{l}\text { Pre-course questionnaire questions } \\
3 . \text { I feel as though my peers are able to support } \\
\text { me sufficiently }\end{array}$} & Likert scale. Results in percentages \\
\hline & Strongly Agree $\quad 5.556 \%$ \\
\hline & $44.444 \%$ \\
\hline & $\begin{array}{l}\text { Neither Agree nor38.889\% } \\
\text { Disagree }\end{array}$ \\
\hline & Disagree \\
\hline & Strongly Disagree $0.00 \%$ \\
\hline & Not Applicable \\
\hline & Unanswered \\
\hline \multirow{7}{*}{$\begin{array}{l}5 . \text { I am motivated by the interaction I will have with } \\
\text { native speakers of the language I am learning }\end{array}$} & Strongly Agree \\
\hline & $38.889 \%$ \\
\hline & $\begin{array}{l}\text { Neither Agree nor } 0.00 \% \\
\text { Disagree }\end{array}$ \\
\hline & Disagree \\
\hline & Strongly Disagree $0.00 \%$ \\
\hline & Not Applicable \\
\hline & Unanswered \\
\hline \multirow{5}{*}{$\begin{array}{l}\text { 15. I understand that the other students' success } \\
\text { on this course depends on my participation }\end{array}$} & Strongly Agree \\
\hline & $72.222 \%$ \\
\hline & $\begin{array}{l}\text { Neither Agree nor } 11.111 \% \\
\text { Disagree }\end{array}$ \\
\hline & Disagree \\
\hline & Strongly Disagree $0.00 \%$ \\
\hline
\end{tabular}




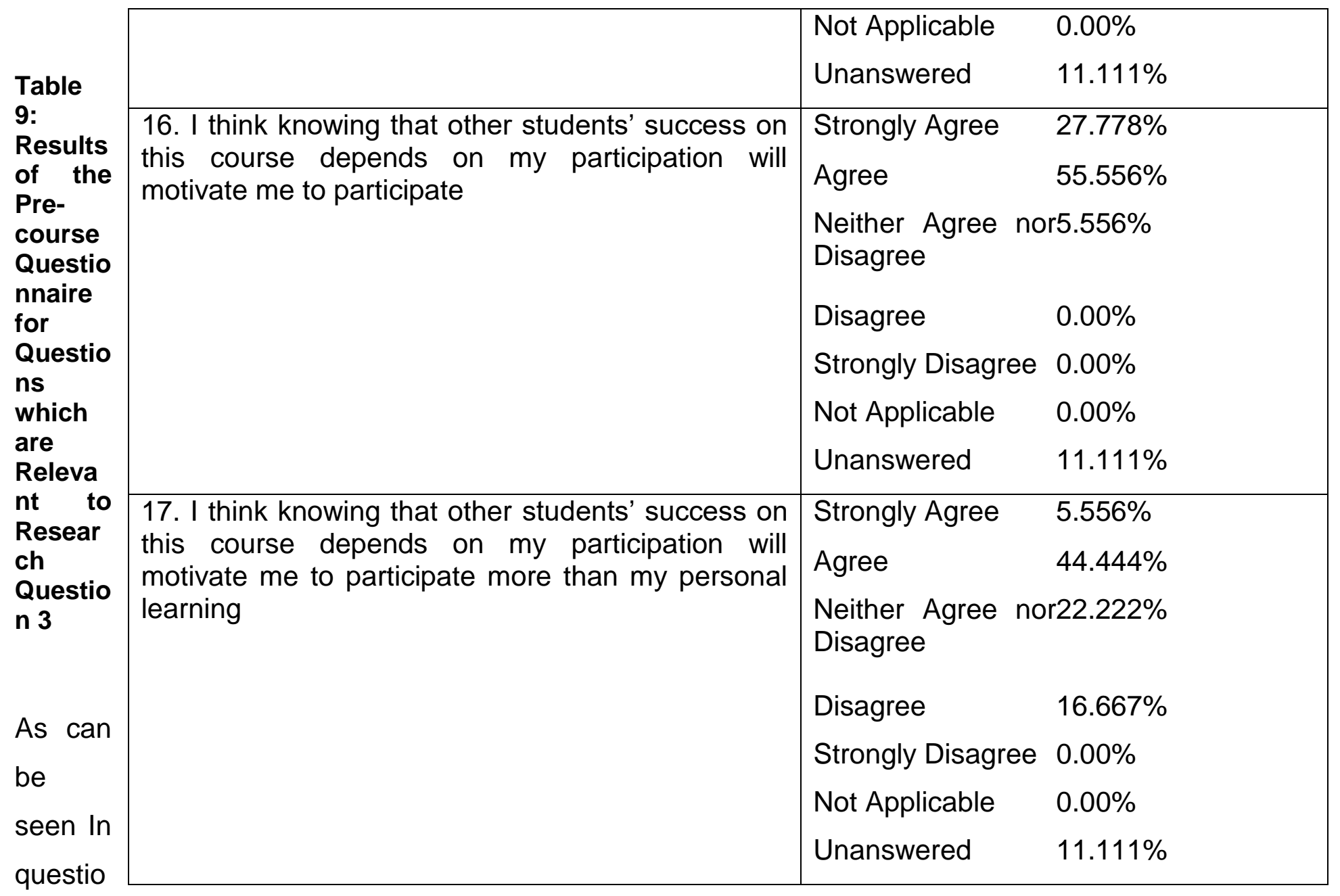

n 3 , before the course $5.56 \%$ of students strongly agreed, $44.43 \%$ agreed and $38.89 \%$ neither agreed nor disagreed with the pre-course questionnaire question number 3 , "I feel as though my peers are able to support me sufficiently". Conversely, the results of question 6 in the post-course questionnaire saw this figure jump quite a bit. This comparison is extremely relevant because it shows that there was sufficient peer support to give students a sense that they were being supported during the course, probably preventing students from abandoning as one of the most significant reasons for noncompletion of online courses is the feeling of isolation in distance and online learning environments.

Question 5 shows that there was no room for doubt to students being motivated by the interaction they would have with other students, 50.00\% strongly agreed and $38.89 \%$ agreed that they would be motivated by the interaction they were going to have with 
native speakers of the language they were learning.

In question 15, almost all participants (88.89\%) believed their peers' success in the course depended on their participation. This was probably because students were aware of the need a student has to practise the target language they are studying with native speakers in order to improve their target language skills, probably because they are language students themselves and are in exactly the same position. There is no doubt that this pressure encouraged students to continue with the course (as seen by their participation in the language exchange sessions, participation in the group assignment, effort to read the course content so as to be able to discuss those ideas in the exchange sessions etc.) and in turn motivate them to work on the course.

Question 16 further supports the idea emerging from question 15. In addition, question 3 in the post-course questionnaire in Table 4 showed that $63.64 \%$ of the students answered that one of the reasons they were able to complete the course (with no teacher support) was because they knew the success of their peers depended on their participation. Question 17 shows that however motivated students were about participating in order to ensure other students' success they stopped short of thinking that this was more important than their own personal learning, but surprisingly not by much. 


\subsection{Results for research question 3 - Post-course questionnaire}

Table 10 shows the results of the post-course questionnaire questions. The questions are shown in the first column and the percentages generated are shown in the second, following a Likert-type scaling method.

\begin{tabular}{|c|c|c|}
\hline \multirow{4}{*}{\begin{tabular}{|l|} 
Post-course questionnaire questions \\
6. I felt as though my peers were able to \\
sufficiently support me in my learning \\
process
\end{tabular}} & \multicolumn{2}{|c|}{ Likert scale. Results in percentages } \\
\hline & Strongly Agree & $18.182 \%$ \\
\hline & Agree & $63.636 \%$ \\
\hline & Neither Agree nor Disagree & $9.091 \%$ \\
\hline & Disagree & $0.00 \%$ \\
\hline & Strongly Disagree & $9.091 \%$ \\
\hline & Not Applicable & $0.00 \%$ \\
\hline & Unanswered & $0.00 \%$ \\
\hline 7. I was motivated by the interaction I & Strongly Agree & $72.727 \%$ \\
\hline $\begin{array}{l}\text { had with native speakers of the } \\
\text { lanquage I am learning }\end{array}$ & Agree & $27.273 \%$ \\
\hline & Neither Agree nor Disagree & $0.00 \%$ \\
\hline & Disagree & $0.00 \%$ \\
\hline & Strongly Disagree & $0.00 \%$ \\
\hline & Not Applicable & $0.00 \%$ \\
\hline & Unanswered & $0.00 \%$ \\
\hline 9. I will keep in touch with other & Strongly Agree & $27.273 \%$ \\
\hline & Agree & $54.545 \%$ \\
\hline & Neither Agree nor Disagree & $18.182 \%$ \\
\hline & Disagree & $0.00 \%$ \\
\hline & Strongly Disagree & $0.00 \%$ \\
\hline & Not Applicable & $0.00 \%$ \\
\hline
\end{tabular}




\begin{tabular}{|c|c|c|}
\hline & Unanswered & $0.00 \%$ \\
\hline \multirow{7}{*}{$\begin{array}{l}\text { 18. My peers were able to motivate me } \\
\text { to participate }\end{array}$} & Strongly Agree & $18.182 \%$ \\
\hline & Agree & $81.818 \%$ \\
\hline & Neither Agree nor Disagree & $27.273 \%$ \\
\hline & Disagree & $0.00 \%$ \\
\hline & Strongly Disagree & $0.00 \%$ \\
\hline & Not Applicable & $0.00 \%$ \\
\hline & Unanswered & $0.00 \%$ \\
\hline \multirow[t]{5}{*}{$\begin{array}{l}\text { 22. The most important part of the } \\
\text { course for me was: }\end{array}$} & \multicolumn{2}{|c|}{$\begin{array}{l}\text { Learning about intercultural27.273\% } \\
\text { communication }\end{array}$} \\
\hline & Working autonomously & $0.00 \%$ \\
\hline & Interacting with other students & $72.727 \%$ \\
\hline & Other & $0.00 \%$ \\
\hline & Unanswered & $0.00 \%$ \\
\hline
\end{tabular}

Table 10: Results of the Post-course Questionnaire for Questions which are Relevant to Research Question 3

In question 7, the results of this question show clearly that students were motivated by the interaction with native speakers of the language they were learning. As we have seen throughout this study, this is probably because students believed that by practising their target language they would improve their level in it. In question 9, the bond created between participants becomes clear from the response to it. This can also be seen in example 10, 11 and 12 from Table 8.

In question 18 the results were also very significant as it shows that participants strongly believed that their peers motivated them to continue studying in the course. This is also seen in example 13 in Table 8. The phrase she uses, 'unwritten compromise [commitment, obligation or promise, from compromiso in Spanish]', is interesting as it highlights another reason why the creation of a bond between learners can motivate 
students to continue in online learning courses: learners felt as though they had to participate in the exchanges or they would let their peers down. Finally, in question 22 students believe that the most important part of the course was interacting with other students. This is obvious because it is generally believed that practising your target language will make you more proficient in it. However, it also seems that interaction was important to the students in terms of understanding the course concepts and the technical aspects of their target language (see example 14 in Table 8). 


\subsection{Students' reflections on their foreign language learning environment - pre- and post-course questionnaire}

The last part of the Results Chapter is in regard to students' reflections on their foreign language learning environment. The questions are presented in the first column and the percentages generated are presented in the second, following a Likert-type scaling method.

\begin{tabular}{|c|c|}
\hline \multirow{8}{*}{$\begin{array}{l}\text { Pre-course questionnaire questions } \\
\text { 13. I feel that learning online is not as } \\
\text { effective as face to face learning in } \\
\text { regard to foreign language learning }\end{array}$} & Likert scale. Results in percentages \\
\hline & Strongly Agree $\quad 5.556 \%$ \\
\hline & $33.333 \%$ \\
\hline & $\begin{array}{l}\text { Neither Agree nor27.778\% } \\
\text { Disagree }\end{array}$ \\
\hline & Disagree \\
\hline & Strongly Disagree $16.667 \%$ \\
\hline & Not Applicable \\
\hline & Unanswered \\
\hline \multirow{7}{*}{$\begin{array}{l}\text { 12. I feel that learning online is not as } \\
\text { effective as face to face learning }\end{array}$} & Strongly Agree \\
\hline & $22.222 \%$ \\
\hline & $\begin{array}{l}\text { Neither Agree nor } 44.444 \% \\
\text { Disagree }\end{array}$ \\
\hline & $16.667 \%$ \\
\hline & Strongly Disagree $0.00 \%$ \\
\hline & Not Applicable \\
\hline & Unanswered \\
\hline \multirow{3}{*}{$\begin{array}{l}\text { 7. I understand what intercultural } \\
\text { communication means }\end{array}$} & Strongly Agree \\
\hline & $44.444 \%$ \\
\hline & $\begin{array}{l}\text { Neither Agree nor } 16.667 \% \\
\text { Disagree }\end{array}$ \\
\hline
\end{tabular}




\begin{tabular}{|l|ll|}
\hline & Disagree & $55.556 \%$ \\
Strongly Disagree & $0.00 \%$ \\
Not Applicable & $0.00 \%$ \\
& Unanswered & $11.111 \%$ \\
\hline
\end{tabular}

Table 11: Results of the Pre-course Questionnaire in regard to Students' Reflections on their Foreign Language Learning Environment - Both Traditional and Online

\begin{tabular}{|c|c|}
\hline Post-course questionnaire questions & Likert scale. Results in percentages \\
\hline \multirow{7}{*}{$\begin{array}{l}\text { 15. I feel more confident about learning } \\
\text { online after taking this course }\end{array}$} & Strongly Agree $\quad 27.273 \%$ \\
\hline & $63.636 \%$ \\
\hline & $\begin{array}{l}\text { Neither Agree nor0.00\% } \\
\text { Disagree }\end{array}$ \\
\hline & Disagree \\
\hline & Strongly Disagree $0.00 \%$ \\
\hline & Not Applicable \\
\hline & Unanswered \\
\hline \multirow{7}{*}{$\begin{array}{l}\text { 16. I feel that learning languages online } \\
\text { is possible after taking this course }\end{array}$} & Strongly Agree \\
\hline & $27.273 \%$ \\
\hline & $\begin{array}{l}\text { Neither Agree nor36.364\% } \\
\text { Disagree }\end{array}$ \\
\hline & Disagree \\
\hline & Strongly Disagree $0.00 \%$ \\
\hline & Not Applicable \\
\hline & Unanswered \\
\hline \multirow{4}{*}{$\begin{array}{l}\text { 11. I feel as though I now understand } \\
\text { what intercultural communication is } \\
\text { better than before I started the course }\end{array}$} & Strongly Agree \\
\hline & Agree \\
\hline & $\begin{array}{l}\text { Neither Agree nor0.00\% } \\
\text { Disagree }\end{array}$ \\
\hline & Disagree \\
\hline
\end{tabular}




\begin{tabular}{|l|ll|}
\hline & Strongly Disagree & $0.00 \%$ \\
Not Applicable & $0.00 \%$ \\
Unanswered & $0.00 \%$ \\
\hline
\end{tabular}

Table 12: Results of the Post-course Questionnaire in regard to Students' Reflections on their Foreign Language Learning Environment - Both Traditional and Online

Example 2 in Table 5 shows observations about learning English in Spain made by one of the students who participated in this course and is of particular interest. It seems that access to native speakers is not common so they are unable to practise their target language. This was also the case for English students learning Spanish in England. The examples mentioned describe the participants' personal situations and this resulted in students being motivated to participate during this course.

Question 13 in Table 11. Before taking this course, students in this study believed that the foreign language classroom was the natural site for learning; a traditional view of the guided learning model where interaction between the student and the instructor or teacher occurs. However, traditional learning methodologies in the context of an online learning environment might not favour or encourage autonomous learner behaviour or encourage peer support as neither are strictly necessary and these classes are not normally planned for those outcomes.

Question 12 in Table 11. It was important to find out what learners thought an effective learning environment would entail prior to their participation in this online ICC course as these ideas served as foundations from which to contrast learners' engagement with the target language, their peers and motivation to continue with online learning as it seemed that students were undecided about whether learning online could be effective or not. From questions 12 and 13 of the pre-course questionnaire it is clear students were not at all convinced that learning foreign languages online, i.e. not in a traditional classroom environment, was possible or at least straight-forward. However, this attitude changed dramatically after the students completed the course as shown by the results of 
questions 15 and 16 in Table 12.

Question 7 in Table 11. Students' thoughts on the topic of the course were important to gauge as relevance played an extremely significant part in their motivation. Although there is a growing trend towards using ICC in foreign language learning courses, there is not yet an emphasis for teaching it either separately or integrated in the foreign language classroom. Question 7 in Table 11 shows that students thought they were informed about the topic of ICC but, in fact, question 11 in Table 12 shows that they still had a lot to learn. It is in this gap where students' motivation truly develops. It seems for this particular case, motivation was not fully present (or not to the potential it was at the end) at the beginning of the course ('I already know about this subject so I will take this course simply to practise my target language') but really took shape throughout and during the course. It seems from these results that while students were learning about something they thought was relevant they began to realise they needed to know more about it and found they could learn more about it in the course itself, which not only served to further motivate them, but to maintain awareness of the subject in their daily lives as well as keeping the relevance of the subject present throughout the course. 


\section{CONCLUSIONS}

The purpose of this thesis was to tie together the motivational issues that are believed to be relevant for successful online foreign language learning today. Because of the significantly high abandonment rates in online foreign language learning this thesis wished to address what motivational factors influence students' desire to continue working towards their objectives of learning a foreign language in an online environment. As stated in the Introduction section of this thesis, the aims were to identify the norms and practices of successful online foreign language learning and to examine those practices in such a way that the patterns motivating students to continue learning - and those implicated in the construction of successful learning outcomes - are exposed and developed, to then suggest applying these findings to useful language learning programmes, in particular by raising awareness of ways in which students are sufficiently motivated to not abandon their course of language studies.

The study sought to answer the following question: is autonomous working behaviour, peer support and interaction and awareness of the relevance of course studies (in this case, Intercultural Communication) sufficient to motivate students in an online foreign language learning environment and ensure continuity in their chosen course of studies?

More specifically, the objectives of this thesis are to explore the co-existence and interconnectedness between peers, students' indications of autonomous behaviour and the significance of relevance for continuity within a distant / online learning environment and how these issues relate to motivation.

This study started off by mapping the changing political and philosophical discussions during the second half of the twentieth century that shifted the focus of language learning onto the individual and away from the teacher. During this time a mentalist approach to language learning began to take shape, moving away from behaviourist approaches which saw learning as a stimulus-response mechanism. Foreign languages had to be understood and absorbed before real language learning took place and this required that 
the learner learnt for themselves rather than passively being taught or merely repeating foreign language utterances and phrases. This could only be achieved through autonomous learning process as it was the learner who knew what they did and did not understand. Moving through the historical approaches to language learning to outline the trajectory towards today's more mentalist approach, the thesis found that the current cognitive focus on learning necessarily means a more autonomous method of language learning is required and ideal. It naturally follows that an autonomous learner will be a motivated learner. This concept of motivation was not only explored from an autonomous perspective, it was a running theme that emerged as an integral part of the other areas necessary to the construction of this thesis, including how peer support and student interaction within a group can ensure that students are sufficiently motivated to finish an online foreign language learning course. It has been stated that language cannot be learnt in isolation because much of the meaning that comes from communication is not only through words and phrases, and that foreign languages can only be fully understood in context. In the case of learning a foreign language this means that learning the background and history of a language, specifically the culture of that language, is necessary for successful, meaningful and deep communication to take place. Students who participated in the ICC course agreed that studying the culture of the foreign language they were learning was important in order to better understand that language and thus perceived the study of intercultural communication to be an integral and important part of the broader language learning curriculum. Results showed that participants placed a heavy emphasis on this factor and that it significantly motivated them during the course. New language learning approaches also require embracing new technologies and methods. Online learning parallels pre-computer distance and postal learning in many ways, but the most significant and relevant analogous point for this thesis was the difficulty in maintaining students' motivation in these non-traditional environments; abandonment rates are significantly higher in these settings due to a lack of interaction with other peers or teachers, especially important in the case of foreign language learning.

The main empirical findings were products of an analysis of the data gathered from the 
Online ICC Foreign Language course delivered on the Blackboard Learning Management platform. This information was collected and then analysed to be exposed and summarised within the results and data analysis chapter, formulated into three research areas:

1. The motivational influences of autonomous behaviour on the continuity in online language courses and distance language learning.

2. The importance of course relevance as a motivational influence in online language courses and distance language learning

3. The motivational influences of peer support and interaction on the continuity in online language courses and distance language learning

The conclusions reached through the research conducted and course carried out was that students were motivated to continue with their course of study and practicing their chosen foreign language learning when:

Thesis question 1: they had opportunities to work autonomously

Thesis question 2: they felt supported by, dependent on, indebted to and interacted with their peers in the online language learning context provided by the thesis ICC course.

Thesis question 3: a perception of the relevance of studying ICC for further improvement of their abilities in their target language was maintained. 


\subsection{Thesis question 1}

When defining autonomy for this thesis in Chapter 3 there was a special emphasis placed on the social and motivational aspects of autonomy, running counter to the conventional definition of autonomy as working in isolation. During the ICC course the autonomous working skills that participants showed proved to be a major reason retention rates were so high (69.23\%). The psychological and emotional attachment the students formed with the course process and content was a result of their self-directed learning abilities and opportunities the course gave them to determine their own learning process (Little 1991). Learners inadvertently shaped their own learning process and because they directed themselves, they not only understood the course material better and felt more relaxed practising their target language, but they were also more motivated and more engaged with the learning process. The results which showed that autonomous learning has a significant impact on motivating students and continuity in online language learning courses, came from an analysis of the pre- and post-course questionnaires that participants were asked to fill out and the Google Hangouts language and cultural exchange sessions and tutorials that were conducted twice a week. This was despite the fact that students did not start the course with a particularly strong sense of autonomous work ethic. Less than half of the students who started the course believed they would be motivated enough to complete the course with no teacher support, however $69.23 \%$ did in fact see the course though until completion. In addition, in the post-course questionnaire a full $100 \%$ of the students agreed to the question that "my personal learning motivated me to participate". It was also interesting to see that $100 \%$ of the students in the course accessed course content folders (suggesting they at least read and may have even completed the coursework). During the Google Hangouts and language exchange sessions' discussions, the main topic of conversation was often the course content, further suggesting a strong autonomous work ethic. The connections between autonomy and motivation are also emphasised by Dickinson (1987) and Ushioda (2008), who believe that autonomy is closely linked to language learning motivation. The results from this experiment provided much evidence to show that when 
learners take control of their learning they feel more motivated to learn in online learning environments. These autonomous skills were further supported and encouraged by the peer interaction students were exposed to during the Google Hangouts. In addition, Bobb-Wolf (2002) believes that when the learner realises that they can learn from and be motivated by peers, the learning process becomes more autonomous. In the case of the results seen from the ICC course, students decided to work on the course content autonomously because they felt they needed to be able to interact with their peers during the linguistic exchanges twice a week. Anita from group 4 explains the concept of needing peer interaction to foster and support autonomous learning in group four's exchange session on $28^{\text {th }}$ May:

“... I was looking for a Master's degree. I was thinking about doing a Master's degree online. But I checked, and I didn't feel as though I wanted to do that because I'm a quite social person and I didn't, I thought well, what if I pay that money and I get unmotivated. I'm not sure about it. And I'm looking for a Master's and I would like to do one and I don't know where. But the online option, I didn't see it so clear. Because I remember studying at the University [in Spain, where there are no tutorials], well in my year in England, was absolutely good for me... for me, I worked harder, I worked even twice the hours I worked in Spain [because of the tutorial group], because I had to meet the guys [in the tutorial group], talk to them, be in a small group, interact and give my opinions."

At a different point in the exchange session, Anita emphasises that the exchange session were an important part of the course and one of the most motivating factors about the course:

"It's like an unwritten compromise, let's say. The Hangouts make that difference. It's the idea of a seminar, when you're at university, that apart from the lectures and all that, seminars, I remember for me being Spanish, we didn't have that, I went to England and we had that part, and I felt really, really, good, I felt so motivated. In the case of online course I didn't know that before... and ah, it's the same kind of idea of just giving the exercises as if it was a book, but through the screen and I didn't feel motivated [she was referring to the fact that she thinks that most online courses are very similar to traditional courses as they simply transfer the course content, material and exercises onto a screen] but in this one [the ICC course] I felt, yeah it's like a seminar online, you're going to be talking about it [the course content] you're going to be interacting with your class-mates".

This is particularly interesting because the students did not have an instructor or teacher coordinating their activities and they did not have any obligations to carry out the coursework and assignments, in addition, completion of the course would not have given them any credit towards their official studies, so it seemed relatively easy for students to 
either abandon the course or simply use it for interaction with native speakers. There was also evidence that students felt as though they would let their peers down if they had not kept up with the work. In one particular relationship that was developed between Ana and Anna in group 4, each student agreed to correct and review the other student's work.

Dam, Little, Millander and Trebbi comment on the social dimension of the concept of learner autonomy:

"Learner autonomy is characterized by a readiness to take charge of one's own learning in the service of one's own needs and purposes. This entails a capacity and willingness to act independently and in co-operation with others, as a socially responsible person." (Dam, Eriksson, Little, Millander, \& Trebbi, 1990:102) 


\subsection{Thesis question 2}

The results and findings of the thesis are consistent with previous research into the motivational aspects of the need for peer interaction in education in general and language learning in particular. It has been suggested that one of the biggest issues for distance education is a lack of student retention and the reasons for this have often been attributed to a feeling of isolation and a lack of adequate communication between students and their teachers, which might even be bridged with more interaction between the students themselves (Baath, 1984b; Holmberg, 1995; Kember, 1990). The particularity of the findings in this thesis is that it has been evidenced in a non-traditional online language learning environment. If the reasons for low retention rates are a feeling of isolation it is surprising that with the abundance of communicative tools offered by technological advances, course abandonment percentages seem to be particularly high for MOOCs and online courses (Moody 2004). It seems obvious then that there should be research conducted into this area in order to ensure proper pedagogical application of interaction into courses. Moore and Kearsley (1996) propose increasing the degree of interaction that is available in distance education courses and encouraging students to interact with each-other to try to ensure that learners continue with their studies. In addition, the benefits of interaction for students with native speakers of the target language they are learning are also obvious (Hall \& Beggs 1998; Pennycook 1997). Because participants of this ICC course met on Google Hangouts twice a week, and because they all had the shared interest of practising their target language and learning about the course content, they built quite a strong emotional bond and this served as a clear example of how this peer support could motivate them to continue studying. They encouraged each-other through the construction of a group environment that was based on respect and capability. In the session on 14 ${ }^{\text {th }}$ May, Anna tells Ana that, "Your English is very good" and Ana is surprised, she expresses her dismay at her accent and Anna assures her that it is not 'weird' at all. There are also many instances of polite turn-taking, showing how naturally the conversation was orderly and respectful. (Harvey, Emanuel, \& 
Gail, 1974). There are many examples that show the students thoroughly enjoyed themselves and felt comfortable during the exchanges. One being a session carried out by group 1 on $17^{\text {th }}$ May. For about 10 minutes the participants experimented and laughed with the Google effects that are available on the Google Hangouts program. They put virtual hats and eye glasses on each-other and role-played starting a business together. It was also extremely relevant because they role-played their chosen characters culturally, using - without any prompting - cultural communication knowledge they were learning in the course. Peer rapport was constructed through talking about personal stories and also through helping each-other with the course concepts and content, resulting in informal peer-learning. Boud (2001) highlights the importance of peer learning for autonomy, group cohesion and motivation by stating that students become more heavily involved in the learning process when they are engaged in these sorts of activities. The 'unwritten compromise [commitment, obligation or promise, from compromiso in Spanish]' Anita mentions, as well as other examples given in the Results Chapter, highlight the fact that the importance for peer interaction works both ways, that is, it influences students to maintain continuity not only because student's believe that it is beneficial for themselves, but also because they have an obligation to their peers to continue with their course of studies. 


\subsection{Thesis question 3}

Another theme that manifests itself with vigour was the importance students placed on the relevance of the work they were doing and the concepts they were learning during the course as well as the opportunities to practise the target language they were exposed to during the exchanges with native speakers. There are endless amounts of components that motivate students to continue working and learning, but one of the most significant for this thesis is the psychological state of learners when they are consciously aware of their individual objectives and have an interest in the learning situation (Hidi \& Ainley, 2008; Krapp, 2002). Interest and effort shown by learners towards the learning process vary according to age, past experiences, immediate needs and long-term goals and the sociocultural context of the subjects, but motivation to reach a desired objective is often seen as one of the strongest motivational factors. One example often cited in the literature is an immigrant's need or desire to learn the language of their new host country in order to find work and establish a more comfortable life or even for basic day-to-day survival. The language learning process depends on what the learner wants to learn, what they already know, how often they practise their target language and how important it is for them to learn; these are the basic and indispensable personal conditions that enable or facilitate the acquisition and application of new linguistic knowledge. According to Dörnyei and Ushioda (2013) it is easy to lose sight of established objectives or give way to distractions if those objectives are not a serious need for basic survival. So maintaining view of the relevance of what learners are learning is of high importance. The results were broadly in line with this: there were two main areas that made this particular course and its language exchange sessions with other students relevant for participants: 1) students overwhelmingly believed that learning about ICC would help them develop their language learning skills and 2) they believed that improving their target language would help them in their present and future personal life, studies or professional career. The importance participants placed in this was seen throughout the exchange sessions when they related what they were learning to their daily lives. Anita 
from group 4 related the course content to her host culture in an exchange session on $14^{\text {th }}$ May:

\begin{abstract}
"I mentioned before about Costa Rica being a collectivist society. They have got that sense of community. And their families and communities are so important as a result of this that for example in this case [donating blood] I heard that in general people feel forced to go to hospitals to give blood, just for one reason: to protect their family. Because in the case of a huge important surgery, they can receive blood, transfuse, is that the word? Only in the case that one of the family are a regular donor. So in this case you could think the other way around, that they are more individualist, but no, it's because they want to protect their people. To them in every way family is really, really important."
\end{abstract}

She analyses aspects of her host culture by using complex concepts learnt during the course. By doing so she shows how she keeps the relevance of ICC present both while she is learning and practising her target language and in her daily life outside of the course. The reasons ICC is relevant to foreign language acquisition stems from the belief that language is intertwined with culture, an extension of the theory of linguistic relativity - that language shapes thought. Many authors, including Franz Boas, have explored the relationship between language and culture and concluded that language comes from a coexistence established between people and their world, and that culture is created from the interaction that happens within a given society with that language. Edward Hall borrowed Benjamin Lee Whorf's idea that language was conceived not just as a medium of expressing thought, but as a major element in the formation of thought and applied those studies to all human behaviour and their cultures. Because language, thought and culture are so closely intertwined, one cannot be fully understood without the other. Hall (1959) categorises culture into various categories so that they can be compared by and with other cultures. These categories formed the basis for the ICC course and aimed to teach students about how different cultures see the world. Hall stated that when a foreigner interacts with a new culture, they are "[...] faced with a different way of organizing life, of thinking and of conceiving the underlying assumptions about the family and the state, the economic system, and the man himself." (Hall, 1959: 26). One of the reasons why intercultural competence is so important to language learners is because much of people's culturally motivated behaviour occurs at a subconscious level; learners need to be aware of this is because it will help them better understand the messages members of those cultures are sending which are not verbalised or obvious and the 
many meanings that may be hidden from them. Because each of Hall's categories exist in every culture Gudykunst and Kim (1996) noted that learners can easily understand them if they are first aware of their own culture's perspectives of them. Once these categories were taught to the students, they could use them to compare their culture with that of their target language culture. This in turn made the course even more relevant for students. Throughout the course, students often mentioned how a second foreign language would help them in their future studies or careers and they believed that learning about ICC and practising their target language could help them to improve their foreign language skills. This belief kept them motivated throughout the course and ensured the relevance of the course was always present for them.

Current studies into online language learning are minimal. Although there is a concern about retention rates in online learning and MOOCs, there have not been thorough studies into what aspects may influence further understanding of why they are so low or how to apply the knowledge of the subject that is available. This is exactly what the findings that have emerged from this study aim to do. This study has found that several things can be done to stimulate learner motivation and minimise abandonment rates in an online foreign language course:

- Establish autonomous learning opportunities for learners. Although this does not mean completely abandoning the learner, a teacher must prepare the course and the objectives as they do in a traditional course. It is also important for a teacher to be present in order to guide the students and be contactable so that the learner does not feel completely isolated. This can also be achieved by arranging spaces where students can contact with other students.

- Provide spaces to facilitate peer communication and interaction. This will facilitate students meeting or coming together to support each-other in addition to motivating learners through their own sense of responsibilities towards their peers. This was done in this course by using Google Hangouts however there are many other technical tools that can be used to facilitate this interaction and sense of 
responsibility. Social media is imbedded in young people and digital natives' lives and is certainly one way this can ensure the interaction that is required.

- Ensure the course is relevant for learners who are accepted into the course of study. Students feel motivated when they perceive that what they are doing will be helpful for them in either the short or the long term. These concepts should be clear and repeated throughout the course in order to ensure students do not lose sight of them. 


\subsection{Limitations and future lines of investigation}

One of the limitations of the study was the small sample size that participated in the experiment. Given the size of the study it was not possible to draw any significant statistical data which would be an interesting aspect to explore. Running the course a second time in order obtain a greater sample size would allow for statistical data gathering. It may also expose any other motivational aspects of the online learning process which might also be useful for designing and preparing course structure and pedagogic methodologies. Another limitation was the fact that aspects of social networks were not analysed nor included in the study. This thesis found that that was an important issue in a learner's learning process and also found that students are naturally drawn to interacting through social media as it is so present in their everyday life. Thorpe (1998) notes that this issue has not been adequately explored because technological changes have taken place at such a fast pace. He believes, and it seems obvious from the findings in this thesis, that the potential these new technologies has brought the distance language learning field has not been completely exploited. This new way of learning and interacting in learning environments needs to be further analysed and considered in terms of creating a suitable learning theory in order to arrange and unify all these new possibilities. As McLoughlin and Lee state:

Theories that underpin technology based learning designs need to be carefully examined. It is imperative that educational technologies are conceptualized within theoretical models that relate how pedagogy can be transformed to harness the potential of social software tools for learning (McLoughlin \& Lee, 2008:642).

In addition to encouraging students to interact using the social media tools they normally do on a daily basis, future general lines of study should also be conducted into further exploiting other technological and communication tools that are available for online language learning in traditional language learning classrooms. Up until now, linguistic and cultural exchanges have been carried out as an add-on to traditional classroom teaching, there seems to be a need and trend towards these exchanges being brought to the forefront of language learning. It seems obvious that the ever more popular trend 
towards online learning - because it is an economically and conveniently viable choice for many people - will continue to grow, which is why this area must be explored more in depth. If approaches and methodologies to online foreign language learning are established on solid foundations from an early stage, future courses will be more successful in achieving their knowledge imparting objectives and in retaining students during their course of studies. 


\section{ANNEXES}

The content of each folder found in the attached CD is described in this section. 


\subsection{Annex 1}

The 'E-mail communications regarding course' folder contains two emails and one document. One email is an example discussion of contact made requesting participation with a higher education institution and their positive reply. The second is the permission granted by the University of Florida to use, modify and translate parts of their course for the purpose of this research study. The document is the announcement sent to possible participants to inform them of the course. 


\subsection{Annex 2}

The 'Structure and information for students' folder includes documents that contain the information uploaded to the platform to orientate students: the course outline, structure, objectives, description, resources and instructions on how to use the platform. It also includes the initial announcement sent to students. 


\subsection{Annex 3}

The 'Course' folder contains three folders (A, B and C).

\section{$3 \mathrm{~A}$ and $\mathrm{B}$ :}

The 'English' and 'Spanish' folders (A and B) contain the Intercultural Communication Course in English and Spanish respectively. They include the course content in addition to three other folders (i, ii, iii).

\section{$3 \mathrm{~A}$ and $\mathrm{Bi}$ :}

The 'Interactive exercise in each of the week's content' folder contains the interactive exercises that were presented together with the course content

\section{$3 A$ and $B$ ii:}

The 'Further questions for exchange sessions' folder contains a template for the Google Hangouts linguistic exchange sessions. They were questions related to that week's course content and served to reinforce concepts learnt during that week and encourage conversation between the students.

\section{$3 A$ and $B$ iii:}

The 'Scripts and MP3s recording' folder contains the MP3 format recordings for the course and their written scripts in word format.

3 C:

The third folder in the 'Course' folder. The 'Activities for language exchanges sessions' folder contains extra activities for the Google Hangouts language exchange sessions. These interactive activities can be used to reinforce concepts learnt during the course in 
general and encourage conversation between the students. 


\subsection{Annex 4}

The 'Examples of the Google Hangouts' folder includes examples of the Google Hangouts linguistic exchange sessions that were recorded 


\subsection{Annex 5}

The pre- and post-course questionnaires folder contains the pre- and post-course questionnaires 


\subsection{Annex 6}

The 'Results generated by Blackboard' folder contains the documents and statistics that are generated by the Blackboard platform in regards to user access, usage and activity on the platform. It also includes the pre- and post-course questionnaires results. 


\section{BIBLIOGRAPHY}

Abdallah-Pretceille, M. (1998). Apprendre une langue, apprendre une culture, apprendre l'altérité. Les Cahiers Pédagogiques, 360, 49-51.

Alexander, J. (1980). Threshold Level English. Oxford: Pergamon.

Analytics, L. (2012). Learning Analytics MOOC course. Last retrieved $12^{\text {th }}$ May, 2015 from https://www.edx.org/course/data-analytics-learning-utarlingtonx-link5-10x

Aoki, N., \& Smith, R. (1999). Learner autonomy in cultural context: The case of Japan. In Learner autonomy in language learning: Defining the field and effecting change (pp. 19-28). Frankfurt am Main: Lang.

Appel, C., \& Gilabert, R. (2002). Motivation and task performance in a task-based, web-based tandem project. ReCALL, 14, 16-21.

Au, S. (1988). A critical appraisal of Garner's social-sychological theory of second-language (L2) learning. Language learning, 38, 75-100.

Austin G., \& Warnock, J. (1962). Sense and Sensibilia. Oxford: Oxford University Presss.

Austin, J. (1962). Sense and Sensibilia . Oxford : Oxford University Press.

Ausubel, D. (1968). Educational psychology: A cognitive view. New York: Holt, Rinehart \& Winston.

Azadeh, S., \& Mehran, N. (2008). Global Practices of Language Teaching. IOKSP: Universal-Publishers.

Baath. (1980). Postal Two-Way Communication in Correspondence. Lund: Gleerup.

Baath, J. (1984b). Research on completion and discontinuation in distance education. Epistolodidaktika, 1, 31-34.

Baath, J. (1979). Correspondence Education in the Light of a Number. Malmö: Liber Hennods .

Baker, L., \& Brown, A. (1980). Metacognitive skills. Urbana: University of Illinois.

Bandura, A. (1986). Social foundations of thought and action: A social cognitive theory. Englewood Cliffs, NJ: Prentice-Hall.

Bandura, A. (2000). Exercise of human agency through collective efficacy. Current Directions in Psychological Science, 9, 75-78.

Bandura, A. (2001). Social cognitive theory: An agentic perspective. Annual review of psychology, 52, 126.

Bates, A. (2012). What's right and what's wrong about Coursera-style MOOCs? 
Beatty, K., \& Nuan, D. (2004). Computer-mediated collaborative learning. Systems, 32, 165-183.

Beeman, W. (1987). Hypertext and Pluralism: From Lineal to Non lineal Thinking. Proceedings of the ACM conference on Hypertext (pp. 67-88). New York: AMC.

Beltran, L., Salo-Lee, L., \& Maestro, J. (2002). European Peripheries in Interaction: The Nordic Countries and the Iberian Peninsula. Madrid: Universidad de Alcala Servicio de Publicacion.

Belz, J. (2007). The development of intercultural communicative competence in telecollaborative partnerships. In R. O'Dowd, Online intercultural exchange: An introduction for foreign language teachers (pp. 127-166). Clevedon: Multilingual Matters.

Belz, J. (2002). Social dimensions of telecollaborative foreign langauge study. Language Learning \& Technology, 6, 60-81.

Benson, P. (1997). The philosophy and politics of learner autonomy. In P., \& Benson, Autonomy and Independence in Language Learning (pp. 18-34). London: Longman.

Benson, P. (1996). Concepts of autonomy in language learning. In S. E. R. Pemberton (Ed.), Taking Control: Autonomy in Language Learning (pp. 27-34). Hong Kong: Hong Kong University Press.

Benson, P. (2001). Teaching and researching autonomy (2 ed.). Harlow: Pearson Education.

Benson, P. (2007). Learner Autonomy 8: Teacher and Learner Perspectives. (P. Benson, Ed.) Dublin: Authentik.

Benson, P., \& Voller, P. (1997). Introduction. In P., \& Benson, Autonomy and Independence in Language Learning (pp. 1-13). London; New York: Longman.

Benson, P., \& Voller, P. (1997). Autonomy and independence in language learning. London: Longman.

Ben-Zvi, D. (2000). Towards understanding the role of technical tools in learning. Thinking and learning, 127-155.

Berge, Z. (2002). Active, interactive, and reflective e-learning. The Quarterly Review of Distance Education, 3, 181-190.

Berge, Z. (2004). A model for sustainable student retention: A holistic perspective on the student dropout problem with special attention to e-Learning. American center for the study of distance education, Online.

Blattner, G., \& Fiori, M. (2009). Facebook in the language classroom: Promises and possibilities. International Journal of Instructional Technology and Distance Learning, Online.

Blay, T. (1994). How to reactivate drop-outs. Epistolodidaktika: The European journal of distance education, 1, 40-48. 
Blue, G. (1988). Self-assessment: The limits of learner independence. In A. B. Grundy (Ed.), Individualization and autonomy in language learning (pp. 100-118). London: Modern English Publications/British Council.

Boas, F. (1887). Museums of Ethnology and their classification. Science, 9.

Boas, F. (1989). A Franz Boas Reader: The Shaping of American Anthropology, 1883-1911. Chicago: University of Chicago Press

Bobb-Wolff, L. (2002). Assessment: Changing assumptions and attitudes. In M. A. F. Vieira (Ed.), Pedagogy for autonomy and English learning (pp. Proceedings of the 1st conference of the working group - Pedagogy for autonomy). Braga: University of Minho.

Bochner, S. (1982). Cultures in Contact: Studies in Cross-Cultural Interaction. New York: Pergamon Press.

Bodley, J. (1994). Cultural Anthropology: Tribes, States, and the Global System. Mountain View, CA: Mayfield Publishing Co.

Bodner, G. (1986). Constructivism: A theory of knowledge. Journal of Chemical Education, 63(10), 873878.

Bogdan, R., \& Knopp Biklen, S. (1997). Qualitative research for education. Boston: Allyn \& Bacon.

Boroditsky, L. (2000). Metaphoric Structuring: Understanding time through spatial metaphors. Cognition, $75(1), 1-28$.

Boroditsky, L. (2001). Does language shape thought? English and Mandarin speakers' conceptions of time. Cognitive Psychology, 43(1), 1-22.

Boroditsky, L. (2003). Linguistic relativity. In L. Nadel, Encyclopedia of cognitive science (pp. 917-922). London: Macmillan.

Boroditsky, L. (2010, July 23). Lost in translation. The Wall Street Journal. Last retrieved $12^{\text {th }}$ May, 2015 from http://www.wsj.com/articles/SB10001424052748703467304575383131592767868

Boroditsky, L. (2011, February). How language shapes thought. Scientific American, 63-65.

Boroditsky, L. (2003). Sex, Syntax, and Semantics. In D. G. Goldin-Meadow, Language in mind: Advances in the study of language and cognition (pp. 61-80). Cambridge: A Bradford Book - The MIT Press.

Boroditsky, L., \& Ramscar, M. (2002). The roles of body and mind in abstract thought. Psychological Science, 13(2), 185-188.

Boud, D. (2001). Introduction. In D. C. Boud, Peer Learning in Higher Education: Learning from and with Each Other (pp. 1-21). New York: Routledge. 
Boud, D. (1999). Peer learning and assessment. Assessment \& Evaluation in Higher Education, 24(4), 413-426.

Boud, D. (2001). Peer Learning in Higher Education: Learning from and with Each Other. New York: Routledge.

Bourdieu, P. (1984). Distinction: A Social Critique of the Judgement of Taste. Oxon: Routledge.

Bourdieu, P. (1990). The Logic of Practice. Cambridge: Polity Press.

Breen, M. (1997). Shooting arrows at the sun: Perspectives on a pedagogy for autonomy. In P. B. Voller (Ed.), Autonomy and independence in language learning (pp. 132-149). London: Longman.

Brislin, R. (1981). Cross-Cultural Encounters: Face-to-Face Interaction. New York: Pergamon Press.

Brislin, R. (1980). Cross Cultural Encounters Face to Face Interaction. Boston: Allyn \& Bacon.

Brooks, N. (1960). Language and language learning. New York: Harcourt, Brace and World.

Brown, H. (1987). Principles of Language Learning and Teaching. Englewood Cliffs, New Jersey : Prentice Hall.

Brown, H. (1994). Teaching by principles. Englewood Cliffs, NJ: Prentice Hall.

Brown, J. (1989). Anchored instruction and situated cognition revisited. Educational Technology, 33(3), 5270.

Brown, J. (1989). Situated Cognition and the Culture of Learning. Educational Researcher, 18(1), 32-42.

Brown, R., \& Lenneberg, E. (1954). A study in language and cognition. The Journal of Abnormal and Social Psychology, 49(3), 454-462.

Bruner, J. (1960). The Process of Education. Cambridge: Harvard University Press.

Bruner, J. (1966). Toward a theory of instruction. Cambridge: Harvard University Press.

Bruner, J. (1973). Beyond the Information Given: Studies in the Psychology of Knowing. New York: W. W. Norton \& Company.

Bruner, J. (1985). Child's talk: Learning to use language. Child Language Teaching and Therapy, 111-114.

Bruner, J. (1986). Actual Minds, Possible Worlds. Cambridge: Harvard University Press.

Bruner, J. (1990). Acts of Meaning. Cambridge: Harvard University Press.

Bruner, J. (1996). The culture of education. Cambridge MA: Harvard University Pres.

Buttjes, D., \& Bryam, M. (1991). Mediating Languages and Cultures. Clevedon: Multilingual Matters.

Byram, M. (1997). Teaching and Assessing Intercultural Communicative Competence . Clevedon: Multilingual Matters. 
Byram, M. (2002). Developing the intercultural dimension: A practical guide for teachers. Strasbourg: Language Policy Division - Council of Europe.

Byram, M. (2001). Developing Intercultural Competence in Practice. Clevedon: Multilingual Matters.

Candlin, M. (1980). The Communicative Curriculum in Language Teaching. London: Longman.

Comaroff, J. \& Comaroff, J. (1992). Ethnography and the Historical Imagination (Studies in the Ethnographic Imagination). Boulder: Westview Press

Carr, S. (2000). As distance education comes of age, the challenge is keeping the students. The Chronicle of Higher Education, 46(23), 39-41.

Carrió-Pastor, M. (2010). The Collaborative Approach in Content and Language Integrated Learning. Revista Alicantina de Estudios Ingleses, 23, 69-81.

Carrió-Pastor, M. (2011). Multiple Voices in Academic and Professional Discourse: Current Issues in Speacilised Language Research, Teaching and New Technologies. In S. Maruenda-Bataller \& B. Clavel-Arroitia (Eds.), Collaborative Teaching Strategies: The Internet In Content And Language Integrated Learning. (pp. 32-45). Newcastle: Cambridge Scholars Publishing.

Carrió-Pastor, M. (2013). Motivation in Second Language Acquisition. Procedia - Social and Behavioral Sciences, 116, 240-244.

Carroll, J. (1966). The Contributions of Psychological Theory and Education Research to the Teaching of Foreign Language. In A. Valdman, Trends in Language Teaching (pp. 102-152). New York: McGraw Hill.

Carroll, J. (1966). The Contributions of Psychological Theory and Education Research to the Teaching of Foreign Languages. In A. Valdman, Trends in Language Teaching (Vol. 49, pp. 99-108). New York: McGraw-Hill.

Carter, K. (1993). The place of story in the study of teaching and teacher education. Educational Researcher, 22, 5-12.

Carver, D., \& Dickinson, L. (1982). Learning to be self-directed. In M. G. Sturtridge (Ed.), Individualisation (pp. 15-21). Basingstoke: Modern English Publications Ltd (Macmillan).

Cashman, S. (2010). Web 2.0: Concepts and Applications. Boston: Cengage Learning.

Casmir, F. (1997). Ethics in intercultural and international communication. New York: Routledge .

Caulk, N. (1994). Comparing teacher and student responses to written work. TESOL, 28, 181-188.

Cavallaro, F., \& Tan, K. (2006). Computer-mediated peer-to-peer mentoring. AACE Journal, 14(2), 129138. 
Charmaz, K. (2005). Grounded theory in the 21st Century. In N. K. Denzin, The Sage handbook of qualitative research (pp. 507-535). Thousand Oaks: SAGE.

Chomsky, N. (1957). Syntactic Structures. Berlin: Walter de Gruyter.

Clarke, M., \& Silberstein, S. (1977). Toward a realization of the psycholinguistic principles in the ESL reading class. Language Learning, 21(1), 135-154.

Clarke, M., \& Silberstien, S. (1977). Toward a realization of the psycholinguistic principles in the ESL reading class. Language Learning, 21(1), 135-154.

Clément, R., Dörnyei, Z., \& Noels, K. (1994). Motivation, self-confidence and group cohesion in the foreign language classroom. Language Learning, 44, 417-448.

Cohen, B. (1972). Sociology. New York: McGraw-Hill Companies.

Cohen, L., \& Manio, L. (1994). Triangulation. In L. M. Cohen, Research Methods in Education. London: Routledge.

Cohen, L., \& Manio, L. (1994). Educational research methodology. Athens: Metaixmio.

Cole, P. (1984). Current activity for the future: The Zo-ped. In B. R. Wertsch, Children's learning in the zone of proximal development (pp. 45-64). San Fransisco: Jossey-Bass.

Comaroff, J. (1992). Ethnography And The Historical Imagination. Boulder, Colorado: Westview Press.

Conklin, J. (1987). Hypertext: An Introduction and Survey. IEEE Computer, 20, 17-41.

Conole, G. (2013). MOOCs as disruptive technologies: strategies for enhancing the learner experience and quality of MOOCs. Revista de Educación a Distancia, 39, 1-17.

Corbin, J., \& Anselm, S. (2014). Basics of qualitative research: Techniques and procedures for developing grounded theory. Boston: Sage publications.

Crookes, G., \& Schmidt, R. (1991). Motivation: 'Reopening the research agenda'. Language Learning , $41(4), 469-512$.

Cross, K. (1998). Why learning communities? Why now? About Campus, 3(3), 4-11.

Cummins, J., \& Sayers, D. (1995). Brave New Schools. Challenging Cultural Literacy Through Global Learning Networks. New York: St. Martin's Press.

Dam, L. (1991). Learner autonomy 3: from theory to classroom practice. Dublin: Authentik.

Dam, L. (1994). How do we recognize an autonomous classroom? . Die Neuere Sprache , 93(5), 503-527.

Dam, L. (1995). Learner autonomy 3: From theory to classroom practice. Dublin: Authentik. 
Dam, L., \& Gabrielsen, G. (1988). Developing learner autonomy in a school context - A six-year experiment beginning in the learners' first year of English. In H. Holec (Ed.), Autonomy and selfdirected learning: Present fields of application (pp. 19-30). Strasbourg: Council of Europe.

Dam, L., Eriksson, R., Little, D., Millander, J., \& Trebbi, T. (1990). Towards a definition of Autonomy. In T. Trebbi (Ed.) Third Nordic Workshop on developing autonomous learning in the FL classroom (pp1119). Bergen: University of Bergen.

Daniel, J. (2012). Making Sense of MOOCs: Musings in a Maze of Myth, Paradox and Possibility. Journal of Interactive Media in Education, 3, 1-18.

Daniel, J. (1982). Learning at a distance: a world perspective. Edmonton:: Athabasca University.

Daniels, B. (2008). Motivation, academic success, and learning environments: Comparing high school face-to-face and online courses. Kuala Lumpur: University of Malaya.

Davis, K. (1992). Validity and reliability in qualitative research on second language acquisition and teaching. TESOL Quarterly, 605-608.

Deardoff, D. (2006). Identification and Assessment of Intercultural Competence as a Student Outcome of Internationalization. Journal of Studies in International Education, 10(3), 241-266.

Deardorff, D. (2009). The SAGE handbook of intercultural competence (2 ed.). California: SAGE Publications.

Deci, E., \& Flaste, R. (1995). Why We Do What We Do. The Dynamics of Personal Autonomy. New York: Putman.

Deci, E., \& Ryan, R. (1985). Intrinsic Motivation and Self-Determination in Human Behavior. New York: Plenum Press.

Deci, E., \& Ryan, R. (2002). Handbook of Self-Determination Research. Rochester: The University of Rochester Press.

Delahoussaye, M., \& Zemke, R. (2001). 10 things we know for sure about learning online. Training, 38(9), 48-59.

Delling, R. (1987). Towards a theory of distance education. ICDE Bulletin, 13, 21-25.

Dempsey, J. (2007). Distributed Learning and the Field of Instructional. In J. V. Dempsey, Trends and issues in (pp. 288-300). Upper Saddle River: Pearson.

Deutscher, G. (2010). Through the Language Glass: Why the World Looks Different in Other Languages. New York: Metropolitan Books. 
Develotte, C. (2010). The use of the webcam for teaching a foreign language in a desktop videoconferencing environment. ReCALL, 22, 293-312.

deWaard, I. (2011). Using mLearning and MOOCs to understand chaos, emergence, and complexity in education. The International Review of Research in Open \& Distance Learning, 12, 94-115.

Dewey, J. (1938). Experience and education. New York: Macmillan.

Dewey, J. (2004). Democracy and Education: An introduction to the philosophy of education. New York: Courier Corporation.

Dewey, J. (2007). How We Think. Kansas City: Neeland Media LLC.

Diaz, D. (2002). Online drop rates revisited. The Technology Source. Last retrieved $12^{\text {th }}$ May, 2015 from http://technologysource.org/article/online_drop_rates_revisited/

Dickinson, L. (1976). Self-directed learning and autonomy. Cambridge: Cambridge University Press.

Dickinson, L. (1978). Autonomy, self-directed learning and individualization. In E. D. 103 (Ed.), Individualization and Autonomy in Language Learning (pp. 7-28). London: Modern English Publications and the British Council.

Dickinson, L. (1987). Self-instruction in language learning. Cambridge: Cambridge University Press.

Dickinson, L. (1992). Learner Autonomy 2: Learner Training for Language Learning. Dublin: Authentik.

Dirckinck-Holmfeld, L. (2009). Analysing Networked Learning Practices in Higher Education and Continuing Professional Development. Rotterdam: Sense Publishers.

Dooly, M. (2008). Telecollaborative language learning. Bern: Peter Lang.

Dörnyei, Z. (1994). Motivation and Motivating in the Foreign Language Classroom. The Modern Language Journa, 78(3), 273-284.

Dörnyei, Z. (1997). Psychological processes in cooperative language learning: group dynamics and motivation. The Modern Language Journal, 81, 482-493.

Dörnyei, Z. (2001). Teaching and Researching Motivation. London: Pearson Education Limited.

Dörnyei, Z. (2007). Research Methods in Applied Linguistics. Oxford: Oxford University Press.

Dörnyei, Z., \& Csizér, K. (1998). Ten commandments for motivating language learners: results of an empirical study. Language Teaching Research , 2(3), 203-229.

Dörnyei, Z., \& Ushioda, E. (2013). Teaching and Researching: Motivation. New York: Routledge.

Downes, S. (2006). Learning networks and connective knowledge. Instructional Technology Forum, Paper 92. 
Downes, S. (2008). An Introduction to Connective Knowledge. In T. Hug, Media, Knowledge \& Education Exploring new Spaces, Relations and Dynamics in Digital Media Ecologies (pp. 77-102). Innsbruck: Innsbruck university press.

Downes, S. (2009). Learning Networks and Connective Knowledge. In H., \&-Y. Hao Yang, Collective Intelligence and E-Learning 2.0: Implications of Web-Based Communities and Networking (pp. 127). Hershey: Information Science Reference (IGI Global).

Driscoll, M. (2005). Psychology of Learning for Instruction. New York: Allin \& Bacon.

Eckman, F. (1995). Studies in Second Language Acquisition Theory and Pedagogy. New York: Routledge.

Ellis, G., \& Sinclair, B. (1989). Learning to learn English: a course in learner training. Cambridge: Cambridge University Press.

Ellis, R. (1997). The study of second language acquisition. Oxford : Oxford University Press.

Erickson, F. (2004). Demystifying data construction and analysis. Anthropology \& education quarterly, 486493.

Esch, E. (1997). Learner training for autonomous language learning. In . In P. B. Voller (Ed.), AUtonomy and independence in language learning (pp. 164-176). London: Longman.

Esch, E. (2009). Crash or clash? Autonomy 10 years on. In R. T. Pemberton (Ed.), Maintaining control: Autonomy and language learning (pp. 27-44). Hong Kong: Hong Kong University press.

Esch, E., \& Zähner C. (2000). The Contribution of ICT to Language Learning Environments or the Mystery of the Secret Agent. ReCALL, 5-18.

European Council. (2002). Common European framework of reference for languages: Learning, Teaching, Assessment. Strasbourg: Cambridge University Press - Modern Languages Division.

Farris-Berg, K. (2005). Listening to student vioces on technology - A summary of available research on student attitudes, perceptions, and behavior. Saint Paul, Minnesota: Education evolving.

Fausey, C. (2010). Constructing Agency: The Role of Language. Front Psychol, 1, 162.

Felder, R., \& Silverman, L. (1988). Learning and teaching styles in engineering education. ngr. Education, 78, 674-681.

Fini, A. (2009). The technological dimension of a massive open online course: The case of the CCK08 course tools. The International Review of Research in Open and Distance learning, 10, online.

Fleming, S. (2002). Foreign language distance education: The University of Hawaii experience. In C. A. Spreen, New technologies and language learning: Cases in less commonly taught langauges (pp. 13-54). Honolulu: University of Hawai'i, Second Language Teaching \& Curriculum Center. 
Flick, U. (2009). An Introduction to Qualitative Research. London: Sage.

Flinck, R. (2003). Introduction. In V. Rao, Distance Education (p. 370). Kashmir: APH Publishing Corporation.

Forsyth, D. (2006). Group Dynamics (5th ed.). Wadsworth: Cengage Learning.

Friesen, P., \& Ekman, W. (1969). The repertoire or nonverbal behavior: categories, origins, usage, and coding. Semiotica, 49-98.

Furstenberg, G. (2001). Giving a virtual voice to the silent language of culture: the Culture Project. Language Learning and Technology, 5(1), 55-102.

Gagne, R. (1970). Conditions of Learning. Austin : Holt,Rinehart \& Winston of Canada Ltd.

Gagne, R. (1977). Conditions of learning (3 ed.). Connecticut: Thomson Learning.

Gardner, R. (1983). Learning another language: A true social psychological experiment. Journal of Language and Social Psychology, 2, 219-239.

Gardner, R. (1985). Social Psychology and Second Language Learning: the Role of Attitudes and Motivation. London: Edward Arnold.

Gardner, R. (1992). Second language learning in adults: Correlates of proficiency. Applied Language Learning, 2(1), 1-28.

Gardner, R. (2010). Motivation and Second Language Acquisition: The Socio-Educational Model. New York: Peter Lang Publishing.

Gardner, R, \& Lambert, W. (1972). Attitudes and motivation in Second Language acquisition. Canadian Journal of Psychology, 13, 266-272.

Garland, M. (1993a). Student perceptions of the situational, institutional, dispositional and epistemological barriers to persistence. Distance Education, 14 (2), 181-198.

Garrison, D. (1985). Three generations of technological innovations in distance education. Distance Education, 6, 235-241.

Garrison, D. (1989). Understanding distance education. A framework for the future. London: Routledge.

Garrison, D. (1997). Self-directed learning: Toward a comprehensive model. Adult Education Quarterly, 48 (1), 18-33.

Garrison, D. (2003). E-Learning in the 21st century: A framework for research and practice. London: Routledge/Falmer.

Ge, X. (2000). Pre-class planning to scaffold students for online collaboration learning activities. Educational Technology and Society, 3(3), 1-16. 
Geertz, C. (1973). The interpretation of cultures. New York: Basic Books.

Geertz, C. (1994). Thick description: Toward an interpretive theory of culture. Readings in the philosophy of social science, 213-231.

Gibson, C. (1996). Toward an understanding of academic self-concept in distance education. American Journal of Distance Education, 10(1), 23-36.

Giddens, A. (1976). New Rules of Sociological Method. London: Hutchinson.

Gill, W., \& Powel, C. (2003). Web content management systems in higher education. Educause Quarterly, 26(2), 43-50.

Glaser, B., \& Strauss, A. (1967). The discovery grounded theory: strategies for qualitative inquiry. Chicago: Aldin.

Goetz, J. (1984). Ethnography and qualitative design in educational research. Orlando: FL: Academic Press.

González, J. (1986). Cultura(s). Mexico D.F.: Universidad de Colima.

Goodenough, W. (1957). Cultural Anthropology and Linguistics. Georgetown University Monograph Series on Language and Linguistics, 167-173.

Gremmo, M., \& Riley, P. (1995). Autonomy, self-direction and self-access in language teaching and learning: the history of an idea. System, 23(2), 151-64.

Gudykunst, W. (2004). Bridging Differences. California - Thousand Oaks: Sage Publications.

Gudykunst, W. (2003). Cross-Cultural and Intercultural Communication . New York: SAGE Publications.

Gudykunst, W., \& Ting-Toomey, S. (1988). Culture and interpersonal communication. Newbury Park: SAGE Publications.

Guth, S., \& Helm, F. (2010). Introduction. In S., \& Guth, Telecollaboration 2.0: Language, literacy and intercultural learning in the 21st century (pp. 69-106). Bern: Peter Lang.

Hains, A. (2000). Moving towards cross-cultural competence in lifelong personnel development: A review of the literature. Champaign: University of Illinois at Urbana Champaign Early Childhood Research Institute on Culturally and Linguistically Appropriate Services.

Hall, D., \& Beggs, E. (1998). Defining learner autonomy. In Learners and language learning (pp. 26-39). Singapore: SEAMO Regional Language Centre.

Hall, E. (1959). The Silent Language. New York: Random House - Doubleday division.

Hall, E. (1966). The Hidden Dimension. New York: Random House - Doubleday division. 
Hall, E. (1976). Beyond Culture. New York: Anchor Books - Random House.

Hall, E. (1983). The Dance of Life: The Other Dimension of Time. New York: Anchor Books - Random House.

Hall, E. (1990). The Hidden Dimension. New York: Anchor Books.

Hall, E. (1997). Beyond Culture. New York: Anchor Books.

Halliday, M. (1961). Categories of the theory of grammar. Word, 17(3), 241-92.

Halliday, M. (1973). Explorations in the Functions of Language. London: Edward Arnold.

Halliday, M. (1973). Explorations in the Functions of Language. London: Edward Arnold.

Halliday, M. (1973). Explorations in the Functions of Language. Hodder \& Stoughton: London.

Hampel, R., \& Hauck, M. (2004). Towards an effective use of audio-conferencing in distance language courses. Language Learning and Technology (LLT), 8, 66-82.

Harasim, L. (1990). Online Education: an environment for collaboration and intellectual amplification. New York: Praeger.

Harrasim, L. (1999). What are we learning about teaching and learning online: An anlysis of the Virtual-U field trials. Réseau des centres d'excellence en téléapprentissage., Online.

Harvey, S., Emanuel, S., \& Gail, J. (1974). A Simplest Systematics for the Organization of Turn-Taking for Conversation. Language, 50(4), 696-735.

Henner-Stanchina, C., \& Riley, C. (1978). Aspects of autonomous learning. In B. council (Ed.), Individualization in language learning. London: ETIC Publications.

Hennink, M, Hutter, I, Bailey, A. (2001). Qualitative Research Methods. London: Sage.

Hidi, S., \& Ainley, M. (2008). Interest and self-regulation: Relationships. In D. H. Zimmerman (Ed.), Motivation and Self-Regulated Learning: Theory, Research, and Applications (pp. 78-109). Mahwah, NJ: Lawrence Erlbaum Associates.

Hill, J. (1996). Distance Learning Environments Via the World Wide Web. In B. Khan, Web-Based Instruction. New Jersey: Educational Techology Publications.

Hiltz, S., \& Turoff, M. (1978). The Network Nation: Human Communication via Computer,. New York: Addison-Wesley Publishing Co.

Hiple, D., \& Fleming, S. (2002). Models for distance education in critical languages. In Spreen, 1-12.

Ho, M. (1998). Culture studies and motivation in foreign and second language learning in Taiwan. Language, Culture and Curriculum, 11(2), 165-182. 
Hofstede, G. (2001). Culture's Consequences: Comparing Values, Behaviours, Institutions and Organizations Across Nations. Thousand Oaks CA: SAGE Publications.

Hofstede, G. (1980). Culture's Consequences: International Differences in Work-Related Values. Beverly Hills CA: Sage Publications.

Hofstede, G. (1984). Culture's Consequences. New York: SAGE Publications.

Hofstede, G. (1984). National cultures and corporate cultures. Belmont, CA: Wadsworth.

Hofstede, G. (1991). Cultures and Organizations: Intercultural cooperation and its importance for survival. New York: McGraw-Hill.

Hofstede, G. (2002). Exploring Culture: Exercises, Stories and Synthetic Cultures. Yarmouth: Intercultural Press.

Hofstede, G. (2011). Dimensionalizing cultures: The Hofstede model in context. Online readings in psychology and culture , 2, 1-8.

Hofstede, G., \& Pedersen, P. (2002). Exploring Culture: Exercises, Stories and Synthetic Cultures. London: Intercultural Press.

Holec, H. (1980). Learner training: Meeting needs in self-directed learning. In H. B. James (Ed.), Foreign language learning: Meeting individual needs (pp. 30-45). Oxford: Pergamon.

Holec, H. (1981). Autonomy and foreign language learning. Oxford: Pergamon.

Holec, H. (1985). On autonomy: Some elementary concept. In P. Riley (Ed.), Discourse and learning (pp. 173-190). London: Longman.

Holmberg, B. (1983). Guided didactic conversation in distance education. In D. K. D. Sewart, Distance education: International perspectives (pp. 114-122). London: Croom Helm (Routledge).

Holmberg, B. (1985). Status and Trends of Distance Education. London: Kogan Page.

Holmberg, B. (1986). Growth and Structure of Distance Education. London/Syndey: Croom Helm.

Holmberg, B. (1989b). The concepts and applications of distance education and open learning. International Journal of Innovative Higher Education, 6, 24-28.

Holmberg, B. (1995). Theory and practice of distance education. London and New York: Routledge.

Holmberg, B. (2005). Distance education and languages: Evolution and change. Clevedon: Multilingual Matters.

Hoover, W. (1996). The practice implications of constructivism. SEDL Letter, 9(3), 1-12. 
Horowitz, F. (2005). Educating teachers for developmentally appropriate practice. In L. D.-H. Bransford, Preparing teachers for a changing world: What teachers should learn and be able to do (pp. 88125). San Fransisco: Jossey-Bass.

Howland, J. (2002). Student perceptions as distance learners in Internet-based courses. Distance Education, 23(2), 183-195.

Hulsizer, M., \& Woolf, L. (2009). A guide to teaching statistics: Innovations and best practices. Oxford: Wiley-Blackwell.

Hurd, S. (2001). Managing and supporting language learners in open and distance learning environments. In M. M.-M. Vismans, Beyond language teaching towards language advising (pp. 135-148). London: CILT.

Hymel, S., Comfort, C., Schonert-Reichl, K., \& McDougall, P. (1996). Academic failure and school dropout: The influence of peers. In Social motivation: Understanding children's school adjustment (pp. 313345). New York: Cambrdige University Press.

Hymes, D. (1967). Models of the interaction of language and social setting. Journal of Social Issues, 23(2), 8-38.

Illich, I. (1971). Deschooling society. New York: Harper \& Row.

Innes, S. (1982). Teaching languages through the BBC. Teaching at a Distance, 21, 56-59.

Ipsos MORI. (2007). Student expectations study: Key findings from online research and. UK and Ireland: Joint Information Systems Committee.

Jefferson, W. (2000). Doing Qualitative Research Differently: Free association, narrative and the interview method. London: Sage.

Jiménez Raya, M. (2007). Pedagogy for Autonomy in Language Education in Europe - Towards a framework for learner and teacher development. Dublin: Authentik.

Johnson, D., \& Johnson, R.(1991). Learning together and alone: Cooperative, competitive, and individualistic. New Jersey: Prentice Hall.

Johnson, D., \& Johnson, R. (1996). Cooperation and the use of technology. In D. Jonassen (Ed.), Handbook of research for educational telecommunications and technology (pp. 1017-1044). New York: Simon \& Schuster.

Johnson, S. (2003). An instructional strategy framework for online learning environments. In S. R. Aragon, Facilitating learning in online environments (pp. 31-43). San Francisco: Jossey-Bass.

Jones, S. (1995). Understanding community in the information age. In S. G. Jones, Cybersociety: Computer-Mediated Communication and Community (pp. 10-35). Thousand Oaks CA: Sage. 
Jones, S. (2003). Encyclopedia of New Media: An Essential Reference to Communication and Technology. New Tork: SAGE Publications / The Moschovitis Group.

Kagan, S. (1985). Co-op Co-op: A flexible cooperative learning technique. In S. S.-L. R.E. Slavin, Learning to cooperate: Cooperating to learn. New York: Plenum.

Kagan, S. (1989/90). The structural approach to cooperative learning. Educational Leadership, 47(4), 12 16.

Kalman, C., Bolotin, M., \& Antimirova, T. (2010). Comparison of the effectiveness of collaborative groups and peer instruction. Canadian Journal of Physics, 88(5), 325-332.

Kaye, A., \& Rumble, G. (1981). Distance Teaching for Higher and. London: Croom Helm/Open University.

Keegan, D. (1990). The Foundations of Distance Education. London: Crom Helm.

Keesing, R. (1997). Cultural Anthropology: A Contemporary Perspective. Ohio: Wadsworth Publishing Co Inc.

Keiner, L., \& Burns, T. (2010). Interactive engagement: How much is enough? . The Physics Teacher, $48(2), 108-111$.

Keller, J. (1983). Motivation design of instruction. In Instructional-design theories and models: An overview of their current status (C. Reigeluth ed., pp. 383-434). New Jersey: Lawrence Erlbaum Associates.

Keller, J. (1984). The use of the ARCS model of motivation in teacher training. In K. S. Trott (Ed.), Aspects of Educational Technology Volume XVII: staff Development and Career Updating (pp. 140-145). London: Kogan Page.

Kelly, R. (1996). Language counselling for learner autonomy: The skilled helper in self-access language learning. In e. a. R. Pemberton (Ed.), Taking control: Autonomy in language learning (pp. 93-113). Hong Kong: Hong Kong University Press.

Kember, D. (1990). The use of a model to derive interventions which might reduce drop-out from distance education courses. Higher Education, 20, 11-24.

Kern, R., Ware, P., \& Warschauer. M. (2004). Crossing frontiers: New directions in online pedagogy and research. Annual Review of Applied Linguistics, 24, 243-260.

Kern, R., \& Warschauer, M. (2008). Network-based language teaching. In N. V. Deusen-Scholl \& N. H. Hornberger. Encyclopedia of language and education (pp. 281-292). New York: Springer.

Keshavarz, M. (1997). Contrastive Analysis and Error Analysis. Tehran: Rahnama Press.

Kim, B. (1996). Communicating With Strangers: An Approach to Intercultural Communication (3 ed.). New York: Mcgraw-Hill College. 
Kluckhohn, F. (1973). Variations in value orientations. Westport CT: Green-wood Press.

Knapp, M. (1972). Nonverbal Communication in Human Interaction. New York: Holt, Rinehart and Winston, Inc.

Knowles, M. (1975). Self-directed Learning: A guide for learners and teachers. New York: The Adult Education Company.

Koester, M. (1999). Intercultural Competence: interpersonal communication across culture. New York: HarperCollins.

Kop, R. (2011). A pedagogy of abundance or a pedagogy to support human beings? Participant support on massive open online courses. The International Review of Research in Open and Distance Learning, 12(7), 74-93.

Kötter, M. (2003). Negotiation of meaning and codeswitching in online tandems. Language Learning \& Technology, 145-172.

Kozulin, A. (1990). Vygotsky's psychoiogy: A biography of ideas. Cambridge: Harvard University Press.

Kozulin, A. (2003). Vygotsky's educational theory in cultural context. Cambridge: Cambridge University Press.

Kramsch, C. (1993). Context and culture in language teaching. Oxford: Oxford University Press.

Kramsch, C. (1998). Language and Culture. Oxford: Oxford University Press.

Kramsch, C. (2003). Language acquisition and language socialization: Ecological perspectives. London: Continuum.

Kramsch, C., \& Thorne, S. (2002). Foreign Language Learning as Global Communicative Practice. In D.

Block, \& D. Cameron, Globalization and Language Teaching (pp. 83-100). London: Routledge.

Krapp, A. (2002). An educational-psychological theory of interest and its relation to SDT. In E. L. Ryan (Ed.), Handbook of self-determination research (pp. 405-427). Rochester, NY: University of Rochester Press.

Krashen, S. (1998). Foreign Language Education the Easy Way. Culver City: Language Education Association.

Krashen, S. (1982). Principles and Practice in Second Language Acquisition. Hayward, CA: Alemany Press.

Krashen, S. (1988). Second Language Acquisition and Second Language Learning. New Jersey: Prentice Hall. 
Kumaravadivelu, B. (2003). Beyond methods: Macrostrategies for language teaching. New Haven, NH: Yale University Press.

Lado, R. (1957). Linguistics Across Cultures: Applied Linguistics for Language Teachers. Michigan: University of Michigan Press ELT.

Lado, R. (1957). Linguistics Across Cultures: Applied Linguistics for Language Teachers. Ann Arbor: University of Michigan Press ELT.

Lake, D. (1999). Reducing isolation for distance students: An online initiative. In N. S. K. Martin, Teaching in the disciplines /learning in context (pp. 210-214). Perth: University of Western Australia.

Lake, D. (1999). Reducing isolation for distance students: An online initiative. In Teaching in the disciplines /learning in context: Proceedings of the 8th Annual Teaching and Learning Forum (pp. 210-214). Perth: University of Western Australia.

Lake, D. (1999). Reducing isolation for distance students: An on-line initiative. Open Learning, 14(3), 1423.

Lakoff, G. (1985). Women, Fire and Dangerous Things. Chicago: University of Chicago Press.

Lamb, T. (2001). Metacognition and motivation: learning to learn. In G. Chambers (Ed.), Reflections on Motivation (pp. 85-93). London: CILT.

Lantolf, J. (2003). Intrapersonal communication and internalisation in the second language classroom. In A. G. Kozulin, Vygotsk y's Educational Theory in Cultural Context (pp. 349-70). Cambridge: Cambridge University Press.

Leach, E. (1976). Culture and Communication: The Logic by which Symbols Are Connected. . New York: Cambridge University Press.

Lee, J. (2002). The impact of self-efficacy and task value on satisfaction and performance in a Web-based course. Orlando, Florida: University of Central Florida.

Lee, J., \& Gibson, C. (2003). Developing self-direction in an online course through computer-mediated interaction. TheAmerican Journal of Distance Education, 17(3), 173-187.

Legenhausen, L. (1999). The emergence and use of grammatical structures in conversational interactions: comparing traditional and autonomous learners. In B. M. Multhaup (Ed.), The construction of knowledge, learner autonomy and related issues in foreign language learning (pp. 27-40). Tübingen: Stauffenberg. 
Legenhausen, L. (2003). Second language acquisition in an autonomous learning environment. In D. Little (Ed.), Learner autonomy in foreign language classrooms: teacher, learner, curriculum and assessment (pp. 65-77). Dublin: Authentik.

Leiner, B. (2009). A brief history of the internet. ACM SIGCOMM Computer Communication Review, 39 (5), 22-31.

Levy, M. (1990). Concordances and their integration into word-processing environment for language learners. System, 18, 177-188.

Lewis, M., Sullivan, M., Stanger, C., \& Weiss, M. (1989). Self development and self-conscious emotions. Child development, 146-156.

Linder, P. (1982). Individualisation in our secondary school. In Individualisation (pp. 22-23). London: Modern English Publications.

Little, D. (1990). Autonomy and language learning: Some theoretical and practical considerations. In I. Gathercole, Autonomy in language learning (pp. 7-15). London: Centre for Information on Language Teaching.

Little, D. (1991). Learner Autonomy 1: Definitions, Issues and Problems. Dublin: Authentik.

Little, D. (1991). Learner autonomy 1: definitions, issues and problems. Dublin: Authentik.

Little, D. (1995). Learning as dialogue: the dependence of learner autonomy on teacher autonomy. System, 23(2), 175-181.

Little, D. (1995). Learning as dialogue: the dependence of learner autonomy on teacher autonomy. Systems, 23(2), 175-81.

Little, D. (1997). Language awareness and the autonomous language learner. Language Awareness, 6(2/3), 93-104.

Little, D. (1999). Learner autonomy is more than a Western cultural construct. In S. C. Crabbe (Ed.), Learner autonomy in language learning: Defining the field and effecting change (pp. 11-18). Frankfurt am Main: Lang.

Little, D. (2001a). We're all in it together: exploring the interdependence of teacher and learner autonom. In F. K. L. Karlsson, All together now (pp. 45-56). Helsinki: University of Helsinki Language Centre.

Little, D. (2008). Knowledge about language and learner autonomy. In J. C. Hornberger (Ed.), Encyclopaedia of Language and Education (pp. 247-258). New York: Springer Science.

Littlewood, W. (1981). Communicative language teaching: An introduction. Cambridge : Cambridge University Press. 
Liu, S. (2008). Student interaction experiences in distance learning courses: A phenomenological study. Online Journal of Distance Learning Administration, 11(1), online.

Logan, G. (1980). Individualized foreign languages instruction: American patterns for accommodating learner differences in the classroom. In H. B. James (Ed.), Foreign Language Teaching: Meeting Individual Needs. (pp. 94-110). Oxford: Pergamon Press.

Long, M. (1985). Input and second language acquisition theory. In S. G. Madden, Input in second language acquisition (pp. 377-393). Cambridge: Newbury House.

Long, M. (1991). Focus on form: A design feature in language teaching methodology. In D. C. K. de Bot, Foreign language reseach in cross-cultural perspective (pp. 39-52). Amsterdam: John Benjamins.

Lorenzetti, J. (2005). Lessons learned about student issues in on-line learning. Distance Education Report, 9, 3-14.

Lucy, J. (1992b). Language diversity and thought: A reformulation of the linguistic relativity hypothesis. Cambridge: Cambridge University Press.

Lucy, J. (1997). Linguistic relativity. Annual Review of Anthropology, 26, 291-312.,.

Lukmani, Y. (1972). Motivation to learn and language proficiency. Language Learning, 22, 261-273.

Luppicini, R. (2007). Review of computer mediated communication research for education. Instructional Science, 35, 141-185.

Mangan, K. (2012). Minnesota gives Coursera the boot, citing a decades-old law. Web log post, October.

Martinez, H. (2008). The subjective theories of student. In Learner and teacher autonomy: (pp. 103-124). Amsterdam: John Benjamins.

Martinez, M. (2003). High attrition rate in e-learning: Challenges, predictors, and. The eLearning Developers Journal, 1-7.

Masgoret, M., \& Gardner, R. (2003). Attitudes, Motivation, and Second Language Learning: A MetaAnalysis of Studies Conducted by Gardner and Associates. Language Learning, 53(1), 167-221.

Mayadas, A. (1997). Asynchronous learning networks: A Sloan foundation perspective. Journal of Asynchronous Learning Networks, Online.

McBride, K. (2009). Social-networking sites in foreign language classes: Opportunities for re-creation. In L. L. Lord, The next generation: Social networking and online collaboration in foreign language learning (pp. 35-58). San Marcos, Texas: CALICO.

McCaslin, M., \& Good, T. (1996). The informal curriculum. In D. Berliner, \& R. Calfee (Eds.), Handbook of Educational Psychology (pp. 622-670). New Jersey: Routledge. 
McLaren, M. (1998). Interpreting Cultural Differences: Challenge of Intercultural Communication. Norfolk: Peter Francis Publishers.

McLoughlin, C., \& Lee, M. (2008). Mapping the digital terrain: New media and social software ascatalysts for pedagogical change. In A., \& Farley, Hello! Where are you in the landscape of educational technology? (pp. 641-652). Melbourne: Deakin University.

McLoughlin, C., \& Lee, M. (2008). The three ps of pedagogy for the networked society: personalization, participation and productivity. Internatinoal Journal of Teaching and Learning in Higher Education, 10-27.

Meacham, D., \& Evans, D. (1989). Distance education: The design of study materials. Wagga Wagga: Open Learning Institute, Charles Sturt University.

Mehrabian, A. (1972). Silent Messages: Implicit Communication of Emotions and Attitudes. Belmont, CA: Wadsworth Publishing Company.

Mendonça, C., \& Johnson, K. (1994). Peer review negotiations: revision activities in ESL writing instruction. TESOL, 745-769.

Meyer, M. (1991). Developing Transcultural Competence: Case Studies of Advanced Foreign Language Learners. In B. a. Byram, Mediating Languages and Cultures (pp. 136-158). Clevedon: Multilingual Matters.

Meyer, M. (1991). Developing Transcultural Competence: Case Studies of Advanced Foreign Language Learners. In B. a. (eds), Mediating Languages and Cultures (pp. 136-158). Clevedon: Multilingual Matters.

Miles, M. (1994). Qualitative data analysis: An expanded sourcebook. London: Sage.

Mody, W. (2002). Handbook of International and Intercultural Communication. California: SAGE Publications.

Moody, J. (2004). Distance education: Why are the attrition rates so high? The Quarterly Review of Distance Education, 5, 205-210.

Moore, M., \& Kearsley, G. (1996). Distance education: a systems view. Wadsworth: Wadsworth Publisihing Co.

Moore, M. (1977). A model of independent study. Epistolodidaktika, 6-40.

Moore, M. (1973). Towards a theory of independent learning and teaching. Journal of Higher Education, 44, 661-679.

Moore, M. G. (1989). Three types of interaction. The American Journal of Distance Education, 3 (2), 1-6. 
Moore, M. (1993). Editorial: Is teaching like Flying? A total systems view of distance education. American Journal of Distance, 7:1, 1-10.

Moore, W. (1968). The Tutorial System and its Future. Oxford: Pergamon Press.

Morgan, C., \& Byram, M. (1994). Teaching and Learning Language and Culture. Clevedon: Multilingual Matters.

Morris, C. (2001). Understanding psychology. New Jersey: Prentice Hall.

Morris, C., \& Maisto, A. (2002). Psychology: An Introduction. New Jersey: Prentice Hall College Div.

Muirhead, B. (2000). Interactivity in a graduate distance education school. Educational Technology \& Society, 3.

Naiman, N. (1978). The good language learner - Research in Education Series No. 7. Toronto: Ontario Institute for Studies in Education.

Neto, F. (2006). Advances in Computer-supported Learning . Pennsylvania: Information Science Publishing (IGI).

Newman, D. (1989). The construction zone: working for cognitive change in school. Cambridge: Cambridge University Press.

Nkuyubwatsi, B. (2013). Evaluation of Massive Open Online Courses (MOOCs) from the learner's perspective. The 12th European Conference on e-Learning ECEL-2013 (pp. Pre-print version). Last retrieved $12^{\text {th }}$ May, 2015 from http://issuu.com/acpil/docs/ecel2013-proceedings-vol2/39.

Noels, K. (2005). Orientations to Learning German: Heritage Language Learning and Motivational Substances. The Canadian Modern Language Review, 62(2), 285-312.

Noels, K., Clément, R., \& Pelletier, L. (2001). Intrinsic, extrinsic, and integrative orientations of French Canadian learners of English. Canadian Modern Language Review, 57(3), 424-444.

Noels, K., Pelletier, L., Clément, R., \& Vallerand, R. (2000). Why are you learning a second language? Motivational orientations and self-determination theory. Language Learning, 50(1), 57-85.

Noles, K. (2009). The internalisation of language learning into the self and social identity. In Dornyei, Z. and Ushioda, A. (Eds.), Motivation, Language Identity and the L2 Self (pp. 295-313). Bristol: Multilingual Matters.

Nunan, D. (1988). The learner-centred curriculum: A study in second language teaching. Cambridge: Cambridge University Press.

Nunan, D. (1995). Closing the gap between learning and instruction. TESOL Quarterly, 29(1), 133-158. 
O'Dowd, R. (2007). Online intercultural exchange: An introduction for foreign language teachers. Clevedon: Multilingual Matters.

O'Dowd, R. (2012). Intercultural communicative competence through telecollaboration. In J. Jackson, The Routledge Handbook of Language and Intercultural Communication (pp. 342-358). New York: Routledge.

O'Dowd, R., \& Ritter, M. (2006). Understanding and working with 'Failed Communication' in telecollaborative exchanges. CALICO Journal, 23, 623-642.

ODonnell, A. (1999). Cognitive perspectives on peer learning. Mahwah, NJ: Erlbaum.

O'Dowd, R. (2003). Understanding the "other side": Intercultural learning in a Spanish-English email exchange. Language Learning \& Technology, 118-144.

Okun, M. (1996). Journal of Higher Education. Staying in college: Moderators of the relation between intention and institutional departure, 13(2), 577-596.

Oliveras, A. (2000). Hacia la competencia intercultural en el aprendizaje de una lengua extranjera. Madrid: Edinumen.

O'Rourke, B. (2005). Form-focused interaction in online tandem learning. CALICO, 22(3), 433-466.

Oxford, R. (2003). Toward a more systematic model of L2 learner autonomy. In D. P. Smith (Ed.), Learner autonomy across cultures: Language education perspectives (pp. 75-91). Basingstoke: Palgrave Macmillan.

Park, C. (2008). The taught postgraduate student experience: Overview of a Higher Education Academy survey. York: The Higher Education Academy.

Patton, M. (2015). Qualitative Research \& Evaluation Methods: Integrating Theory and Practice. Thousand Oaks: Sage.

Patton, M. (2005). Qualitative research. Hoboken, NJ: John Wiley \& Sons, Ltd.

Pavlov, I. (1927). Conditioned Reflexes: An Investigation of the Physiological Activity of the Cerebral Cortex. London: Routledge and Kegan Paul.

Pavlov, I. (1928). Lectures on Conditioned Reflexes: Twenty-five Years of Objective Study of the High Nervous Activity (Behavior) of Animals. New York: International.

Pavlov, I. (1955). Selected Works. Moscow: Foreign Languages Publishing House.

Pemberton, R. (2001). Approaches to advising for self-directed language learning. The AILA Review, 15, 16-25. 
Pennycook, A. (1997). Cultural alternatives and autonomy. In Autonomy and independence in language learning (pp. 35-53). London: Longman.

Peters, O. (1983). Distance teaching and industrial production: A comparative interpretation in outline. In D. K. Sewart, Distance education: International perspectives. London: Croom Helm.

Peters, O. (1989). Further reflections on the concept of industrialization and distance teaching. In D. Keegan, Otto Peters on distance education: The industrialization of teaching and learning (pp. 195-209). London and New York: Routledge.

Peters, O. (1998). Learning and Teaching in Distance Education: Analyses and Interpretations . New York: Routledge.

Peterson, E., \& Coltrane, B. (2003). Culture in second language teaching. CAL Digest, 3(9), 1-6.

Piaget, J. (1953). The origin of intelligence in the child. London: Routledge \& Paul.

Piaget, J. (1959). The Language and Thought of the Child. Sussex : Psycology Press.

Piaget, J. (1964). The early growth of logic in the child. London: Routledge and Kegan Paul.

Piaget, J. (1969). The Psychology of the Child. New York: Basic Books.

Pica, T. (1989). Comprehensive output as an outcome of linguistic demands on the learner. Studies in Second Language Acquisition, 11, 63-90.

Pinker, S. (1997). How the mind works. New York: Norton.

Pintrich, P., \& Schunk, D. (2002). Motivation in education: Theory, research, and applications. Englewood Cliffs, NJ: Prentice-Hall.

Plunkett, K. (1998). Language Acquisition and Connectionism. In K. Plunkett, A Special Issue og Language and Cognitive Processes: Language Acquisition and Connectionism (pp. 97-104). Hove: Psychology Press Ltd.

Porter, M. (1985). Group work, interlanguage talk, and second language acquisition. TESOL Quartely, 19, 305-325.

Porter, P. (1986). How learners talk to eachother: INput and interaction in task-centered discussions. In R. Day, Talking to lear (pp. 200-221). Rowley: Newbury House.

Poyatos, F. (1994). La comunicación no verbal. Madrid: Ediciones Istmo.

Prensky, M. (2001a). Digital natives, digital immigrants -- A new way to look at ourselves and our kids. On the Horizon - NCB University Press, 9 (5), Online. 
Sajja, P., \& Akerkar, R. (2012). Intelligent Technologies for Web Applications. Boca Raton, Florida: Taylor \& Francis Group.

Rao, V. (2003). Distance Education. Kashmir: APH Publishing Corporation.

Richards, J. (2006). Communicative language teaching today. Cambridge: Cambridge University Press.

Richards, J. (2006). Communicative Language Teaching Today. Cambridge: Cambridge University Press.

Richards, J., \& Theodore, R. (1986). Approaches and methods in language teaching: A description and analysis. Cambridge: Cambridge University Press.

Richards, J., \& Schmidt, R. (2002). Longman dictionary of Language Teaching and Applied Linguistics. Harlow: Pearson Education Limited.

Riley, P. (1986). Who's who in self-access. TESOL France News, 6(2), 23-35.

Risager, K. (2006). Language And Culture: Global Flows And Local Complexity. London: Multilingual Matters.

Risager, K. (2007). Language And Culture Pedagogy: From a National to a Transnational Paradigm. London: Multilingual Matters.

Ritchie, J. (2004). Carrying out qualitative analysis. In L. J. Ritchie J, Qualitative research practice (pp. 219-262). London: Sage Publications.

Roberts, D. (2008). Learning in clinical practice: the importance of peers. Nursing Standard, 12, 35-41.

Rodgers, C. (2001). Approaches and Methods in Language Teaching. New York: Cambridge University Press.

Rodgers, J. (1986). Approaches and methods in language teaching: A description and analysis. Cambridge: Cambridge University Press.

Rogers, P. (1990). Student retention and attrition in college. In Handbook of developmental education (pp. 305-327). New York: Praeger.

Rokeach, M. (1973). The Nature of Human Values. New York: The Free Press.

Rollinson, P. (2005). Using peer feedback in the ESL writing class. ELT Journal, 59, 23-30.

Rothenberg, M. (1998). The new face of distance learning in language instruction. In J. N. S. Jager, Language teaching and language technology (pp. 146-148). Lisse: Swets \& Zeitlinger.

Rovai, A. (2005). Improving retention in distance learning classes. International Journal of, 2 (1), 59-64.

Rubin, J. (1975). What the "good language learner" can teach us. TESOL Quarterly, 9, 41-51. 
Rust, C., O'Donovan, B., \& Price, M. (2005). A social constructivist assessment process model: How the research literature shows us this could be best practice. Assessment and Evaluation in Higher Education, 30, 231-240.

Ryan, G., \& Russell, B. (2000). Data Management and Analysis Methods. In N. D. Lincoln, Handbook of Qualitative Research (pp. 769-802). Thousand Oaks: Sage Publications.

Ryberg, T. \& Dirckinck-Holmfeld, L. (2008). Power Users and patchworking - An analytical approach to critical studies of young people's learning with digital media. Educational Media International, 45, 143-156.

Sakui, K. (2002). Situated Evaluation of Communicative Language Teaching in Curriculum Innovation. Explorations in Teacher Education, 10(1), 19-23.

Sánchez-Algarra, P., \& Anguera, T. (2003). Qualitative/quantitative integration in the inductive observational study of interactive behaviour: impact of recording and coding among predominating perspectives. Quality \& Quantity, 1237-1257.

Sapir, E. (1921). Language: An Introduction to the Study of Speech. New York: Harcourt, Brace and company.

Sarkar, G. (1993). SIAST retention study. Vancouver: Canadian Institutional Researchers and Planners Conference.

Savignon, S. (1983). Communicative competence: theory and classroom practice; texts and contexts in second language learning. Reading: Addison-Wesley.

Schroeder, R. (1992). Max Weber and the Sociology of Culture . California: SAGE Publications.

Schunk, D., \& Zimmerman, B. (1998). Self-regulated learning: From teaching to self-regulated practice. New York: Guildford Press.

Schwienhorst, K. (2010). Evaluating Tandem Language Learning in the MOO: Discourse Repair Strategies in a Bilingual Internet Project. Computer Assisted Language Learning, 135-145.

Searle, J. (1969). Speech acts: An essay in the philosophy of language. Cambridge: Cambridge University Press.

Seely Brown, J., Collins, A., \& Duguid, P. (1989). Situated Cognition and the Culture of Learning. Educational Researcher, 32-42.

Seliger, H., \& Shohamy, E. (1989). Second language research methods. London: Oxford University Press.

Selinker, L. (1972). Interlanguage. International Review of Applied Linguistics, 10, 209-241. 
Sercu, L. (2004). Intercultural Communicative Competence in Foreign Language Education. In K. a. van Esch, New Insights into Foreign Language Learning and Teaching (pp. 115-130). Frankfurt am Main: Peter Lang.

Sercu, L. (2005). Foreign Language Teachers and Intercultural Communication. Clevedon: Multilingual Matters.

Sereno, E. (1975). Trans-Per: A Teaching Strategies Guide. Boston: Houghton Mifflin.

Siemens, G. (2010b). Thought experiment on social networked learning. Last retrieved 2012 from http://www.connectivism.ca/?p=297

Siemens, G. (2005). Connectivism: A learning theory for the digital age. International Journal of Instructional Technology \& Distance Learning. Last retrieved $12^{\text {th }}$ May, 2015 from http://www.itdl.org/Journal/Jan_05/article01.htm

Siemens, G. (2006). Knowing Knowledge. Last retrieved $12^{\text {th }}$ May, 2015 from http://www.elearnspace.org/KnowingKnowledge_LowRes.pdf: Creative Commons licence.

Silverman, D. (2000). Doing qualitative research. London: Sage Publications.

Silverman, D. (2000). Doing qualitative research. London: Sage Publications.

Silverman, D. (2010). Qualitative research. Boston: Sage.

Simon, B., \& Cutts, Q. (2012). Peer instruction: A teaching method to foster deep understanding. Communications of the ACM, 55(2), 27-29.

Simonson, M. (1999). Theory and distance education: a new discussion. The American Journal of Distance Education, 13, 60-75.

Simonson, M. (2000). Teaching and learning at a distance: Foundations of distance education. Boston MA: Pearson Education.

Sinclair, B. (2000). Learner autonomy and its development in the Teaching of English to Speakers of Other Languages (TESOL). University of Nottingham: Nottingham.

Skinner, B. (1938). The Behavior of Organisms: An Experimental Analysis. Michigan: Appleton-CenturyCrofts.

Skinner, B. (1954). The science of learning and the art of teaching. Harvard Educational Review, 24, 8697.

Skinner, B. (1957). Verbal behavior. Michigan: Appleton-Century-Crofts.

Skinner, B. (1958b). Reinforcement today. American Psychologist, 13, 94-99. 
Slavin, R. (1983). When does cooperative learning increase achievement? Psychological Bulletin, 94, 429445.

Spolsky, B. (1969). Attitudinal aspects of second language learning. Language learning, 19, 271-285.

Spradley, J. (1980). Participant Observation. Belmont: Wadsworth, Cengage Learning.

Stanchina, C. (1975). The logic of autonomy as a strategy for adult learners. CRAPEL.

Stanley, B. (2001). Language development and maintenance at a distance: Methodology and technology. Applied Language Learning, 12.1, 1-30.

Stern, H. (1975). What can we learn from the good language learner? Canadian Modern Language Review, 31, 304-318.

Strauss, A. (1990). Basics of qualitative research. Newbury Park: Sage.

Sturtridge, G. (1982). Individualised learning: What are the options for the classroom teacher? In M. G. Sturtridge (Ed.), Individualisation (pp. 8-14). London: Modern English Publications - Pavilion Publishing and Media Ltd.

Sturtridge, G. (1997). New roles for learners: Developing learners as "learner-teachers". In L. Dickinson (Ed.). Bangkok: King Mongkut's Institute of Technology Thonburi.

Sudman, S., Bradburn, N., \& Schwarz, N. (2010). Thinking About Answers: The Application of Cognitive Processes to Survey Methodology. San Fransisco: Jossey-Bass.

Suh, P., Ellis, J., \& Thiemecke, D. (2002). Content Management Systems (Tools of the Trade). New York: Glasshaus Apress L. P.

Swain, M. (1980). Theoretical bases of communicative approaches to second language teaching and testing. Applied Linguistics, 1, 1-47.

Talyor, J. (1995). Distance education technologies: the fourth generation. Australian Journal of Education, $11,1-7$.

Thomas, C. (2010). When Web 2.0 becomes an organizational learning tool: evaluating Web 2.0 tools. Development and Learning in Organizations: An International Journal, 24, 17-22.

Thomas, D. (2006). A General Inductive Approach for Analyzing Qualitative Evaluation Data. American Evaluation Association, 237-246.

Thorndike, E. (1911). Animal Intelligence. New York: The Macmillan company. 
Thorne, S. (2006). Pedagogical and praxiological lessons from Internet-mediated intercultural foreign language education research. In J. B. Thorne, Internet-mediated intercultural foreign language education (pp. 2-30). Boston: Heinle \& Heinle.

Thorpe, M. (1998). Assessment and 'third generation' distance education. Distance Education, 19, 265286.

Thrun, S., \& Norvig, P. (Based on Stanford CS221, Introduction to Artificial Intelligence). Online Introduction to Artificial Intelligence. Information for students.

Thurston, A., \& Topping, K. (2007). Peer tutoring in schools: Cognitive models and organisational typography. Journal of Cognitive Education and Psychology, 6 (3), 356-372.

Tinto, V. (1982). Limits of theory and practice in student attrition. Journal of Higher Education, 53(6), 687700.

Tippins, K. (1993). Constructivism as a referent for teaching and learning. In K. Tobin, The practice of constructivism in science education (pp. 3-21). Washington: AAAS Press.

Tomalin, B., \& Stempleski, S. (1993). Cultural Awareness. Oxford: Oxford University Press.

Tomlin, R. (1990). Functionalism in SLA. Studies in Second Language Acquisition, 12, 155-177.

Topping, K. (2005). Trends in Peer Learning. Educational Psychology, 25(6), 631-645.

Tort-Moloney, D. (1997). Teacher autonomy: A Vygotskian theoretical framework. Occasional paperCentre for Language and Communication Studies, 48, 1-54.

Triandis, H. (1972). Analysis of Subjective Culture: An Approach to Cross-cultural Social Psychology. New Jersey: John Wiley \& Sons Inc.

Triandis, H. (1995). Individualism \& collectivism. Boulder: Westview Press.

Trim, J. (1988). Consolidated report on the programme of international workshops for trainers of teachers of modern language 1984 - 87. Strasbourg: Council of Europe.

Tudini, V. (2003). Using native speakers in chat. Language Learning and Technology, 7, 141-159.

Tuijnman, A. (1999). Lifelong learning policies in a new technological era. In S. M. Bastos, Europe and developing countries in the globalised information economy (pp. 155-167). London: Routledge.

Tumposky, N. (1982). The learner on his own. In M. G. Sturtridge (Ed.), Individualisation (pp. 4-7). London: Modern English Publications.

Turpen, C., \& Finkelstein, N. (2010). The construction of different classroom norms during peer instruction: Students perceive differences. Physical Review Special Topics - Physics Education Research, 6(2), 1-22. 
Ushioda, E. (1996). Learner autonomy 5: The role of motivation. Dublin: Authentik.

Ushioda, E. (2001). Language learning at university: exploring the role of motivational thinking. In Z., \& Dörnyei (Ed.), Motivation and Second Language Acquisition (pp. 93-125). Honolulu: University of Hawaii.

Ushioda, E. (2003). Motivation as a socially mediated process. In Learner autonomy in the foreign language classroom: Learner, teacher, curriculum, and assessment (pp. 90-103). Dublin: Authentik.

Ushioda, E. (2008). Motivation and good language learners. In C. Griffiths (Ed.), Lessons from Good Language Learners (pp. 19-34). Cambridge: Cambridge University Press.

Utley, D. (2004). The Intercultural Resource Pack. Cambridge: Cambridge University Press.

Van Esch, K., \& St. John, O. (2003). A framework for freedom: Learner autonomy in foreign language teacher education. Frankfurt am Main: Peter Lang.

van Esch, K., Schalkwijk, E., Elsen, A., \& Setz, W. (1999). Autonomous learning in foreign language teacher training. In W. G. P. Faber (Ed.), English teacher education in Europe (pp. 15-31). Frankfurt am Main: Peter Lang Verlag.

van Lier, L. (2004). The Ecology and Semiotics of Language Learning. Norwell, MA: Kluwer Academic Publishers.

Vander Zanden, J. (1996). Social: The Core. New York: McGraw-Hill Companies.

Vívelo, F. (1987). Cultural Anthropology Handbook: a Basic Introduction. New York: McGraw-Hill.

Voller, P. (1997). Autonomy and Independence in Language Learning. Harlow: Longman.

von Glasersfeld, E. (1995). Radical constructivism: A way of knowing and learning. London \& Washington: The Falmer Press.

von Humboldt, W. (1836). New edition (1999). On language: On the Diversity of Human Language Construction and its Influence on the Mental Development of the Human Species. (M. Losonsky, Ed.) Cambridge: Cambridge University Press.

Vygostsky, L. (1980). Mind in Society: Development of Higher Physcological Processes. Cambridge: Harvard University Press.

Vygotsky, L. (1962). Thought and language. Cambridge : MIT Press.

Vygotsky, L. (1978). Mind in society. Cambridge: Harvard University Press.

Vygotsky, L. (1978). Mind in Society. Cambridge, MA.: Harvard University Press. 
Vygotsky, L. (1978). Mind in society: The development of higher psychological processes. Cambridge: Harvard University Press.

Vygotsky, L. (1981). The development of higher forms of attention in childhood. In J. V. Wertsch, The concept of activity in Soviet psychology. Armonk, N.Y.: Sharpe.

Vygotsky, L. (1986). Thought and Language. Cambridge, Massachusetts: The MIT Press.

Wall, S. (2003). Freedom as a political ideal. In F. D. E. Frankel, Autonomy (pp. 307-34). Cambridge: Cambridge University Press.

Wang, Y., \& Sun, C. (2001). Internet-based real time language education: Towards a fourth generation distance education. CALICO Journal, 539-561.

Wanguri, D. (1996). Diversity, equity and communicative openness. The Journal of Business Communication, 33 (4), 443-457.

Ware, P. (2005). "Missed communication" in online communication: Tensions in fostering successful online interaction. Language Learning \& Technology, 9(2), 64-89.

Warschauer, M. (1996). Computer-assisted language learning: An introduction. In S. Fotos, Multimedia Language Teaching (pp. 3-20). Tokyo: Logos International.

Warschauer, M. (2000). The changing global economy and the future of English teaching. TESOLQuarterly, 34, 511-535.

Waterhouse, P. (1990). The Curriculum. In I. Gathercole (Ed.), Autonomy in language learning (pp. 4-6). London: CILT.

Watson, J. (1913). Psychology as the behaviorist views it. Psychological Review, 158-177.

Watson, J. (1913). Psychology as the behaviorist views it. Psychological Review, 20, 158-177.

Watson, J. (1919). Psychology from the standpoint of a behaviorist. Philadelphia: Philadelphia Lippincott.

Watson, J. (1919). Psychology from the standpoint of a behaviorist. Philadelphia: J. B. Lippincott.

Watson, J. (1928). Psychological Care of Infant and Child. New York: W.W. Norton \& Co.

Watson, J. (1928). The ways of behaviorism. Harper \& Brothers: New York.

Watson, J. (1930). Behaviorism. Chicago: University of Chicago Press.

Watson-Gegeo, K. (1992). Thick explanation in the ethnographic study of child. New Directions , 51-66.

Watzlawick, P. (1977). How Real Is Real? New York: Vintage Books - Random House.

Wedemeyer, C. (1973). The Use of Correspondence Education for Post Secondary Education. In Akalwasa, \& M. Kaunda, Correspondence. London: Routledge. 
Wedemeyer, C. (1981). Learning at the Back Door. Reflections on NonTraditional. Madison: University of Wisconsin Press.

Wedemeyer, C. A. (1968). With whom will you dance? The new educational technology. Journal of the American Dietetic Association, 53, 325-328.

Wegner, S. (1999). The effects of internet-based instruction on student learning. Journal of Asynchronous Learning Network, 3, 98-106.

Weiner, B. (1983). Some methodological pitfalls in attributional research. Journal of Educational Psychology, 75, 530-543.

Wellros, S. (1999). Språk, kultur och social identitet. In $\varnothing$. Dahl, Meanings in Madagascar: Cases of Intercultural Communication. Westport: Greenwood Publishing Group.

Wenger, E. (1998). Communities of practices. Learning, meaning, and identity. Cambridge: Cambridge University.

Wentzel, K. (1999). Social-motivational processes and interpersonal relationships: implications for understanding motivation at school. Journal of Educational Psychology, 91(1), 76-97.

Wheatley, G. (1991). Constructivist Perspectives on Science and Mathematics Learning. Science Education, 75, 9-21.

White, C. (2007). Innovation and identity in distance learning and teaching. Innovation in Language Learning and Teaching, 1, 97-110.

Whorf, B. (1956). Language, Thought, and Reality: Selected Writings of Benjamin Lee Whorf. Massachusetts, USA: Massachusetts institute of technology.

Wicks, R. (2014). Kant. A complete Introduction. New York : McGraw-Hill Companies.

Widdowson, H. (2003). Defining Issues in English Language Teaching. Oxford : Oxford University Press.

Widdowson, H. (1990). Aspects of Language Teaching. Oxford: Oxford University Press.

Wigfield, A., \& Wagner, A. (2007). Competence, motivation, vation, and identity development during adolescence. In A. E. Dweck (Ed.), Handbook of competence and motivation (pp. 222-256). New York: Guildford Press.

Wiley, D. (2012). The MOOC misnomer. Blog post, July.

Williams, M., \& Burden, R. (1997). Psychology for Language Teachers. Cambridge: Cambridge University Press. 
Williams, M., \& Burden, R. (1999). Students' developing conceptions of themselves as language learners. The Modern Language Journal, 88(2), 193-201.

Wittgenstein, L. (1922). Tractatus Logico-Philosophicus. London: Kegan Paul.

Wlodkowski, R. (1999). Enhancing Adult Motivation to Learn: A Comprehensive Guide for Teaching All Adults. San Fransisco: Jossey-Bass.

Wood, D. (1976). The Role Of Tutoring In Problem Solving. Journal of Child Psychology and Psychiatry, 17, 89-100.

Yaroshevsky, M. (1989). Lev Vygotsky. Progress Publishers: Moscow.

Young, J. (2012b). Inside the Coursera contract: How an upstart company might profit from free courses. The Chronicle of Higher Education, July.

Young, R. (1986). Personal Autonomy: Beyond Negative and Positive Liberty. London: Croom Helm.

Yule, E. (1989). Focus on the language learner. Oxford: Oxford University Press.

Zarate, G., \& Neuner, G. (1997). Sociocultural Competence in Language Learning and Teaching: Studies Towards. Stasbourg: Council of Europe Publishing.

Zimmerman, B. (2000). Attainment of self-regulation: A social cognitive perpective. In P. P. M. Boekaerts, Handbook of self-regulation (pp. 13-39). Orlando, Florida: Academic Press. 